\title{
The link between ceramide transporters, innate immunity and Alzheimer's disease
}

Citation for published version (APA):

Bode, G. H. (2016). The link between ceramide transporters, innate immunity and Alzheimer's disease. [Doctoral Thesis, Maastricht University]. Maastricht University. https://doi.org/10.26481/dis.20161014gb

Document status and date:

Published: 01/01/2016

DOI:

10.26481/dis.20161014gb

Document Version:

Publisher's PDF, also known as Version of record

\section{Please check the document version of this publication:}

- A submitted manuscript is the version of the article upon submission and before peer-review. There can be important differences between the submitted version and the official published version of record.

People interested in the research are advised to contact the author for the final version of the publication, or visit the DOI to the publisher's website.

- The final author version and the galley proof are versions of the publication after peer review.

- The final published version features the final layout of the paper including the volume, issue and page numbers.

Link to publication

\footnotetext{
General rights rights.

- You may freely distribute the URL identifying the publication in the public portal. please follow below link for the End User Agreement:

www.umlib.nl/taverne-license

Take down policy

If you believe that this document breaches copyright please contact us at:

repository@maastrichtuniversity.nl

providing details and we will investigate your claim.
}

Copyright and moral rights for the publications made accessible in the public portal are retained by the authors and/or other copyright owners and it is a condition of accessing publications that users recognise and abide by the legal requirements associated with these

- Users may download and print one copy of any publication from the public portal for the purpose of private study or research.

- You may not further distribute the material or use it for any profit-making activity or commercial gain

If the publication is distributed under the terms of Article $25 \mathrm{fa}$ of the Dutch Copyright Act, indicated by the "Taverne" license above, 


\section{The link between ceramide transporters, innate immunity and Alzheimer's disease}

Gerard Hendrik Bode 
The link between ceramide transporters, innate immunity and Alzheimer's disease Gerard Hendrik Bode ISBN:

Cover design by Jan Pieter Bode

Printed by CPI - Koninklijke Wöhrmann - Zutphen

(C) Gerard Hendrik Bode, Maastricht 2016 


\section{The link between ceramide transporters, innate immunity and Alzheimer's disease}

\section{PROEFSCHRIFT}

ter verkrijging van de graad van doctor aan de Universiteit Maastricht, op gezag van de Rector Magnificus, prof. dr. Rianne M. Letschert volgens het besluit van het College van Decanen, in het openbaar te verdedigen op Vrijdag 14 Oktober 2016 om 12.00 uur

door

Gerard Hendrik Bode 
Promotor

Prof. dr. M. De Baets

Co-promotores

Dr. P. Martinez-Martinez

Dr. M. Losen

Beoordelingscommissie

Prof. dr. T. Hackeng (voorzitter)

Prof. dr. E. Bieberich (Augusta University, Georgia, United States)

Prof. dr. C. Bruggeman

P.D. dr. G. van Echten-Deckert (Kekulé-Institute, Bonn, Germany)

Prof. dr. C. Reutelingsperger 


\section{CONTENTS}

General Introduction

Chapter 1

Goodpasture Antigen-binding Protein/Ceramide Transporter Binds to Human Serum Amyloid P-Component and Is Present in Brain Amyloid Plaques

Chapter 2

Complement Activation by Ceramide Transporter Proteins 55

Chapter 3

Unchanged expression of the ceramide transfer protein in the acute 6-OHDA neurodegenerative model

Chapter 4

Detection of Peptide-Based Nanoparticles in Blood Plasma by ELISA 107

Chapter 5

An in vitro and in vivo study of peptide-functionalized nanoparticles for brain targeting:

The importance of selective blood-brain barrier uptake 133

General discussion 183

Valorization appendix 189

References 191

Summary 193

Curriculum vitae 195 

General introduction

\section{GENERAL INTRODUCTION}


Historically lipids have long been viewed as inert structural components of membranes. However, advances in lipid analysis techniques such as mass spectrometry have resulted in an ever growing range of biological functions being attributed to them (Piomelli, Astarita et al. 2007).

This is particularly relevant for the brain, as lipids make up half of the total dry mass of this organ. It comes as no surprise that there is increasing interest in the role of lipids in diseases afflicting the brain. Ceramides are of particular interest in this regard. These cone-shaped sphingolipids are composed of sphingosine and a fatty acid with varying chain length. Even though ceramides are often viewed as pro-apoptotic molecules involved in cell death, this is an over-generalization and simplification of their functions. In fact, ceramides have a wide range of different, and sometimes opposing, biological functions depending on the chain length and number of desaturations of the fatty acid (Hannun and Obeid 2011). In addition, ceramides form the basis of sphingomyelin and other more complex sphingolipids.

One of the neurological conditions in which sphingolipids are thought to play an important role is Alzheimer's disease (AD). AD is a neurodegenerative disease characterized by progressive cognitive decline, associated with the deposition of amyloid-beta plaques and the presence of neurofibrillary tau tangles in the brain. Disturbances in brain ceramide and sphingomyelin levels have been reported in brain tissue of AD patients (Cutler, Kelly et al. 2004, Filippov, Song et al. 2012). Additionally, serum ceramide levels have been found to be highly predictive for the risk of developing AD (Mielke, Bandaru et al. 2012). On a mechanistic level, it has been reported that certain ceramides increase generation of amyloid-beta peptides by interacting with amyloid precursor protein cleaving enzymes (Puglielli, Ellis et al. 2003, Liu, Martin et al. 2013, Takasugi, Sasaki et al. 2015). However, the 
precise mechanisms linking ceramides to increased risk of AD still remain to be elucidated.

Intracellularly ceramides are transported from the endoplasmic reticulum, where they are synthesized, to the Golgi apparatus by the ceramide transfer protein (CERT) (Hanada, Kumagai et al. 2003). Interestingly, CERT and in particular its longer extracellular isoform, $\mathrm{CERT}_{\mathrm{L}}$ (also known as Goodpasture Antigen Binding Protein, GPBP), was first described in the autoimmune disease Goodpasture syndrome (Raya, Revert-Ros et al. 2000, Revert, Ventura et al. 2008, Mencarelli, Losen et al. 2010). In addition, ceramides and sphingolipids have already been linked to inflammation (Maceyka and Spiegel 2014). These findings provide an intriguing possibility that ceramides are linked to inflammation and the immune system via CERT (Chapter 1 3).

In addition to studying the function of CERT, we have investigated novel drug delivery methodologies for the brain (Chapter 4 and 5). Targeted delivery of drugs across endothelial barriers remains a formidable challenge, in particular in the case of the brain, where the blood-brain barrier limits entry of drugs into the central nervous system. Nanoparticle-mediated transport of peptide/protein based drugs across endothelial barriers shows great promise as a therapeutic strategy in a wide variety of diseases. Functionalizing nanoparticles with peptides allows for more efficient targeting to specific organs.

In Chapter 1 we investigate the interaction between CERT/GPBP and Serum amyloid P component (SAP). SAP is a non-fibrillar glycoprotein which belongs to the pentraxin family of the innate immune system. SAP is present in plasma, basement membranes and amyloid deposits in diseases such as Alzheimer's.

In Chapter 2 we report the interaction between CERT/GPBP and the complement component $\mathrm{C} 1 \mathrm{q}$. $\mathrm{C} 1 \mathrm{q}$ is the initiator of the classical 
complement pathway and, as such, is essential for efficient opsonization and clearance of pathogens, altered self-structures, and apoptotic cells. Extensive activation of the complement system in the brain is seen in Alzheimer's disease.

The objective of the study in Chapter 3 was to define whether levels of CERT/GPBP are altered in the acute neurodegenerative process. We used design-based stereology to quantify the number of CERT/GPBP immunoreactive cells in the striatum of 6-hydroxydopamine (6-OHDA) lesioned rats as an animal model of Parkinson's disease. In addition, gray value measurement was performed to quantify CERT/GPBP immunoreactivity-levels within individual cells. Finally, CERT/GPBP expression was quantified by Western blot in brain homogenates.

The aim of the study described in Chapter 4 was to develop a method to detect peptide-linked nanoparticles in blood plasma. An enzyme linked immunosorbent assay (ELISA) was developed for the detection of peptides functionalized with biotin and fluorescein groups. As a proof of principle, polymerized pentafluorophenyl methacrylate nanoparticles linked to biotin-carboxyfluorescein labeled peptides were intravenously injected in Wistar rats. Serial blood plasma samples were analyzed by ELISA and by liquid chromatography mass spectrometry (LC/MS) technology.

In Chapter 5 we evaluated the efficacy of delivery and safety of liposome, polyester, poly(glycidol) and acrylamide based nanoparticles functionalized with peptides targeting brain endothelial receptors, in vitro and in vivo. The hemocompatibility, toxicity and endothelial uptake of these nanoparticles was assessed in vitro in various cell lines. We used an ELISA based method for the detection of intravenously injected nanoparticles in blood plasma, CSF, brain homogenate and liver homogenate of Wistar rats. In addition, brain and liver uptake of nanoparticles was assessed by immunohistochemistry. 


\section{General introduction}

\section{REFERENCES}

Cutler, R. G., J. Kelly, K. Storie, W. A. Pedersen, A. Tammara, K. Hatanpaa, J. C. Troncoso and M. P. Mattson (2004). "Involvement of oxidative stress-induced abnormalities in ceramide and cholesterol metabolism in brain aging and Alzheimer's disease." Proc Natl Acad Sci U S A 101(7): 2070-2075.

Filippov, V., M. A. Song, K. Zhang, H. V. Vinters, S. Tung, W. M. Kirsch, J. Yang and P. J. Duerksen-Hughes (2012). "Increased ceramide in brains with Alzheimer's and other neurodegenerative diseases." I Alzheimers Dis 29(3): 537-547.

Hanada, K., K. Kumagai, S. Yasuda, Y. Miura, M. Kawano, M. Fukasawa and M. Nishijima (2003). "Molecular machinery for non-vesicular trafficking of ceramide." Nature 426(6968): 803-809.

Hannun, Y. A. and L. M. Obeid (2011). "Many ceramides." \Biol Chem 286(32): 2785527862.

Liu, L., R. Martin and C. Chan (2013). "Palmitate-activated astrocytes via serine palmitoyltransferase increase BACE1 in primary neurons by sphingomyelinases." Neurobiol Aging 34(2): 540-550.

Maceyka, M. and S. Spiegel (2014). "Sphingolipid metabolites in inflammatory disease." Nature 510(7503): 58-67.

Mencarelli, C., M. Losen, C. Hammels, J. De Vry, M. K. Hesselink, H. W. Steinbusch, M. H. De Baets and P. Martinez-Martinez (2010). "The ceramide transporter and the Goodpasture antigen binding protein: one protein--one function?" L Neurochem 113(6): 1369-1386.

Mielke, M. M., V. V. Bandaru, N. J. Haughey, J. Xia, L. P. Fried, S. Yasar, M. Albert, V. Varma, G. Harris, E. B. Schneider, P. V. Rabins, K. Bandeen-Roche, C. G. Lyketsos and M. C. Carlson (2012). "Serum ceramides increase the risk of Alzheimer disease: the Women's Health and Aging Study II." Neurology 79(7): 633-641.

Piomelli, D., G. Astarita and R. Rapaka (2007). "A neuroscientist's guide to lipidomics." Nat Rev Neurosci 8(10): 743-754.

Puglielli, L., B. C. Ellis, A. J. Saunders and D. M. Kovacs (2003). "Ceramide stabilizes beta-site amyloid precursor protein-cleaving enzyme 1 and promotes amyloid betapeptide biogenesis." ЦBiol Chem 278(22): 19777-19783.

Raya, A., F. Revert-Ros, P. Martinez-Martinez, S. Navarro, E. Rosello, B. Vieites, F. Granero, J. Forteza and J. Saus (2000). "Goodpasture antigen-binding protein, the kinase that phosphorylates the goodpasture antigen, is an alternatively spliced variant implicated in autoimmune pathogenesis." Ц Biol Chem 275(51): 40392-40399.

Revert, F., I. Ventura, P. Martinez-Martinez, F. Granero-Molto, F. Revert-Ros, J. Macias and J. Saus (2008). "Goodpasture antigen-binding protein is a soluble exportable protein that interacts with type IV collagen. Identification of novel membrane-bound isoforms." LBiol Chem 283(44): 30246-30255.

Takasugi, N., T. Sasaki, M. Shinohara, T. Iwatsubo and T. Tomita (2015). "Synthetic ceramide analogues increase amyloid-beta 42 production by modulating gammasecretase activity." Biochem Biophys Res Commun 457(2): 194-199. 
General introduction 
CERT binds SAP and is present in brain amyloid plaques

\section{CHAPTER 1}

\section{Goodpasture Antigen-Binding Protein/CERAmide TRANSPORTER Binds TO HUMAN SERUM AMYLOID P- Component ANd IS PRESENT in BRAIn AMYloid Plaques}

Chiara Mencarelli, Gerard H. Bode, Mario Losen, Mahesh Kularia, Peter C. Molenaar, Robert Veerhuis, Harry W.M. Steinbusch, Marc H. De Baets, Gerry A.F. Nicolaes and Pilar Martínez-Martínez

Published in JBC 
Chapter 1

Background: The Goodpasture antigen binding protein (GPBP) and serum amyloid $\mathrm{P}$ component (SAP) bind to type IV collagen and are found in plasma.

Results: GPBP binds to human SAP.

Conclusion: GPBP and SAP form complexes under physiological and pathological conditions.

Significance: This interaction might be involved in protein aggregation in Alzheimer's disease and the resulting innate immune response

\section{SUMMARY}

Serum amyloid P component (SAP) is a non fibrillar glycoprotein belonging to the pentraxin family of the innate immune system. SAP is present in plasma, basement membranes and amyloid deposits. This study demonstrates, for the first time, that the Goodpasture antigen binding protein (GPBP) binds to human SAP. GPBP is a nonconventional Ser/Thr kinase for basement membrane type IV collagen. Also GPBP is found in plasma and in the extracellular matrix. In the present study we demonstrate that GPBP specifically binds SAP in its physiological conformations, pentamers and decamers. The START domain in GPBP is important for this interaction. SAP and GPBP form complexes in blood and partly colocalize in amyloid plaques from Alzheimer's disease patients. These data suggest the existence of complexes of SAP and GPBP under physiological and pathological conditions. These complexes are important for understanding basement membrane, blood physiology and plaque formation in Alzheimer's disease.

\section{INTRODUCTION}

Serum amyloid P component (SAP) is present in the blood as single uncomplexed pentamers and decamers (1). SAP has been found to 
decorate amyloid deposits in different amyloid diseases where it was first identified (2). In Alzheimer's disease (AD), SAP colocalizes with amyloid- $ß$ deposits $(A ß)(3,4)$ in the brain and is thought to protect the amyloid from proteolysis (5). Below we will first introduce known properties of SAP and subsequently of the Goodpasture-antigen binding protein (GPBP), which we identify and characterize as a new SAP binding protein in this paper.

SAP is a $23 \mathrm{kDa}$ glycoprotein (6) of the pentraxin family which is characterized by Ca2+-dependent ligand binding (7-10). SAP selfassociation and aggregation is also influenced by $\mathrm{Ca} 2+(11)$.

SAP binds to proteins involved in immunological responses (12-15) and can activate the classical complement pathway through interaction with C1q (16). In addition, SAP interacts with extracellular matrix (ECM) components such as proteoglycans $(8,17)$, fibronectin (18), laminin (10) and collagen IV (9). Collagen molecules are heterotrimers composed of three alpha chains. In collagen IV, each of these $\alpha$-chains consists of an amino-terminal 7S domain, a central helical structure and a carboxyl-terminal globular non-collagenous (NC1) domain. The distribution of SAP in basal membranes (BMs) coincides with the restricted localization of the $\alpha 3-\alpha 4-\alpha 5$ heterotrimer of collagen IV (17). The NC1 domain of the collagen IV $\alpha 3$ subunit ( $\alpha 3(\mathrm{IV}) \mathrm{NC1}$ ) is the autoantigen in Goodpasture (GP) syndrome, an autoimmune disease in which autoantibodies are observed along glomerular and alveolar BMs, causing glomerulonephritis and lung hemorrhage (19).

The Goodpasture antigen binding protein (GPBP) binds to the $\alpha 3($ IV)NC1 in the glomerular basal membrane (GBM) of GP patients (20). GPBP exist in different isoforms which are found in the extracellular compartment; either soluble or associated with the surface of the plasma membrane $(21,22)$ and in blood (23). A shorter splicing isoform, CERT, is located inside the cell and functions as carrier 


\section{Chapter 1}

for ceramide from the ER to the Golgi apparatus (24). GPBP and CERT (also known as CERTL and GPBP $\triangle 26$, respectively) are identical in sequence with the exception of an additional 26 amino acid domain present only in GPBP (25).

Because both SAP and GPBP have been reported to self aggregate $(11,25)$ and have similar properties the question arose as to whether SAP and GPBP could bind to each other. Thus, the aim of the present study was to characterize in detail the direct interaction between these proteins using surface plasmon resonance (SPR), far Western blotting and microscale thermophoresis technology (MST). We report, for the first time, that SAP binds to GPBP and moreover, that SAP and GPBP are co-localized in amyloid plaques from $\mathrm{AD}$ patients. Our data suggest the existence of complexes of SAP and GPBP under normal and pathological conditions.

\section{EXPERIMENTAL PROCEDURES}

\section{Purification of SAP protein from human serum}

SAP was purified from human plasma through an immuno-affinity procedure applying $\mathrm{Ca}^{2+-i o n}$ dependent interactions of SAP with complement factor $\mathrm{C} 4 \mathrm{~b}$-binding protein (C4BP). A monoclonal antibody against C4BP (CLB-C4BP), which is directed against the alpha chains of human C4BP [a kind gift from Dr Jan van Mourik, Sanquin Research, Central Laboratory of the Blood Transfusion Service (CLB), Amsterdam, the Netherlands] was coupled to CNBr-activated Sepharose 4B (GE healthcare, Hoevelaken, the Netherlands) according to manufacturers instructions. Human plasma was fractionated by barium citrate precipitation and eluted with $30 \%$ ammonium sulfate. After precipitation with $70 \%$ ammonium sulfate the protein fraction was dialyzed against Tris buffered saline (TBS: $50 \mathrm{mM}$ Tris-HCl pH 7.4, 150 $\mathrm{mM} \mathrm{NaCl}$ ) supplemented with $3 \mathrm{mM} \mathrm{CaCl}_{2}$ and applied to the anti-C4BP 
CERT binds SAP and is present in brain amyloid plaques

column. After binding of the C4BP-SAP complex, the column was washed with TBS containing $3 \mathrm{mM} \mathrm{CaCl}_{2}$ until $\mathrm{OD}_{280 \mathrm{~nm}}<0.05$. Subsequently, SAP was specifically eluted with TBS containing $2 \mathrm{mM}$ EDTA. Purified human SAP appeared as a single band (>95\% purity) on a Coomassie Blue-stained 4-15\% SDS gel and fractions were pooled and frozen at $-80^{\circ} \mathrm{C}$ until use. The identity of SAP was confirmed by peptide mass fingerprinting using a tandem MALDI-TOF protein analyzer (Applied Biosystems 4800)

\section{Production of recombinant GPBP and CERT proteins}

For recombinant expression of GPBP and CERT we used the vector pHILD2 (Invitrogen, Breda, the Netherlands). The expression cassettes were synthesized (GeneArt, Regensburg, Germany) using the cDNA sequences that encode the human GPBP protein (NP_005704.1) and the human CERT protein (NP_112729.1) preceded by a cassette including an EcoRI restriction site, a standard Kozak consensus for translation initiation, followed by a sequence encoding for MAPLA and a FLAG tag peptide (DYKDDDDK). An EcoRI site was introduced after the stop codon. The plasmids were transfected and expressed in Pichia pastoris (Invitrogen). FLAG-tagged recombinant proteins were purified from the cell lysate with an anti-FLAG M2 affinity agarose gel column (Sigma, A2220, Zwijndrecht, the Netherlands) according to the manufacturer's instructions. The unbound material was washed off the column with TBS and FLAG-tagged proteins were eluted using $100 \mu \mathrm{g} / \mathrm{mL}$ FLAG peptide (Sigma, F3290).

CERT and CERT mutants constructs were synthesized by LifeTechnologies, GeneArt (Regensburg, Germany) in pET28b (Novagen) expression vectors through a PCR-based method. Flagtagged proteins were produced by overexpression in E. coli BL21(DE3) pLYSs (Promega, UK), induced with $1 \mathrm{mM}$ IPTG for 4 hours at $37^{\circ} \mathrm{C}$. 
Chapter 1

Recombinant protein was isolated using the FLAG-tag as described above.

\section{Sample preparation and SPR analysis}

SAP self-aggregation was controlled by optimization of the buffers. To this end, native SAP was diluted at final concentrations of 25, 50 and $100 \mathrm{nM}$ in: 1) sodium acetate buffer $\mathrm{pH} 4.5$; 2) sodium acetate buffer $\mathrm{pH}$ 4.5 with $5 \mathrm{mM} \mathrm{Ca}^{2+}$; 3) 25 mM HEPES buffer pH 7.4; 4) 25 mM HEPES buffer pH 7.4 and sonicated; 5) 25 mM HEPES buffer with $0.01 \%$ Tween 20 at pH 7.4 and sonicated. Sonication was performed before SPR experiments using a probe (Beun-De Ronde B.V., Abcoude, the Netherlands) for 3 pulses of $30 \mathrm{~s}$ each with a $30 \mathrm{~s}$ rest on ice between pulses. Each sample was centrifuged at 20,000 g for $5 \mathrm{~min}$ to remove protein aggregates immediately before SPR analysis.

SPR experiments were performed on a Biacore T100 apparatus (GE healthcare) (26). The guidelines from the manufacturer were followed for the preparation of the sensor surfaces and interpretation of the sensorgrams. Purified human SAP, GPBP and CERT (50 $\mu \mathrm{g} / \mathrm{mL}$ in 10 $\mathrm{mM}$ sodium acetate buffer $\mathrm{pH} 4.5$ ) were covalently coupled via amine groups onto the carboxymethylated dextran surface of CM5 sensor chips (GE healthcare) resulting in a signal of up to 15000 resonance units (RU). Injection of specific antibodies recognizing both GPBP and CERT demonstrated the presence of the proteins immobilized in each flow cell [rabbit polyclonal anti-GPBP/CERT, epitope 1-50 of human GPBP/CERT, Bethyl Laboratories, Montgomery, TX; rabbit polyclonal anti SAP (P-16), Santa Cruz Biotechnology, CA]. Analytes for binding studies were prepared in $25 \mathrm{mM}$ HEPES buffer $\mathrm{pH} 7.4,150 \mathrm{mM} \mathrm{NaCl}$ with $0.01 \%$ Tween 20 . To perform binding experiments, protein samples (purified SAP, human collagen IV (Sigma), human laminin (Sigma), bovine serum albumin (BSA, Sigma), were injected onto the 
chip over a concentration range of $100 \mathrm{nM}-1 \mu \mathrm{M}$ at a flow rate of 10 $\mu \mathrm{L} / \mathrm{min}$ for $5 \mathrm{~min}$ at $25^{\circ} \mathrm{C}$. To test the effect of $\mathrm{Ca}^{2+}$ on protein-protein interaction, the same buffer with addition of $5 \mathrm{mM} \mathrm{Ca}^{2+}$ was used for some of the experiments.

Wild type and five mutant CERT proteins were serially diluted in 25 mM HEPES, $150 \mathrm{mM} \mathrm{NaCl}, 0.01 \%$ Tween 20, pH 7.4, over a wide concentration range (up to $500 \mathrm{nM}$ ) by using 2-fold dilution steps. Samples were injected over a SAP-coated surface of CM5 sensor chip (density, $5000 \mathrm{RU}$ ), for $3 \mathrm{~min}$ at a flow rate of $30 \mu \mathrm{L} / \mathrm{min}$, at $25^{\circ} \mathrm{C}$. At the end of each run, the sensor surface was regenerated (removal of bound complex) by using $25 \mathrm{mM} \mathrm{NaOH}$ before additional samples were injected. As an internal reference, a control channel was routinely activated and blocked in absence of protein. The signals from the control channel were subtracted from the signals generated by the flow cells containing immobilized protein. Analysis was performed on the data using BIAevaluation 3.0 software. Sensorgrams were recorded and normalized to a base line of $0 \mathrm{RU}$.

\section{Microscale Thermophoresis binding analyses}

Microscale thermophoresis (MST) is a new immobilization-free technique for the analysis of biomolecules interaction (27-29). The term Microscale Thermophoresis refers to the directed movement of molecules in optically generated microscopic temperature gradients. This thermophoretic movement is determined by the entropy of the hydration shell around molecules. The microscopic temperature gradient is generated by an IR-Laser. The readout method of the interaction analysis is based on fluorescence. In a typical MSTexperiment the concentration of the labeled molecule is kept constant, while the concentration of the unlabeled interaction partner is varied. 


\section{Chapter 1}

The MST signal will detect the binding by a quantification of the change in the normalized fluorescence (27).

MST analysis was performed on the Monolith NT.115 instrument (NanoTemper, München, Germany). In brief, a constant concentration of 1-50 nM of NT647-labeled GPBP was incubated for $20 \mathrm{~min}$ at room temperature in the dark with different concentrations of SAP (up to $5000 \mathrm{nM}$ ) in PBS/0.01\% Tween 20. Afterwards, 3-5 $\mu \mathrm{L}$ of the samples were loaded into glass capillaries (Monolith NT Capillaries, Cat \# K002) and the thermophoresis analysis was performed (LED 40-51\%, IR laser 80\%). Statistical analysis was performed with Origin8.5 software.

\section{Gel filtration chromatography}

A Superose 6 column with a bed volume of $24 \mathrm{~mL}$ (Perkin-Elmer Series 4 FPLC system) connected to a FPLC system (GE healthcare) was washed with ethanol (20\% v/v) and $0.5 \mathrm{M} \mathrm{NaOH}$, and pre-equilibrated with 3 column volumes of 25 mM HEPES buffer ( $\mathrm{pH} 7.4$ ) with $150 \mathrm{mM}$ $\mathrm{NaCl}$. Samples of purified SAP were run on this column with a buffer flow rate of $0.4 \mathrm{~mL} / \mathrm{min}$. The approximate molecular mass of the fractionated proteins was calculated from peak elution volumes by comparison with molecular weight standards(thyroglobulin, $669 \mathrm{kDa}$; ferritin, $440 \mathrm{kDa}$; fibrinogen, $340 \mathrm{kDa}$; IgG, $160 \mathrm{kDa}$; BSA, $67 \mathrm{kDa}$; ribonuclease A, $13.7 \mathrm{kDa}$; GE healthcare).

\section{Immunoprecipitation and Western blot}

Immunoprecipitation and co- immunoprecipitation of SAP and GPBP from human serum were performed after depletion of albumin (ProteoExtract Albumin Removal Kit; Calbiochem, La Jolla, CA) to increase the resolution of the lower-abundance proteins of interest. Albumin depleted serum was centrifuged at 20,000 g for $30 \mathrm{~min}$. Pull down of endogenous SAP and endogenous GPBP was performed with 
mAb 4E8 (Sigma) and mAb 3A1-C1, respectively. Rabbit polyclonal anti Dok-7 antibody (H-77, Santa Cruz Biotechnology, Heidelberg, Germany) and a mouse monoclonal anti syntaxin 6 (clone 3D10, Abcam, Cambridge, UK) were used as isotype controls. After incubation ( $1 \mu \mathrm{g}$ antibody per $15 \mu \mathrm{L}$ serum; at room temperature for $1 \mathrm{~h}$ ), samples were centrifuged at $20000 \mathrm{~g}$ for $30 \mathrm{~min}$ at $4{ }^{\circ} \mathrm{C}$. Pellets were washed three times in $50 \mu \mathrm{L}$ PBS and boiled in reducing sample buffer containing mercaptoethanol to dissolve immunocomplexes.

Brain tissue from 8 months old control and Alzheimer's transgenic mice (APPswe PS1 $1 \mathrm{E} 9 \mathrm{C} 57 \mathrm{BL} / 6$ ) were thawed and homogenized as described (30). In brief rat cortex was placed in ice cold lysis buffer containing PBS, 0.1\% SDS, 0.1\% Triton X-100, 1\% glycerol, 1 mM EDTA, $1 \mathrm{mM}$ EGTA, $30 \mathrm{mM} \mathrm{NaF}$, and $16.7 \mathrm{mM}$ sodium orthovanadate and a Complete Protease Inhibitor Cocktail tablet (Roche Diagnostics, Almere, the Netherlands) per $50 \mathrm{ml}$ of buffer, following the manufacturers recommendations. Glass beads and a bead beater (Biospec products, Bartlesville, OK) were used for the homogenization of the tissue. The homogenization consisted of 3 cycles of $30 \mathrm{~s}$ in $1.0 \mathrm{ml}$ lysis buffer.

Total protein concentration was determined by a conventional method (BCA protein assay Kit, Pierce). For immunoprecipitation, 2 mg brain homogenates were incubated for $1 \mathrm{~h}$ at room temperature with $3 \mu \mathrm{g}$ of one of the following mAbs: anti-SAP (4E8), anti-GPBP (3A1-C1) or anti$\mathrm{A} \beta$ (human recombinant antibodies bapineuzumab, solanezumab and 20C2, produced recombinantly in house, based on published sequences). Negative controls consisted of IgG mAb anti syntaxin 6 (clone 3D10) or anti-rapsyn (clone 1234, Sigma). Next we added goat anti-mouse (Euroegentec, Maastricht, the Netherlands) during $30 \mathrm{~min}$ at room temperature ( $1 \mu \mathrm{g}$ per sample). Samples were centrifuged at $20000 \mathrm{~g}$ for $30 \mathrm{~min}$ at $4^{\circ} \mathrm{C}$ and immunocomplexes were processed as described above. 
Chapter 1

Proteins were separated by SDS and native-PAGE using precast Criterion Tris- $\mathrm{HCl}$ glycine 4-20\% gradient gels (Bio-Rad, Veenendaal, the Netherlands) followed by electroblotting to nitrocellulose membrane (Millipore, Amsterdam Zuid-Oost, the Netherlands). The membranes were incubated with primary antibodies specific for SAP (4E8), or GPBP using either mAb 3A1-C1, or polyclonal rabbit antiGPBP epitope 1-50 (Bethyl laboratories). or specific for $A \beta$ using anti$A \beta$ (6E10). After PBS washes, the membrane was incubated with goat anti-rabbit-IRdye 800 and donkey anti-mouse-IRdye 680 (Rockland Immunochemicals, Gilbertsville, PA). Finally, the membrane was washed with PBS, dried and scanned using the Odyssey infrared imaging system (Westburg, Leusden, the Netherlands).

\section{Far Western}

For far-Western experiments SAP (80 ng) and BSA (2 $\mu$ g) (Sigma) were separated by SDS-PAGE under reducing conditions and transferred to Immobilon $\mathrm{P}$ membranes (Millipore). For renaturation of SAP, the membranes were incubated in TBS with Tween 20 (0.05\%) over night. Renatured proteins were probed for $1 \mathrm{~h}$ at $37^{\circ} \mathrm{C}$ with either GPBP, CERT or CERT mutants $(30 \mu \mathrm{g} / \mathrm{mL})$ in the same buffer (20). Next, membranes were blocked with 5\% BSA. Bound material was detected using antiGPBP (3A1-C1), anti-SAP (4E8) and donkey anti-mouse-Alexa 680 followed by detection as described above. BSA was detected by standard Coomassie staining.

\section{Immunohistochemistry in kidney}

Sections of monkey control kidney tissue (macaques) (Probetex, San Antonio, TX) were incubated over night at room temperature with primary antibodies [mouse monoclonal anti-GPBP antibody (3A1-C1) and anti-SAP (4E8)], followed by the corresponding secondary 
CERT binds SAP and is present in brain amyloid plaques antibody [donkey anti-mouse biotinylated IgG (Jackson ImmunoResearch Laboratories Europe Ltd., Newmarket, Suffolk, UK)]. Subsequently, sections were incubated with the ABC-kit (Vector Laboratories, Burlingame, CA) followed by 3,3-diaminobenzidine tetrahydrochloride (DAB).

Slides were mounted with $80 \%$ glycerol in TBS. Images were acquired using an Olympus AX70 microscope (Olympus, Zoeterwoude, the Netherlands) and recorded using Cell P software (Olympus).

\section{Immunohistochemistry in human brain}

In order to investigate the presence and localization of GPBP in human brain, post mortem specimens from 3 male and 3 female donors were studied by immunohistochemistry. This material was obtained from the Netherlands Brain Bank (Amsterdam, the Netherlands). Staging of AD was neuropathologically evaluated according to the Braak and Braak criteria (see Table 1) (31). For immunohistochemical staining, $5 \mu \mathrm{m}$ cryosections were mounted on coated glass slides (Menzel Gläser super frost PLUS, Braunschweig, Germany), and fixed in acetone for $10 \mathrm{~min}$. Next, sections were incubated overnight with primary antibodies, including rabbit anti-SAP (Dako), mouse monoclonal anti-A $\beta$ (clone 6F/3D; Dako), affinity purified rabbit antibody specific for the residue 300-350 of human GPBP/CERT (Bethyl laboratories) or polyclonal rabbit anti-GPBP/CERT epitope 1-50. Subsequently, sections were incubated with EnVision goat-anti-mouse horseradish peroxidise (HRP) or EnVision goat-anti-rabbit HRP (Dako). Peroxidase labeling was visualized by EnVision DAB (EV-DAB; Dako). Sections were counterstained with hematoxylin. For co-localization studies, cryosections were incubated in thioflavin $S$ solution to stain $A \beta$ fibrils and washed subsequently three times in ethanol 70\%. Sections were incubated with a mix of primary antibodies: anti-SAP (mAb-14) (32) in 


\section{Chapter 1}

combination with anti-GPBP/CERT $1-50$ or $300-350$ diluted in PBS containing 1\% BSA. After washing in PBS, sections were incubated with a mix of secondary antibodies: biotin conjugated goat-anti-rabbit (Dako) and EnVision goat-anti-mouse HRP (Dako). Upon washing with PBS, sections were incubated with streptavidin Alexa-633; HRP signal was developed with rhodamin tyramide (in presence of $0.01 \% \mathrm{H}_{2} \mathrm{O}_{2}$ ). Slides were covered with Aqua-Poly/Mount (Polysciences Inc, Warrington, PA).

RESULTS

\section{Binding of SAP and GPBP to type IV collagen}

Previously it has been reported that both SAP and GPBP specifically bind to $\alpha 3$ (IV)NC1 monomer (20,33). In order to analyze if this binding occurs in vivo, we studied whether SAP and GPBP colocalize in glomerular basal membrane (GBM), which expresses collagen IV. To this end, frozen monkey kidney sections were stained by immunohistochemistry. SAP showed a linear staining pattern along the GBM as described (34) (Figure 1A upper panel). A monoclonal antibody that recognizes GPBP specifically (mAb3A1-C1) also resulted in a strong staining of the GBM (Figure 1A middle panel). Thus, the reported immunoreactivity of polyclonal antibodies against both GPBP and CERT to tubules and glomerulus in human kidney (20) can be at least partially attributed to the expression of the longer isoform GPBP.

We further examined the binding of SAP and GPBP to collagen IV by SPR technology. Collagen IV bound to immobilized human GPBP and human SAP (Figure 1B and C).

Binding of SAP to several ligands is dependent on the presence of $\mathrm{Ca}^{2+}$ $(7,8,35)$. Binding of collagen IV to SAP was enhanced by $3-4$ fold by the addition of $5 \mathrm{mM} \mathrm{Ca}^{2+}$ (Figure 1C). In contrast, binding of collagen IV to 
GPBP was independent of the presence of $\mathrm{Ca}^{2+}$ (Figure 1B). Binding of BSA to immobilized SAP or GPBP was minimal (data not shown).

A

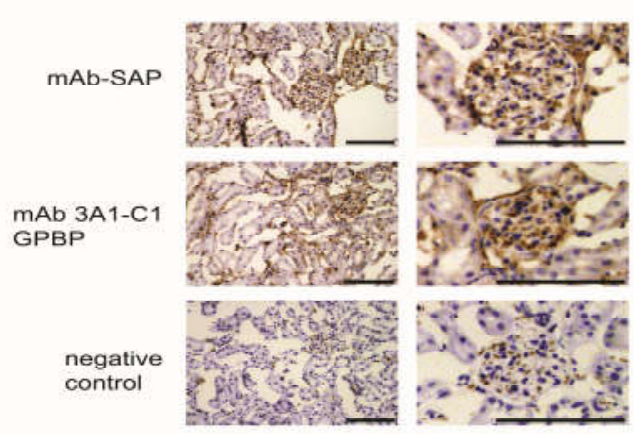

B

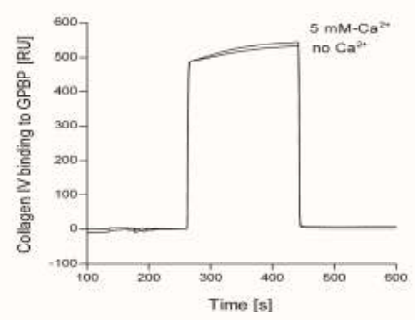

Figure 1

C

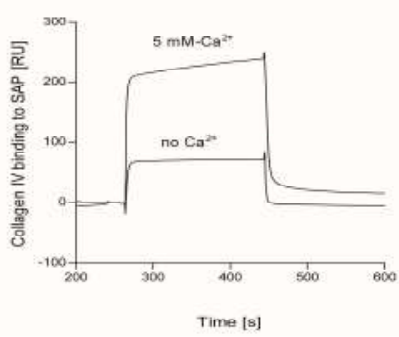

FIGURE 1. Collagen IV binds to SAP and to GPBP

(A) Representative monkey kidney sections with glomeruli stained for GPBP and SAP; SAP with $\mathrm{mAb}$; GPBP with mAb 3A1-C1. No staining was observed when the primary antibodies were omitted. Scale bars represent $100 \mu \mathrm{m}$. (B-C) The detection of the protein-protein interaction was performed with specific antibodies against SAP and GPBP using SPR technology. (B) Collagen IV was filtered (0.45- $\mu \mathrm{m}$ Millipore filter), and then injected $(100 \mathrm{nM})$ over immobilized GPBP (101 RU; flow rate, $15 \mu \mathrm{L} / \mathrm{min}$; injected volume, $60 \mu \mathrm{L}$ ) in $25 \mathrm{mM}$ HEPES buffer $\mathrm{pH} 7.4,150 \mathrm{mM} \mathrm{NaCl}$ (either without $\mathrm{Ca}^{2+}$ or with $5 \mathrm{mM} \mathrm{Ca}{ }^{2+}$ ). In panel (C) collagen IV was injected at $100 \mathrm{nM}$ over immobilized SAP (101 RU; flow rate, $15 \mu \mathrm{L} / \mathrm{min}$; injected volume, $60 \mu \mathrm{L})$ in $25 \mathrm{mM}$ HEPES buffer pH 7.4, $150 \mathrm{mM} \mathrm{NaCl}$ (either without $\mathrm{Ca}^{2+}$ or with $5 \mathrm{mM} \mathrm{Ca}^{2+}$ ). 


\section{Chapter 1}

Kinetic analysis of the binding of soluble collagen IV to immobilized SAP and to GPBP was performed by SPR. Collagen IV (concentrations ranging between 10 to $250 \mathrm{nM}$ ) bound to GPBP strongly; increasing the concentration of collagen IV up to $250 \mathrm{nM}$ did not saturate this binding (Figure 2A). As expected, collagen IV also bound to immobilized SAP (Figure 2B) and in this case binding was already almost saturated at 10 nM collagen IV. These data suggest that once collagen IV has bound to immobilized GPBP, additional collagen IV can bind by forming GPBPcollagen-collagen complexes. In contrast, SAP binding to collagen IV does not induce formation of larger collagen aggregates Binding of collagen IV to CERT was also studied and compared with GPBP (Figure 2C). Collagen IV rapidly associated with both immobilized proteins. However, collagen IV dissociated faster from CERT than from full-length GPBP.

\section{Binding of laminin to immobilized GPBP}

SAP has been shown to bind laminin, another important component of basement membranes (10). However, the binding of GPBP to laminin has yet to be reported. By SPR binding experiments we found that laminin binds to immobilized GPBP (Figure3). Binding of laminin to GPBP was enhanced by approximately $25 \%$ with the addition of $5 \mathrm{mM}$ $\mathrm{Ca}^{2+}$ (Figure 3). 
CERT binds SAP and is present in brain amyloid plaques

A

Figure 2

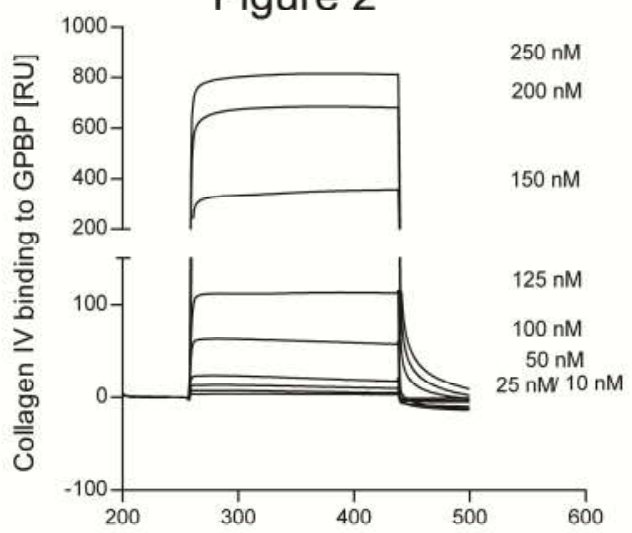

B

Time [s]

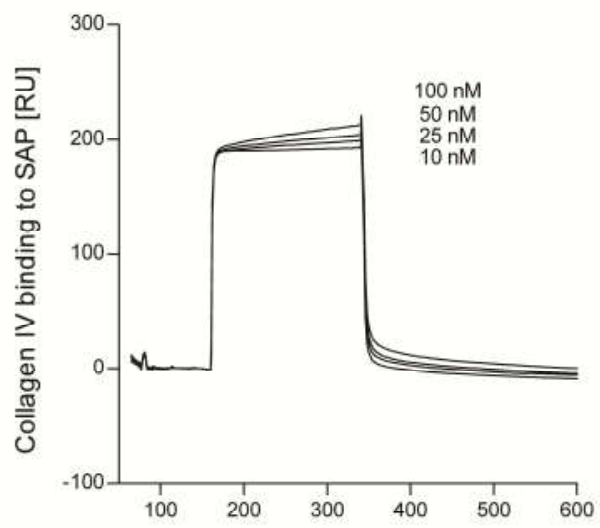

C

Time [s]

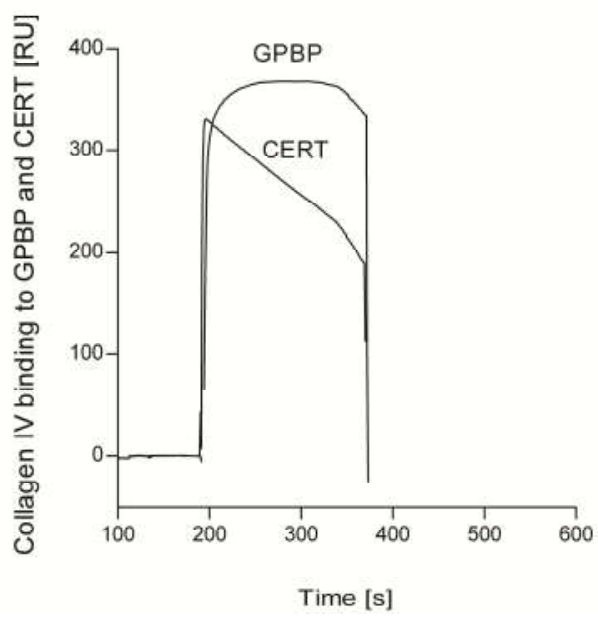




\section{Chapter 1}

FIGURE 2. Collagen IV binds to SAP, GPBP and CERT Overlay of sensograms resulting from the injection of different concentrations (10-250 nM) of collagen IV over immobilized GPBP (96 RU, flow rate, $15 \mu \mathrm{L} / \mathrm{min}$; injected volume, $60 \mu \mathrm{L}$ ) (A) and over immobilized SAP (96 RU, flow rate, $15 \mu \mathrm{L} / \mathrm{min}$; injected volume, $60 \mu \mathrm{L}$ ) (B). Binding of collagen IV (100 nM) to immobilized GPBP and CERT $(50 \mu \mathrm{g} / \mathrm{mL}$ in $10 \mathrm{mM}$ sodium acetate buffer $\mathrm{pH} 4.5$ ) (C). The sensograms were corrected for the signal in the empty cell (i.e. calculated as the difference between the signal in Fc2 (flow channel 2) that contained the immobilized ligand and the signal in Fc1 (empty channel), which includes injection noise, instrument drift, and nonspecific binding).

\section{Figure 3}

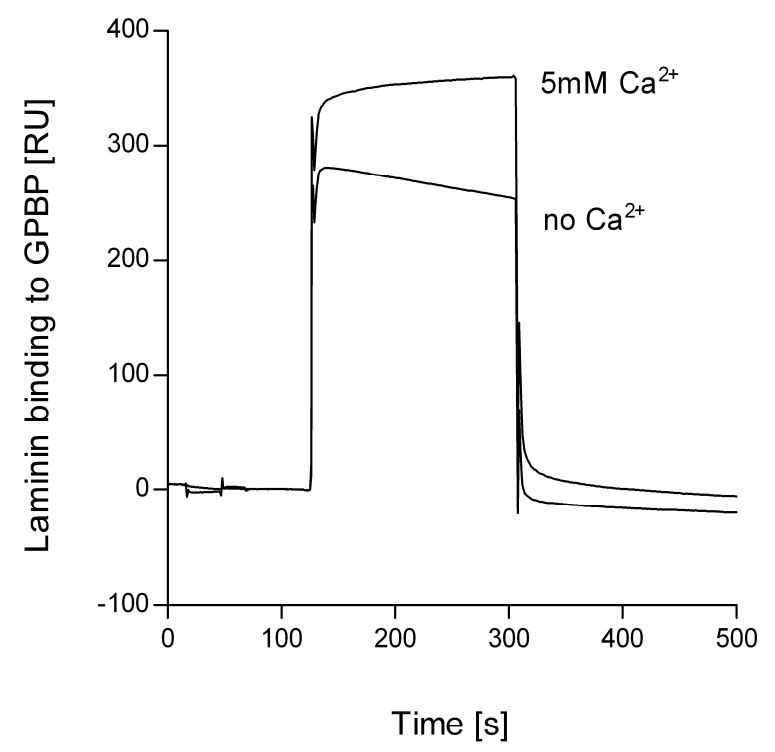

FIGURE 3. Laminin binds to GPBP

(A) Binding of laminin (100 $\mathrm{nM}$ ) to immobilized GPBP (215 RU; flow rate, $15 \mu \mathrm{L} / \mathrm{min}$; injected volume, $60 \mu \mathrm{L}$ ) in buffer containing $5 \mathrm{mM} \mathrm{Ca}^{2+}$ or buffer without $\mathrm{Ca}^{2+}$. The binding was first recorded in the absence of added $\mathrm{Ca}^{2+}$. The experiments were performed by SPR technology.

\section{Binding of SAP to immobilized GPBP}

Since SAP and GPBP bind to collagen IV, and colocalize at GBM, we asked the question whether they could interact with each other. We measured the binding of GPBP to immobilized SAP by far-Western (Figure 4A) (36,37). For this purpose, membranes containing SAP (80 
CERT binds SAP and is present in brain amyloid plaques

ng) and BSA (2,000 ng) as negative control were incubated in renaturation buffer over night and subsequently probed with GPBP. Our experiment showed that GPBP strongly bound to SAP but not to BSA, suggesting that SAP and GPBP interact. This interaction is dependent on renaturation of SAP on the membrane since Western blot separation of SAP followed by immediate membrane incubation with GPBP without renaturation did not lead to significant binding of GPBP to SAP (Figure $4 \mathrm{~A})$.

We further investigated the molecular characteristics and the kinetics of this binding by SPR. SAP is a highly interactive protein prone to extensive self-aggregation (38). We found that by careful selection of buffer conditions as $\mathrm{pH}$, presence/absence of $\mathrm{Ca} 2+$ and of detergent, it was possible to control the process of self-association (Figure 4B). Human SAP was found to be highly aggregated $(>250 \mathrm{kDa})$ at $\mathrm{pH} 7.4$ (with or without $\mathrm{Ca} 2+$ ) and did not migrate into a $4 \%$ polyacrylamide gel under native and non-reducing conditions. However, it was found that sonication of SAP in HEPES buffer pH 7.4 with $0.01 \%$ Tween 20 to a large extent prevented this protein aggregation and precipitation; sonication disrupted aggregates and the presence of the detergent stabilized SAP in physiological pentameric and decameric species. High temperature treatment, high salt and organic solvent were also tested but resulted in irreversible denaturation (data not shown). We studied the binding of fluid phase SAP to immobilized GPBP and CERT by SPR (Figure 4C and D). Interestingly, we found that SAP (stabilized as pentamers and decamers, as described above) binds both GPBP and CERT in the absence of $\mathrm{Ca} 2+$. Conversely, in the presence of $5 \mathrm{mM} \mathrm{Ca} 2+$ this binding was reduced 5-7-fold.

SAP interaction with both GPBP and CERT was characterized by a rapid association rate; however, SAP binding to GPBP was stronger than to CERT. 
Chapter 1

To explore in more detail the different affinity of SAP for the two protein isoforms, we immobilized SAP on the sensor chip and applied as analyte a peptide containing 14 (385-398) of the 26 amino acids encoded by exon 11 of GPBP. Exon 11 encodes a short domain that is absent in CERT. This peptide was shown to bind immobilized SAP (Figure 4E) which supports the notion that this region of GPBP participates in the interaction with SAP.

A

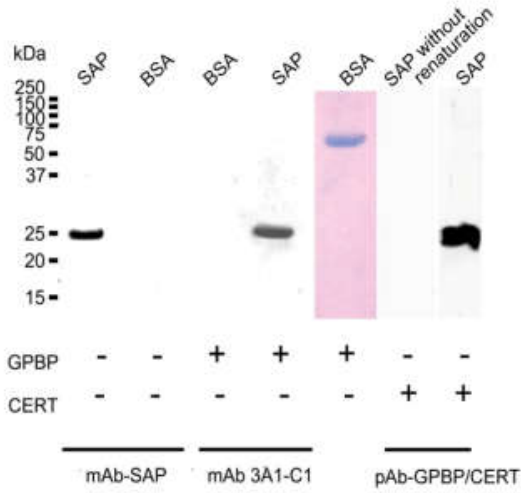

B

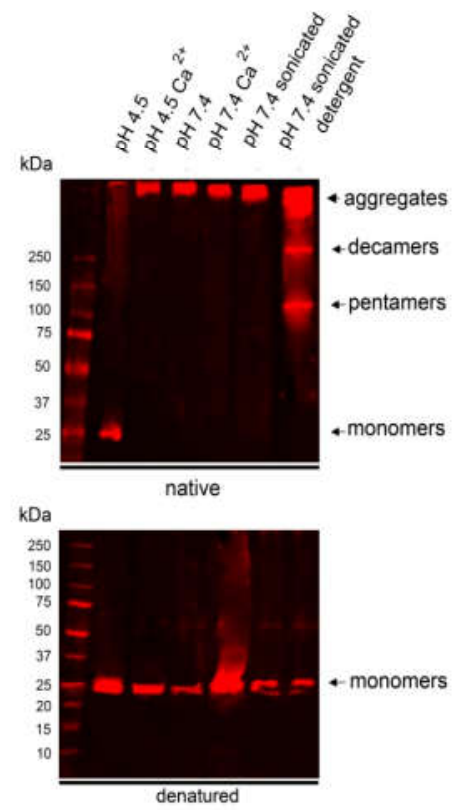

C
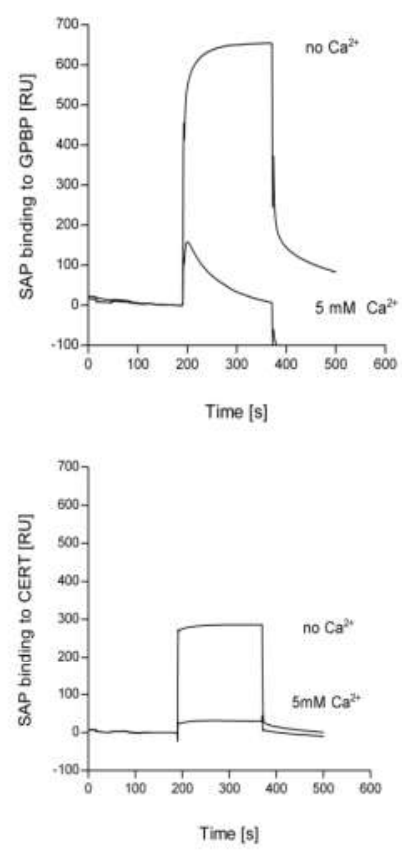

E

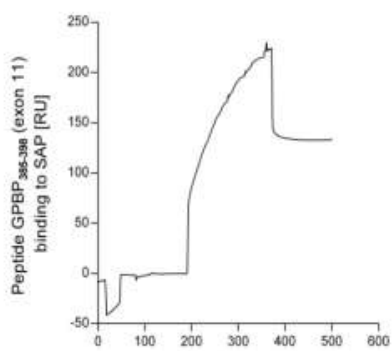

Figure 4
Time [s] 
FIGURE 4. Solid phase interaction of SAP with GPBP

(A) Far-Western blot experiments. Human SAP and BSA were separated by SDS-PAGE, transferred to a nitrocellulose membrane and renatured. As a negative control for the renaturation, SAP was kept in $6 \mathrm{M}$ urea ('SAP without renaturation'). After blocking, membranes were incubated with either GPBP or with CERT as a probe using immobilized SAP as bait. Bound proteins were detected with mAb anti-SAP, anti GPBP (3A1-C1) or a polyclonal antibody against GPBP/CERT. The presence of BSA was confirmed by Coomassie. Both GPBP and CERT bound specifically to renatured SAP, but not to BSA or denatured SAP.

(B) SAP aggregation is influenced by $\mathrm{pH}$, the composition of the buffer and the presence or absence of $\mathrm{Ca} 2+$. The treatment of SAP before the Western blot was performed as follows: SAP was diluted at $10 \mathrm{ng} / \mu \mathrm{L}$ : (lane 1 ) in $10 \mathrm{mM}$ sodium acetate buffer $\mathrm{pH}$ 4.5; (lane 2) in sodium acetate buffer $\mathrm{pH} 4.5$ in the presence of $5 \mathrm{mM}$ calcium; (lane 3) in 25 mM HEPES buffer pH 7.4; (lane 4) in HEPES buffer pH 7.4 in the presence of $5 \mathrm{mM}$ calcium; (lane 5) in HEPES buffer pH 7.4 followed by sonication with a probe sonicator for 3 pulses of $30 \mathrm{~s}$ each with a $30 \mathrm{~s}$ rest on ice between each pulse; (lane 6) in $25 \mathrm{mM}$ HEPES buffer $\mathrm{pH} 7.4$ followed by sonication as aforementioned in the presence of $0.01 \%$ Tween 20. Different percentages of Tween $20(1 \%, 0.1 \%$ and $0.001 \%)$ were tested before choosing the optimal at $0.01 \%$. SAP was separated using native-PAGE and SDS-PAGE 4-20\% gradient gels. The proteins were transferred to nitrocellulose membranes and incubated with anti-SAP antibody. $10 \mathrm{ng} / \mu \mathrm{L}$ SAP diluted in sodium $10 \mathrm{mM}$ acetate buffer $\mathrm{pH} 4.5$ and run in native conditions separated unique SAP species of $25 \mathrm{kDa}$ (monomers). $10 \mathrm{ng} / \mu \mathrm{L}$ SAP diluted in HEPES buffer $\mathrm{pH} 7.4$, sonicated in the presence of $0.01 \%$ Tween and run in native PAGE separated SAP species corresponding to: high molecular aggregates > $250 \mathrm{kDa}, 250 \mathrm{kDa}$ (decamers) and $100 \mathrm{kDa}$ (pentamers). As expected, independently of the buffer in which SAP has been diluted, in SDS-PAGE, SAP separated as a band of $25 \mathrm{kDa}$ (monomers).

(C) Binding of SAP to immobilized GPBP (215 RU; flow rate, $15 \mu \mathrm{L} / \mathrm{min}$; injected volume, $60 \mu \mathrm{L}$ ). The binding was recorded in $25 \mathrm{mM}$ HEPES buffer $\mathrm{pH} 7.4,150 \mathrm{mM}$ $\mathrm{NaCl}$. The presence of $5 \mathrm{mM} \mathrm{Ca} 2+$ decreased the binding of SAP to immobilized GPBP.

(D) Binding of SAP to immobilized CERT (215 RU; flow rate, $15 \mu \mathrm{L} / \mathrm{min}$; injected volume, $60 \mu \mathrm{L}$ ). The binding was first recorded in the absence of added $\mathrm{Ca}^{2+}$ in $25 \mathrm{mM}$ HEPES buffer $\mathrm{pH} 7.4,150 \mathrm{mM} \mathrm{NaCl}$. The presence of $5 \mathrm{mM} \mathrm{Ca}^{2+}$ decreased the binding of SAP to immobilized CERT. The general shape of the curves revealed that SAP had very fast association rates with both proteins, although SAP remained bound to GPBP for a longer period at the end of the injection.

(E) Binding of a peptide containing amino acids 385-398 from GPBP exon 11 to immobilized SAP (215 RU; flow rate, $15 \mu \mathrm{L} / \mathrm{min}$; injected volume, $60 \mu \mathrm{L}$ ) in $25 \mathrm{mM}$ HEPES buffer $\mathrm{pH} 7.4,150 \mathrm{mM} \mathrm{NaCl}$.

Kinetic analysis of SAP binding to immobilized GPBP was performed by varying the concentrations of SAP added (ranging from $25 \mathrm{nM}$ to 100 $\mathrm{nM}$ ) (Figure 5). We found that the binding of SAP to GPBP does not saturate, suggesting that GPBP-SAP-SAP complexes can be formed, in 
analogy to what is described for type IV collagen binding above (Figure $2 \mathrm{~A}$ and $\mathrm{B}$ ). Therefore, these data indicate that SAP binding to GPBP in solid phase is non saturable, making it difficult to reliably estimate the binding constant. In this respect, the SPR data should be regarded as qualitative evidence, demonstrating the direct binding of proteins involved.

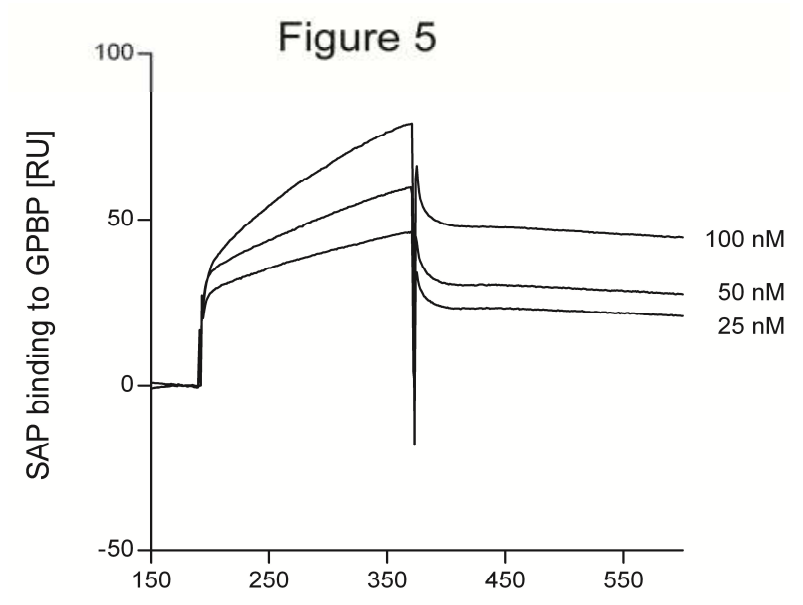

Time [s]

FIGURE 5. Overlay of sensorgrams resulting from the injection of different concentrations (25-100 nM) of SAP over immobilized GPBP (96 RU, flow rate, 15 $\mu \mathrm{L} / \mathrm{min}$; injected volume, $60 \mu \mathrm{L}$ ). The sensograms were corrected for the signal in the empty cell (i.e. calculated as the difference between the signal in Fc2 and the signal in Fc1, which includes injection noise, instrument drift, and nonspecific binding).

\section{Binding of SAP to GPBP in solution}

Microscale thermophoresis (MST) was performed in order to determine the dissociation constant of SAP to fluorescently labeled GPBP in fluid phase. $10 \mathrm{nM}$ of NT-647 labeled GPBP was mixed with increasing SAP concentrations. After a short incubation time the samples were loaded into glass capillaries and a thermophoretic analysis was performed on the Monolith.NT115 using 51\% LED-Power and $80 \%$ IR-Laser power. The normalized fluorescence Fnorm is 
plotted for different concentrations of SAP. An apparent $K_{D}$ of $5.7 \mathrm{nM}$ $+/-2.66 \mathrm{nM}$ was determined for this interaction (Figure 6).

\section{Figure 6}

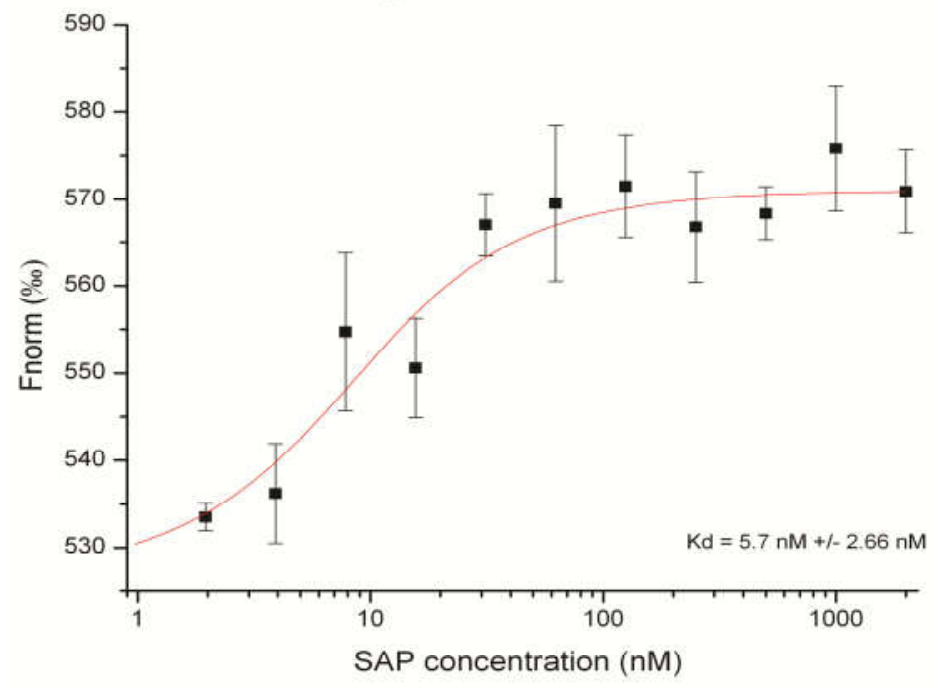

FIGURE 6. SAP binds to GPBP in solution

Microscale thermophoresis (MST) was performed in order to determine the dissociation constant of SAP to fluorescently labeled GPBP. $10 \mathrm{nM}$ of NT-647 labeled GPBP was mixed with increasing SAP concentrations. The normalized fluorescence Fnorm is plotted for different concentration of SAP. A Kd of $5.7 \mathrm{nM}+/-2.66 \mathrm{nM}$ was determined for this interaction.

Binding of different molecular weight species of SAP to immobilized GPBP

To further study the capacity of the different SAP species to interact with GPBP, we isolated fractions of SAP by size exclusion chromatography for immediate SPR analysis. Three peaks were separated by gel filtration chromatography from SAP (sonicated in HEPES buffer pH 7.4 with $0.01 \%$ Tween 20) (Figure 7A). SAP peaks I to III corresponded to high molecular aggregates ( $>250 \mathrm{kDa})$, decamers $(250 \mathrm{kDa})$ and pentamers (125 kDa) as judged from native-PAGE gels (Figure 7B, native). SAP peaks separated by SDS-PAGE under reducing 
Chapter 1

conditions corresponded to $25 \mathrm{kDa}$ (monomers) (Figure 7B, denatured). SAP decamers and pentamers (peaks II and III, respectively) bound immobilized GPBP, whereas SAP aggregates (peak

I) did not (Figure 7C-E). Likewise, peak IV which consists of benzamidine was found not to bind to GPBP (Figure 7F). In summary, these data indicate that SAP pentamers and decamers, the physiologically active species, bind to GPBP and that the binding observed (in the previous experiments, Figures 4C and D and 6) was not a result of non-specific binding of SAP aggregates.

\section{SAP and GPBP form complexes in blood under physiological conditions}

SAP is present in human serum at a concentration between 30 and 50 $\mathrm{mg} / \mathrm{L}(37,38)$. Recently, the presence of GPBP in human serum has been described (23). To study whether SAP associates with GPBP in serum, co-immunoprecipitation experiments were performed. After precipitation with anti-SAP antibodies, both SAP and GPBP were detected by Western blot. Antibodies against GPBP epitopes 1-50 (Figure 8) and 300-350 (data not shown) detected a GPBP fragment of approximately 35-37 kDa which has been previously described (22). This fragment was not present in a pull-down performed with an isotype control antibody, when detected with the same GPBP-specific antibodies. Based on the antibody specificities, these results suggest that SAP associates in the blood with a $\sim 37 \mathrm{kDa}$ GPBP fragment containing the $\mathrm{N}$-terminal region and the middle domain. 
CERT binds SAP and is present in brain amyloid plaques

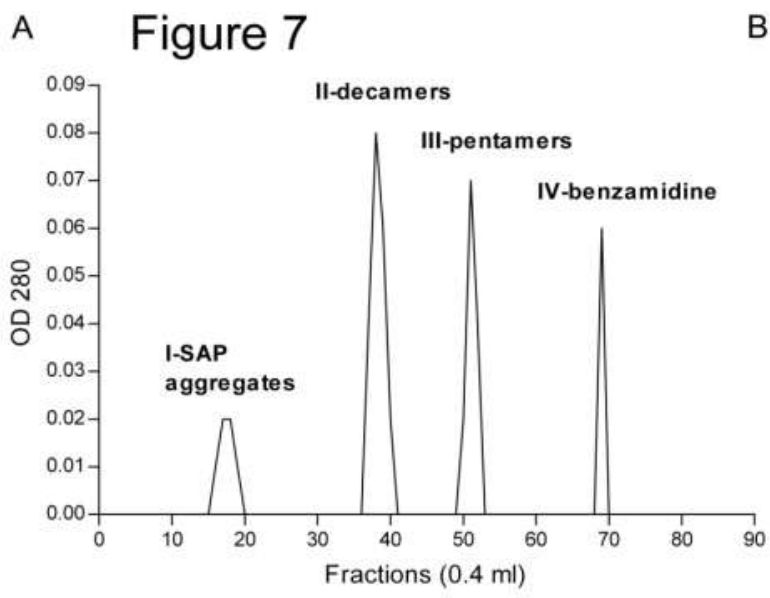

B Native I II III IV

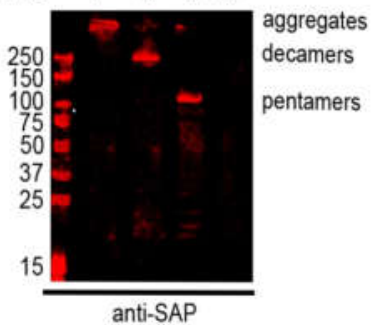

C

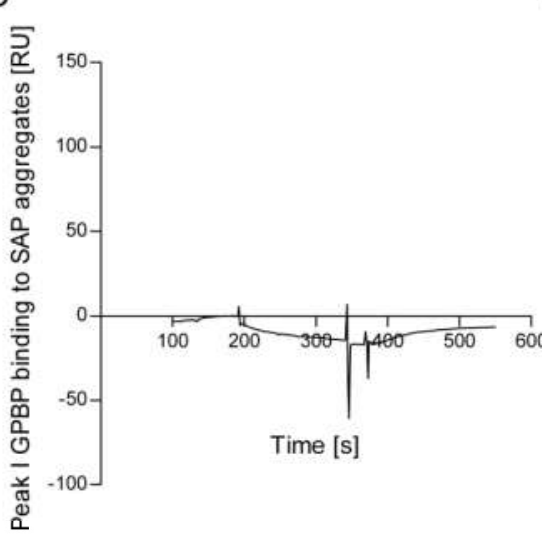

D

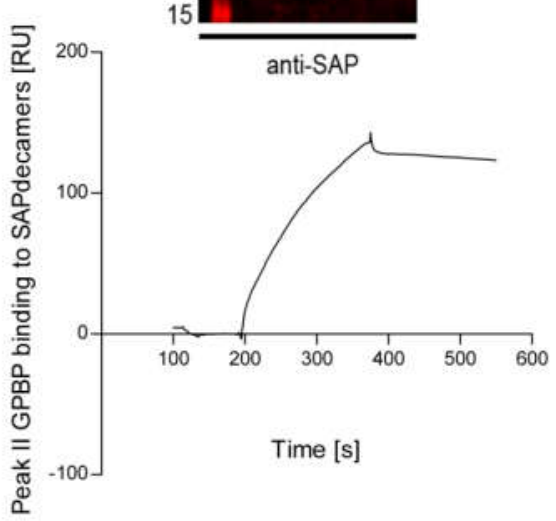

E

$\mathrm{F}$

Denatured I II III IV
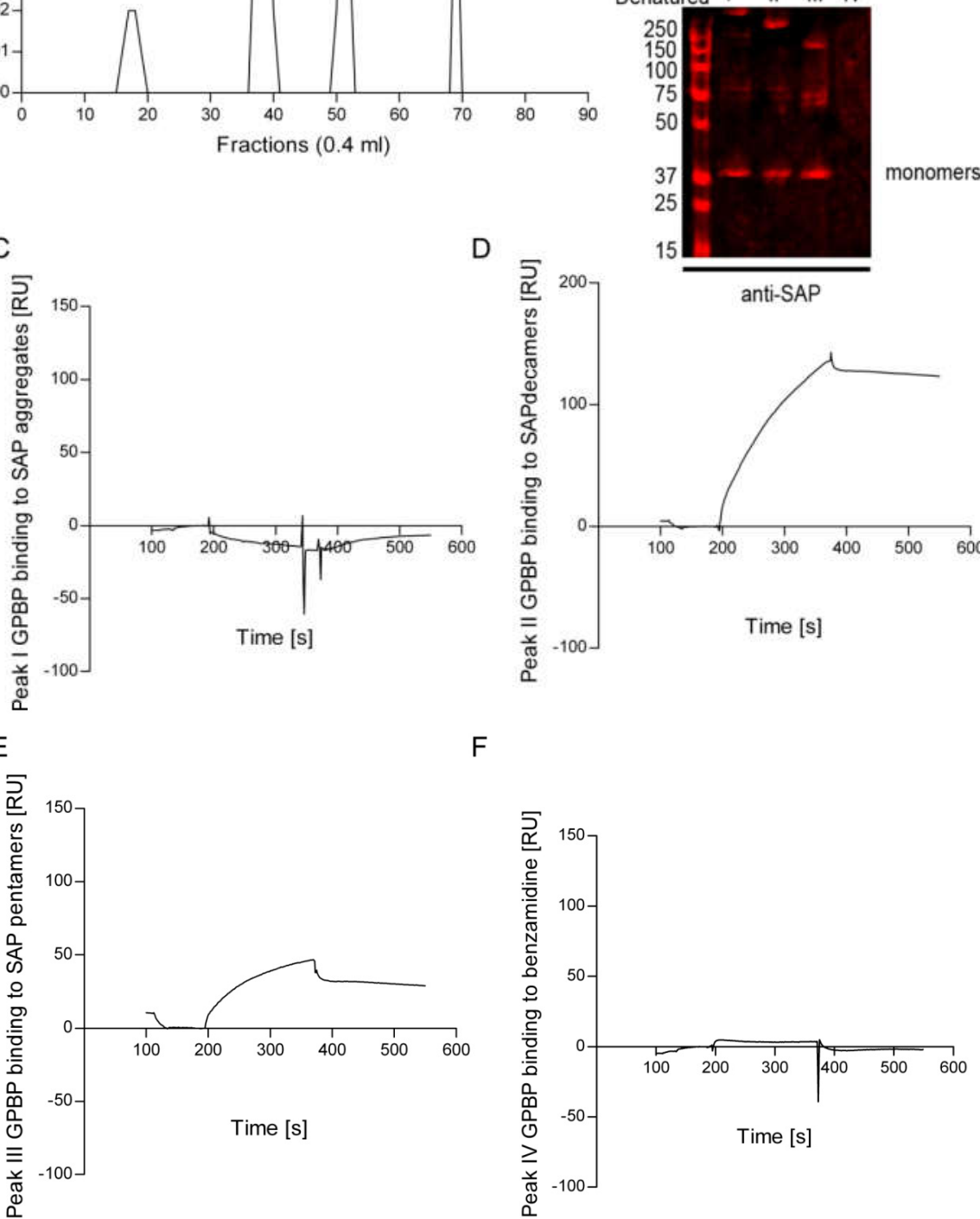


\section{Chapter 1}

FIGURE 7. SAP decameric and pentameric species bind to GPBP

Purification of different SAP species was performed by Superose 6 column size exclusion chromatography. Samples diluted in 25 mM HEPES buffer (pH 7.4), 150 mM $\mathrm{NaCl}$ were then injected at a concentration of $0.5 \mathrm{mg} / \mathrm{mL}$ and were chromatographed at a flow rate of $0.4 \mathrm{~mL} / \mathrm{min}$. Four peaks were observed. (B) Fractions from peaks I to IV from the Superose 6 gel filtration column were separated using native-PAGE and SDS-PAGE 4-20\% gradient gels. The proteins were transferred to nitrocellulose membranes and incubated with anti-SAP antibody. Upper panel, native electrophoresis. Lower panel, denatured electrophoresis. The anti-SAP antibody detected bands of molecular weights: $>250 \mathrm{kDa}$ in peak I, $250 \mathrm{kDa}$ (decamers) in peak II and $100 \mathrm{kDa}$ (pentamers) in peak III in native conditions, and $25 \mathrm{kDa}$ (monomers) in denatured conditions in fractions from peaks I to III. (C to F) Sensograms resulting from the injection of peaks I to IV over immobilized GPBP (96 RU, flow rate, $15 \mu \mathrm{L} / \mathrm{min}$; injected volume, $60 \mu \mathrm{L}$ ). (C) No binding was observed with SAP peak I which corresponds to high molecular weight SAP aggregates. (D and E) 50150 RU were observed in SAP peak fractions II and III, which correspond to decamers and pentamers respectively (F) Peak IV corresponds to benzamidine and did not bind to immobilized GPBP.

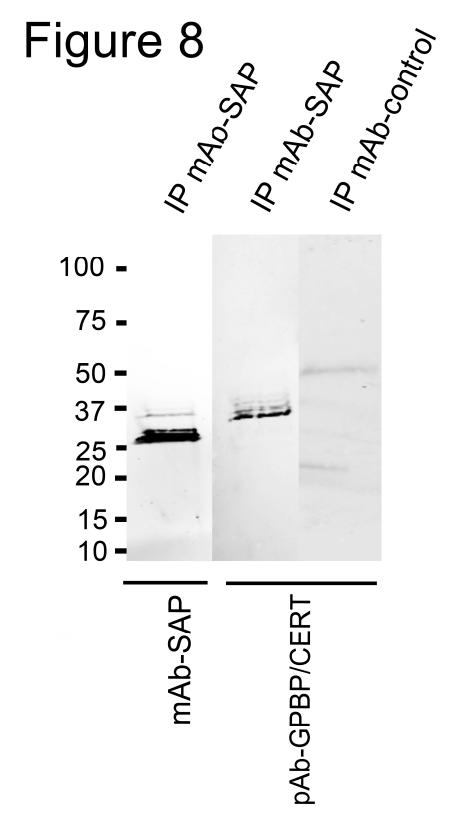

FIGURE 8. SAP-GPBPs complexes in plasma SAP was immunoprecipitated with mouse mAb anti SAP, (clone 4E8, Sigma) followed by immunoblotting with the same antibody to detect immunoprecipitated SAP (first lane) and a polyclonal antibody against GPBP/CERT1-50 detect GPBPs (second lane). The control using an isotype control mAb (mouse monoclonal anti-syntaxin 6, clone 3D10) for immunoprecipitation was negative when detected with the same polyclonal antibody against GPBP (third lane).

GPBP is efficiently co-precipitated with SAP in a band of $\sim 37 \mathrm{kDa}$, suggesting that a part of GPBP molecule corresponding to the amino terminal domains of the protein interacts with SAP. Results shown are representative of 5 experiments. 
CERT binds SAP and is present in brain amyloid plaques

\section{GPBP is present in brain amyloid plaques}

Since SAP is a universal component of all types of amyloid deposits, possible associations of GPBP with amyloid deposits in human brain were studied by immunohistochemistry. Stainings were performed on cryostat sections of post mortem temporal cortex specimens from aged donors, including: non-demented controls, control cases with amyloid deposits and with cortical changes (though not sufficient to be classified as $\mathrm{AD}$ ), and $\mathrm{AD}$ patients (Table 1 ).

Considerable SAP immunoreactivity was found to be associated with $A B$ plaques in the $\mathrm{AD}$ and demented cases (81, 135 and 294, Figure 9A middle right panel). SAP was less abundant but also associated with $A ß$ plaques in the non demented control cases (not shown). Polyclonal antibodies reacting with GPBP/CERT stained vague, globular plaquelike structures (e.g. case 47, Figure 9A upper right panel and case 294, Figure 9A middle left panel). Occasional dense deposits, possibly representing plaque cores were observed (case 115, not shown). Plaque-associated microglia were immunoreactive in the AD cases (e.g. case 264, Figure 9B). Additionally, microglia in the white matter were strongly immunopositive for GPBP/CERT, in all cases (e.g. case 47; Figure 9A, upper left panel); In the demented control case 294, plaques and associated microglia in the grey matter were strongly immunoreactive (Figure 9A, lower panel), as were white matter microglia.

In order to determine possible colocalization of GPBP/CERT with SAP in tissue specimens, double immunofluorescent stainings were performed. To visualize fibrillar Aß deposits, sections were also stained with Thioflavin S. In AD case 264, SAP was found to completely colocalize with fibrillar $A ß$ in plaques, whereas GPBP/CERT was associated with cellular structures in the centre of the plaque, possibly 


\section{Chapter 1}

representing recruited microglia partially colocalizing with SAP (Figure 9B).

A number of GPBP immunopositive neuronal cells were observed, also in plaques; occasionally the endothelial cell lining as well as the basement membrane of a blood vessel were GPBP immunopositive (Figure 9B upper panel).

Additionally we performed immunoprecipitation experiments using homogenates from control and $\mathrm{AD}$ mouse brains to confirm the interaction of SAP with GPBP and to distinguish between GPBP and CERT (Figure 9C). Immunoprecipitation of either GPBP (mAb 3A1-C1) or SAP from brain lysates from the AD mouse model co-isolated $A ß$ (detected with 6E10) in a few bands of $\sim 100 \mathrm{kDa}$. The same bands were also found in a control experiment following immunoprecipitation of $A B$ from $A D$ mouse brain with a combination of recombinant human antibodies recognizing different aggregation forms of $A ß$ (bapineuzumab directed against plaques, 20C2 directed against fibrils, solanezumab directed against monomers). In wild type littermates, these bands were not observed. The observed $A ß$ bands $(\sim 100 \mathrm{kDa})$ could correspond to $A ß$ aggregates which are preserved using the tissue disruption protocol and/or to amyloid precursor protein (APP). The possible presence of APP would not be surprising since it is several times upregulated in this animal model. Lower $A ß$ molecular weight forms were not detected using anti-A $\beta$ (6E10) as reported previously (41). Western blotting with a monoclonal anti-Aß revealed that immunoprecipitation of either GPBP (mAb 3A1-C1) or SAP from brain lysates from an AD mouse model, but not from wild type littermates, coisolated $A ß$, which suggests the presence of Aß-SAP and Aß-GPBP complexes in $\mathrm{AD}$ model mouse brain. Immunoprecipitation with nonspecific immunoglobulins performed as a control did not co-isolate $A ß$. 
CERT binds SAP and is present in brain amyloid plaques

A
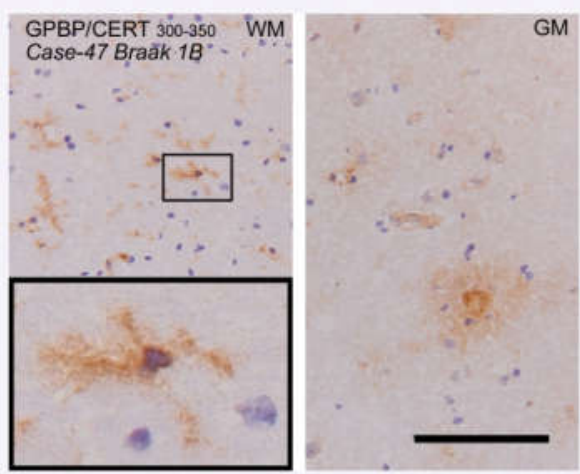

GPBPICERT $300-350$
Case-294 Braak $2 B$

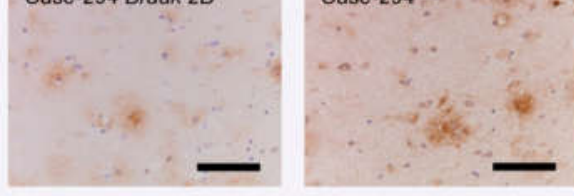

GPBP/CERT 1-50

Case-294

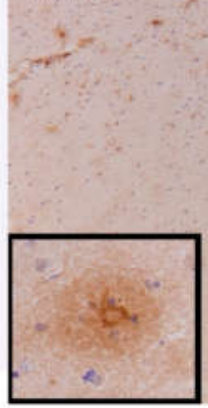

C

\begin{tabular}{|c|c|c|c|}
\hline $\begin{array}{l}\text { IP } \\
\text { mAb } \\
\text { anti-A } \beta\end{array}$ & $\begin{array}{l}\text { IP } \\
\text { GPBP } \\
\text { mAb } \\
3 A 1-C 1\end{array}$ & $\begin{array}{l}\text { IP } \\
\text { MAb } \\
\text { SAP }\end{array}$ & $\begin{array}{l}\text { IP } \\
\text { Isotype } \\
\text { control }\end{array}$ \\
\hline Wt $A D$ & Wt $A D$ & Wt $A D$ & Wt $\quad A D$ \\
\hline
\end{tabular}

150 -

$100-\quad 2-5$

$75-$

$\mathrm{mAb}$ anti-A $\beta$
B
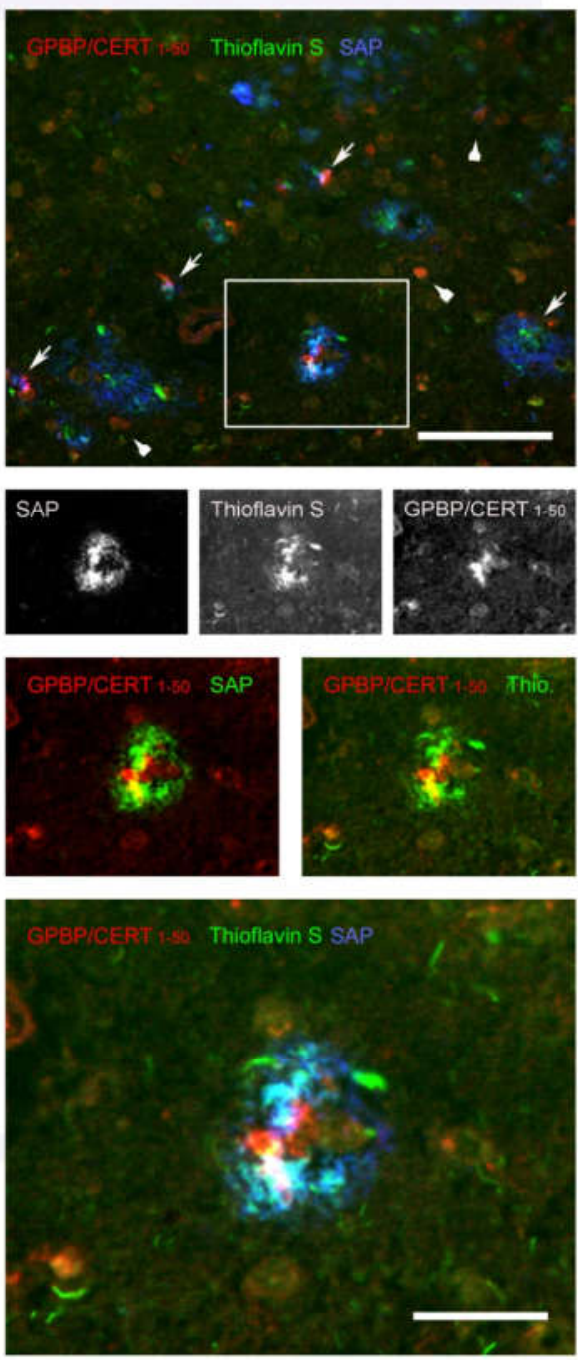

Figure 9 


\section{Chapter 1}

FIGURE 9. GPBP is present in amyloid plaques

Immunohistochemical stainings of GPBP/CERT and SAP in midtemporal cortex of AD and demented and non-demented control cases (cryostat sections). (A) Upper panel: Control case 47 (Braak 1B) white matter (WM) immunostained with antiGPBP/CERT $300-350$ shows many ramified microglia (see insert) and to some extent endothelial lining of blood vessels, whereas in the grey matter (GM) amyloid plaque staining and intense GPBP staining around the plaque core, reminiscent of clustered microglia, and in addition cytoplasmatic staining of neuronal cells is seen. Lower panel: Demented control case (\#294) with cortical changes but not sufficient to be

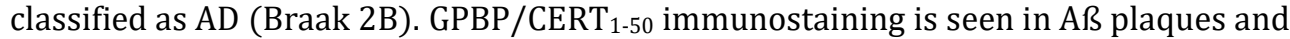
microglia, especially microglia in the white matter (upper right) and near the core of a classical plaque (see also higher magnification insert). Similar as with antiGPBP/CERT $1-50$, plaque and microglial staining was seen with anti-GPBP/CERT ${ }_{300-350 \text {, }}$ but less pronounced. With anti SAP, in addition to plaques, also some cytoplasmatic neuronal staining was observed (two central panels). (B) Immunofluorescence staining was performed to further investigate co-localization of GPBP and SAP. Fibrillar Aß deposits in an AD case (case \# 264) were visualized with Thioflavin S, SAP with monoclonal SAP-14 followed by goat-anti-mouse HRP and rhodamine-tyramide and GPBP with anti-GPBP/CERT ${ }_{1-50}$ and Cy5 labeled goat-anti-rabbit. Whereas both SAP and GPBP immunoreactivity co-localize with thioflavin positivity, their exact distribution differs (black and white Figures showing complete overlap in localization of thioflavin and SAP, but not of GPBP). GPBP seems present in small cells resembling microglia clustered around $A ß$ and SAP deposits (arrow and lower panel (magnification)), as well as in many neuronal cells (arrowheads). Partial overlap in localization of GPBP and SAP within Aß plaques was more clearly seen, when in the separate channels the GPBP signal was visualized as red and thioflavin or SAP as green (inserts). Scale bars represent $100 \mu \mathrm{m}$. (C) Western blotting with a mAb anti-Aß revealed that immunoprecipitation of either GPBP or SAP from brain lysates from an $A D$ mouse model (APPswe/PS1 $\triangle E 9$ ), but not from wild type littermates, co-isolated $A ß$, which suggests the presence of Aß-SAP and Aß-GPBP complexes in AD model mouse brain. Aß, GPBP and SAP were immunoprecipitated from brain homogenates of control and Alzheimer's transgenic mice using mouse mAb anti SAP, clone 4E8, Sigma; mAb GPBP clone 3A1-C1; mAb ß Amyloid clone 6E10, Covance. immunoprecipitation with nonspecific immunoglobulins was performed for control. Results shown are representative of 3 experiments. 
Functional implications of SAP to GPBP binding and protein-protein interaction interface prediction

In order to identify the binding site of GPBP on SAP, we used two wellknown ligands of SAP [C1q and PE $(16,32)]$ and analyzed by SPR if they could compete with GPBP. To test this, either SAP alone, or SAP that had been preincubated with either PE or C1q were added as analytes and flown over a surface onto which GPBP was immobilized. Using an equimolar ratio of SAP and C1q, binding of SAP to GPBP was inhibited by $59 \%$. In contrast SAP preincubated with PE even at a 3 -fold molar ratio of PE as compared to SAP had no effect on the binding of SAP to GPBP.

Since the crystal structures of SAP and the GPBP START domain are published (PDB IDs 2A3Y and 2E30) we attempted to predict the possible protein-protein interaction surfaces by structural bioinformatics analysis using the ICM-pro package (Figure 10). For SAP, our in silico analysis indicated the presence of two potential protein interaction hotspots with a five-fold symmetry in the pentamer: one on the internal surface of the pentameric ring (Figure 10A, red) around Glu86 and a second one more dispersed on the outer side of the ring, around residues Gly122-Phe124 (light red). In the GPBP START domain an interactive region is located at the protein surface near Ala501 (Figure 10B and C, arrow). 
Chapter 1
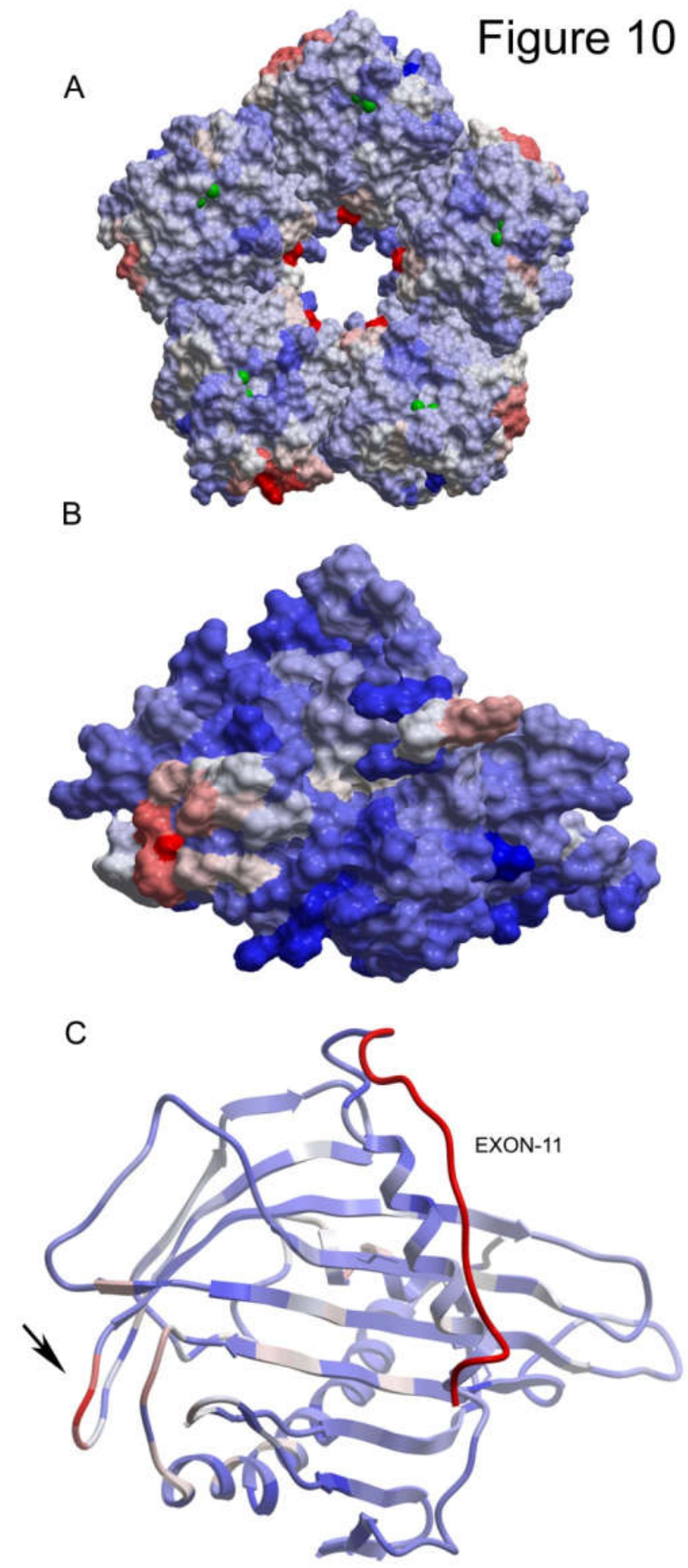
FIGURE 10. Protein-protein interaction interface prediction of SAP with GPBP

(A) Human SAP pentameric structure and predicted protein-protein interaction hotspots as obtained after structural analysis using the ICM Pro package of the published coordinates from 2a3y.pbd (46).

(B) Homology model for the structure of GPBP including the region important for the interaction with SAP (shown in red). The homology model was built using the WhatIfYasara Twinset and ICM Pro package, while the coordinate file 2E30.pdb (CERT START domain structure) was used as a template.

(C) GPBP structure and predicted protein-protein interaction hotspots based on the homology model as shown in (B), a structural bioinformatics analysis was performed using ICM Pro to predict potential protein-protein interactions. Interaction scores are color-coded with red having high potential for interaction and blue low potential. On the right, exon 11 containing 26 aa is indicated in red. The arrow indicates a hypothetical protein-protein interaction region

\section{Binding of CERT mutants to SAP}

In order to experimentally test the importance of the START domain for SAP binding, we generated 5 CERT mutants containing 2 amino acid substitutions each. We targeted the region near Ala501 and three additional regions with hydrophobic amino acids near the protein surface. Protein surface hydrophobicity is known to be a good determinant of protein-protein recognition (42). For consistency with the numbering used above we will refer to the GPBP amino acid numbering throughout (see Table 2).

Mutant 1: Ile439 (present in a short $\beta$-strand that flanks the $\mathrm{N}$-terminus of Ala591-Ala618 helix) and Trp588 (located in a loop structure that precedes Ala591-Ala618 helix) are predicted to be arranged closely in the 3D structure of GPBP. This hydrophobic pair represents a potential protein contact site which was effectively removed by substitution for two less hydrophobic Ala residues. Mutant 2: Asn460 and the adjacent Tyr461 (present in a short alpha-helix that is located on the opposite side of the molecule as compared to the other mutations) are substituted for two Ala residues; thereby removing a potential protein interacting site. Mutant 3: Adjacent to the changed amino acids of mutant 2, the hydrophobic Tyr461 and Phe462 residues were replaced 
Chapter 1

with Ala residues. Phe462 faces the core of the protein. Mutant 4: We substituted Val498 and Trp499 with two Ala residues. These hydrophobic residues are located in an unstructured loop. Mutant 5: The adjacent Pro500 and Ala501 were substituted with Gly and Gln, respectively.

All mutants described above and the wild type protein were expressed in E. coli and purified on a Flag column (Figure 11A). Using SAP as ligand, the relative affinity of CERT and CERT mutant (1-5) proteins were tested by SPR (Figure 11B). The binding of Mutants 2 and 4 to SAP was similar to the wild type CERT, while mutants 1 and 3 showed reduced binding, and mutant 5 showed a greatly reduced binding for SAP.

The relative affinity of CERT and CERT mutant (1-5) proteins were also tested by far-Western blot with in blot-renaturation (Figure 11C). The results were similar to those obtain by SPR, and showed reduced binding of mutants 1,3 and 5 to SAP.

In conclusion, the START domain of GPBP and CERT significantly contributes, or might even be essential for SAP binding. 
CERT binds SAP and is present in brain amyloid plaques

A

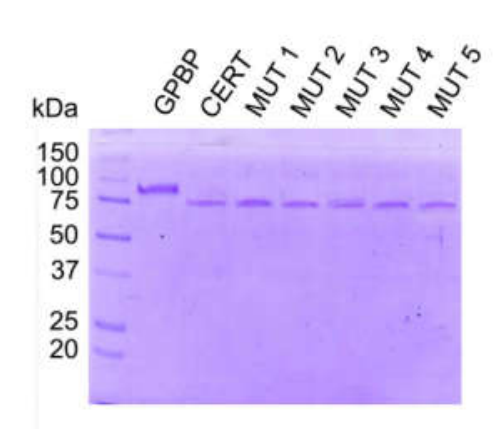

Figure 11

B

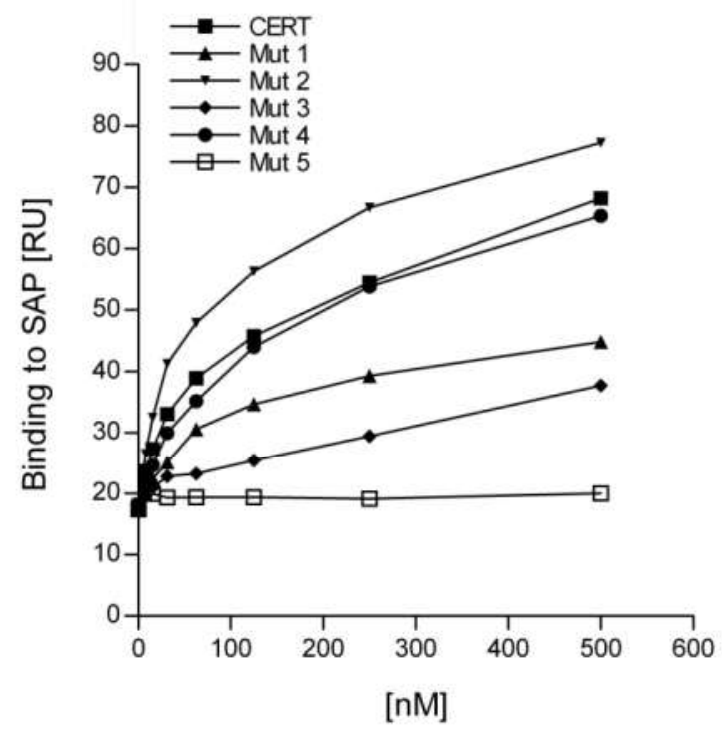

C

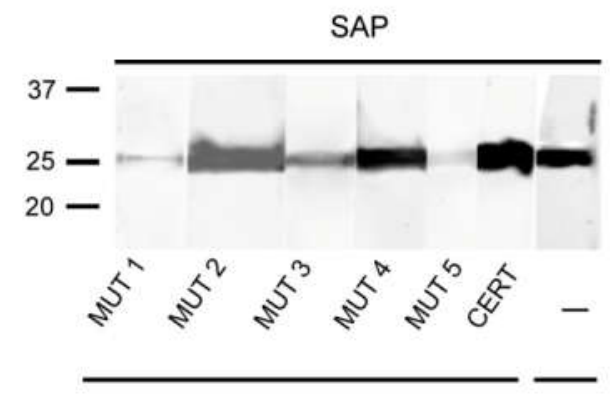

pAb anti GPBP/CERT mAb anti SAP 
FIGURE 11. Binding of CERT and CERT mutants to SAP

(A) Coomassie staining of immunopurified wild type and (1-5) mutant CERT proteins (2 $\mu \mathrm{g}$ of each sample were loaded per lane).

(B) Two-fold serial dilutions (3.9-500 nM) of wild type and mutant (1-5) CERT proteins in $25 \mathrm{mM}$ HEPES pH 7.4, $150 \mathrm{mM} \mathrm{NaCl}$ with $0.01 \%$ Tween 20 were tested for binding on immobilized SAP by SPR. At each concentration, the highest binding signal was measured.

(C) SAP was separated on a 12\% SDS-PAGE gel, electroblotted to nitrocellulose and prepared for far-Western analyses as described in Figure 4A. The membrane with renatured SAP was cut into strips and probed with CERT mutants (1 to 5), WT (6) or $\mathrm{mAb}$ anti SAP (7). Membrane strips incubated with CERT proteins were detected with anti-GPBP/CERT $300-350$.

\section{DISCUSSION}

Our results demonstrate, for the first time, that GPBP binds SAP. Both, GPBP and SAP are present in amyloid plaques and co-precipitate with $A ß$. Therefore, the interaction of GPBP with SAP might be involved in protein aggregation in Alzheimer's disease and the resulting innate immune response.

SAP is a very compact and highly structured molecule. Its incorporation within specific types of BM may contribute to the structural conformation and consequently the correct functionality of extracellular matrix proteins. This is supported by its altered distribution in the GBM in glomerular diseases $(33,43)$.

Our SPR analysis has shown that GPBP binds type IV collagen, laminin and SAP, while our immunohistochemical studies have shown the presence of SAP and GPBP in GBMs. Intriguingly, this raises the possibility that SAP and GPBP interact to support matrix extracellular proteins, helping to maintain their biologically active conformations in a particular group of tissues, including kidney, lungs and choroid plexus; tissues that perform a filtering function and are therefore more vulnerable.

We also found SAP and GPBP interaction in human blood. By immunoprecipitation studies in human sera we were able to pull down 
complexes of SAP and a N-terminal $\sim 37 \mathrm{kDa}$ fragment of GPBP which has been previously described (22). However, it is worth noting that proteolysis of GPBP remains a possibility as our in vitro mutagenesis show that the (C-terminal) START domain of GPBP is important for interaction with SAP. Moreover, full length GPBP is the only isoform which has been described so far that is secreted and present in blood (23). Since this amino-terminal domain is identical in the GPBP and CERT isoforms, our results demonstrate that both GPBP and the shorter isoform CERT could form complexes with SAP under physiological conditions. Several studies have investigated the 3D structure of SAP in order to establish whether SAP stably associates with another protein or exists free in solution (44-46). Despite these efforts, it remains unclear how SAP can remain in physiological conformation (i.e. avoid aggregation) in a high $\mathrm{Ca} 2+$ environment. One suggestion is that SAP forms a complex with an as yet unidentified low molecular weight component that prevents self-association (6). To date, no such factor or protein has been reported. In our experiments, aggregation of SAP by $\mathrm{Ca} 2+$ might have reduced binding to GPBP, because GPBP specifically binds to pentamers and decamers.

Our molecular characterization of the SAP GPBP/CERT interaction suggests that residues P500 and A501 (mutant 5) of the START domain of GPBP/CERT are essential. Although, we cannot rule out the possibility that the loss of SAP to CERT binding affinity seen with mutant 5 is due to drastic changes in protein conformation, our results are in line with what is known about this domain. The START domain of CERT binds one ceramide molecule in its central amphiphilic cavity and mediates ceramide transfer from donor to acceptor membranes (24). The $\Omega 1$ loop region of the CERT START domain (496KRVWPAS502 in GPBP) is an important regulatory element for the binding of ceramide $(47,48)$. This $\Omega 1$ loop has been proposed to function as a gate of the 


\section{Chapter 1}

cavity. Specifically, the interaction between the W499 residue of the $\Omega 1$ loop and the membrane results in a conformational change of the protein which allows opening the cavity. We found that substitution of either the V498 or W499 had no effect on the SAP to GPBP binding, whereas mutation of the P500 and A501 abolishes SAP-GPBP interaction. This suggests that GPBP binding to SAP is independent of the ceramide transfer function. This would be consistent with the notion that ceramide function is important within the cell and that the SAP GPBP interaction described here occurs primarily extracellularly.

SAP has been observed decorating the majority of $A ß$ plaques in $A D$ (49), where it has been found to enhance Aß fibrilization. Also, SAP has been shown to hamper the uptake of $A ß$ by adult human microglia in vitro (50).

The binding of SAP and GPBP to plaques in AD raises the important question of whether this interaction has a role in disease progression. It may be the case that GPBP and SAP are found in the pathological plaques of $\mathrm{AD}$ because these plaques, that consist of amyloid deposits, are 'sticky', and thus incorporate GBPB and SAP from the extracellular matrix. On the other hand, it has been reported that binding of SAP to amyloid fibrils slows proteolysis of plaque material and contributes to the pathogenesis of amyloidosis (5). Here we show that GPBPs are present in $A \beta$ plaques, localized in the core and partially colocalizing with SAP. In agreement with this, pull-downs of extracts of AD mouse brain with antibodies against $A \beta$ yield high molecular weight aggregates containing GPBP, indicating that GPBP, similarly to SAP, interacts with $A \beta$.

Additionally, we observed GPBP staining in the white matter corresponding to round and ramified microglia. Interestingly, clustering of microglia was only observed in SAP and C1q immunopositive Aß 
deposits, and has been shown to precede neurodegenerative changes in AD brain (4).

SAP, when aggregated, can bind C1q and initiate the activation of the complement system (16). Our finding that C1q and GPBP can compete for their binding to SAP raises the question as to whether GPBP and C1q share an identical SAP binding site. This implies that when SAP binds to GPBP, the C1q binding site on the SAP molecule is blocked and this might help to control the activation of the complement system.

These findings may then have important implications in several human diseases where complement activation plays a role and SAP and GPBP are in close proximity e.g. in AD. Our results further raise the question of whether GPBP, similarly to SAP, could serve as an innate immune system regulator. 


\section{REFERENCES}

1. Ashton, A. W., Boehm, M. K., Gallimore, J. R., Pepys, M. B., and Perkins, S. J. (1997) J Mol Biol 272, 408-422

2. Cathcart, E. S., Comerford, F. R., and Cohen, A. S. (1965) N Engl J Med 273, 143-146

3. Schwab, C., and McGeer, P. L. (2008) JAlzheimers Dis 13, 359-369

4. Veerhuis, R., Van Breemen, M. J., Hoozemans, J. M., Morbin, M., Ouladhadj, J., Tagliavini, F., and Eikelenboom, P. (2003) Acta Neuropathol 105, 135-144

5. Tennent, G. A., Lovat, L. B., and Pepys, M. B. (1995) Proc Natl Acad Sci U S A 92, 4299-4303

6. Painter, R. H., De Escallon, I., Massey, A., Pinteric, L., and Stern, S. B. (1982) Ann N Y Acad Sci 389, 199-215

7. Hamazaki, H. (1995) J Biol Chem 270, 10392-10394

8. Hamazaki, H. (1987) J Biol Chem 262, 1456-1460

9. Zahedi, K. (1996) J Biol Chem 271, 14897-14902

10. Zahedi, K. (1997) J Biol Chem 272, 2143-2148

11. Nielsen, E. H., Sorensen, I. J., Vilsgaard, K., Andersen, O., and Svehag, S. E. (1994) APMIS 102, 420-426

12. de Beer, F. C., Baltz, M. L., Holford, S., Feinstein, A., and Pepys, M. B. (1981) J Exp Med 154, 1134-1139

13. Bristow, C. L., and Boackle, R. J. (1986) Mol Immunol 23, 1045-1052

14. Hutchcraft, C. L., Gewurz, H., Hansen, B., Dyck, R. F., and Pepys, M. B. (1981) J Immunol 126, 1217-1219

15. Garcia de Frutos, P., Hardig, Y., and Dahlback, B. (1995) J Biol Chem 270, 26950-26955

16. Ying, S. C., Gewurz, A. T., Jiang, H., and Gewurz, H. (1993) JImmunol 150, 169176

17. Dyck, R. F., Lockwood, C. M., Kershaw, M., McHugh, N., Duance, V. C., Baltz, M. L., and Pepys, M. B. (1980) J Exp Med 152, 1162-1174

18. Tseng, J., and Mortensen, R. F. (1986) Immunol Invest 15, 749-761

19. Stanton, M. C., and Tange, J. D. (1958) Australas Ann Med 7, 132-144

20. Raya, A., Revert, F., Navarro, S., and Saus, J. (1999) J Biol Chem 274, $12642-$ 12649

21. Mencarelli, C., Losen, M., Hammels, C., De Vry, J., Hesselink, M. K., Steinbusch, H. W., De Baets, M. H., and Martinez-Martinez, P. J Neurochem 113, 1369-1386

22. Revert, F., Ventura, I., Martinez-Martinez, P., Granero-Molto, F., Revert-Ros, F., Macias, J., and Saus, J. (2008) J Biol Chem 283, 30246-30255

23. Saus, J. V., ES) , and Revert, F. M., ES) (01/28/2010) Goodpasture Antigen Binding Protein and Its Detection (Application, U. S. P. ed., United States

24. Hanada, K., Kumagai, K., Yasuda, S., Miura, Y., Kawano, M., Fukasawa, M., and Nishijima, M. (2003) Nature 426, 803-809

25. Raya, A., Revert-Ros, F., Martinez-Martinez, P., Navarro, S., Rosello, E., Vieites, B., Granero, F., Forteza, J., and Saus, J. (2000) J Biol Chem 275, 40392-40399 
26. Jonsson, U., Fagerstam, L., Ivarsson, B., Johnsson, B., Karlsson, R., Lundh, K., Lofas, S., Persson, B., Roos, H., Ronnberg, I., and et al. (1991) Biotechniques $11,620-627$

27. Jerabek-Willemsen, M., Wienken, C. J., Braun, D., Baaske, P., and Duhr, S. Assay Drug Dev Technol 9, 342-353

28. Baaske, P., Wienken, C. J., Reineck, P., Duhr, S., and Braun, D. Angew Chem Int Ed Engl 49, 2238-2241

29. Wienken, C. J., Baaske, P., Rothbauer, U., Braun, D., and Duhr, S. Nat Commun 1,100

30. Mencarelli, C., Hammels, C., Van Den Broeck, J., Losen, M., Steinbusch, H., Revert, F., Saus, J., Hopkins, D. A., De Baets, M. H., Steinbusch, H. W., and Martinez-Martinez, P. (2009) J Chem Neuroanat 38, 97-105

31. Braak, H., and Braak, E. (1995) Neurobiol Aging 16, 271-278; discussion 278284

32. Familian, A., Zwart, B., Huisman, H. G., Rensink, I., Roem, D., Hordijk, P. L., Aarden, L. A., and Hack, C. E. (2001) JImmunol 167, 647-654

33. Melvin, T., Kim, Y., and Michael, A. F. (1986) Am J Pathol 125, 460-464

34. al-Mutlaq, H., Wheeler, J., Robertson, H., Watchorn, C., and Morley, A. R. (1993) Histochem J25, 219-227

35. Potempa, L. A., Kubak, B. M., and Gewurz, H. (1985) J Biol Chem 260, $12142-$ 12147

36. Baltz, M. L., De Beer, F. C., Feinstein, A., and Pepys, M. B. (1982) Biochim Biophys Acta 701, 229-236

37. Pepys, M. B., Dash, A. C., Markham, R. E., Thomas, H. C., Williams, B. D., and Petrie, A. (1978) Clin Exp Immunol 32, 119-124

38. Bottazzi, B., Doni, A., Garlanda, C., and Mantovani, A. Annu Rev Immunol 28, 157-183

39. Young, L., Jernigan, R. L., and Covell, D. G. (1994) Protein Sci 3, 717-729

40. Dyck, R. F., Evans, D. J., Lockwood, C. M., Rees, A. J., Turner, D., and Pepys, M. B. (1980) Lancet 2, 606-609

41. Hohenester, E., Hutchinson, W. L., Pepys, M. B., and Wood, S. P. (1997) J Mol Biol 269, 570-578

42. Thompson, D., Pepys, M. B., Tickle, I., and Wood, S. (2002) J Mol Biol 320, 1081-1086

43. Haverkate, F., Thompson, S. G., Pyke, S. D., Gallimore, J. R., and Pepys, M. B. (1997) Lancet 349, 462-466

44. Zhan, S. S., Veerhuis, R., Kamphorst, W., and Eikelenboom, P. (1995) Neurodegeneration 4, 291-297

45. Familian, A., Eikelenboom, P., and Veerhuis, R. (2007) Neurosci Lett 416, 8791

46. Ho, J. G., Kitov, P. I., Paszkiewicz, E., Sadowska, J., Bundle, D. R., and Ng, K. K. (2005) J Biol Chem 280, 31999-32008 
Chapter 1

\section{ACKNOWLEDGEMENTS}

We are very grateful to Eline van der Esch and Marlies Jacobs for their excellent technical assistance, to Anna Carrano (Pathology dept, VUmc, Amsterdam) for preparing the human brain fluorescence micrographs and to Roy L.J. Schrijver for his excellent technical assistance with the SPR technology. M.L. was supported by grant F2008(1)-28 from the Hersenstichting Nederland. This work was supported by grant no. 91107006 from the Netherlands Organization for Scientific Research (N.W.O. to G.A.F.N.) and a grant from the transnationale Universiteit Limburg (tUL, to G.A.F.N.). The authors wish to thank Prof. T. Hackeng from the Department of Biochemistry, Cardiovascular Research Institute Maastricht, Maastricht University, for his kind gift of the purified SAP and advice with the FPLC. We also wish to thank to Moran Jerabek-Willemsen for his help with the MST technology. We are very grateful to Prof. W. Buurman for critical reading of the manuscript, advice and encouragement. 
CERT binds SAP and is present in brain amyloid plaques 
Chapter 1 
Complement activation by ceramide transporter proteins

\section{CHAPTER 2}

\section{Complement ACtivation By Ceramide Transporter PROTEINS}

Gerard H. Bode, Mario Losen, Wim A. Buurman, Robert Veerhuis, Peter C. Molenaar, Harry W.M. Steinbusch, Marc H. De Baets, Mohamed R. Daha, Pilar Martinez-Martinez

Published in the Journal of Immunology 
Chapter 2

\section{ABSTRACT}

$\mathrm{C} 1 \mathrm{q}$ is the initiator of the classical complement pathway and as such essential for efficient opsonization and clearance of pathogens, altered self structures and apoptotic cells. The ceramide transporter protein (CERT) and its longer splicing isoform CERT $_{\mathrm{L}}$ are known to interact with extracellular matrix components such as type IV collagen and with the innate immune protein serum amyloid P (SAP). Here, we report a novel function of CERT in the innate immune response. Both CERT isoforms, when immobilized, were found to bind the globular head region of $\mathrm{C} 1 \mathrm{q}$, and to initiate the classical complement pathway leading to activation of $\mathrm{C} 4, \mathrm{C} 3$ and generation of the membrane attack complex C5b-9. In addition, $\mathrm{C} 1 \mathrm{q}$ was shown to bind to endogenous $\mathrm{CERT}_{\mathrm{L}}$ on the surface of apoptotic cells. These results demonstrate the role of ceramide transporter proteins in innate immunity, especially in the clearance of apoptotic cells.

\section{INTRODUCTION}

The innate immune system plays a key role in recognition and clearance of pathogens, maintenance of tissue integrity and removal of cellular debris. Pattern recognition receptors of the innate immune system can bind to pathogen associated molecular patterns (PAMP) (1), and to damaged or altered self structures including danger associated molecular patterns (DAMP) $(2,3)$. The latter also include potentially harmful protein aggregates, damaged proteins, oxidized lipids, and apoptotic cell-associated molecular patterns (ACAMP) (4). Removal of apoptotic cells is a continuous physiological process, which proceeds in an efficient and non-inflammatory way. (5) During apoptosis, the extracellular composition of a cell changes to decrease immunogenicity and enhance its uptake by phagocytic cells. By changing their 
extracellular composition, apoptotic cells acquire the ability to bind innate immune molecules (6) including recognition molecules of the complement system $(7,8)$. Binding of the first complement component C1q to apoptotic cells leads to the activation of the classical pathway (7, 9-12). However, many aspects of the molecular mechanisms involved in the recognition of apoptotic cells by $\mathrm{C} 1 \mathrm{q}$ are not fully understood. C1q has been proposed to bind to apoptotic cells directly via exposed DNA, or indirectly via IgM (13), SAP, CRP (14), PTX3 (15) and annexin A2/A5 (16), but also other proteins may be involved in the regulation of complement activation on apoptotic cells (17).

We recently identified the ceramide transporter proteins (CERT) as ligands for SAP and found that this interaction was inhibited by $\mathrm{C} 1 \mathrm{q}$ (18). Several isoforms of CERT proteins exist and are present in various tissues and in blood (18-20). The shorter splicing isoform CERT is ubiquitously present inside the cell and functions as carrier for ceramide between ER and the Golgi apparatus $(19,21)$. The longer splicing isoform $\mathrm{CERT}_{\mathrm{L}}$ is a non-conventional serine/threonine kinase that is found in the extracellular compartment either in soluble form or associated with the surface of the plasma membrane (22). Based on the known properties of CERT, we hypothesize that it has a function in the innate immune system.

The longer splicing isoform $\mathrm{CERT}_{\mathrm{L}}$, also known as Goodpasture antigenbinding protein (GPBP) was initially characterized as a protein bound to the Goodpasture antigen (NC1 domain on the $\alpha 3$ chain of type IV collagen) at the glomerular basal membrane of Goodpasture syndrome patients (23). Expression of $\mathrm{CERT}_{\mathrm{L}}$ is induced by TNF-alpha (24) and transgenic overexpression of human $\mathrm{CERT}_{\mathrm{L}}$ triggers immune-complex mediated glomerulonephritis in the absence of antibodies (25). Moreover, $\mathrm{CERT}_{\mathrm{L}}$ expression is increased in skin biopsies from patients with other autoimmune conditions including cutaneous lupus 
erythematosus, pemphigoid, and lichen planus, where $\mathrm{CERT}_{\mathrm{L}}$ is found on structures resembling apoptotic blebs (23).

The existing evidence of an immune related function for $\mathrm{CERT}_{\mathrm{L}}$, together with the reported inhibitory effects of $\mathrm{C} 1 \mathrm{q}$ on $\mathrm{CERT}_{\mathrm{L}}$ interaction with SAP (18), led us to investigate $\mathrm{CERT}_{\mathrm{L}}$ and CERT interaction with C1q. Here, we demonstrate that C1q binds to $\mathrm{CERT}_{\mathrm{L}}$ and CERT, resulting in activation of the complement system. Furthermore, we show that $\mathrm{CERT}_{\mathrm{L}}$ binds to apoptotic cells and colocalizes with $\mathrm{C} 1 \mathrm{q}$ on the cell surface, suggesting possible involvement of $\mathrm{CERT}_{\mathrm{L}}$ in the clearance of apoptotic cells.

METHODS

\section{Production of recombinant human $\mathrm{CERT}_{\mathrm{L}}$ and CERT in Pichia pastoris}

Recombinant human CERT $_{\mathrm{L}}$ and CERT were produced in the Pichia pastoris expression system as described(18). Briefly, FLAG-tagged recombinant proteins were purified from the cell lysate with an antiFLAG M2 affinity agarose gel column (A2220, Sigma, St. Louis, MO) according to manufacturer's instructions. The unbound material was washed out with TBS and the recombinant material eluted by using 100 $\mu \mathrm{g} / \mathrm{mL}$ FLAG peptide (Sigma, F3290).

\section{Ion exchange purification of $\mathrm{CERT}_{\mathrm{L}}$ and CERT}

Affinity purified recombinant FLAG-tagged CERT $_{\mathrm{L}}$ and CERT were further purified by ion exchange using an AKTA FPLC system (GE Healthcare, Waukesha, WI). The affinity purified recombinant proteins were diluted 1:10 in $20 \mathrm{mM}$ Tris- $\mathrm{HCl}$ buffer $\mathrm{pH} 7.6$ and applied to a DEAE FF anion exchange column (GE Healthcare). Unbound material was removed from the column by washing with 5 column volumes of 20 $\mathrm{mM}$ Tris-HCl buffer $\mathrm{pH}$ 7.6. The recombinant proteins were eluted from the column by increasing the $\mathrm{NaCl}$ concentration with a gradient from 0 
$\mathrm{M}$ to $0.5 \mathrm{M}$. Proteins were stored in aliquots at $-80^{\circ} \mathrm{C}$ until further use. Purity of the eluted proteins was assessed by Coomassie staining of SDS-PAGE gels and found to be $>85 \%$ for CERT and $>95 \%$ for $\mathrm{CERT}_{\mathrm{L}}$ (Figure S1). C1q binding to the elution fractions of the ion exchange purification was tested by far Western dot blot (Figure S2).

\section{Serum}

EDTA plasma was obtained from healthy blood bank donors. Serum was prepared from EDTA plasma by reconstitution with $12 \mathrm{mM} \mathrm{CaCl}_{2}$ after which the plasma was allowed to clot at $37^{\circ} \mathrm{C}$ for $20 \mathrm{~min}$. Thereafter the sample was centrifuged for $10 \mathrm{~min}$ at $1300 \times \mathrm{g}$ to remove the fibrin clot. All samples were stored in aliquots at $80^{\circ} \mathrm{C}$. C4depleted serum was prepared as described (26), diluted 1:50 and used as a complement source lacking both classical and lectin pathway activity. The C4-depleted serum had no detectable classical complement pathway activity at a dilution of $1 / 5$ in a hemolytic test using sheep erythrocytes sensitized with rabbit IgG anti-SRBC, while the starting serum induced 1 unit of $C$ activity at a dilution of $1 / 240$. Additionally, C4 hemolytic activity could be restored fully in 1/25 diluted C4deficient serum with $10 \mu \mathrm{g} / \mathrm{mL}$ purified C4. Factor B depleted human serum was obtained from Quidel (San Diego, CA).

\section{ELISA}

For all ELISAs, Nunc Maxisorp plates (Nunc, Roskilde, Denmark) were used. C1q $(15,27)$ and MBL $(27,28)$ were purified from pooled human serum from volunteer donors as described. Plates were coated using coating buffer ( $100 \mathrm{mM} \mathrm{Na}_{2} \mathrm{CO}_{3} / \mathrm{NaHCO}_{3}, \mathrm{pH}$ 9.6) containing $2 \mu \mathrm{g} / \mathrm{mL}$ of the relevant protein overnight at room temperature. Plates were washed three times after each step with PBS containing $0.05 \%$ Tween 20 and blocked with PBS containing $1 \%$ BSA for $1 \mathrm{~h}$ at $37{ }^{\circ} \mathrm{C}$. All 
Chapter 2

following steps were performed in PBS containing 0.05\% Tween 20 and $1 \%$ BSA and incubated for $1 \mathrm{~h}$ at $37{ }^{\circ} \mathrm{C}$, unless mentioned otherwise. Antibodies used for detection were conjugated to digoxigenin (Dig) using Dig-3- $O$-methylcarbonyl- $\varepsilon$-aminocaproic acid- $N$ hydroxysuccinimide ester (Roche, Basel, Switzerland) according to instructions provided by the manufacturer. Binding of purified C1q was assessed using $\mathrm{F}\left(\mathrm{ab}^{\prime}\right)_{2}$ from rabbit IgG anti-human $\mathrm{C} 1 \mathrm{q}$ conjugated to Dig. Deposition of C3, C4 and C5b-C9 was determined after incubation with different concentrations of normal human serum as a source of complement diluted in gelatine veronal buffer (Veronal buffered saline containing $0.5 \mathrm{mM} \mathrm{MgCl}$, $2 \mathrm{mM} \mathrm{CaCl}_{2}, 0.05 \%$ Tween-20 and $0.1 \%$ gelatin; $\mathrm{pH} 7.5$ ) for $1 \mathrm{~h}$ at $37^{\circ} \mathrm{C}$. $\mathrm{C} 3$ deposition was determined with a Dig-conjugated mAb anti-human C3 (clone RFK22, Nephrology department, Leiden university medical center)(29) and C4 deposition was determined with a Dig-conjugated mAb C4-4a (anti-human C4d) (30). C5b-9 deposition in the wells was detected using a mAb against a C9 neoantigen (AE-11) coupled to Dig as described (28). Detection of Dig-conjugated antibodies was performed with sheep anti-Dig Fab fragments conjugated to HRP (Roche). Enzyme activity of HRP was detected with 2,2'azino-bis(3-ethylbenzthiazoline-6-sulfonic acid) (ABTS, Sigma). The OD at $415 \mathrm{~nm}$ was measured using a microplate biokinetic reader (EL312e; Biotek Instruments, Winooski, VT).

Assessment of the activation of the lectin and alternative pathway activity by CERT $_{\mathrm{L}}$

Functional activity of the lectin and the alternative pathway was assessed by ELISA as described with modifications $(12,30)$. In brief, microplates were coated with $\mathrm{CERT}_{\mathrm{L}}$, mannan or BSA and MBL binding was detected by anti-MBL mAb 3E7. 


\section{Analysis of regions of $\mathrm{C} 1 \mathrm{q}$ functional in binding to $\mathrm{CERT}_{\mathrm{L}}$ and CERT}

Inhibition of C1q binding by Mabs 2204 (anti globular heads) and 2214 (anti collagen like tail) and mouse IgG as negative control was tested $(12,31) . \mathrm{C} 1 \mathrm{q}$ at a concentration of $1 \mu \mathrm{g} / \mathrm{mL}$ was pre-incubated with several doses of the above mentioned IgGs $(62.5 \mu \mathrm{g} / \mathrm{mL}, 31.2 \mu \mathrm{g} / \mathrm{mL}$, $15.6 \mu \mathrm{g} / \mathrm{mL}$ ) or without antibodies as a control. Microtiter plates were coated with CERT $_{\mathrm{L}}$ or CERT $(2 \mu \mathrm{g} / \mathrm{mL})$ overnight at room temperature, in $0.1 \mathrm{M}$ carbonate buffer ( $\mathrm{pH} 9.6), 100 \mu \mathrm{L} /$ well. The plates were blocked with PBS containing 2\% BSA. Thereafter, the pre-incubated C1q was added to the plates for 1 hour. C1q binding was detected as described above. Potential C1q binding sites on $\mathrm{CERT}_{\mathrm{L}}$ and CERT were analyzed by aligning the $\mathrm{CERT}_{\mathrm{L}}$ protein sequence (Uniprot ID Q9Y5P4) with known C1q binding motifs using Clustal Omega (32).

\section{SAP mediated inhibition of C1q binding to $\mathrm{CERT}_{\mathrm{L}}$ and CERT}

C1q (1 $\mu \mathrm{g} / \mathrm{mL})$ was incubated with a concentration range of SAP purified from human plasma (Sigma) for 15 minutes at room temperature and subsequently transferred to ELISA plates coated with $2 \mu \mathrm{g} / \mathrm{mL}$ of $\mathrm{CERT}_{\mathrm{L}}$ or CERT. Immobilized BSA was used as a negative control, and $1 \mathrm{M} \mathrm{NaCl}$ was used as a positive control for inhibiting the interaction between $\mathrm{C} 1 \mathrm{q}$ and $\mathrm{CERT}_{\mathrm{L}} / \mathrm{CERT}$. C1q/SAP solutions were incubated on the plate for $1 \mathrm{~h}$ at $37^{\circ} \mathrm{C}$ and $\mathrm{C} 1 \mathrm{q}$ binding was detected as described above.

\section{Binding of CERT $\mathrm{L}$ and C1q to apoptotic cells}

Binding of $\mathrm{CERT}_{\mathrm{L}}$ to apoptotic cells was investigated using etoposidetreated Jurkat cells. Affinity purified $\mathrm{CERT}_{\mathrm{L}}$ and ovalbumin (Sigma) were biotinylated using a kit according to the manufacturer's instructions (Invitrogen, Carlsbad, CA). CERT $_{\mathrm{L}}$ was studied at 
concentrations from 0 to $30 \mu \mathrm{g} / \mathrm{mL}$ and ovalbumin was used at a concentration of $50 \mu \mathrm{g} / \mathrm{mL}$.

Jurkat cells were maintained in RPMI-1640 (Invitrogen) with 10\% FBS and penicillin/streptomycin at $37{ }^{\circ} \mathrm{C}$ with $5 \% \mathrm{CO}_{2}$. Apoptosis was induced by exposing the cells to $50 \mu \mathrm{M}$ etoposide (Sigma) in serum-free medium for up to 40 hours. Apoptotic Jurkat cells were washed with serum-free medium, resuspended in ice cold PBS with 1\% BSA (Fraction V, PAA Laboratories, Pasching, Austria) and 0.01\% $\mathrm{NaN}_{3}$. Thereafter, all steps were performed on ice. Endogenous $\mathrm{CERT}_{\mathrm{L}}$ on the membrane was detected with mouse monoclonal antibody 3A1H9 for $\mathrm{CERT}_{\mathrm{L}}$ and visualized with Alexa-594 conjugated donkey anti-mouse IgG (Invitrogen). Binding of purified human C1q (A099, Complement Technology, Tyler, TX) at a concentration of $30 \mu \mathrm{g} / \mathrm{mL}$ was detected with FITC conjugated rabbit anti-C1q (F0254, DAKO, Glostrup, Denmark) or unconjugated rabbit anti-C1q followed by Alexa-488 conjugated donkey anti-rabbit IgG (Invitrogen).

Intracellular staining of $\mathrm{CERT}_{\mathrm{L}}$ and $\mathrm{C} 1 \mathrm{q}$ in non-apoptotic Jurkat cells was obtained by fixing the cells in 4\% paraformaldehyde (Sigma) for 15 minutes and permeabilizing with ice-cold methanol for 10 minutes.

Binding of exogenous $\mathrm{CERT}_{\mathrm{L}}$ was studied by incubating apoptotic Jurkat cells with biotinylated recombinant $\mathrm{CERT}_{\mathrm{L}}$ or biotinylated ovalbumin for 30 minutes on ice. Bound proteins were detected after incubating with Alexa-488 conjugated streptavidin (Invitrogen) on ice for 20 minutes. The cells were analyzed by flow cytometry on a FACSCalibur (BD Biosciences, San Jose, CA), or transferred to a MicroClear 96-well microplate (655090, Greiner bio-one, Frickenhausen, Germany) for analysis by immunofluorescence microscopy. Photomicrographs were taken using a 100x oil immersion objective on an Olympus IX81 microscope. 
Complement activation by ceramide transporter proteins

\section{Far-Western immunoblotting}

100 and $500 \mathrm{ng}$ of both recombinant $\mathrm{CERT}_{\mathrm{L}}$ and $\mathrm{BSA}$ were electrophoretically separated on a SDS-PAGE gel and transferred to PVDF membrane (Millipore, Billerica, MA). Proteins were renatured by incubating the membrane overnight at $4^{\circ} \mathrm{C}$ in renaturation buffer (PBS containing $0.05 \%$ Tween-20). After blocking the membrane with 5\% BSA in renaturation buffer, it was probed with $30 \mu \mathrm{g} / \mathrm{mL}$ of $\mathrm{C} 1 \mathrm{q}$ (Complement Technology) for 1 hour at $37^{\circ} \mathrm{C}$. Bound C1q was detected with rabbit $\mathrm{pAb}$ anti-C1q and $\mathrm{CERT}_{\mathrm{L}}$ was detected with mouse $\mathrm{mAb}$ 3A1H9. IRdye800 conjugated goat anti-rabbit and IRdye 680 conjugated donkey anti-mouse were used as secondary antibodies. Images were captured on an Odyssey imaging system (LI-COR, Lincoln, $\mathrm{NE})$.

\section{Statistical analysis}

All statistical analyses were performed using Graphpad Prism (Graphpad Software, La Jolla, CA). Data were analyzed by two-way ANOVA with Bonferroni posttest and differences were considered statistically significant at $\mathrm{P}<0.05$.

RESULTS

\section{Binding of C1q to $\mathrm{CERT}_{\mathrm{L}} / \mathrm{CERT}$ leads to complement activation}

Previously, we described that $\mathrm{CERT}_{\mathrm{L}}$ forms complexes with SAP at physiological conditions. This interaction between SAP and $\mathrm{CERT}_{\mathrm{L}}$ was inhibited by $\mathrm{C1q}$ (18), prompting us to investigate the relationship between these proteins in more detail. Binding of $\mathrm{C} 1 \mathrm{q}$ to immobilized $\mathrm{CERT}_{\mathrm{L}}$ and CERT was observed by ELISA while C1q did not bind to BSA used as negative control (Figure 1A; $\mathrm{P}<0.001$ ). 
Chapter 2

Next, we assessed whether binding of $\mathrm{C} 1 \mathrm{q}$ to $\mathrm{CERT}_{\mathrm{L}}$ and CERT results in complement activation. Deposition of C4 (Figure 1B), C3 (Figure 1C) and C5b-9 (Figure 1D) was seen on CERT and CERT $_{\mathrm{L}}$ coated plates, but not on BSA coated plates $(\mathrm{P}<0.001)$ with a serial dilution of normal human serum as complement source. C4 deposition on immobilized CERT and $\mathrm{CERT}_{\mathrm{L}}$ was similar to IgM, a strong activator of the classical pathway of the complement system. Likewise, C3 deposition was similar while C5b-9 deposition on CERT and CERT $_{\mathrm{L}}$ was lower compared to $\operatorname{IgM}(\mathrm{P}<0.05)$.

Binding of $\mathrm{C} 1 \mathrm{q}$ to $\mathrm{CERT}_{\mathrm{L}}$ was also evaluated by far-Western blotting. $\mathrm{C} 1 \mathrm{q}$ bound to recombinant $\mathrm{CERT}_{\mathrm{L}}$ while it did not bind to equal amounts of BSA (Figure 1E and F). 

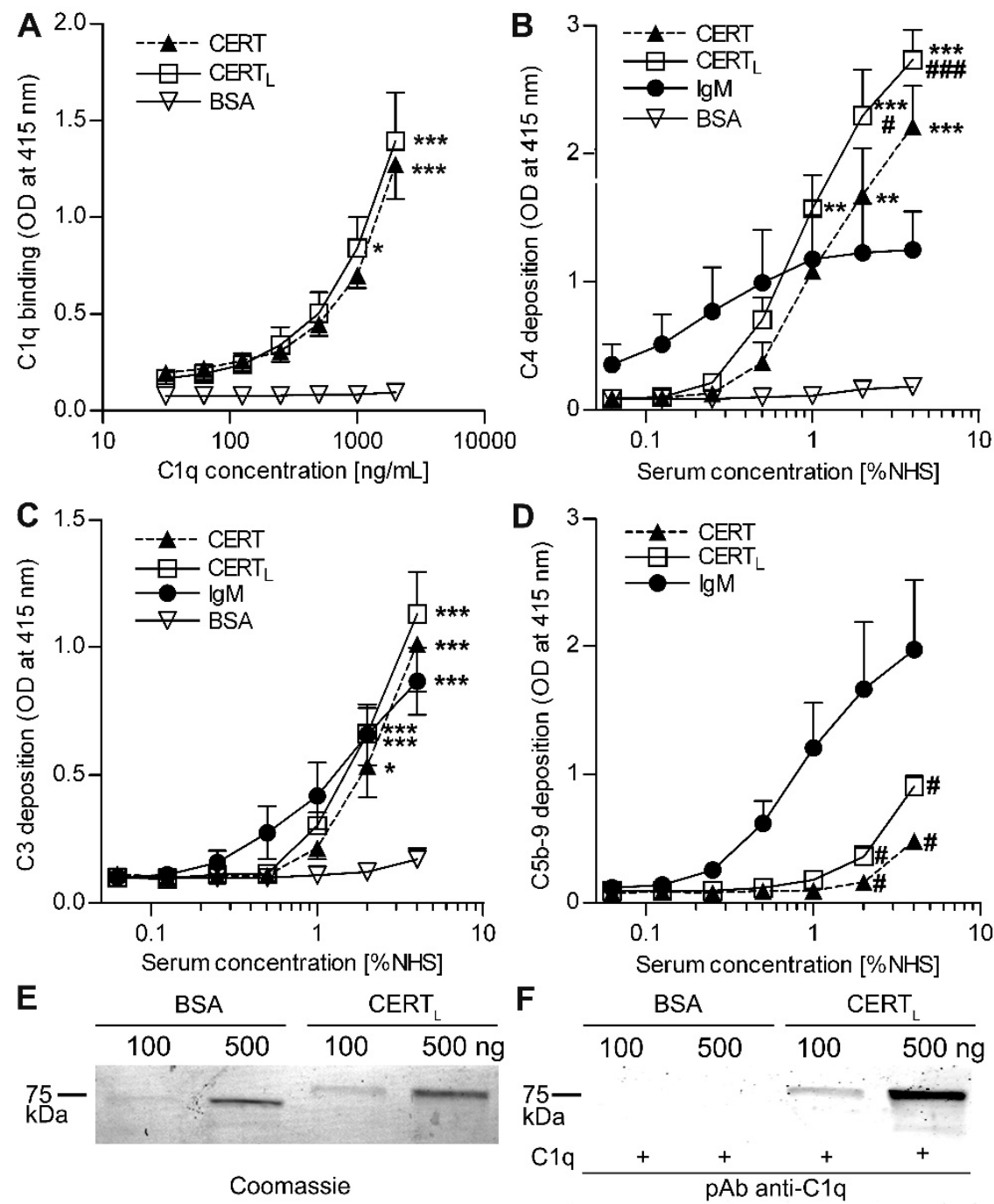

Figure 1. $\mathrm{C} 1 \mathrm{q}$ binding to immobilized $\mathrm{CERT}_{\mathrm{L}}$ and CERT results in concentration dependent activation of complement. Binding of C1q to $\mathrm{CERT}_{\mathrm{L}}$ and CERT was detected by ELISA (A). Deposition of complement activation products of C3 (B), C4 (C) and C5b-9 (D) on immobilized CERT $\mathrm{L}_{\mathrm{L}}$ or CERT detected with specific mAbs was dependent on the concentration (expressed as \%) of normal human serum (NHS) added as complement source. Data shown are the mean and S.E.M. of independent experiments. Significant differences versus BSA are denoted by * $(\mathrm{P}<0.05)$, ** $(\mathrm{P}<0.01)$ and $* * *$ $(\mathrm{P}<0.001)$. Significant differences versus IgM are denoted by \# $(\mathrm{P}<0.05)$, \#\# $(\mathrm{P}<0.01)$ and \#\#\# $(\mathrm{P}<0.001)$. Additionally, the interaction between $\mathrm{C} 1 \mathrm{q}$ and $\mathrm{CERT}_{\mathrm{L}}$ was investigated by far-Western blot; 100 and $500 \mathrm{ng}$ of both BSA and $\mathrm{CERT}_{\mathrm{L}}$ were electrophoretically separated and stained with Coomassie (E). Probing the membrane with purified $\mathrm{C} 1 \mathrm{q}$ followed by $\mathrm{C} 1 \mathrm{q}$ antibody showed that $\mathrm{C} 1 \mathrm{q}$ bound to $\mathrm{CERT}_{\mathrm{L}}$ while no binding of C1q to BSA was observed (F). 
Chapter 2

Complement activation by $\mathrm{CERT}_{\mathrm{L}} / \mathrm{CERT}$ is mediated by the classical pathway

Binding of $\mathrm{C} 1 \mathrm{q}$ to $\mathrm{CERT}$ and $\mathrm{CERT}_{\mathrm{L}}$, and subsequent deposition of $\mathrm{C} 3, \mathrm{C} 4$ and C5b-9 in normal human serum suggests that the classical pathway is activated as a result of this interaction. To investigate the role of the classical pathway in complement activation by immobilized CERT and $\mathrm{CERT}_{\mathrm{L}}$, C4-depleted human serum was used as complement source. C4depletion of human serum reduced the deposition of $\mathrm{C} 3$ and C5b-9 on immobilized CERT and $\mathrm{CERT}_{\mathrm{L}}$ to near background levels (Figure $2 \mathrm{~A}$ and $2 \mathrm{~B} ; \mathrm{P}<0.001)$. This dependency on $\mathrm{C} 4$ implies that the alternative pathway does not play a significant role in the activation of the complement system by CERT and $\mathrm{CERT}_{\mathrm{L}}$. In addition, using factor $\mathrm{B}$ depleted human serum as a complement source instead of normal human serum did not affect C3 deposition (Figure 2C). To investigate possible involvement of the lectin pathway, we tested whether mannose-binding lectin (MBL) binds to $\mathrm{CERT}_{\mathrm{L}}$. MBL did not bind to immobilized $\mathrm{CERT}_{\mathrm{L}}$ whereas it binds in significant amounts to the positive control mannan (Figure 2D; $\mathrm{P}<0.01$ ). Taken together, these results indicate that activation of the complement system by $\mathrm{CERT}_{\mathrm{L}}$ and CERT is largely mediated by the classical pathway. 

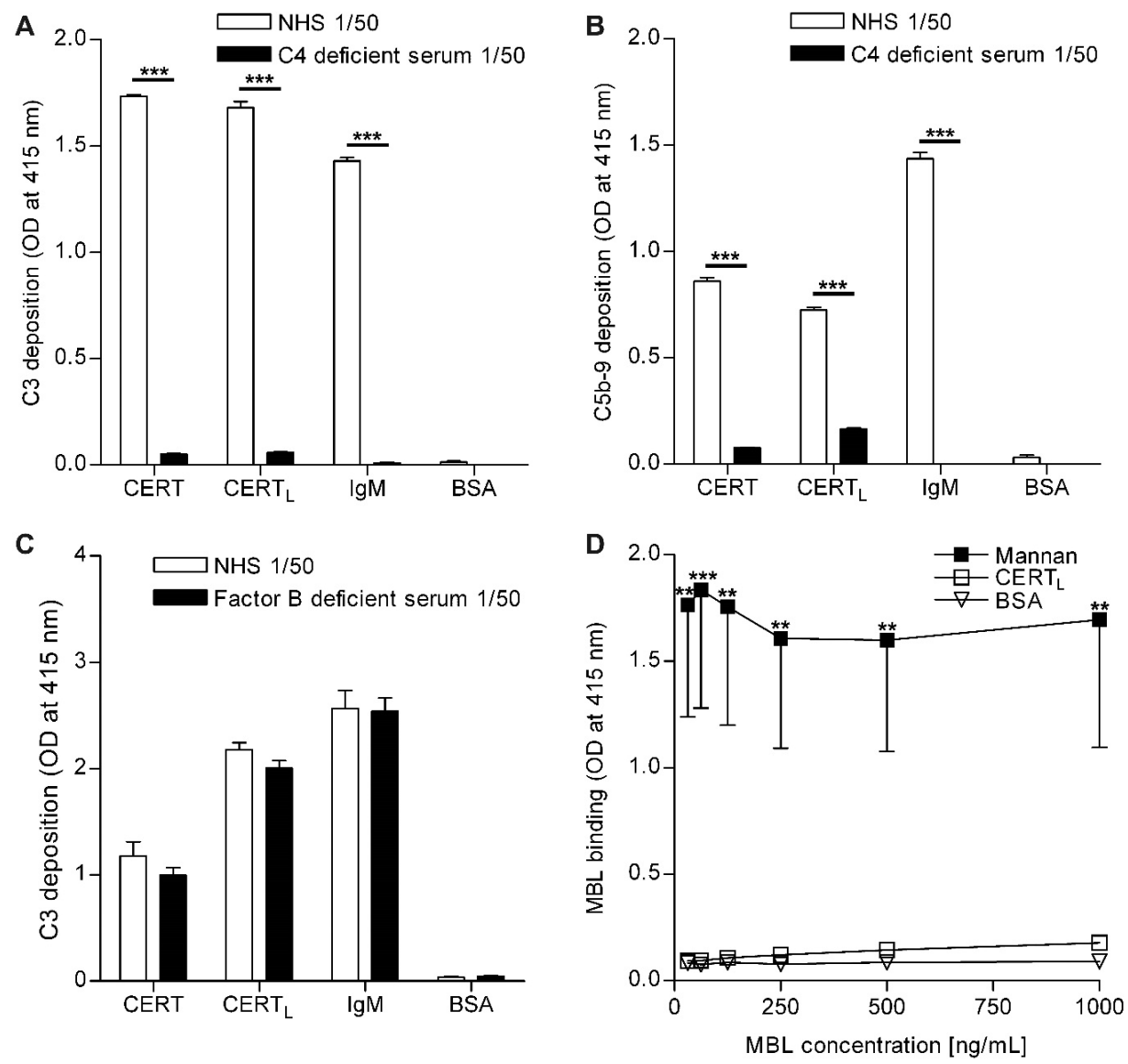

Figure 2. CERT $_{\mathrm{L}}$ and CERT activate the classical pathway of the complement system. Deposition of C3 (A) and C5b-9 (B) on immobilized CERT $\mathrm{L}_{\mathrm{L}}$ and CERT was strongly reduced when $2 \%$ of C4-depleted serum instead of normal human serum (NHS) was used as a complement source. Data shown are the mean and S.E.M. of a representative experiment performed in triplicate. Significant differences versus NHS are denoted by *** $(\mathrm{P}<0.001)$. When human serum depleted of factor B was used, the extent of C3 deposition did not differ from that obtained with NHS (C). Possible activation of the lectin pathway was excluded as MBL did not bind to immobilized CERT $_{\mathrm{L}}$ while $\mathrm{MBL}$ did bind the positive control mannan (D). Data shown are the mean and S.E.M. of independent experiments. Significant differences versus BSA are denoted by ** $(\mathrm{P}<0.01)$ and $* * *(\mathrm{P}<0.001)$. 
Chapter 2

\section{CERT and $\mathrm{CERT}_{\mathrm{L}}$ bind to the globular head region of C1q}

Next, we examined whether the interaction between $\mathrm{C} 1 \mathrm{q}$ and $\mathrm{CERT}_{\text {CERT }} \mathrm{L}$ is mediated via the globular head region or via the collagen-like tail region of C1q. A monoclonal antibody (mAb 2204) directed against the globular head region blocked the binding of $\mathrm{C} 1 \mathrm{q}$ to $\mathrm{CERT}_{\text {CERT }}$, indicating that the globular region is involved in the binding. In contrast, a mAb against the collagen-like tail of C1q (2214) increased the binding (Figure 3A; $\mathrm{P}<0.001$ ). This is in line with the expected cross-linking of $\mathrm{C} 1 \mathrm{q}$ molecules by the antibody and binding of the complex via the free globular regions to CERT/CERT . $_{\text {. }}$

Since the interaction between C1q globular heads and its ligands are believed to be charge mediated (33), we analyzed the amino acid

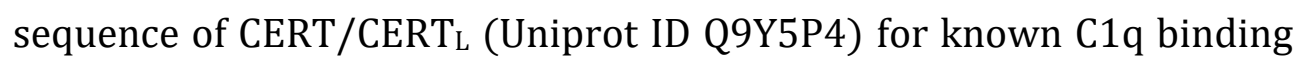
motifs. We identified a Glu297-Xxx-Lys ${ }^{299}-X x x-$ Lys $^{301}$ motif on $\mathrm{CERT}_{\text {CERT }}$ as a potential C1q binding site.

Previously, we reported that the interaction between SAP and $\mathrm{CERT}_{\mathrm{L}}$ was inhibited by C1q (18). This led us to investigate whether SAP inhibits the binding of $\mathrm{C} 1 \mathrm{q}$ to CERT/CERT $\mathrm{L}_{\mathrm{L}}$. The data show that SAP inhibited the binding of $\mathrm{C} 1 \mathrm{q}$ to CERT and $\mathrm{CERT}_{\mathrm{L}}$ in a concentration dependent manner, with $55 \%$ and $65 \%$ inhibition respectively at 100 $\mu \mathrm{g} / \mathrm{mL}$ of SAP (Figure 3B). 
Complement activation by ceramide transporter proteins
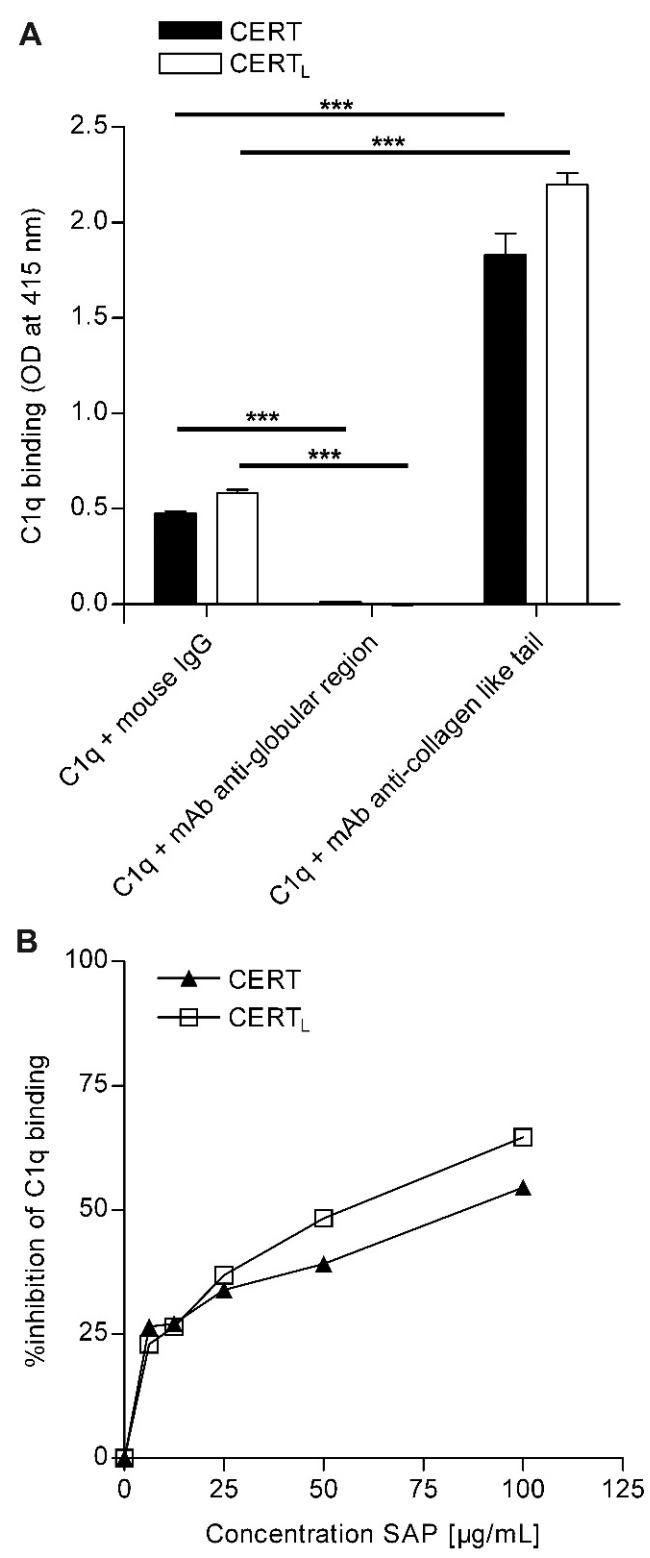

Figure $3 \mathrm{C} 1 \mathrm{q}$ binds via its globular region to $\mathrm{CERT}_{\mathrm{L}}$ and CERT. Binding of $\mathrm{C} 1 \mathrm{q}$ to immobilized $\mathrm{CERT}_{\mathrm{L}}$ and CERT was inhibited by a monoclonal antibody (mAb) against the globular head region of $\mathrm{C} 1 \mathrm{q}$ (mAb 2204), but not by irrelevant mouse IgG or a mAb against the collagen like tail (mAb 2214) (A). In addition, SAP inhibited binding of $\mathrm{C} 1 \mathrm{q}$ to CERT and $\mathrm{CERT}_{\mathrm{L}}$ in a concentration dependent manner (B). ${ }^{* * *}$ denotes statistically significant difference $(\mathrm{P}<0.001)$. 
Chapter 2

\section{CERT $_{\mathrm{L}}$ is present on apoptotic cells and colocalizes with C1q}

CERT and CERT $\mathrm{L}_{\mathrm{L}}$ are expressed by a wide range of tissues and cells (20, 23) and both extracellular and membrane bound isoforms of $\mathrm{CERT}_{\mathrm{L}}$ have been described (22). To assess whether endogenous $\operatorname{CERT}_{L}$ is involved in the interaction of $\mathrm{C} 1 \mathrm{q}$ with apoptotic cells, the binding of purified C1q on etoposide-treated apoptotic Jurkat cells was studied. Non-permeabilized viable Jurkat cells had little to no $\mathrm{CERT}_{\mathrm{L}}$ on the outer membrane as determined by immunocytochemistry with a mAb against $\mathrm{CERT}_{\mathrm{L}}$ (Figure 4). These cells also showed no C1q binding. However, when permeabilized non-apoptotic Jurkat cells showed colocalization of CERT $\mathrm{L}_{\mathrm{L}}$ and C1q (Figure 4). Apoptotic Jurkat cells were found to carry membrane bound $\mathrm{CERT}_{\mathrm{L}}$ colocalized with C1q (Figure 5), indicating that endogenous $\mathrm{CERT}_{\mathrm{L}}$ becomes accessible to $\mathrm{C} 1 \mathrm{q}$ during apoptosis. Moreover, C1q was only detected on apoptotic cells that stained positive for $\mathrm{CERT}_{\mathrm{L}}$. The interaction of $\mathrm{C} 1 \mathrm{q}$ and membrane associated $\mathrm{CERT}_{\mathrm{L}}$ was confirmed by far-Western blot (Figure S3). 
Complement activation by ceramide transporter proteins

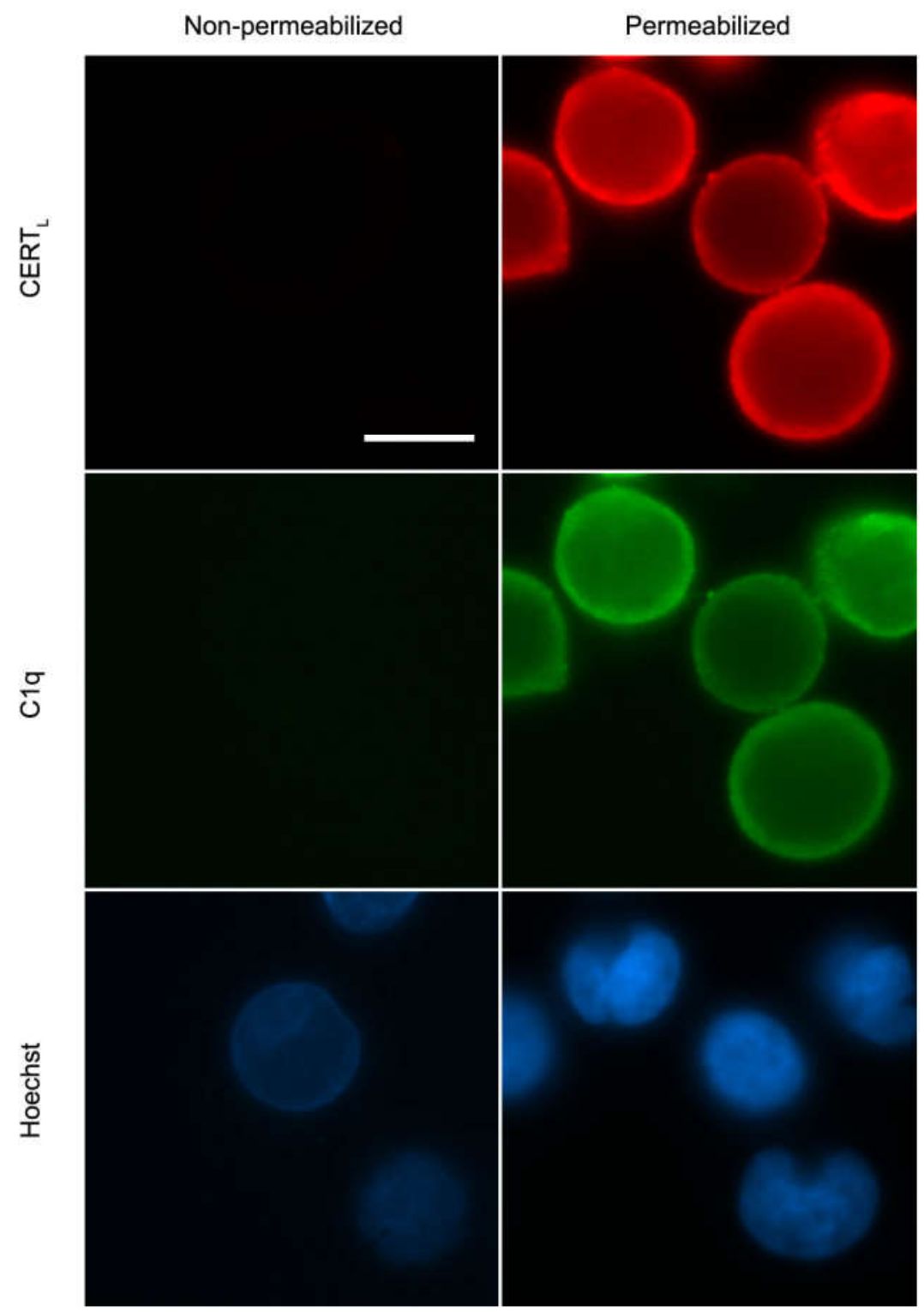

Figure $4 \mathrm{C} 1 \mathrm{q}$ binds to $\mathrm{CERT}_{\mathrm{L}}$ in permeabilized non-apoptotic Jurkat cells. Nonpermeabilized and fixed permeabilized Jurkat cells were incubated with purified C1q and stained for $\mathrm{CERT}_{\mathrm{L}}$ (red) and C1q (green). DNA was stained with Hoechst (blue). Strong staining of $\mathrm{CERT}_{\mathrm{L}}$ and $\mathrm{C} 1 \mathrm{q}$ was observed on permeabilized cells compared to non-permeabilized cells. Scale bar is $10 \mu \mathrm{m}$. The contrast of the blue channel (Hoechst) was increased in the non-permeabilized condition in order to visualize the nucleus. 

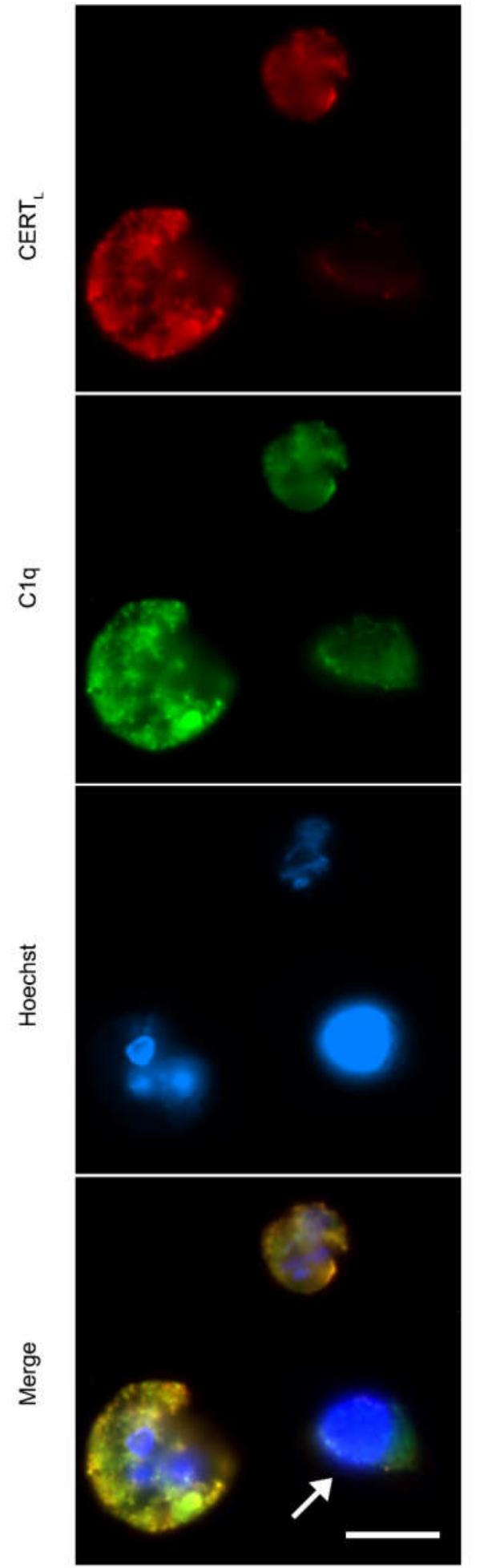

Figure 5. C1q binds to membrane associated $\mathrm{CERT}_{\mathrm{L}}$ on apoptotic Jurkat cells. Etoposide-treated Jurkat cells were incubated with purified $\mathrm{C} 1 \mathrm{q}$ and stained for $\mathrm{CERT}_{\mathrm{L}}$ with a monoclonal antibody (red) and a FITC-conjugated polyclonal $\mathrm{C} 1 \mathrm{q}$ antibody (green). Hoechst was used to stain nuclear material (blue). Merging the three channels (row 4) revealed colocalization of CERT $_{L}$ (red) and C1q (green). Arrow indicates cell with minimal staining for both $\mathrm{CERT}_{\mathrm{L}}$ and C1q. Scale bar is $10 \mu \mathrm{m}$. 
Complement activation by ceramide transporter proteins

Recombinant $\mathrm{CERT}_{\mathrm{L}}$ binds to apoptotic Jurkat cells

Next, we determined the binding of exogenous CERT $_{L}$ to apoptotic cells. Apoptotic Jurkat cells were incubated with biotinylated purified recombinant $\mathrm{CERT}_{\mathrm{L}}$. Alexa-488 conjugated streptavidin was used to specifically detect exogenous biotin-labeled proteins. Immunofluorescence microscopy revealed a patch-like staining for $\mathrm{CERT}_{\mathrm{L}}$ while biotinylated ovalbumin showed a much weaker and diffuse staining pattern (Figure 6A). Binding of recombinant $\mathrm{CERT}_{\mathrm{L}}$ to apoptotic cells was restricted to propidium iodide positive cells; no binding was seen on early apoptotic cells (Annexin V positive, PI negative; not shown). In addition, $\operatorname{CERT}_{\mathrm{L}}$ was found to bind in a concentration dependent manner to apoptotic cells, as assessed by flow cytometry (Figure 6B). 
Chapter 2

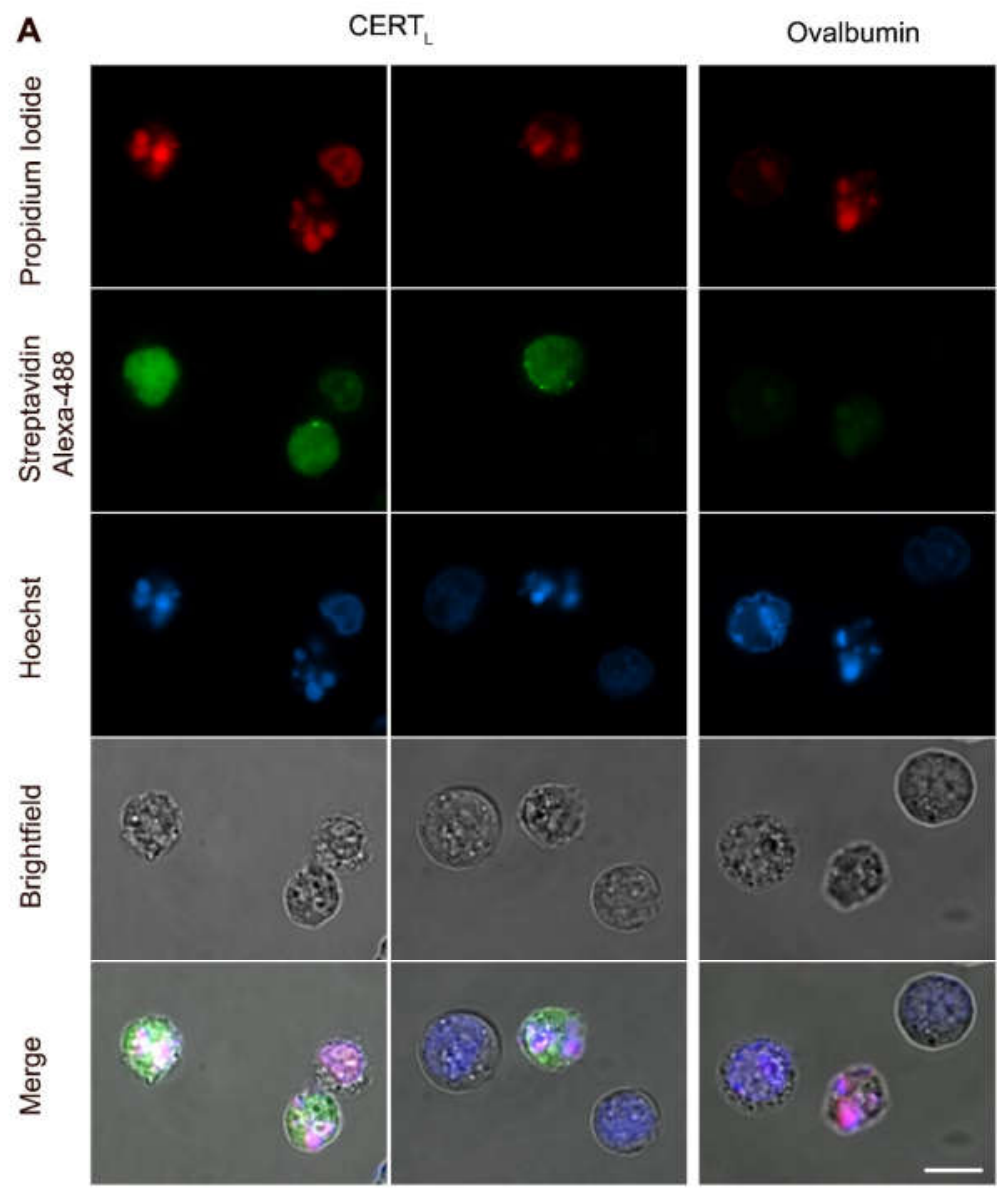

B

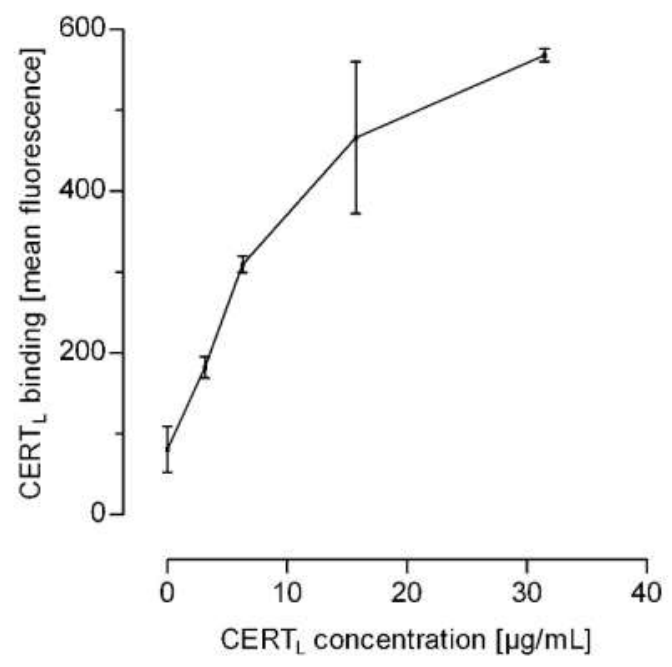


Figure 6. Recombinant $\mathrm{CERT}_{\mathrm{L}}$ binds concentration dependent to apoptotic Jurkat cells. Etoposide-treated Jurkat cells were incubated with biotin labeled recombinant $\mathrm{CERT}_{\mathrm{L}}$ (A, column 1 and 2 ) or biotin labeled ovalbumin (A, column 3). The cells were stained with propidium iodide (red channel) and biotinylated $\mathrm{CERT}_{\mathrm{L}}$ or ovalbumin was used with Alexa-488 conjugated streptavidin (green channel). The nucleus was stained with Hoechst (blue channel) and brightfield images were taken to visualize all cells. The four channels were merged in the bottom panel showing that binding of $\mathrm{CERT}_{\mathrm{L}}$ was restricted to late apoptotic cells with a fragmented nucleus. $\mathrm{CERT}_{\mathrm{L}}$ bound to propidium iodide positive apoptotic cells in a patch-like manner which was not observed with ovalbumin. Flow cytometry was used to quantify the binding of recombinant $\mathrm{CERT}_{\mathrm{L}}$ to etoposide-treated apoptotic Jurkat cells (B). Mean fluorescence intensity of the biotin-CERT $\mathrm{L}_{\mathrm{L}}$ signal on apoptotic cells was plotted in relation to the concentration of $\mathrm{CERT}_{\mathrm{L}}$. Data shown are the mean and S.E.M. of two independent experiments. Scale bar is $10 \mu \mathrm{m}$.

\section{DISCUSSION}

Earlier studies have demonstrated a relationship between $\mathrm{CERT}_{\mathrm{L}}$ and inflammatory/autoimmune conditions $(20,23,25)$, but little is known about the biological relevance or the mechanism of this association. The general objective of the present study was to assess a putative innate immune function of $\mathrm{CERT}_{\mathrm{L}}$. Here we show that both CERT and $\mathrm{CERT}_{\mathrm{L}}$ activate the classical complement pathway by binding C1q. $\mathrm{CERT}_{\mathrm{L}}$ was also present on the surface of apoptotic cells, colocalizing with bound C1q. In addition, we demonstrated that recombinant $\mathrm{CERT}_{\mathrm{L}}$ binds to late apoptotic PI positive cells. These results suggest that $\mathrm{CERT}_{\mathrm{L}}$ could be involved in the recognition of apoptotic cells by C1q.

A relationship between $\mathrm{CERT}_{\mathrm{L}}$ and apoptosis has been suggested before. Increased $\mathrm{CERT}_{\mathrm{L}}$ staining was found on apoptotic bleb-like structures in the skin of patients with the auto-immune conditions lichen planus and cutaneous lupus erythematosus (20). Furthermore, both CERT and $\mathrm{CERT}_{\mathrm{L}}$ bind and transport ceramide. Ceramide levels are tightly regulated in the cell and changes in ceramide levels or localization are associated with apoptosis (34-36). For example, extracellularly oriented ceramide is generated during apoptosis via the sphingomyelinase pathway $(37,38)$ and the de novo synthesis pathway 
(39). This ceramide could be a potential ligand for extracellular CERT $_{L}$ on apoptotic cells.

Activation of the classical complement pathway is crucial for complement deposition on late apoptotic cells and for the clearance of these cells (40). It has been proposed that C1q prevents autoimmunity and maintains self-tolerance by supporting the efficient clearance of apoptotic cells $(41,42)$. C1q binds via the globular heads to CERT and $\mathrm{CERT}_{\mathrm{L}}$, similar to previously described $\mathrm{C} 1 \mathrm{q}$ ligands involved in pattern recognition such as pentraxins $(12,14)$ and immunoglobulins $(13,43)$. C1q shows structural similarity with collagen type IV, a known ligand of $\mathrm{CERT}_{\mathrm{L}}$. Both $\mathrm{C} 1 \mathrm{q}$ and collagen type IV contain a collagen tail and a noncollagenous globular region. $\mathrm{CERT}_{\mathrm{L}}$ binds to the globular region of collagen type IV $(23,44)$. Here, we present evidence suggesting that C1q interaction with $\mathrm{CERT}_{\mathrm{L}}$ takes place through its globular head region and that this interaction can be inhibited by SAP. This competitive effect has been described for other C1 activators (12). In addition, we analyzed the sequence of $\mathrm{CERT}_{\mathrm{L}}$ for potential $\mathrm{C} 1 \mathrm{q}$ binding sites and identified a Glu297-Xxx-Lys ${ }^{299}$-Xxx-Lys ${ }^{301}$ motif. This and similar motifs have been described as essential for the interaction between $\mathrm{C1q}$ globular heads and other ligands such as IgG (45), calreticulin (46) and CRP (47). Interestingly, the Glu-Xxx-Lys-Xxx-Lys motif in $\mathrm{CERT}_{\mathrm{L}}$ is evolutionary conserved as it is even present in the zebrafish (Danio rerio, Uniprot ID Q5M7Y0), whereas it is not conserved in Drosophila melanogaster that, like other non-chordates, lacks factors of the classical pathway of complement (48).

Our data also indicate that the interaction of the C1q globular head with $\mathrm{CERT}_{\mathrm{L}}$ activates the classical complement pathway. This conclusion is based on the following observations: (i) C1q bound to immobilized $\mathrm{CERT}_{\mathrm{L}}$; (ii) this binding resulted in a concentration-dependent activation of C4, C3 and C5b-9; (iii) incubation of immobilized $\mathrm{CERT}_{\mathrm{L}}$ 
with C4 depleted serum abolished the activation of C3 and C5b-9, while factor B depletion had no effect; (iv) C1q binding to immobilized $\mathrm{CERT}_{\mathrm{L}}$ is inhibited by SAP. The data point towards activation of the classical pathway by $\mathrm{CERT}_{\mathrm{L}}$ since complement deposition was found to be $\mathrm{C} 4$ dependent and not dependent on factor $\mathrm{B}$, excluding the alternative pathway. Because no binding of MBL to $\mathrm{CERT}_{\mathrm{L}}$ was detected, the lectin pathway is unlikely to be involved, although activation of this pathway via ficolins cannot be excluded.

These data support previous studies that proposed a role for $\mathrm{CERT}_{\mathrm{L}}$ as mediator of immune responses. In autoimmune conditions associated with increased $\mathrm{CERT}_{\mathrm{L}}$ levels, the complement system is known to contribute to the pathology (49). In line, overexpression of $\mathrm{CERT}_{\mathrm{L}}$ causes immune complex formation and glomerulonephritis (25). In addition, the promoter of $\mathrm{CERT}_{\mathrm{L}}$ gene is activated by TNF-alpha (24). This cytokine is mainly produced by activated macrophages and is a mediator of apoptosis (50), suggesting an association between apoptosis, phagocytic clearance and CERT $\mathrm{L}_{\mathrm{L}}$

The findings in the present study are relevant for pathologies in which complement activation is involved. For example, Alzheimer's disease is characterized by extensive complement activation in the brain (51). In fact, we have observed CERT $_{\mathrm{L}}$ associated to activated microglia in brain amyloid plaques of Alzheimer's disease patients (18). Moreover, microglia in Alzheimer's disease brain secrete pro-inflammatory cytokines, including TNF-alpha (52), which could drive $\mathrm{CERT}_{\mathrm{L}}$ expression. Considering the complement activating potential of $\mathrm{CERT}_{\mathrm{L}}$, this could imply that $\mathrm{CERT}_{\mathrm{L}}$ is involved in complement activation and microglial uptake of amyloid-beta or apoptotic cells in Alzheimer's disease. Interestingly, complement activation by CERT and $\mathrm{CERT}_{\mathrm{L}}$ resulted in relatively low amounts of C5b-9 deposition. A similar phenomenon has been described for CRP, where binding of CRP to 
Chapter 2

apoptotic cells results in recruitment of C1q and C3 while limiting membrane attack complex formation $(53,54)$. This suggests that assembly of the lytic membrane attack complex is not the main function of complement activation by CERT and $\mathrm{CERT}_{\mathrm{L}}$. A similar pattern is seen in $\mathrm{AD}$, with extensive upregulation and deposition of $\mathrm{C} 1, \mathrm{C} 4$ and $\mathrm{C} 3$ in the brain, and limited C5b-C9 activation $(51,55)$.

Another pathology associated with dysregulation of the complement system is cancer. Tumor cells are known to evade the immune system by down-regulating complement activation (56). Interestingly, a recent study found down-regulation of CERT in cancers refractory to treatment (57). Thus, the loss of CERT could be a mechanism by which tumor cells reduce complement activation, resulting in reduced clearance of tumor cells by the immune system.

In summary, the evidence presented in this paper suggests that $\mathrm{CERT}_{\text {CERT }}$ has a role in the innate immune system and is involved in apoptosis. In addition, these findings imply that complement activation by CERT/CERT $\mathrm{L}_{\mathrm{L}}$ could provide a novel link between ceramides and inflammation.

\section{ACKNOWLEDGEMENTS}

We are very grateful to Ngaisah Klar for her excellent technical support. 


\section{Complement activation by ceramide transporter proteins}

\section{REFERENCES}

1. Medzhitov, R. 2007. Recognition of microorganisms and activation of the immune response. Nature 449:819-826.

2. Matzinger, P. 2002. The danger model: a renewed sense of self. Science 296:301-305.

3. Ghebrehiwet, B., K. K. Hosszu, A. Valentino, and E. I. Peerschke. 2012. The C1q family of proteins: insights into the emerging non-traditional functions. Front Immunol 3.

4. Litvack, M. L., and N. Palaniyar. 2010. Review: Soluble innate immune patternrecognition proteins for clearing dying cells and cellular components: implications on exacerbating or resolving inflammation. Innate Immun 16:191-200.

5. Poon, I. K., M. D. Hulett, and C. R. Parish. 2010. Molecular mechanisms of late apoptotic/necrotic cell clearance. Cell Death Differ 17:381-397.

6. Trouw, L. A., A. M. Blom, and P. Gasque. 2008. Role of complement and complement regulators in the removal of apoptotic cells. Mol Immunol 45:1199-1207.

7. Daha, M. R. 2010. Role of complement in innate immunity and infections. Crit Rev Immunol 30:47-52.

8. Lambris, J. D., D. Ricklin, and B. V. Geisbrecht. 2008. Complement evasion by human pathogens. Nat Rev Microbiol 6:132-142.

9. Chen, M., M. R. Daha, and C. G. Kallenberg. 2010. The complement system in systemic autoimmune disease. J Autoimmun 34:J276-286.

10. Walport, M. J. 2001. Complement. First of two parts. N Engl J Med 344:10581066.

11. Walport, M. J. 2001. Complement. Second of two parts. $N$ Engl J Med 344:1140-1144.

12. Nauta, A. J., B. Bottazzi, A. Mantovani, G. Salvatori, U. Kishore, W. J. Schwaeble, A. R. Gingras, S. Tzima, F. Vivanco, J. Egido, O. Tijsma, E. C. Hack, M. R. Daha, and A. Roos. 2003. Biochemical and functional characterization of the interaction between pentraxin 3 and C1q. Eur J Immunol 33:465-473.

13. Gadjeva, M. G., M. M. Rouseva, A. S. Zlatarova, K. B. Reid, U. Kishore, and M. S. Kojouharova. 2008. Interaction of human C1q with IgG and IgM: revisited. Biochemistry 47:13093-13102.

14. Agrawal, A., A. K. Shrive, T. J. Greenhough, and J. E. Volanakis. 2001. Topology and structure of the C1q-binding site on C-reactive protein. I Immunol 166:3998-4004.

15. Nauta, A. J., L. A. Trouw, M. R. Daha, O. Tijsma, R. Nieuwland, W. J. Schwaeble, A. R. Gingras, A. Mantovani, E. C. Hack, and A. Roos. 2002. Direct binding of C1q to apoptotic cells and cell blebs induces complement activation. Eur J Immunol32:1726-1736.

16. Martin, M., J. Leffler, and A. M. Blom. 2012. Annexin A2 and A5 serve as new ligands for C1Q on apoptotic cells. J Biol Chem.

17. Sjoberg, A. P., L. A. Trouw, and A. M. Blom. 2009. Complement activation and inhibition: a delicate balance. Trends Immunol30:83-90. 


\section{Chapter 2}

18. Mencarelli, C., G. H. Bode, M. Losen, M. Kulharia, P. C. Molenaar, R. Veerhuis, H. W. Steinbusch, M. H. De Baets, G. A. Nicolaes, and P. Martinez-Martinez. 2012. Goodpasture antigen-binding protein/ceramide transporter binds to human serum amyloid P-component and is present in brain amyloid plaques. J Biol Chem 287:14897-14911.

19. Mencarelli, C., M. Losen, C. Hammels, J. De Vry, M. K. Hesselink, H. W. Steinbusch, M. H. De Baets, and P. Martinez-Martinez. 2010. The ceramide transporter and the Goodpasture antigen binding protein: one protein--one function? J Neurochem 113:1369-1386.

20. Raya, A., F. Revert-Ros, P. Martinez-Martinez, S. Navarro, E. Rosello, B. Vieites, F. Granero, J. Forteza, and J. Saus. 2000. Goodpasture antigen-binding protein, the kinase that phosphorylates the goodpasture antigen, is an alternatively spliced variant implicated in autoimmune pathogenesis. J Biol Chem 275:40392-40399.

21. Hanada, K., K. Kumagai, S. Yasuda, Y. Miura, M. Kawano, M. Fukasawa, and M. Nishijima. 2003. Molecular machinery for non-vesicular trafficking of ceramide. Nature 426:803-809.

22. Revert, F., I. Ventura, P. Martinez-Martinez, F. Granero-Molto, F. Revert-Ros, J. Macias, and J. Saus. 2008. Goodpasture antigen-binding protein is a soluble exportable protein that interacts with type IV collagen. Identification of novel membrane-bound isoforms. J Biol Chem 283:30246-30255.

23. Raya, A., F. Revert, S. Navarro, and J. Saus. 1999. Characterization of a novel type of serine/threonine kinase that specifically phosphorylates the human goodpasture antigen. J Biol Chem 274:12642-12649.

24. Granero, F., F. Revert, F. Revert-Ros, S. Lainez, P. Martinez-Martinez, and J. Saus. 2005. A human-specific TNF-responsive promoter for Goodpasture antigen-binding protein. FEBS J272:5291-5305.

25. Revert, F., R. Merino, C. Monteagudo, J. Macias, A. Peydro, J. Alcacer, P. Muniesa, R. Marquina, M. Blanco, M. Iglesias, F. Revert-Ros, J. Merino, and J. Saus. 2007. Increased Goodpasture antigen-binding protein expression induces type IV collagen disorganization and deposit of immunoglobulin A in glomerular basement membrane. Am J Pathol171:1419-1430.

26. Xu, W., S. P. Berger, L. A. Trouw, H. C. de Boer, N. Schlagwein, C. Mutsaers, M. R. Daha, and C. van Kooten. 2008. Properdin binds to late apoptotic and necrotic cells independently of $\mathrm{C} 3 \mathrm{~b}$ and regulates alternative pathway complement activation. J Immunol 180:7613-7621.

27. Groeneveld, T. W., T. H. Ramwadhdoebe, L. A. Trouw, D. L. van den Ham, V. van der Borden, J. W. Drijfhout, P. S. Hiemstra, M. R. Daha, and A. Roos. 2007. Human neutrophil peptide-1 inhibits both the classical and the lectin pathway of complement activation. Mol Immunol 44:3608-3614.

28. Groeneveld, T. W., M. Oroszlan, R. T. Owens, M. C. Faber-Krol, A. C. Bakker, G. J. Arlaud, D. J. McQuillan, U. Kishore, M. R. Daha, and A. Roos. 2005. Interactions of the extracellular matrix proteoglycans decorin and biglycan with $\mathrm{C} 1 \mathrm{q}$ and collectins. J Immunol 175:4715-4723.

29. Roos, A., M. Essers, D. van Gijlswijk-Janssen, N. V. Bovin, and M. R. Daha. 2001. Both IgG and IgM anti-pig antibodies induce complement activation and cytotoxicity. Xenotransplantation 8:3-14. 
30. Roos, A., L. H. Bouwman, J. Munoz, T. Zuiverloon, M. C. Faber-Krol, F. C. Fallaux-van den Houten, N. Klar-Mohamad, C. E. Hack, M. G. Tilanus, and M. R. Daha. 2003. Functional characterization of the lectin pathway of complement in human serum. Mol Immunol 39:655-668.

31. Hoekzema, R., M. Martens, M. C. Brouwer, and C. E. Hack. 1988. The distortive mechanism for the activation of complement component C1 supported by studies with a monoclonal antibody against the "arms" of C1q. Mol Immunol 25:485-494.

32. Sievers, F., A. Wilm, D. Dineen, T. J. Gibson, K. Karplus, W. Li, R. Lopez, H. McWilliam, M. Remmert, J. Soding, J. D. Thompson, and D. G. Higgins. 2011. Fast, scalable generation of high-quality protein multiple sequence alignments using Clustal Omega. Mol Syst Biol 7:539.

33. Kishore, U., R. Ghai, T. J. Greenhough, A. K. Shrive, D. M. Bonifati, M. G. Gadjeva, P. Waters, M. S. Kojouharova, T. Chakraborty, and A. Agrawal. 2004. Structural and functional anatomy of the globular domain of complement protein C1q. Immunol Lett 95:113-128.

34. Pettus, B. J., C. E. Chalfant, and Y. A. Hannun. 2002. Ceramide in apoptosis: an overview and current perspectives. Biochim Biophys Acta 1585:114-125.

35. Arboleda, G., L. C. Morales, B. Benitez, and H. Arboleda. 2009. Regulation of ceramide-induced neuronal death: cell metabolism meets neurodegeneration. Brain Res Rev59:333-346.

36. Babiychuk, E. B., A. P. Atanassoff, K. Monastyrskaya, C. Brandenberger, D. Studer, C. Allemann, and A. Draeger. 2011. The targeting of plasmalemmal ceramide to mitochondria during apoptosis. PLoS One 6:e23706.

37. Grassme, H., A. Jekle, A. Riehle, H. Schwarz, J. Berger, K. Sandhoff, R. Kolesnick, and E. Gulbins. 2001. CD95 signaling via ceramide-rich membrane rafts. J Biol Chem 276:20589-20596.

38. Wajant, H. 2002. The Fas signaling pathway: more than a paradigm. Science 296:1635-1636.

39. Perry, D. K., J. Carton, A. K. Shah, F. Meredith, D. J. Uhlinger, and Y. A. Hannun. 2000. Serine palmitoyltransferase regulates de novo ceramide generation during etoposide-induced apoptosis. J Biol Chem 275:9078-9084.

40. Gullstrand, B., U. Martensson, G. Sturfelt, A. A. Bengtsson, and L. Truedsson. 2009. Complement classical pathway components are all important in clearance of apoptotic and secondary necrotic cells. Clin Exp Immunol 156:303-311.

41. Nauta, A. J., G. Castellano, W. Xu, A. M. Woltman, M. C. Borrias, M. R. Daha, C. van Kooten, and A. Roos. 2004. Opsonization with C1q and mannose-binding lectin targets apoptotic cells to dendritic cells. J Immunol 173:3044-3050.

42. Roos, A., W. Xu, G. Castellano, A. J. Nauta, P. Garred, M. R. Daha, and C. van Kooten. 2004. Mini-review: A pivotal role for innate immunity in the clearance of apoptotic cells. Eur I Immunol 34:921-929.

43. Gaboriaud, C., J. Juanhuix, A. Gruez, M. Lacroix, C. Darnault, D. Pignol, D. Verger, J. C. Fontecilla-Camps, and G. J. Arlaud. 2003. The crystal structure of the globular head of complement protein C1q provides a basis for its versatile recognition properties. J Biol Chem 278:46974-46982. 


\section{Chapter 2}

44. Khoshnoodi, J., V. Pedchenko, and B. G. Hudson. 2008. Mammalian collagen IV. Microsc Res Tech 71:357-370.

45. Duncan, A. R., and G. Winter. 1988. The binding site for C1q on IgG. Nature 332:738-740.

46. Kovacs, H., I. D. Campbell, P. Strong, S. Johnson, F. J. Ward, K. B. Reid, and P. Eggleton. 1998. Evidence that $\mathrm{C} 1 \mathrm{q}$ binds specifically to $\mathrm{CH} 2$-like immunoglobulin gamma motifs present in the autoantigen calreticulin and interferes with complement activation. Biochemistry 37:17865-17874.

47. Agrawal, A., and J. E. Volanakis. 1994. Probing the C1q-binding site on human C-reactive protein by site-directed mutagenesis. J Immunol 152:5404-5410.

48. Nonaka, M., and A. Kimura. 2006. Genomic view of the evolution of the complement system. Immunogenetics 58:701-713.

49. Pickering, M., and H. T. Cook. 2011. Complement and glomerular disease: new insights. Curr Opin Nephrol Hypertens 20:271-277.

50. Sethu, S., and A. J. Melendez. 2011. New developments on the TNFalphamediated signalling pathways. Biosci Rep 31:63-76.

51. Veerhuis, R., H. M. Nielsen, and A. J. Tenner. 2011. Complement in the brain. Mol Immunol 48:1592-1603.

52. Veerhuis, R., M. J. Van Breemen, J. M. Hoozemans, M. Morbin, J. Ouladhadj, F. Tagliavini, and P. Eikelenboom. 2003. Amyloid beta plaque-associated proteins $\mathrm{C} 1 \mathrm{q}$ and SAP enhance the Abeta1-42 peptide-induced cytokine secretion by adult human microglia in vitro. Acta Neuropathol 105:135-144.

53. Gershov, D., S. Kim, N. Brot, and K. B. Elkon. 2000. C-Reactive protein binds to apoptotic cells, protects the cells from assembly of the terminal complement components, and sustains an antiinflammatory innate immune response: implications for systemic autoimmunity. J Exp Med 192:1353-1364.

54. Berman, S., H. Gewurz, and C. Mold. 1986. Binding of C-reactive protein to nucleated cells leads to complement activation without cytolysis. J Immunol 136:1354-1359.

55. Cribbs, D. H., N. C. Berchtold, V. Perreau, P. D. Coleman, J. Rogers, A. J. Tenner, and C. W. Cotman. 2012. Extensive innate immune gene activation accompanies brain aging, increasing vulnerability to cognitive decline and neurodegeneration: a microarray study. J Neuroinflammation 9:179.

56. Fishelson, Z., N. Donin, S. Zell, S. Schultz, and M. Kirschfink. 2003. Obstacles to cancer immunotherapy: expression of membrane complement regulatory proteins (mCRPs) in tumors. Mol Immunol 40:109-123.

57. Heering, J., N. Weis, M. Holeiter, F. Neugart, A. Staebler, T. N. Fehm, A. Bischoff, J. Schiller, S. Duss, S. Schmid, T. Korte, A. Herrmann, and M. A. Olayioye. 2012. Loss of the ceramide transfer protein augments EGF receptor signaling in breast cancer. Cancer Res 72:2855-2866. 


\section{SUPPLEMENTARY FIGURES}

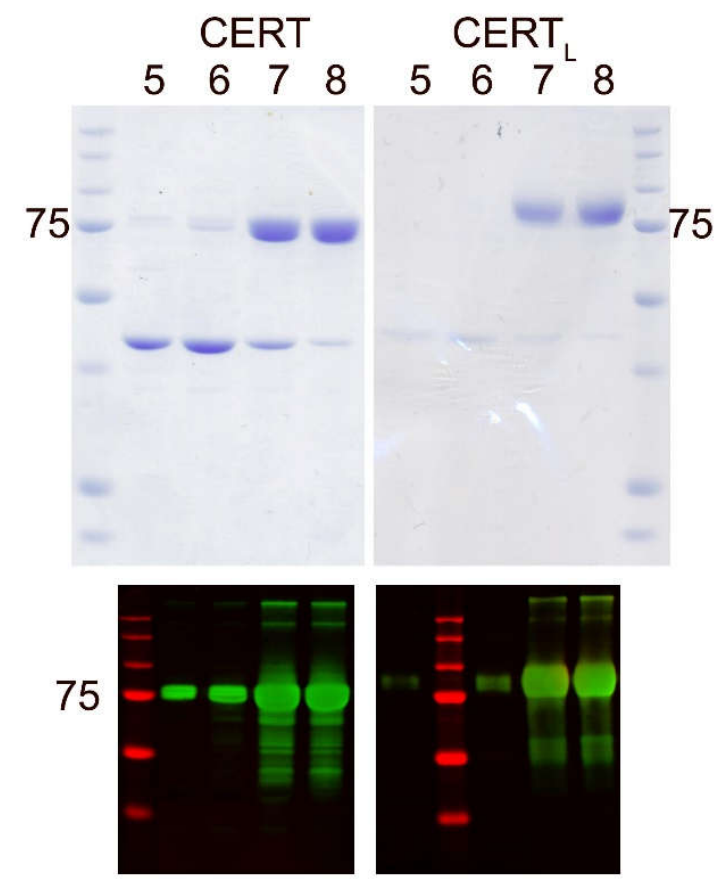

Figure S1: Coomassie staining and Western blot of ion exchange purified CERT and $\mathrm{CERT}_{\mathrm{L}}$. Electrophoretically separated proteins were assessed for purity by Coomassie staining. Ion exchange purification elution fractions of CERT and CERT $\mathrm{C}_{\mathrm{L}}$ were loaded on a 10\% SDS-PAGE gel, electrophoretically separated and either stained with Coomassie or electroblotted on nitrocellulose membrane. Membranes were probed with rabbit anti- CERT $_{\mathrm{L}} / \mathrm{CERT}$ 669A (Bethyl Laboratories, Montgomery, TX) and mouse anti-CERT $\mathrm{L}_{\mathrm{L}}$ 3A1C1. Secondary donkey anti-mouse conjugated to IRdye680 (LICOR, Lincoln, NE) and goat anti-rabbit conjugated to IRdye800 (LI-COR) were visualized on an odyssey scanner (LI-COR) as red and green respectively. The bands at the expected molecular weight for CERT and $\mathrm{CERT}_{\mathrm{L}}$ around $75 \mathrm{kDa}$ were detected by specific antibodies against CERT and $\mathrm{CERT}_{\mathrm{L}}$ in the Western blot. Fractions 7 and 8 were pooled and used for all further experiments. An unidentified protein band of approximately $40 \mathrm{kDa}$ did not show any C1q binding (Figure S2). 
Chapter 2

$\lg \mathrm{G} 1$

$\lg G 4$

CERT IEX fraction 5

CERT IEX fraction 9

FP CERT

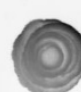

FP CERT

Figure S2: Far Western dot blot of CERT ion exchange purification elution fractions. Fractions 5 and 9 of the CERT ion exchange purification were tested for C1q binding. Fraction 9, consisting almost exclusively of the $\sim 75 \mathrm{kDa}$ protein identified as CERT, showed strong C1q binding which was comparable to the positive control IgG1 (1). In contrast, fraction 5 consisting mostly of the unidentified $40 \mathrm{kDa}$ protein showed no appreciable $\mathrm{C} 1 \mathrm{q}$ binding, comparable to the negative control IgG4 (1). FLAG-purified CERT (FP CERT) and CERT L $_{\mathrm{LP}}$ CERT $_{\mathrm{L}}$ ) also bound C1q. 


\section{Complement activation by ceramide transporter proteins}

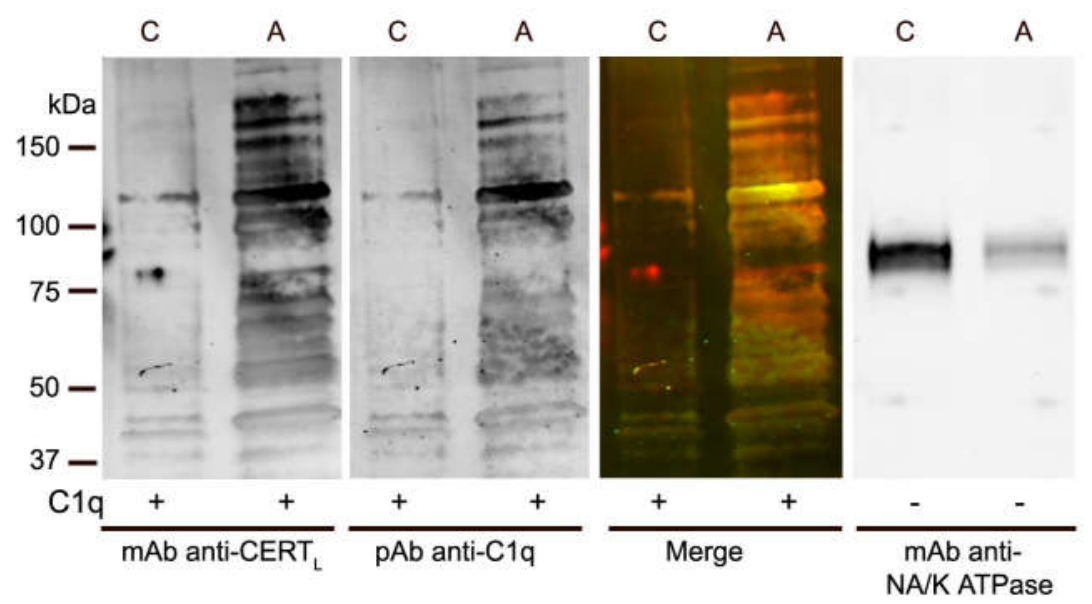

Figure S3: Binding of $\mathrm{C} 1 \mathrm{q}$ to $\mathrm{CERT}_{\mathrm{L}}$ in membrane protein extracts of apoptotic Jurkat cells. Etoposide treated Jurkat cells or untreated control cells were harvested, washed in ice cold PBS with $0.01 \% \mathrm{NaN}_{3}$ and resuspended in lysis buffer (250 mM sucrose, 20 mM HEPES, $10 \mathrm{mM} \mathrm{KCl}, 1.5 \mathrm{mM} \mathrm{MgCl}_{2}, 1 \mathrm{mM}$ EDTA, $1 \mathrm{mM}$ EGTA, $1 \mathrm{mM}$ DTT and protease inhibitor cocktail (according to manufacturer's instructions, Roche, Basel, Switzerland). The lysate was passed through a $25 \mathrm{G}$ needle and incubated on ice for 20 minutes. The membrane fraction was obtained by sequential centrifugation at $720 \mathrm{G}$ for 5 minutes, $10,000 \mathrm{G}$ for 5 minutes and 150,000 G for 90 minutes. The pellet from the last centrifugation step was resuspended in lysis buffer. Electrophoretically separated membrane protein extracts of control (C) and apoptotic (A) Jurkat cells were transferred to PVDF membrane and probed with $\mathrm{C} 1 \mathrm{q}$, revealing binding of $\mathrm{C} 1 \mathrm{q}$ (green) to $\mathrm{CERT}_{\mathrm{L}}$ (red) 
Chapter 2 
Unchanged expression of CERT in 6-OHDA neurodegenerative model

\section{CHAPTER 3}

\section{UNCHANGED EXPRESSION OF THE CERAMIDE TRANSFER PROTEIN IN THE ACUTE 6-OHDA NEURODEGENERATIVE MODEL}

Chiara Mencarelli, Gerard H Bode, Rinske Vlamings, Mark L. Janssen, Mario Losen, Marc H De Baets, Harry W. M. Steinbusch, Yasin Temel and Pilar Martínez-Martínez

Published in Neuroscience Letters 
Chapter 3

\section{ABSTRACT}

Ceramides are lipids that are abundant in brain tissue where they have an important structural role in cellular membranes. Ceramides are also powerful intracellular signaling molecules controlling cell death, growth and differentiation. So far, the ceramide transfer protein (CERT), a shorter splice variant of the Goodpasture antigen-binding protein (GPBP), is the only known protein with the ability to shuttle ceramide from the endoplasmic reticulum to the Golgi apparatus. GPBP/CERT are widely distributed in the central nervous system where they act as key factors for normal brain development and homeostasis. Ceramide accumulates in neurons during acute neurodegeneration. The objective of this study was to define whether levels of the ceramide transfer protein GPBP/CERT are altered in the acute neurodegenerative process. We used design-based stereology to quantify the number of GPBP/CERT immunoreactive cells in the striatum of 6hydroxydopamine (6-OHDA) lesioned rats as an animal model of Parkinson's disease (PD). In addition, gray value measurement was performed to quantify GPBP/CERT immunoreactivity-levels within individual cells. No difference in the striatal expression levels of GPBP/CERT proteins was found between diseased and control animals, suggesting that the expression pattern of GPBP/CERT in the striatum is not affected in the 6-OHDA rat model of PD. 
Unchanged expression of CERT in 6-OHDA neurodegenerative model

\section{INTRODUCTION}

Ceramides are lipids abundant in brain tissue where they were first discovered by Johann LW Thudichum in 1884 (for a review[38]). They have an important structural role in cellular membranes and also act as signalling molecules inside the cell [1]. The balance of ceramide levels extensively regulates cell functions [14].

Due to their hydrophobic nature, ceramides were thought to function exclusively at the site of their synthesis. The existence in the cell of a protein capable of transfering ceramide between two different locations in the cytoplasm was demonstrated in 2003 by Hanada and colleagues [17]. The ceramide transfer protein (CERT), the shorter splice variant of the Goodpasture antigen-binding protein (GPBP) [28] shuttles ceramide between the endoplasmic reticulum (ER) and the Golgi in a non-vesicular manner. The ceramide transporter GPBP/CERT is widely distributed in the brain with higher expression levels in neurons compared to other cell types [25]. Knock-down of the longer isoform GPBP in zebrafish results in extensive loss of myelinated tracts and cell death in the brain during embryogenesis [16]. Knock-out mice for both isoforms CERT and GPBP, die early as a consequence of heart defects due to ER and mitochondrial degeneration.

Ceramide levels are increased in neurodegenerative diseases such as Alzheimer's disease [10], Parkinson's disease (PD) [9], dementia with Lewy bodies and amyotrophic lateral sclerosis [11]. Ceramides were augmented in the cerebrospinal fluid of Alzheimer's disease patients and serum ceramides are early predictors of cognitive impairment in Alzheimer's disease [30].

We hypothesised that the protein levels of the ceramide transporter also change during acute neurodegeneration. 
To study GPBP/CERT levels in a neurodegenerative condition, we used an experimental model to mimic the dopamine depletion. Rats were chronically dopamine (DA) depleted by bilateral striatal injections of 6hydroxydopamine (6-OHDA). 6-OHDA, being similar to DA, shows high affinity for the dopamine transporter, which carries this neurotoxin inside the dopaminergic neurons. 6-OHDA accumulates in the cytosol and undergoes prompt auto-oxidation, promoting a high rate of free radical formation [12]. As a consequence intra-striatal 6-OHDA injection permanently damages the dopaminergic nigrostriatal pathway. The loss of dopaminergic input to the striatum disrupts the basal ganglia circuit and is responsible for the most prominent symptoms of PD in the extent that the degree of neurological deficit is related to the loss of striatal DA [18].

Nigral dopaminergic neurons are naturally exposed to oxidative stress because in the presence of molecular oxygen DA undergoes spontaneous oxidation, leading to the formation of reactive oxygen species (ROS) [15, 23]. In turn, conditions known to promote elevated cellular levels of ROS can lead to ceramide accumulation ([19]) which is associated with the induction of apoptotic cell death $[6,13,38]$.

Here, we have conducted a design-based stereology investigation to quantify GPBP/CERT immunoreactive cells in the striatum of rats treated with bilateral injections of 6-OHDA.

\section{Methods}

All experimental procedures were approved by the Animal Experiments and Ethics Committee of Maastricht University. Animal and surgical procedures used have been described in detail before [36]. Fourteen male Lewis rats at the age of 12 weeks received stereotactic bilateral injections at two sites per hemisphere with either $2 \mu$ of 6-OHDA (5 $\mu \mathrm{g} / \mu \mathrm{l}$ dissolved in $0.9 \%$ saline and $0.2 \%$ ascorbic acid; Sigma, 
Unchanged expression of CERT in 6-OHDA neurodegenerative model

Zwijndrecht, the Netherlands) or saline (0.9\% saline and $0.2 \%$ ascorbic acid) in the striatum. To protect noradrenergic neurons from 6-OHDA, the rats received $20 \mathrm{mg} / \mathrm{kg}$ desipramine one hour before surgery.

After 2 weeks post injection, rats were perfused transcardially with Tyrode's medium $(0.1 \quad \mathrm{M})$ and fixative containing $4 \%$ paraformaldehyde, $15 \%$ picric acid and $0.05 \%$ glutaraldehyde in $0.1 \mathrm{M}$ phosphate buffer ( $\mathrm{pH}$ 7.6). Brains were removed and postfixed for $2 \mathrm{~h}$ in the same medium followed by overnight immersion in $15 \%$ sucrose in $0.1 \mathrm{M}$ phosphate buffer at $4{ }^{\circ} \mathrm{C}$. Then brain tissue was quickly frozen with solid $\mathrm{CO}_{2}$ and stored at $-80^{\circ} \mathrm{C}$. The brains were cut serially in 30$\mu \mathrm{m}$ thick coronal sections on a cryostate and were collected freefloating in series. Of every rat, one series was selected for immunohistochemical stainings.

Immunohistochemistry for GPBP/CERT was carried out using freefloating coronal sections which were incubated for 72 hours at $4^{\circ} \mathrm{C}$ with the primary antibody, a rabbit polyclonal anti-GPBP/CERT antibody (diluted 1:500; epitope 1-50 of human GPBP, Bethyl laboratories, USA). After rinsing with Tris-buffered saline including $50 \mathrm{mM}$ Triton, sections were incubated with the secondary antibody, donkey anti-rabbit biotinylated IgG (diluted 1:800; Jackson ImmunoResearch Laboratories Europe Ltd, Suffolk, United Kingdom) at RT. Subsequently, sections were incubated with the ABC-kit (diluted 1:800, Vector laboratories, Peterborough, United Kingdom) for $1.5 \mathrm{~h}$. To visualize the horseradish peroxide reaction product, the sections were incubated with 3,3'diaminobenzidine tetrahydrochloride (DAB). To stop the reaction, the sections were rinsed in TBS. No labeling was evident in control experiments in which the primary antibody was omitted from the immunostaining protocol (not shown). Tyrosine hydroxylase (TH) immunohistochemistry was carried out as previously described [36] using mouse anti-TH (diluted 1:2000, kindly supplied by Dr. C. Cuello, 
Canada) as primary antibody [37]. After rinsing steps with TBS, and incubation with the secondary antibody (diluted 1:400 donkey antimouse biotin; Jackson Immunoresearch Laboratories, West Grove, USA), the labeling was visualized with $\mathrm{ABC} / \mathrm{DAB}$ procedure as mentioned above.

For the stereologic procedures, a stereology workstation consisting of an Olympus BX51 microscope (Olympus, Tokyo, Japan), motorized specimen stage, color video camera and a PC with StereoInvestigator stereology software (MBF Bioscience, Vermont, USA) was used. The number of cells expressing GPBP/CERT and labelled with the abovementioned polyclonal antibody were quantified in a part of the striatum, with a rostral boundary at Bregma $1.60 \mathrm{~mm}$ where the corpus callosum crosses the midline and a caudal boundary at Bregma -0.90 $\mathrm{mm}$ where the fornix enters the diencephalon. The dorsal and lateral boundaries of this region consisted of the corpus callosum and the medial boundary was defined by the lateral ventricle. A ventral boundary was set by drawing a line from the tip of the lateral ventricle to the rhinal fissure [20]. The region of interest was delineated using a $4 \mathrm{x}$ objective. The optical fractionator technique [32] was used to determine the total numbers of cells positive for GPBP/CERT. Positive cells were counted using a 100x objective in unbiased virtual counting spaces distributed in a systematic random fashion throughout the delineated region of interest (Table 1). The total number of positive cells in the region of interest was estimated as a function of the number of cells counted and the sampling probability [32]. For, quantifying the number of TH immunoreactive (THir) neurons, a similar stereological approach was used. After exactly tracing the boundaries of the substantia nigra pars compacta $(\mathrm{SNc})$ on microscopic video images displayed on a monitor, numbers of neurons were evaluated with the Optical Fractionator [31]. All neurons whose nucleus top came into 
Unchanged expression of CERT in 6-OHDA neurodegenerative model

focus within unbiased virtual counting spaces distributed in a systematic-random fashion throughout the delineated regions were counted. The total numbers of neurons were estimated as a function of the numbers of counted neurons and the corresponding sampling probability. For more details see [36].

\section{Table 1}

Details of the stereologic analysis

\begin{tabular}{l|l|l|l|l|l|l|l|l|}
\hline Region & $\mathrm{Obj}$ & $B\left(\mu \mathrm{m}^{2}\right)$ & $H(\mu \mathrm{m})$ & $D(\mu \mathrm{m})$ & $t(\mu \mathrm{m})$ & $\Sigma \mathrm{OD}$ & $\Sigma Q$ & $\mathrm{CE}_{\text {pred}}[\mathrm{n}]$ \\
\hline Striatum & $100 \times$ & 900 & 6 & 400 & 7.57 & 331 & 655 & 0.039 \\
\hline
\end{tabular}

Obj., objective used; $\mathrm{B}$ and $\mathrm{H}$, base and height of the unbiased virtual counting spaces; $\mathrm{D}$, distance between the unbiased virtual counting spaces in mutually orthogonal directions $x$ and $y$, t, measured actual average section thickness after histological processing; $\sum O D$, average sum of unbiased virtual counting spaces used; $\sum Q$, average number of counted neurons; $\mathrm{CE}_{\text {pred }}[\mathrm{n}]$, average predicted coefficient of error of the estimated total neuron numbers using the prediction method described in [31] and [32].

GPBP/CERT immunostained neurons were evaluated also by gray value. Mean gray values for regions of interest (bregma 0.7 and - 0.4) were calculated using ImageJ software, with images photographed at a magnification of $x 40$. The mean gray value of cells in the selected regions was used as a measurement for the expression levels of GPBP/CERT in the striatum. The statistical analysis of the data was done with GraphPad Prism (Version 5.01 for Windows, GraphPad Software, San Diego CA). The mean and the standard error of the mean (SEM) were determined for the numbers of cells expressing GPBP/CERT and the striatal volume in both 6-OHDA and control rats.

An unpaired two-tailed t-test was performed to compare the means of the 6-OHDA group and the control group, the result was considered statistically significant if its $\mathrm{p}$-value was smaller than 0.05 . Three 
unilateral 6-OHDA lesioned rats were used (disease induction and handling similar to animals describes above). Brains were removed, striatal samples were dissected in two hemispheres the 6-OHDAinjected and from the control hemisphere. The samples were quickly frozen with solid $\mathrm{CO}_{2}$ and stored at $-80^{\circ} \mathrm{C}$ striatal brain homogenization is performed as described previously [25]. Proteins were separated by SDS-PAGE using precast Criterion Tris-HCl Glycine 4-20\% gradient gels (Bio-Rad, CA, USA) followed by electroblotting to nitrocellulose membrane (Millipore, Amsterdam Zuid-Oost The Netherlands). The membranes were incubated with the following primary antibodies: rabbit polyclonal anti-GPBP/CERT antibody (epitope 1-50 of human GPBP, Bethyl laboratories, USA) and mouse monoclonal anti-GAPDH antibody (Ab9484, Abcam, Cambrdige, UK), used as a protein loading control. After PBS washes, the membrane was incubated with goat antirabbit-Alexa 800 and donkey anti-mouse-Alexa 680 (Rockland, USA). The membrane was washed with PBS, dried and scanned using the Odyssey infrared imaging system (Westburg, The Netherlands). The mean intensity of the GPBP/CERT band was measured in ImageJ and corrected for protein loading with the mean intensity of the GAPDH band.

\section{REsults}

Injections of 6-OHDA into the striatum resulted in a substantial loss of THir cells in the SNc as compared to the sham group. High-precision design-based stereological analysis revealed a significant 6-OHDAinduced reduction in the total number of THir cells in the SNc of about 65\% bilaterally $(P<0.01)$ Figure 1 . 
Unchanged expression of CERT in 6-OHDA neurodegenerative model

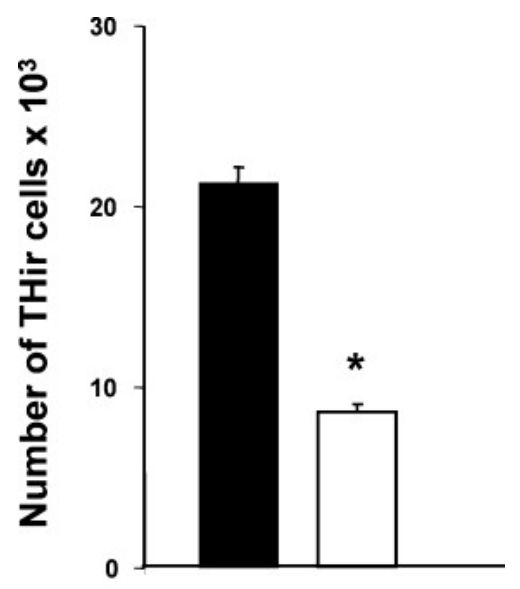

Figure 1: Mean total numbers of THir- neurons of sham-operated rats and rats subjected to dopamine depletion. Data represent means and SEM per group. Since the left and right SNc showed a similar cell count, the data were pooled. The $P$ values from the corresponding post hoc LSD tests are provided as $* P<0.05$

SHAM 6-OHDA

6-OHDA starts its toxic effects in the striatum with dopamine nerve terminal disruptions and consequent progressive retrograde degeneration of nigro-striatal dopamine neurons in the SNc. Therefore in this study we selected the striatum as area of investigation (Figure 2 $\mathrm{C})$, instead of the SNc where the massive death of dopaminergic neurons (Figure $2 \mathrm{~A}$ and $\mathrm{B}$ ) would have masked the quantification of GPBP/CERT levels. For the quantification of GPBP/CERT positive cells in diseased and control animals, the striatum was delineated as depicted in Figure 2C. Figure 2D shows a high-power photomicrograph of the striatum with the $100 x$ objective used during the counting procedure. GPBP/CERT positive cells were neurons as described previously [26]. Intensely stained neurons were present in the striatum, although there was considerable regional variation in the intensity of the stained cells. The stereological analysis revealed no differences in the volume of the striatum in 6-OHDA treated rats compared to the group of rats that received a sham treatment $(p=0.61$; Figure $2 E)$. Additionally the quantification of the total numbers of GPBP/CERT positive cells in the striatum using the fractionator technique showed no significant difference between the saline treated group and the 6OHDA injected group ( $\mathrm{p}=0.48$; Figure $2 \mathrm{~F})$. 
Chapter 3

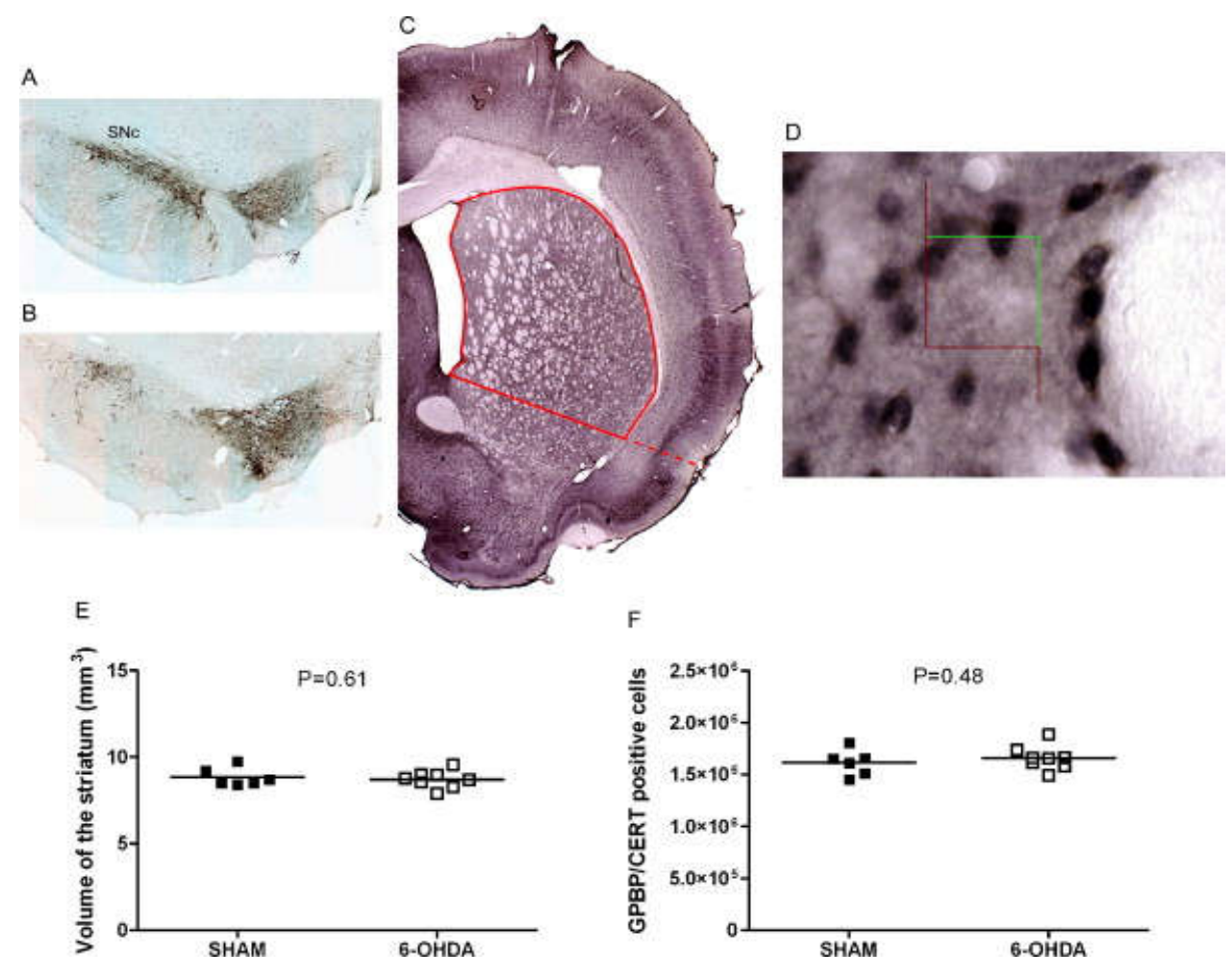

Figure 2: Tyrosine hydroxylase immunohistochemistry of the substantia nigra pars compacta (SNc) of sham treated rats (A) and 6-OHDA treated rats (B). The delineation of the striatum used in the stereological procedure $(C)$ and a representative highpower photomicrograph of the striatum stained for GPBP/CERT (D). The volume of the striatum (E) and the estimated total number of cells positive for GPBP/CERT in the striatum (F) are not different between sham treated and 6-OHDA treated rats. Means were compared with an unpaired two-tailed t-test, data are shown as values of individual animals and the mean of the group.

To further confirm these results, a quantitative Western blotting analysis of the striatum of 6-OHDA-treated and -untreated hemispheres was performed with the same antibody anti-GPBP/CERT used in the immunohistochemical study. The result is consistent with the previous analysis since no difference in GPBP/CERT protein levels were detected in the $72 \mathrm{kDA}$ protein band of untreated and 6-OHDA treated samples (Figure $3 \mathrm{~A}$ and $\mathrm{B}$ ). 
No significant difference was found in the level of GPBP/CERT expression level within individual cells in the striatum of diseased and control animals $(p=0.07$; Figure 3$)$.
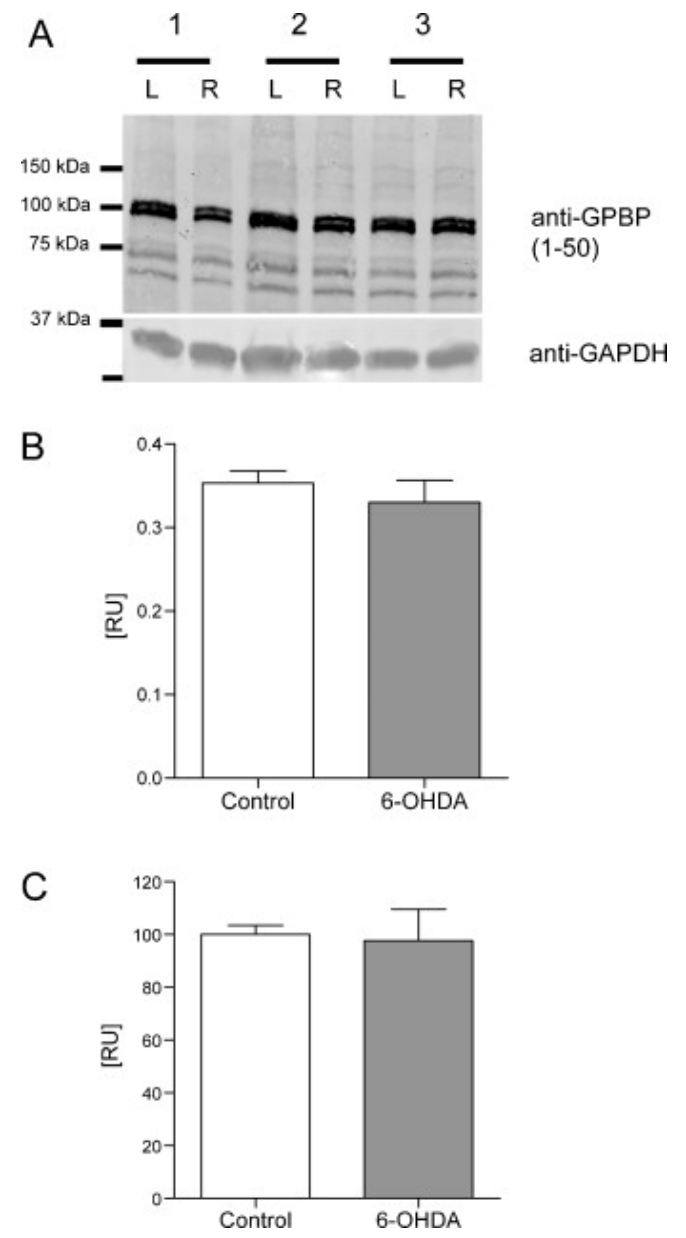

Figure 3: (A) Western blot of striatal brain homogenates detected with antiGPBP/CERT and anti-GAPDH antibodies shows comparable protein amounts between the 6-OHDA-injected (L) and the control (R) hemisphere in three animals (1-2-3). (B) Quantification of the $72 \mathrm{kDa}$ GPBP/CERT band in the Western blot of brain homogenate shown in (A). The mean intensity of the bands was measured and corrected for GAPDH intensity, no significant difference in GPBP/CERT expression was found. (C) Gray value quantification of GPBP/CERT expression in individual cells of the striatum at Bregma -0.4 and 0.7. A minimum of 30 cells per animal were quantified and no statistically significant difference in mean gray value was found between the SHAM and 6-OHDA rats $(\mathrm{P}=0.07)$. 
Chapter 3

\section{DISCUSSION}

Protein levels of the ceramide transfer protein GPBP/CERT were not altered in the striatum in the acute neurodegenerative process of the 6OHDA model. This lack of difference might be explained by several reasons. First, the mode of action of 6-OHDA: injection of 6-OHDA selectively kills dopaminergic neurons after entering the cells via the dopamine transporter, inducing acute effects which differ significantly from the chronic progressive course of PD [4]. Dopaminergic neurotoxicity of 6-OHDA is associated with membrane lipid alteration, cellular loss of phospholipid asymmetry and membrane blebbing [5, 40]. This membrane-associated oxidative stress occurs together with accumulation of ceramide species [27, 33]. Additionally, it has been described that 6-OHDA promotes a high rate of free radical formation in the cytosol of neurons and ROS production also leads to ceramide accumulation $[2,19]$. In our experiments the analysis of the striatum takes place days after the cellular induced toxicity by 6-OHDA. Conversion of palmitate to ceramide in the de novo pathway requires multiple enzymatic steps and it is responsible for a slow but robust accumulation of ceramide over a period of several hours [22]. We studied levels of GPBP/CERT days after the induction of apoptosis by 6OHDA to assure the production of ceramide by the de novo pathway.

Second, a defining pathological hallmark of PD is the presence of neuronal Lewy body formed by protein aggregates. After 6-OHDA lesioning, cytoplasmatic inclusions of aggregate proteins do not occur [35]. The role of protein aggregations in the pathogenesis of PD has not been fully determined, but altered protein processing in the cell could have a negative impact on normal cellular function. Some of the genes involved in Lewy body disease have also an effect on ceramide metabolism (for review, see [8]). In this regard, knock down of LASS2, 
Unchanged expression of CERT in 6-OHDA neurodegenerative model

an aging-associated gene that encodes a ceramide synthase, results in a premature increase in the number of inclusions in Caenorhabditis elegans [39]. Therefore, ceramide and its transporters could play a role in protein self-aggregation processes.

Moreover, mutations that occur in glucosylcerebrosidase gene have been found to predispose to PD [7] and Lewy body disorders [24]. Glucocerebrosidase is an enzyme that catalyzes the breakdown of the lipid glucosylcerebroside to ceramide and glucose. This enzyme is highly enriched in the brain. Loss of glucocerebrosidase activity and a toxic gain-of-function can cause Parkinson disease-like $\alpha$-synuclein pathology [29].

It is important to bear in mind that post translational refolding of normal protein, including the normal prion protein and the amyloidogenic processing of amyloid precursor protein, is affected by the content of sphingomyelin and cholesterol in lipid rafts at the level of the plasma membrane $[3,21,34,36]$. Consequently, dysregulation of sphingolipid metabolism, that seems to be strongly involved in protein aggregation in many neurodegenerative disorders, is a condition that is missing in a 6-OHDA model.

Third, the antibody used in this study recognizes both isoforms, GPBP and CERT. Therefore we cannot rule out the possibility that significant changes in GPBP expression are masked by CERT expression which is higher at basal levels compared to GPBP [28]. These two variants may differ in various properties such as stability, clearance rate, tissue and cellular localization, temporal pattern of expression, up or down regulation mechanisms and responses to agonists or antagonists. Moreover, the presence or level of specific splice variants may vary depending on the pathophysiologic state of a particular condition. Specific antibodies for each isoform were unavailable at the time of this 
Chapter 3

study; the development of these antibodies should help to resolve this issue.

All the data generated using the 6-OHDA model may help to determine if GPBP/CERT could be critical in the molecular pathways leading to degeneration of nigral cells induced by accumulation of toxins. However, our results are only indicative and need post-mortem confirmation to estimate the real occurrence of such processes. Thus to confirm our findings future investigation of intra- and extracellular ceramide abundance and localization in PD brain and thus its possibility to bind to CERT/GPBP are desirable.

\section{CONCLUSIONS}

We tested the hypothesis that GPBP/CERT expression levels were affected in the acute brain injury process of a 6-OHDA PD rat model. Using quantitative stereology we did not observe differences in the number of striatal cells expressing GPBP/CERT. Correlating with this result, also gray value quantification did not detect differences in GPBP/CERT expression levels within individual cells in the acute brain injury process of a 6-OHDA PD rat model. Whereas ceramide levels are known to increase in neurodegenerative diseases, this is the first study to report on the expression levels of the ceramide transporter GPBP/CERT, which were found to remain stable in the PD model used.

\section{ACKNOWLEDGEMENTS}

We would like to thank Mark Janssen for providing the samples used in the Western blot study. 
Unchanged expression of CERT in 6-OHDA neurodegenerative model

\section{REFERENCES}

[1] A.V. Alessenko, The role of sphingomyelin cycle metabolites in transduction of signals of cell proliferation, differentiation and death, Membr Cell Biol 13 (2000) 303-320.

[2] A.V. Alessenko, A.E. Bugrova, L.B. Dudnik, Connection of lipid peroxide oxidation with the sphingomyelin pathway in the development of Alzheimer's disease, Biochem Soc Trans 32 (2004) 144-146.

[3] G.S. Baron, K. Wehrly, D.W. Dorward, B. Chesebro, B. Caughey, Conversion of raft associated prion protein to the protease-resistant state requires insertion of PrP-res (PrP(Sc)) into contiguous membranes, EMBO J 21 (2002) 10311040.

[4] R. Betarbet, T.B. Sherer, J.T. Greenamyre, Animal models of Parkinson's disease, Bioessays 24 (2002) 308-318.

[5] D. Blum, S. Torch, N. Lambeng, M. Nissou, A.L. Benabid, R. Sadoul, J.M. Verna, Molecular pathways involved in the neurotoxicity of 6-OHDA, dopamine and MPTP: contribution to the apoptotic theory in Parkinson's disease, Prog Neurobiol 65 (2001) 135-172.

[6] R. Bose, M. Verheij, A. Haimovitz-Friedman, K. Scotto, Z. Fuks, R. Kolesnick, Ceramide synthase mediates daunorubicin-induced apoptosis: an alternative mechanism for generating death signals, Cell 82 (1995) 405-414.

[7] J. Bras, C. Paisan-Ruiz, R. Guerreiro, M.H. Ribeiro, A. Morgadinho, C. Januario, E. Sidransky, C. Oliveira, A. Singleton, Complete screening for glucocerebrosidase mutations in Parkinson disease patients from Portugal, Neurobiol Aging 30 (2009) 1515-1517.

[8] J. Bras, A. Singleton, M.R. Cookson, J. Hardy, Emerging pathways in genetic Parkinson's disease: Potential role of ceramide metabolism in Lewy body disease, FEBS J 275 (2008) 5767-5773.

[9] B. Brugg, P.P. Michel, Y. Agid, M. Ruberg, Ceramide induces apoptosis in cultured mesencephalic neurons, J Neurochem 66 (1996) 733-739.

[10] R.G. Cutler, J. Kelly, K. Storie, W.A. Pedersen, A. Tammara, K. Hatanpaa, J.C. Troncoso, M.P. Mattson, Involvement of oxidative stress-induced abnormalities in ceramide and cholesterol metabolism in brain aging and Alzheimer's disease, Proc Natl Acad Sci U S A 101 (2004) 2070-2075. 


\section{Chapter 3}

[11] R.G. Cutler, W.A. Pedersen, S. Camandola, J.D. Rothstein, M.P. Mattson, Evidence that accumulation of ceramides and cholesterol esters mediates oxidative stress-induced death of motor neurons in amyotrophic lateral sclerosis, Ann Neurol 52 (2002) 448-457.

[12] B. Ferger, S. Rose, A. Jenner, B. Halliwell, P. Jenner, 6-hydroxydopamine increases hydroxyl free radical production and DNA damage in rat striatum, Neuroreport 12 (2001) 1155-1159.

[13] C.J. Gamard, G.S. Dbaibo, B. Liu, L.M. Obeid, Y.A. Hannun, Selective involvement of ceramide in cytokine-induced apoptosis. Ceramide inhibits phorbol ester activation of nuclear factor kappaB, J Biol Chem 272 (1997) 16474-16481.

[14] A. Gomez-Munoz, Ceramide 1-phosphate/ceramide, a switch between life and death, Biochim Biophys Acta 1758 (2006) 2049-2056.

[15] D.G. Graham, S.M. Tiffany, W.R. Bell, Jr., W.F. Gutknecht, Autoxidation versus covalent binding of quinones as the mechanism of toxicity of dopamine, 6hydroxydopamine, and related compounds toward C1300 neuroblastoma cells in vitro, Mol Pharmacol 14 (1978) 644-653.

[16] F. Granero-Molto, S. Sarmah, L. O'Rear, A. Spagnoli, D. Abrahamson, J. Saus, B.G. Hudson, E.W. Knapik, Goodpasture antigen-binding protein and its spliced variant, ceramide transfer protein, have different functions in the modulation of apoptosis during zebrafish development, J Biol Chem 283 (2008) 20495-20504.

[17] K. Hanada, K. Kumagai, S. Yasuda, Y. Miura, M. Kawano, M. Fukasawa, M. Nishijima, Molecular machinery for non-vesicular trafficking of ceramide, Nature 426 (2003) 803-809.

[18] 0. Hornykiewicz, S.J. Kish, Biochemical pathophysiology of Parkinson's disease, Adv Neurol 45 (1987) 19-34.

[19] I. Ichi, C. Kamikawa, T. Nakagawa, K. Kobayashi, R. Kataoka, E. Nagata, Y. Kitamura, C. Nakazaki, T. Matsura, S. Kojo, Neutral sphingomyelinase-induced ceramide accumulation by oxidative stress during carbon tetrachloride intoxication, Toxicology 261 (2009) 33-40.

[20] O. Kantor, Y. Temel, C. Holzmann, K. Raber, H.P. Nguyen, C. Cao, H.O. Turkoglu, B.P. Rutten, V. Visser-Vandewalle, H.W. Steinbusch, A. Blokland, H. Korr, O. Riess, S. von Horsten, C. Schmitz, Selective striatal neuron loss and alterations 


\section{Unchanged expression of CERT in 6-OHDA neurodegenerative model}

in behavior correlate with impaired striatal function in Huntington's disease transgenic rats, Neurobiol Dis 22 (2006) 538-547.

[21] M. Kivipelto, E.L. Helkala, M.P. Laakso, T. Hanninen, M. Hallikainen, K. Alhainen, H. Soininen, J. Tuomilehto, A. Nissinen, Midlife vascular risk factors and Alzheimer's disease in later life: longitudinal, population based study, BMJ 322 (2001) 1447-1451.

[22] R. Kolesnick, The therapeutic potential of modulating the ceramide/sphingomyelin pathway, J Clin Invest 110 (2002) 3-8.

[23] J. Lotharius, P. Brundin, Pathogenesis of Parkinson's disease: dopamine, vesicles and alpha-synuclein, Nat Rev Neurosci 3 (2002) 932-942.

[24] I.F. Mata, A. Samii, S.H. Schneer, J.W. Roberts, A. Griffith, B.C. Leis, G.D. Schellenberg, E. Sidransky, T.D. Bird, J.B. Leverenz, D. Tsuang, C.P. Zabetian, Glucocerebrosidase gene mutations: a risk factor for Lewy body disorders, Arch Neurol 65 (2008) 379-382.

[25] C. Mencarelli, C. Hammels, J. Van Den Broeck, M. Losen, H. Steinbusch, F. Revert, J. Saus, D.A. Hopkins, M.H. De Baets, H.W. Steinbusch, P. MartinezMartinez, The expression of the Goodpasture antigen-binding protein (ceramide transporter) in adult rat brain, J Chem Neuroanat 38 (2009) 97105.

[26] C. Mencarelli, M. Losen, C. Hammels, J. De Vry, M.K. Hesselink, H.W. Steinbusch, M.H. De Baets, P. Martinez-Martinez, The ceramide transporter and the Goodpasture antigen binding protein: one protein--one function?, J Neurochem 113 1369-1386.

[27] G.J. Pronk, K. Ramer, P. Amiri, L.T. Williams, Requirement of an ICE-like protease for induction of apoptosis and ceramide generation by REAPER, Science 271 (1996) 808-810.

[28] A. Raya, F. Revert-Ros, P. Martinez-Martinez, S. Navarro, E. Rosello, B. Vieites, F. Granero, J. Forteza, J. Saus, Goodpasture antigen-binding protein, the kinase that phosphorylates the goodpasture antigen, is an alternatively spliced variant implicated in autoimmune pathogenesis, J Biol Chem 275 (2000) 40392-40399.

[29] S.P. Sardi, J. Clarke, C. Kinnecom, T.J. Tamsett, L. Li, L.M. Stanek, M.A. Passini, G.A. Grabowski, M.G. Schlossmacher, R.L. Sidman, S.H. Cheng, L.S. Shihabuddin, CNS expression of glucocerebrosidase corrects alpha-synuclein 


\section{Chapter 3}

pathology and memory in a mouse model of Gaucher-related synucleinopathy, Proc Natl Acad Sci U S A 108 12101-12106.

[30] H. Satoi, H. Tomimoto, R. Ohtani, T. Kitano, T. Kondo, M. Watanabe, N. Oka, I. Akiguchi, S. Furuya, Y. Hirabayashi, T. Okazaki, Astroglial expression of ceramide in Alzheimer's disease brains: a role during neuronal apoptosis, Neuroscience 130 (2005) 657-666.

[31] C. Schmitz, P.R. Hof, Design-based stereology in neuroscience, Neuroscience 130 (2005) 813-831.

[32] C. Schmitz, P.R. Hof, Recommendations for straightforward and rigorous methods of counting neurons based on a computer simulation approach, J Chem Neuroanat 20 (2000) 93-114.

[33] D.J. Sillence, Apoptosis and signalling in acid sphingomyelinase deficient cells, BMC Cell Biol 2 (2001) 24.

[34] A. Taraboulos, M. Scott, A. Semenov, D. Avrahami, L. Laszlo, S.B. Prusiner, Cholesterol depletion and modification of $\mathrm{COOH}$-terminal targeting sequence of the prion protein inhibit formation of the scrapie isoform, J Cell Biol 129 (1995) 121-132.

[35] Y. Temel, V. Visser-Vandewalle, B. Aendekerk, B. Rutten, S. Tan, B. Scholtissen, C. Schmitz, A. Blokland, H.W. Steinbusch, Acute and separate modulation of motor and cognitive performance in parkinsonian rats by bilateral stimulation of the subthalamic nucleus, Exp Neurol 193 (2005) 43-52.

[36] Y. Temel, V. Visser-Vandewalle, S. Kaplan, R. Kozan, M.A. Daemen, A. Blokland, C. Schmitz, H.W. Steinbusch, Protection of nigral cell death by bilateral subthalamic nucleus stimulation, Brain Res 1120 (2006) 100-105.

[37] V.J. Thannickal, B.L. Fanburg, Reactive oxygen species in cell signaling, Am J Physiol Lung Cell Mol Physiol 279 (2000) L1005-1028.

[38] G. van Echten-Deckert, T. Herget, Sphingolipid metabolism in neural cells, Biochim Biophys Acta 1758 (2006) 1978-1994.

[39] T.J. van Ham, K.L. Thijssen, R. Breitling, R.M. Hofstra, R.H. Plasterk, E.A. Nollen, C. elegans model identifies genetic modifiers of alpha-synuclein inclusion formation during aging, PLoS Genet 4 (2008) e1000027. 
Unchanged expression of CERT in 6-OHDA neurodegenerative model

[40] G. Walkinshaw, C.M. Waters, Neurotoxin-induced cell death in neuronal PC12 cells is mediated by induction of apoptosis, Neuroscience 63 (1994) 975-987. 
Chapter 3 
Detection of peptide-based nanoparticles by ELISA

\section{CHAPTER 4}

\section{DETECTION OF PEPTIDE-BASEd NANOPARTICleS IN BLOOD PLASMA BY ELISA}

Gerard H. Bode, Karin E. Pickl, Maria Sanchez-Purrà, Berta Albaiges, Salvador Borrós, Andy J.G. Pötgens, Christoph Schmitz, Frank M. Sinner, Mario Losen, Harry W.M. Steinbusch, Hans-Georg Frank, Pilar MartinezMartinez and the European NanoBioPharmaceutics Research Initiative

Published in Plos One 
Chapter 4

\section{ABSTRACT}

Aims

The aim of the current study was to develop a method to detect peptide-linked nanoparticles in blood plasma.

Materials \& Methods

A convenient enzyme linked immunosorbent assay (ELISA) was developed for the detection of peptides functionalized with biotin and fluorescein groups. As a proof of principle, polymerized pentafluorophenyl methacrylate nanoparticles linked to biotincarboxyfluorescein labeled peptides were intravenously injected in Wistar rats. Serial blood plasma samples were analyzed by ELISA and by liquid chromatography mass spectrometry (LC/MS) technology.

Results

The ELISA based method for the detection of FITC labeled peptides had a detection limit of $1 \mathrm{ng} / \mathrm{mL}$. We were able to accurately measure peptides bound to pentafluorophenyl methacrylate nanoparticles in blood plasma of rats, and similar results were obtained by LC/MS.

Conclusions

We detected FITC-labeled peptides on pentafluorophenyl methacrylate nanoparticles after injection in vivo. This method can be extended to detect nanoparticles with different chemical compositions. 
Detection of peptide-based nanoparticles by ELISA

\section{INTRODUCTION}

The work presented here was developed by the FP6 EU biopharmaceutics platform, which aimed at the development of innovative multidisciplinary approaches for the design, synthesis and evaluation of molecular, nano- and micro-scale functionalities for targeted delivery of therapeutic peptides and proteins.

The use of therapeutic peptides in neurodegenerative diseases is an active area of investigation. For example, the NAP peptide (NAPVSIPQ), derived from the activity-dependent neuroprotective protein (ADNP) [1], has shown efficacy in in vitro as well as in vivo models of neurodegenerative diseases [2,3]. However, therapeutic peptides are known to have several limitations such as poor bioavailability, instability and short half-life [4]. A possible way to overcome these limitations is the use of nanoparticles as delivery method. Nanoparticles increase the bioavailability and efficacy of incorporated peptides by facilitating their transfer across biological membranes and protecting bound peptides against enzymatic degradation [5, 6]. Therapeutic nanoparticles are currently being developed for a wide variety of diseases such as cancer [7], cardiovascular disease [8-10] and neurodegenerative diseases $[11,12]$. Although significant progress has been made towards organ-specific delivery of nanoparticles, a drawback is that they often do not reach their intended target tissue in the desired quantities due to filtering by the kidney, liver and spleen [7]. This can be improved by decorating the nanoparticles with functionalized targeting peptides that bind to receptors on the target tissue (Fig. 1) [13]. Another challenge is the evaluation of the pharmacokinetics and biodistribution of the nanoparticles in vivo. In this respect LC-MS techniques can be used to measure peptides attached to nanoparticles. However, this approach requires specialized 
infrastructure. Therefore, it is useful to have reliable methods based on commonly used laboratory techniques, to be able to measure nanoparticles in biological fluids and tissues. In this manuscript we attached labeled reporter peptides to nanoparticles [6]. Subsequently, we used an ELISA-based method to detect the reporter peptide bound to the nanoparticles (Fig. 1C), allowing quantification of these nanoparticles in blood plasma after injection in vivo. This ELISA enabled us to measure peptide bound to nanoparticles in blood plasma from $1 \mathrm{ng} / \mathrm{mL}$. In parallel, LC/MS analysis of the same samples was performed to measure the plasma concentration over time of acrylamide based nanoparticles loaded with reporter peptides in rats.

MATERIALS AND METHODS

\section{Animals}

All animal experiments were approved by the Maastricht University animal ethical committee and complied with Dutch law. Two month old male Wistar rats (Harlan, Ter Horst, the Netherlands) were used for the experiments. The animals were housed three per cage with ad libitum food and water and a 12:12 hour light:dark cyclus. A total of three animals was used in this study.

No anesthetics were used during blood sample collection. The animals were euthanized 24 hours after nanoparticle injection by intramuscular injection of ketamine $(90 \mathrm{mg} / \mathrm{kg})$ and xylazine $(10 \mathrm{mg} / \mathrm{kg})$ followed by transcardial perfusion with Tyrode's buffer.

Nanoparticles and peptides

N-isopropylacrylamide (NIPAAm, 97\%), N,N-dimethylacrylamide (DMAAm, 99\%), acrylic acid (AAc, 99\%), methylenebisacrylamide (MBAAm, 99\%), sodium dodecyl sulphate (SDS, ReagentPlus $\geq 98.5 \%$ ) and ammonium persulphate (98+\%, A.C.S reagent) were all purchased from Sigma-Aldrich (St. Louis, MO) and used without further 
purification unless otherwise stated. Pentafluorophenyl methacrylate (PFM) was purchased from Apollo scientific, UK, cysteamine hydrochloride (purum $\geq 97.0 \%$ ) and AlexaFluor 660 carboxylic acid succinimidyl ester from Invitrogen, US.

Nanoparticles were synthesized by a free-radical polymerization method in a microemulsion system [14], where the monomers used are $\mathrm{N}$-isopropylacrylamide, N,N-dimethylacrylamide and acrylic acid, the cross-linker is methylenebisacrylamide, the surfactant, sodium dodecyl sulphate, and the initiator, ammonium persulphate.

For the synthesis of the nanoparticles a three-neck bottom-flask was charged with $\mathrm{N}$-isopropylacrylamide $(0.35 \mathrm{~g}, 3.09 \mathrm{mmol}), \mathrm{N}, \mathrm{N}$ 'dimethylacrylamide $(0.04 \mathrm{~g}, 0.4 \mathrm{mmol})$, acrylic acid $(0.05 \mathrm{~g}, 0.69 \mathrm{mmol})$, methylenebisacrylamide $(0.01 \mathrm{~g}, 0.06 \mathrm{mmol})$, sodium dodecyl sulphate ( $0.02 \mathrm{~g}, 0.07 \mathrm{mmol}$ ) and $117 \mathrm{~mL}$ of mili-Q water. The reaction mixture was heated at $70^{\circ} \mathrm{C}$ in a hot plate under reflux conditions, nitrogen atmosphere and stirring for four hours. After some minutes, when the reaction mixture was homogeneous and started to reflux, ammonium persulphate $(0.036 \mathrm{~g}, 0.16 \mathrm{mmol})$ was added.

After 1 hour of reaction, pentafluorophenyl methacrylate $(0.04 \mathrm{mmol})$ was added and the reaction mixture was further refluxed for 30 minutes. The obtained nanoparticles were further modified by the addition of the desired coating molecule. For thiolating, cysteamine hydrochloride ( $0.015 \mathrm{~g}, 0.13 \mathrm{mmol})$ was added, for labelling, Alexafluor 660 carboxylic acid succinimidyl ester $(10 \mu \mathrm{g}, 0.01 \mu \mathrm{mol})$. The peptide decoration was achieved via adding peptide $5 \mathrm{~A}$ (1.055 $\mathrm{mg}, 0.39 \mathrm{mmol}$ ). Nanoparticle solutions were dialysed with dialysis membranes (nominal MWCO 6000-8000).

Nanoparticles size and zeta potential were determined using dynamic light scattering in a Nano ZS Nanosizer (Malvern Instruments Ltd., Malvern, UK) with a laser light wavelength of $632.8 \mathrm{~nm}$ and a scattering 
Chapter 4

angle of 173 degrees. Temperature was set at $25^{\circ} \mathrm{C}$. Nanoparticle solutions were measured without previous dilution. The mean diameter of the NPs was $174 \mathrm{~nm}$ and the zeta potential was $-5.89 \mathrm{mV}$.

Peptide 5A (napvsipqKGGC, $\mathrm{MW}=1754.0$, monoisotopic mass = 1752.7; Fig. 1A) was produced by conventional solid phase synthesis (AplaGen, Baesweiler, Germany). Peptide 5A+B ( $\mathrm{MW}=4694.2$, monoisotopic mass $=4691.0$ ) was produced by oxidizing peptide $5 \mathrm{~A}$ with peptide 5B (Ac-CGGKTFFYGGCRGKRNNFKTEEY-COOH). Peptide 5D (isotopically labeled peptide $5 \mathrm{~A}$ used as an internal standard for $\mathrm{LC} / \mathrm{MS}$, MW $=1760.0$, monoisotopic mass $=1752.7$ ) was prepared by labeling the two glycine amino acids with ${ }^{13} \mathrm{C}_{2}$ and ${ }^{15} \mathrm{~N}_{1}$, resulting in a mass difference of $+6 \mathrm{Da}$ compared to peptide $5 \mathrm{~A}$. A schematic representation of peptide $5 \mathrm{~A}, 5 \mathrm{~B}$ and $5 \mathrm{~A}+\mathrm{B}$ is provided in Supporting Information S1 Fig..

Peptide 5A detection in blood plasma after intravenous injection of nanoparticles

The acrylamide based nanoparticles containing peptide $5 \mathrm{~A}$ were injected in the lateral tail vein of 3 Wistar rats at a concentration of $17.25 \mathrm{mg}$ of nanoparticle per $\mathrm{kg}$ of bodyweight, corresponding to 0.5 mg peptide $5 \mathrm{~A}$ per $\mathrm{kg}$ of bodyweight. Blood samples were collected in lithium heparin plasma microtainer tubes (BD, Franklin Lakes, NJ). A small incision was made in the contralateral tail vein and the blood was collected directly into the tube. Immediately after collecting the blood, the tubes were manually inverted 8 times to ensure mixing with the anti-coagulant. Blood samples were stored on ice for up to 30 minutes before separating the plasma by centrifugation at $2000 \mathrm{~g}$ for 10 minutes. No hemolysis was observed. 
Samples were collected from each animal immediately after injection (time point 0 ) and at 15, 30, 60, 120, 240, 480 minutes after injection. All plasma samples were stored at $-80^{\circ} \mathrm{C}$ until further analysis.

\section{ELISA for the detection of peptide $5 \mathrm{~A}$}

The plasma samples were diluted 1/500 in PBS, based on the range of the standard curve and the expected initial plasma concentrations. Streptavidin coated ELISA 96-well microplates (Steffens Biotechnische Analysen, Germany) were rinsed with $100 \mu$ PBS per well and incubated with plasma samples in duplicate, for one hour at room temperature. After washing the wells three times with PBS, the carboxyfluorescein group present on the reporter peptide was detected by incubating with monoclonal (mAb) mouse-anti-fluorescein peroxidase-conjugated IgG (Dianova, Hamburg, Germany) diluted 1:100,000 in PBS with 0.1\% BSA for one hour. Subsequently, the wells were washed three times with PBS and incubated with soluble high sensitivity TMB (SDT, Baesweiler, Germany) for 10 minutes in the dark. The enzymatic peroxidase reaction was stopped with $1 \mathrm{M} \mathrm{HCl}$ and absorbance at $450 \mathrm{~nm}$ was measured on a VICTOR X3 Multilabel Plate Reader (Perkin Elmer, Waltham, MA). All incubations were performed at room temperature on a plate shaker at $650 \mathrm{rpm}$. The wells were washed with PBS three times both after sample and antibody incubation. The TMB reaction was performed in the dark for 10 minutes. Negative controls consisted of incubating the wells with PBS instead of plasma samples and by using plasma without nanoparticles. The absorbance at $450 \mathrm{~nm}$ of the negative controls was considered as background and subtracted from the absorbance of the plasma samples. Free peptide $5 \mathrm{~A}$ was used as a positive control in the ELISA described above with a lower limit of detection of $1 \mathrm{ng} / \mathrm{mL}$ (data not shown). Nanoparticles containing a known concentration of peptide $5 \mathrm{~A}$, were 
Chapter 4

used to generate a standard curve for the quantification of blood plasma samples. The standard curve data were fitted to a Hill curve using Graphpad Prism (Graphpad Software, La Jolla, CA) and the Hill equation was used to calculate the concentration of peptide $5 \mathrm{~A}$ in blood plasma samples from the absorbance at $450 \mathrm{~nm}$ (See S1 Table).

\section{Liquid chromatography-mass spectrometry}

\section{Materials}

Acetonitrile (>99.9\%, for HPLC), water (for HPLC), formic acid (98$100 \%)$, acetic acid (>99\%), trifluoroacetic acid (>99.5\%), tris(2carboxyethyl)phosphine (TCEP, C4706) and albumin from human serum (96-99\%) were purchased from Sigma-Aldrich. Peptide 5A+B (the combined peptide $5 \mathrm{~A}+\mathrm{B}$ was produced by oxidizing peptide $5 \mathrm{~A}$ with peptide $5 \mathrm{~B}$ ), peptide $5 \mathrm{~A}$ and peptide $5 \mathrm{D}$ were synthesized by AplaGen, pooled rat EDTA plasma was received from Harlan. Ultracentrifugation devices (Amicon Ultra 4, $10 \mathrm{kDa}$ MWCO) were obtained from Millipore (Billerica, MA).

\section{Standards preparation}

Peptide $5 \mathrm{~A}$ standards were prepared by spiking rat plasma with peptide $5 A+B$ and subsequently reducing the disulfide bond between peptide $5 \mathrm{~A}$ and $5 \mathrm{~B}$, yielding free peptide $5 \mathrm{~A}$ as depicted in Fig. 1. The concentration range of the standards was $4.1-1674 \mathrm{ng} / \mathrm{mL}$ of peptide $5 \mathrm{~A}$. (Neither the peaks corresponding to the mass of peptide 5B nor the unreduced peptide $5 \mathrm{~A}+\mathrm{B}$ were analyzed, see LC-MS analysis section). In addition, two quality controls were prepared in rat plasma at concentrations of 83.7 and $837.1 \mathrm{ng} / \mathrm{mL}$ peptide $5 \mathrm{~A}$.

\section{Sample preparation}


Plasma samples for LC/MS were prepared by adding $300 \mu \mathrm{L}$ of $10 \mathrm{mM}$ TCEP in loading mobile phase mix to $30 \mu \mathrm{L}$ of sample. $16 \mu \mathrm{L}$ of internal standard (peptide 5D, isotopically labelled peptide 5A) was added and disulfide bonds were reduced by incubating at $60{ }^{\circ} \mathrm{C}$ for 20 minutes. The samples were centrifuged at $8000 \mathrm{~g}$ for 5 minutes and subsequently filtered with $10 \mathrm{kDa}$ MWCO filters at $500 \mathrm{~g}$. The filtrate was transferred to autosampler vials and analyzed or frozen at $-80{ }^{\circ} \mathrm{C}$ until analysis.

Samples with expected concentrations higher than the upper limit of quantification were diluted with rat plasma prior to sample preparation.

\section{LC/MS analysis}

All LC/MS experiments were carried out on an Ultimate 3000 System (Dionex, LC Packings) coupled to a TSQ Quantum Ultra AM mass spectrometer (Thermo Finnigan). The system was controlled by Xcalibur Software 1.4. The chromatographic setup consisted of a capillary precolumn (Zorbax SBC3, $5 \times 0.5 \mathrm{~mm}$ ) in combination with a capillary analytical column (ACE 4, $250 \times 0.3 \mathrm{~mm}$ ). Sample loading was performed at $100 \mu \mathrm{L} / \mathrm{min}$, elution at $4 \mu \mathrm{L} / \mathrm{min}$. Chromatographic separation was carried out at $50{ }^{\circ} \mathrm{C}$. Twenty microliters were injected onto the precolumn using the $\mu \mathrm{L}$-pickup mode. For sample loading onto the precolumn, acetonitrile:water solutions containing $1 \%$ acetic acid and $0.05 \%$ TFA were used (A: 5:94:1:0.05 ACN: $\mathrm{H}_{2} \mathrm{O}: \mathrm{AA}: \mathrm{TFA}, \mathrm{B}$ : 95:4:1:0.05 ACN: $\mathrm{H}_{2} \mathrm{O}: \mathrm{AA}: \mathrm{TFA}$, gradient: 0-5 minutes $10 \% \mathrm{~B}, \quad 5-12$ minutes 10 to $70 \% \mathrm{~B}, 12-14$ minutes 70 - 100\% B, 14-19.9 minutes $100 \%$ B, $19.9-20$ minutes 100 to $10 \%$ B, $20-30$ minutes $10 \%$ B). Elution was performed using a water: acetonitrile gradient containing $0.1 \%$ formic acid (A: 5:95:0.1:ACN: $\mathrm{H}_{2} \mathrm{O}: \mathrm{FA}, \mathrm{B}: 95: 5: 0.1: \mathrm{ACN}: \mathrm{H}_{2} \mathrm{O}: \mathrm{FA}$, gradient: 0-5 minutes $15 \% \mathrm{~B}, 5-10$ minutes 15 to $30 \% \mathrm{~B}, 10-13$ minutes $30 \% \mathrm{~B}$, 
Chapter 4

13-14 minutes 30 to $100 \% \mathrm{~B}, 14-19$ minutes $100 \% \mathrm{~B}, 19-19.1$ minutes 100 to $15 \%$ B, 19.1 - 30 minutes $15 \%$ B). Valve switching times were 5 minutes and 12 minutes.

MS detection was performed in positive electrospray ionization (ESI) with a nanoESI source using the selected reaction monitoring (SRM) mode. The double-protonated molecule ion of the whole intact peptide was chosen as the parent ion, the three most intensive fragment ions were chosen as daughter ions. (Peptide 5A: m/z 877.4 $\rightarrow(341+412+$ 946), peptide $5 \mathrm{D}: \mathrm{m} / \mathrm{z} 880.5 \rightarrow(412.2+341.1+952.4)$. As mentioned in the standards preparation section, the peaks corresponding to peptide $5 \mathrm{~B}$ and the unreduced peptide $5 \mathrm{~A}+\mathrm{B}$ were not analyzed. Quantification (see S2 Table for details) was carried out using the sum of all three SRM chromatograms in order to obtain good sensitivity.

\section{RESUlts}

\section{ELISA for the detection of carboxyfluorescein-labeled peptide 5A}

We developed an ELISA to detect carboxyfluorescein-labeled peptide $5 \mathrm{~A}$ (see Fig. $1 \mathrm{C}$ for schematic representation). In addition to the carboxyfluorescein, peptide $5 \mathrm{~A}$ contains a biotin molecule. The peptide was selectively bound to the streptavidin coated plate via the biotin residue; subsequently a mAb against the carboxyfluorescein was used to detect the bound peptide. To test the sensitivity of the ELISA a dilution range of acrylamide-based nanoparticles with an equivalent of 0 to $20 \mathrm{ng} / \mathrm{mL}$ of carboxyfluorescein-labeled peptide $5 \mathrm{~A}$ was added to the ELISA plate. The particles were detected with high sensitivity and the data were fitted to a standard curve using the Hill equation, with a Hill coefficient of 1.366 and a $K_{d}$ of $27.59 \mathrm{ng} / \mathrm{mL}$ (Fig. 2A). 
Detection of peptide-based nanoparticles by ELISA

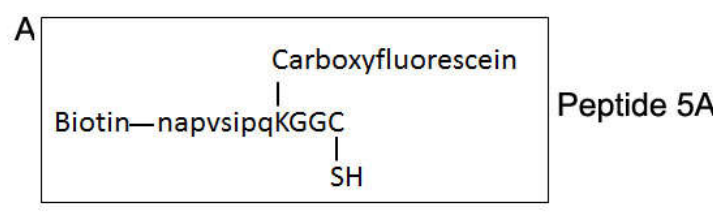

B

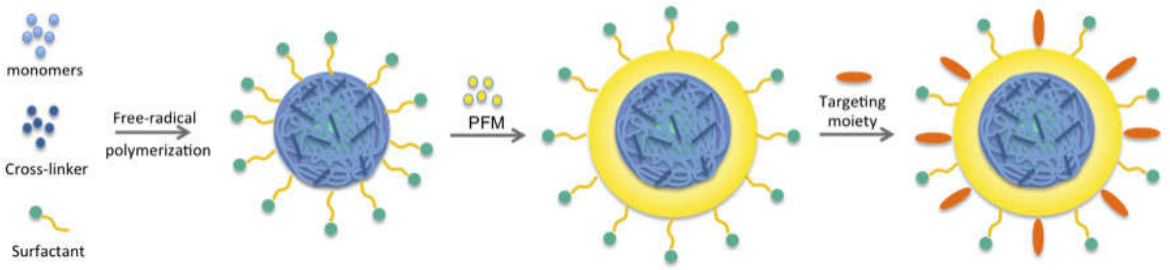

C

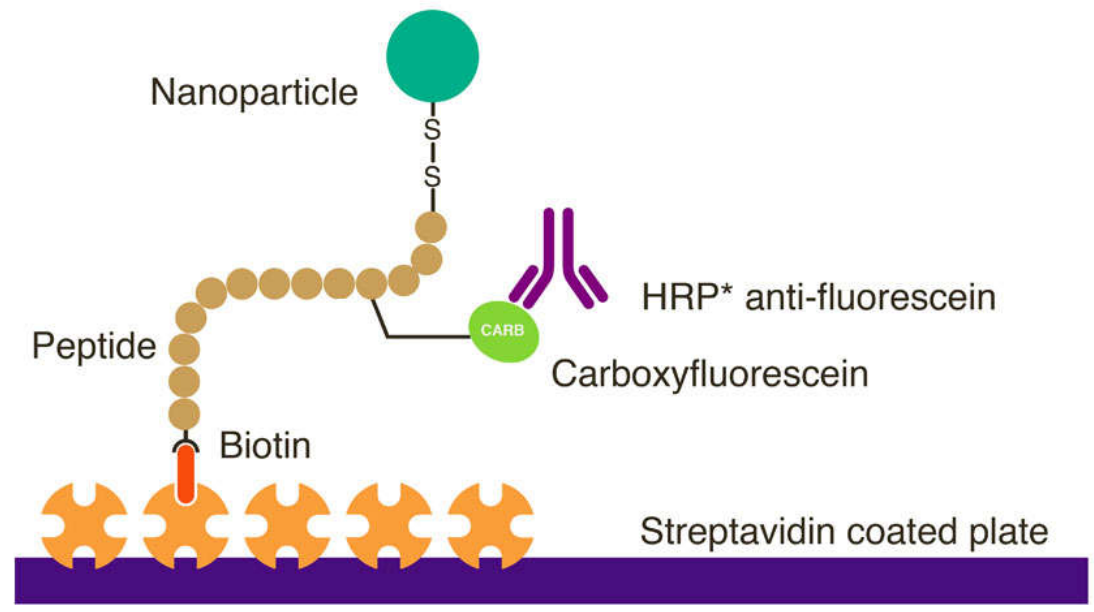

Figure 1: Schematic representation of the nanoparticle and ELISA design. Peptide 5A contains biotin and carboxyfluorescein, lower case letters denote D-amino acids. Nanoparticles were synthesized by a free-radical polymerization method in a microemulsion system. $\mathrm{N}$-isopropylacrylamide, $\mathrm{N}, \mathrm{N}$-dimethylacrylamide and acrylic acid were used as monomers with methylenebisacrylamide as cross-linker. Pentafluorophenyl methacrylate (PFM) was added and the nanoparticles were adorned with peptide 5A (B). An ELISA was designed to detect nanoparticles in biological fluids using the biotin and carboxyfluorescein groups present on peptide $5 \mathrm{~A}$ (C). Streptavidin coated plates were used to capture the peptides by binding the biotin group and bound peptides were detected with a HRP conjugated mAb anti-fluorescein. 
Chapter 4

Detection of peptide 5A nanoparticles in blood plasma by ELISA

After confirming the specificity and sensitivity of the ELISA in vitro, we intravenously injected Wistar rats with the acrylamide based nanoparticle formulation containing the $5 \mathrm{~A}$ reporter peptide described above. Blood samples were collected immediately and up to 24 hours after injection (data not shown). Plasma was prepared from venous blood and diluted 1/500 in PBS. The same ELISA as described above was used to measure the concentration of peptide $5 \mathrm{~A}$ in the plasma samples. At time point 0 the mean \pm S.E.M. of peptide $5 \mathrm{~A}$ plasma concentration in 3 animals was $1661 \pm 514 \mathrm{ng} / \mathrm{mL}$, with the highest mean \pm S.E.M. concentration of $2706 \pm 466 \mathrm{ng} / \mathrm{mL}$ measured 15 minutes after injection (Fig. 2B). We were able to detect the peptide up to 2 hours after injection (Fig. 2B; absorbance data can be found in S3 Table). The results were reproducible when repeated several times. We noted that dilution of samples in normal rat plasma, rather than PBS, increased the maximum OD, while it had very little effect on the background (data not shown). 
A
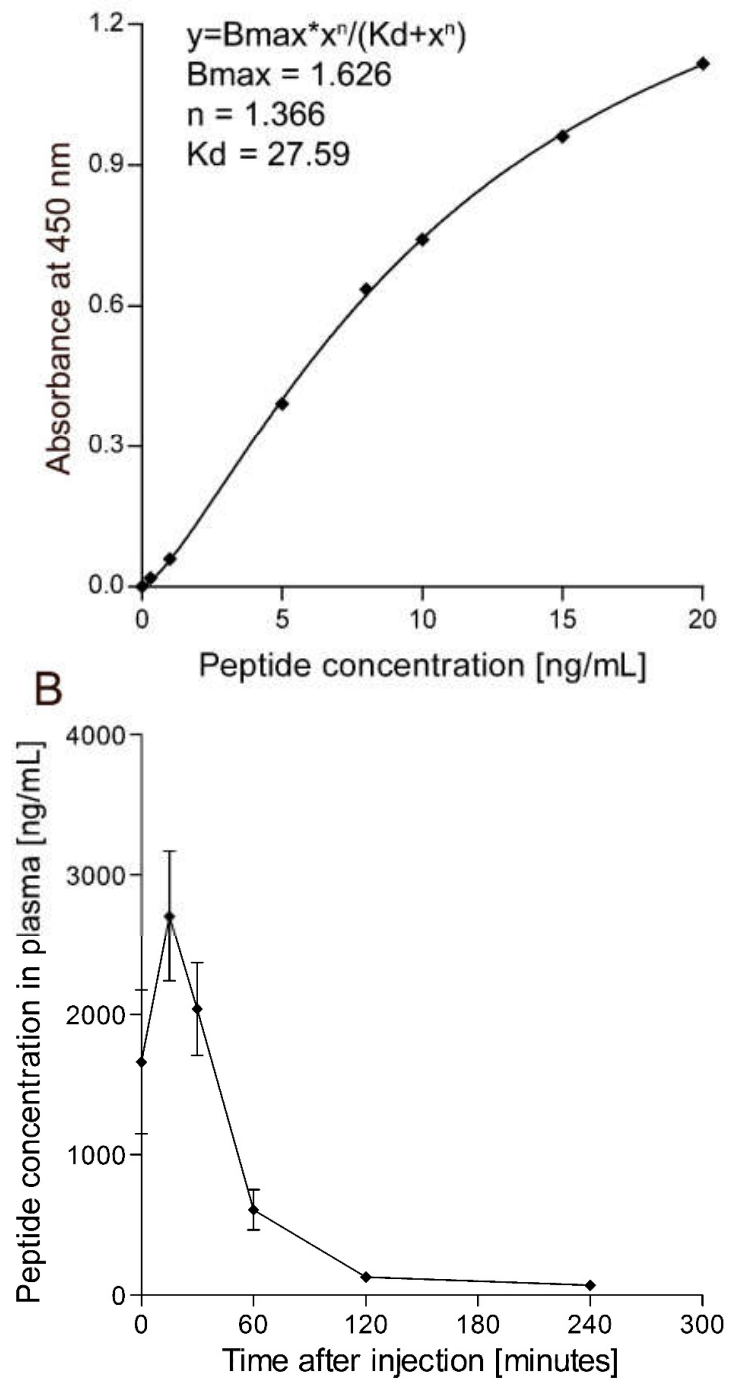

Figure 2: Quantification of peptide 5A in blood plasma by ELISA. A standard curve was generated using nanoparticles decorated with peptide $5 \mathrm{~A}$ in a concentration range of 0.3 to $20 \mathrm{ng} / \mathrm{mL}$ peptide (A). Nanoparticles containing peptide $5 \mathrm{~A}$ were injected into the lateral tail vein of male Wistar rats $(n=3)$. Plasma was prepared from venous blood samples collected at different time points after injection and peptide $5 \mathrm{~A}$ concentration was measured by ELISA (B). Data shown are the mean \pm S.E.M. peptide concentration in the plasma of three individual animals. The standard curve was generated using the Hill equation. 
Chapter 4

Liquid chromatography-mass spectrometry quantification of peptide $5 \mathrm{~A}$ in blood plasma of nanoparticle injected rats

Peptide 5A used for generating the LC/MS standard curve was obtained by diluting the combined $5 \mathrm{~A}+\mathrm{B}$ peptide in plasma and subsequently reducing the disulfide bond between peptide $5 \mathrm{~A}$ and peptide $5 \mathrm{~B}$. The LC/MS method showed good linearity in the range from 4.1 up to 1674 $\mathrm{ng} / \mathrm{mL}$ (Fig. 3A) with an expected lower limit of quantification of 13.5 $\mathrm{ng} / \mathrm{mL}$ (S/N at $13.5 \mathrm{ng} / \mathrm{mL}$ was 330, Fig. 4). Quality controls at 83.7 and $837 \mathrm{ng} / \mathrm{mL}$ measured in parallel with the in vivo study samples showed accuracies ranging between $-7 \%$ and $+7 \%$. 


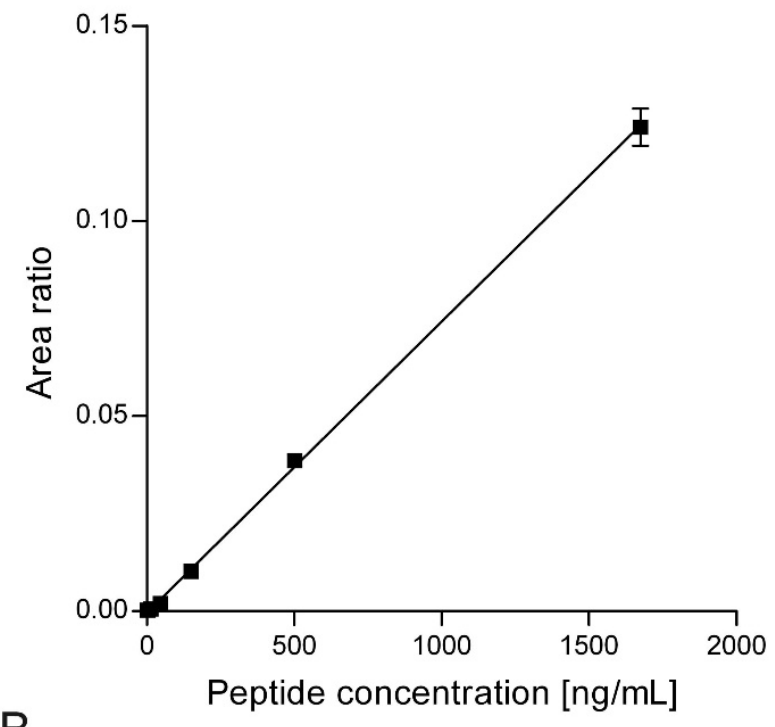

B

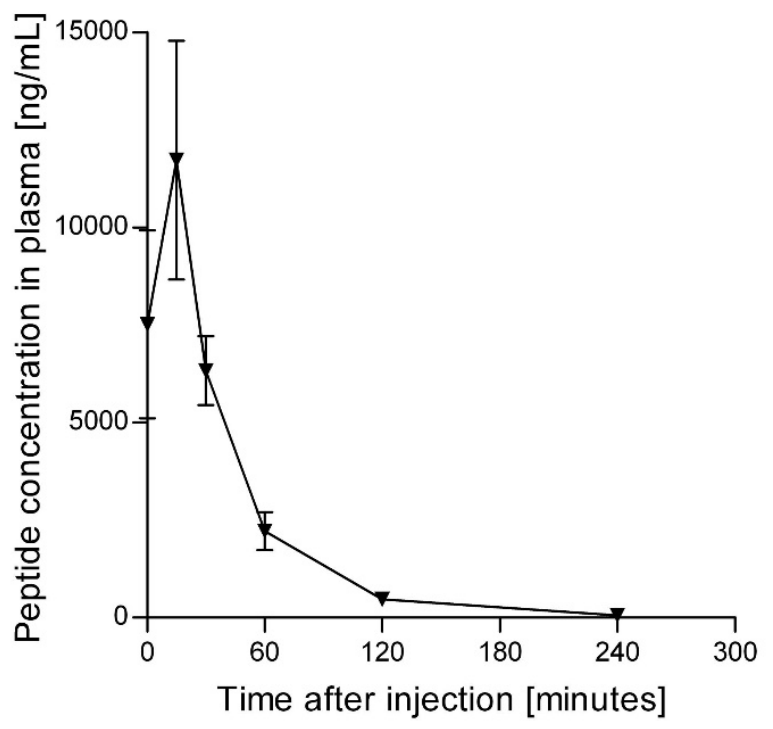

Figure 3: Quantification of peptide 5A in blood plasma by LC/MS. A standard curve for the quantification of peptide by LC/MS was generated using peptide $5 \mathrm{~A}$ in a concentration range of 4.1 to $1674 \mathrm{ng} / \mathrm{mL}$ peptide (A). Blood plasma samples of animals injected with peptide $5 \mathrm{~A}$ decorated nanoparticles were reduced and free peptide was quantified by LC/MS (B). Data shown are the mean \pm S.E.M. peptide concentration in the plasma of three individual animals. 
Chapter 4

LC/MS quantification of peptide 5A in blood plasma showed a similar pharmacokinetic profile as the ELISA based quantification. Interestingly, the peptide concentrations measured by LC/MS were approximately a factor 4 higher compared to the ELISA measurements. Immediately after injection a mean \pm S.E.M. concentration of $7515 \pm$ 2403 ng/mL was measured (Fig. 3B; Peak area ratios can be found in S4 Table). As with the ELISA measurements, the highest concentration of $11724 \pm 3062 \mathrm{ng} / \mathrm{mL}$ was found at the 15 minutes post-injection time point.
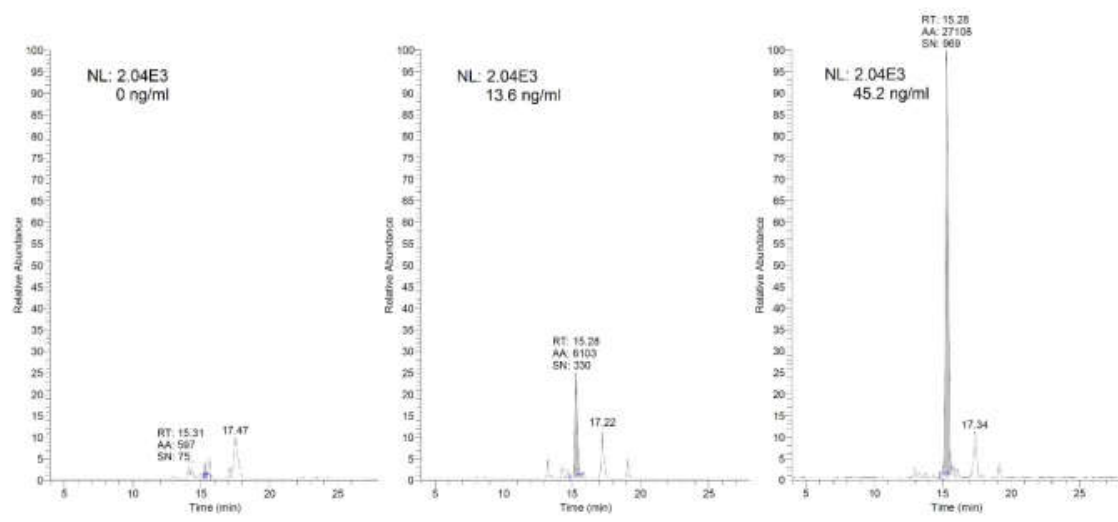

Figure 4: LC/MS chromatograms comparing different concentrations of peptide 5A in blood plasma matrix. Peptide 5A peaks in plasma matrix spiked with $0,13.6$ and 45.2 $\mathrm{ng} / \mathrm{mL}(\mathrm{SRM}$ trace: $877.7 \rightarrow(412.2+341.1+946.4)$.

\section{DISCUSSION}

We have developed a convenient ELISA method for detecting a peptide conjugated to a nanoparticle, in vivo in rat plasma. By using a HRP conjugated antibody against FITC instead of measuring fluorescence directly, high sensitivity can be attained without the need for a spectrofluorometer. The ELISA proved to be highly sensitive, detecting the peptide $5 \mathrm{~A}$ with a detection limit of $1 \mathrm{ng} / \mathrm{mL}$. In addition, the ELISA detected peptide $5 \mathrm{~A}$ in blood plasma after injection of nanoparticles 
decorated with peptide $5 \mathrm{~A}$ in the lateral tail vein of Wistar rats. The blood plasma profile showed a maximum concentration of peptide in plasma 15 minutes after injection. The peptide was detectable in blood plasma up to 2 hours after injection (Fig. 2B). The LC/MS analysis of the same samples also showed the highest peptide concentration after 15 minutes (Fig. 3B). However, the measured peptide concentrations in plasma were higher by LC/MS than those measured by ELISA. There are several potential reasons for this difference. For example, the ELISA detects peptide attached to the nanoparticle and it is possible that not all of the peptide was accessible due to steric hindrance. In contrast, the LC/MS method detects the peptide that is released from the nanoparticle by reduction of the disulfide bond. Another factor that could account for the differences between the ELISA and LC-MS measurements are the different methods which are required for the preparation of the standards/samples.

In conclusion, we demonstrated that, the labeling of acrylamide nanoparticles with peptides containing functional groups such as biotin and carboxyfluorescein allows for detection of these nanoparticles by ELISA in blood plasma. This suggests that this technique is useful for the study of pharmacokinetics of nanoparticles in vivo and the development of therapeutic nano delivery systems. Finally, this method can be easily adapted for labeling of other nanoparticles with different chemical compositions and the detection of nanoparticles in other biological fluids and tissue, such as cerebrospinal fluid, brain and liver (manuscript in preparation).

\section{ACKNOWLEDGEMENTS}

We would like to thank Geertjan van Zonneveld for his excellent assistance with the artwork in the figures. 


\section{Chapter 4}

\section{REFERENCES}

1. Bassan M, Zamostiano R, Davidson A, Pinhasov A, Giladi E, Perl O, et al. Complete sequence of a novel protein containing a femtomolar-activity-dependent neuroprotective peptide. J Neurochem. 1999;72(3):1283-93. Epub 1999/02/26. PubMed PMID: 10037502.

2. Quraishe S, Cowan CM, Mudher A. NAP (davunetide) rescues neuronal dysfunction in a Drosophila model of tauopathy. Mol Psychiatry. 2013;18(7):834-42. Epub 2013/04/17. doi: mp201332 [pii]

10.1038/mp.2013.32. PubMed PMID: 23587881; PubMed Central PMCID: PMC3690421.

3. Magen I, Gozes I. Microtubule-stabilizing peptides and small molecules protecting axonal transport and brain function: focus on davunetide (NAP). Neuropeptides. 2013;47(6):489-95. Epub 2013/11/12. doi: S0143-4179(13)00077-2 [pii]

10.1016/j.npep.2013.10.011. PubMed PMID: 24210139.

4. Craik DJ, Fairlie DP, Liras S, Price D. The future of peptide-based drugs. Chem Biol Drug Des. 2013;81(1):136-47. Epub 2012/12/21. doi: 10.1111/cbdd.12055. PubMed PMID: 23253135.

5. Zhang XX, Eden HS, Chen X. Peptides in cancer nanomedicine: drug carriers, targeting ligands and protease substrates. J Control Release. 2012;159(1):2-13. Epub 2011/11/08. doi: S0168-3659(11)00995-3 [pii]

10.1016/j.jconrel.2011.10.023. PubMed PMID: 22056916; PubMed Central PMCID: PMC3288222.

6. Brasnjevic I, Steinbusch HW, Schmitz C, Martinez-Martinez P. Delivery of peptide and protein drugs over the blood-brain barrier. Prog Neurobiol. 2009;87(4):212-51. Epub 2009/04/28. doi: S0301-0082(09)00012-4 [pii]

10.1016/j.pneurobio.2008.12.002. PubMed PMID: 19395337.

7. Pearce TR, Shroff K, Kokkoli E. Peptide targeted lipid nanoparticles for anticancer drug delivery. Adv Mater. 2012;24(28):3803-22, 710. Epub 2012/06/08. doi: 10.1002/adma.201200832. PubMed PMID: 22674563.

8. Arosio D, Casagrande C, Manzoni L. Integrin-mediated drug delivery in cancer and cardiovascular diseases with peptide-functionalized nanoparticles. Curr Med Chem. 2012;19(19):3128-51. Epub 2012/05/23. doi: CMC-EPUB-20120518-4 [pii]. PubMed PMID: 22612699.

9. Psarros C, Lee R, Margaritis M, Antoniades C. Nanomedicine for the prevention, treatment and imaging of atherosclerosis. Nanomedicine. 2012;8 Suppl 1:S59-68. Epub 2012/05/30. doi: S1549-9634(12)00186-4 [pii]

10.1016/j.nano.2012.05.006. PubMed PMID: 22640906.

10. Lobatto ME, Fuster V, Fayad ZA, Mulder WJ. Perspectives and opportunities for nanomedicine in the management of atherosclerosis. Nat Rev Drug Discov. 2011;10(11):835-52. Epub 2011/10/22. doi: nrd3578 [pii]

10.1038/nrd3578. PubMed PMID: 22015921.

11. Spuch C, Saida O, Navarro C. Advances in the treatment of neurodegenerative disorders employing nanoparticles. Recent Pat Drug Deliv Formul. 2012;6(1):2-18. Epub 2012/01/26. doi: DDF-EPUB-20120125-001 [pii]. PubMed PMID: 22272933. 


\section{Detection of peptide-based nanoparticles by ELISA}

12. Re F, Gregori M, Masserini M. Nanotechnology for neurodegenerative disorders. Nanomedicine. 2012;8 Suppl 1:S51-8. Epub 2012/05/30. doi: S15499634(12)00187-6 [pii]

10.1016/j.nano.2012.05.007. PubMed PMID: 22640910.

13. Svensen N, Walton JG, Bradley M. Peptides for cell-selective drug delivery. Trends Pharmacol Sci. 2012;33(4):186-92. Epub 2012/03/20. doi: S01656147(12)00020-X [pii]

10.1016/j.tips.2012.02.002. PubMed PMID: 22424670.

14. Wei H, Cheng S-X, Zhang X-Z, Zhuo R-X. Thermo-sensitive polymeric micelles based on poly(N-isopropylacrylamide) as drug carriers. Progress in Polymer Science. 2009;34(9):893-910. doi: http://dx.doi.org/10.1016/j.progpolymsci.2009.05.002. 


\section{Chapter 4}

\section{SUPPORTING INFORMATION}

S1 Table: Absorbance data of the ELISA standards. The raw absorbance values of the duplicates at $450 \mathrm{~nm}$ and the average values are shown. A Hill equation was used to fit the data to a curve, which yielded the formula Concentration = $(27.59 * \text { Absorbance/(1.626-Absorbance) })^{\wedge}(1 / 1.366)$. This formula was subsequently used to calculate the peptide $5 \mathrm{~A}$ concentrations of the samples.

\begin{tabular}{|c|c|c|c|c|c|}
\hline $\begin{array}{c}\text { Concentration } \\
\text { of peptide 5A } \\
{[\mathrm{ng} / \mathrm{mL}]}\end{array}$ & \multicolumn{2}{|c|}{$\begin{array}{c}\text { Absorbance at 450 nm } \\
\text { (duplicates) }\end{array}$} & $\begin{array}{c}\text { Absorbance } \\
\text { at 450 nm } \\
\text { (average) }\end{array}$ & $\begin{array}{c}\text { Blank } \\
\text { subtracted } \\
\text { absorbance } \\
\text { at 450 nm }\end{array}$ & $\begin{array}{c}\text { Calculated } \\
\text { concentrations }\end{array}$ \\
\hline 0 & 0.0537024 & 0.055911 & 0.055 & & 0.42 \\
\hline 0.3 & 0.0730453 & 0.072266 & 0.073 & 0.018 & 1.03 \\
\hline 1 & 0.122231 & 0.105595 & 0.114 & 0.059 & 4.89 \\
\hline 5 & 0.458871 & 0.433778 & 0.446 & 0.392 & 8.19 \\
\hline 8 & 0.683941 & 0.696435 & 0.690 & 0.635 & 9.97 \\
\hline 10 & 0.798588 & 0.793714 & 0.796 & 0.741 & 14.85 \\
\hline 15 & 1.02919 & 1.00217 & 1.016 & 0.961 & 20.13 \\
\hline 20 & 1.2159 & 1.12597 & 1.171 & 1.116 & \\
\hline 0 (plasma) & & & & & \\
\hline
\end{tabular}


Detection of peptide-based nanoparticles by ELISA

S2 Table: Concentrations and area ratios of the LC/MS standards. The formula derived from the standard curve to calculate the concentrations of the samples was: Concentration $=\left(\right.$ Area ratio $\left.+4.3225710^{-4}\right) / 7.4670410^{-5}$

\begin{tabular}{|c|c|c|c|c|}
\hline $\begin{array}{c}\text { Concentration } \\
{[\mathrm{ng} / \mathrm{mL}]}\end{array}$ & \multicolumn{3}{|c|}{ Area ratio (triplicates) } & Average \\
\hline 0 & Peak not found & Peak not found & 0.00022 & 0.000222 \\
\hline 4.1 & 0.00022 & 0.00023 & Peak not found & 0.000225 \\
\hline 13.6 & 0.00033 & 0.00074 & 0.00070 & 0.000589 \\
\hline 45.2 & 0.00200 & 0.00068 & 0.00314 & 0.001939 \\
\hline 150.7 & 0.01019 & 0.00989 & 0.01063 & 0.010237 \\
\hline 502.3 & 0.03668 & 0.04084 & 0.03821 & 0.038576 \\
\hline 1674.2 & 0.11930 & 0.12875 & not injected & 0.124024 \\
\hline
\end{tabular}




\section{Chapter 4}

S3 Table: ELISA absorbance data of the plasma samples shown in Fig. 2. Blank subtracted absorbance at $450 \mathrm{~nm}$ of 1 to 500 diluted plasma samples. Values shown are the average of duplicates.

\begin{tabular}{|c|c|c|c|}
\hline & \multicolumn{3}{|c|}{ Blank subtracted absorbance at 450 } \\
\hline $\begin{array}{c}\text { Time after injection } \\
\text { [minutes] }\end{array}$ & Animal 1 & Animal 2 & Animal 3 \\
\hline 0 & 0.374 & 0.081 & 0.314 \\
\hline 15 & 0.407 & 0.315 & 0.566 \\
\hline 30 & 0.384 & 0.205 & 0.374 \\
\hline 60 & 0.093 & 0.032 & 0.101 \\
\hline 120 & 0.010 & 0.008 & 0.009 \\
\hline 240 & 0.004 & 0.005 & 0.003 \\
\hline
\end{tabular}


Detection of peptide-based nanoparticles by ELISA

S4 Table: Raw data of LC/MS analysis. Peak area ratios and dilution factors of the plasma samples shown in Figure 3. Values shown are the average of duplicates.

\begin{tabular}{|c|c|c|c|c|c|c|}
\hline & \multicolumn{2}{|c|}{ Animal 1 } & \multicolumn{2}{c|}{ Animal 2 } & \multicolumn{2}{c|}{ Animal 3 } \\
\hline $\begin{array}{c}\text { Time after } \\
\text { injection [minutes] }\end{array}$ & $\begin{array}{c}\text { peak area } \\
\text { ratio }\end{array}$ & $\begin{array}{c}\text { dilution } \\
\text { factor }\end{array}$ & $\begin{array}{c}\text { peak area } \\
\text { ratio }\end{array}$ & $\begin{array}{c}\text { dilution } \\
\text { factor }\end{array}$ & $\begin{array}{c}\text { peak area } \\
\text { ratio }\end{array}$ & $\begin{array}{c}\text { dilution } \\
\text { factor }\end{array}$ \\
\hline 0 & 0.07512 & 10 & 0.01983 & 10 & 0.07209 & 10 \\
\hline 15 & 0.07085 & 10 & 0.58618 & 1 & 0.13226 & 10 \\
\hline 30 & 0.05131 & 10 & 0.34220 & 1 & 0.05534 & 10 \\
\hline 60 & 0.23438 & 1 & 0.11027 & 1 & 0.11304 & 1.33 \\
\hline 120 & 0.02514 & 1.33 & 0.03947 & 1 & 0.03057 & 1 \\
\hline 240 & 0.00255 & 1 & 0.00511 & 1 & 0.00312 & 1 \\
\hline
\end{tabular}


Chapter 4

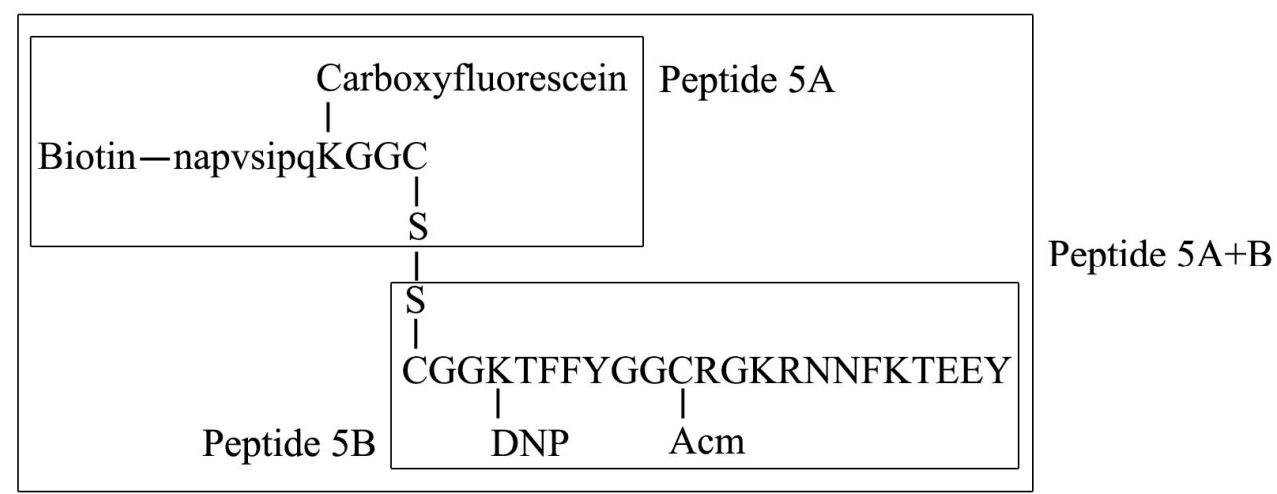

S1 Figure: Schematic representation of the structure of peptide $5 \mathrm{~A}$, peptide $5 \mathrm{~B}$ and peptide $5 \mathrm{~A}+\mathrm{B}$. 
Detection of peptide-based nanoparticles by ELISA 
Chapter 4 
In vitro and in vivo study of peptide functionalized nanoparticles

\title{
Chapter 5
}

\begin{abstract}
AN IN VITRO AND IN VIVO STUDY OF PEPTIDEFUNCTIONALIZED NANOPARTICLES FOR BRAIN TARGETING: THE IMPORTANCE OF SELECTIVE BLOOD-BRAIN BARRIER UPTAKE
\end{abstract}

Gerard H. Bode, Gregory Coué, Christian Freese, Karin E. Pickl, Maria Sanchez-Purrà, Berta Albaiges, Salvador Borrós, Ewoud C. van Winden, Leto-Aikaterini Tziveleka, Zili Sideratou, Johan F. Engbersen, Smriti Singh, Krystyna Albrecht, Jürgen Groll, Martin Möller, Andy J.G. Pötgens, Christoph Schmitz, Eleonore Fröhlich, Christian Grandfils,Frank M. Sinner, C. James Kirkpatrick, Harry W.M. Steinbusch, Hans-Georg Frank, Ronald E. Unger, Pilar Martinez-Martinez

Submitted 
Chapter 5

\section{ABSTRACT}

Targeted delivery of drugs across endothelial barriers remains a formidable challenge, especially in the case of the brain, where the blood-brain barrier severely limits entry of drugs into the central nervous system. Nanoparticle-mediated transport of peptide/proteinbased drugs across endothelial barriers shows great potential as a therapeutic strategy in a wide variety of diseases. Functionalizing nanoparticles with peptides allows for efficient targeting to specific organs. We have evaluated the hemocompatibilty, cytotoxicity, endothelial uptake, efficacy of delivery and safety of liposome, hyperbranched polyester, poly(glycidol) and acrylamide-based nanoparticles functionalized with peptides targeting brain endothelial receptors, in vitro and in vivo. We used an ELISA-based method for the detection of nanoparticles in biological fluids, investigating the blood clearance rate and in vivo biodistribution of labeled nanoparticles in the brain after intravenous injection in Wistar rats. Herein, we provide a detailed report of in vitro and in vivo observations.

\section{BACKGROUND}

Although considerable advances have been made in the last years towards understanding and treatment of central nervous system (CNS) disorders, it is still a major challenge to specifically target the brain using current pharmaceutics [1]. One of the obstacles a drug needs to overcome in order to reach the brain is the blood-brain barrier (BBB) [2]. The purpose of the BBB is both to ensure a constant environment within the CNS and to supply essential nutrients [3]. The BBB is formed by endothelial cell tight junctions in the microvessels of the brain. In contrast to peripheral capillaries, the BBB is more restrictive in the exchange of substances between blood and tissue parenchyma. 
However, contrary to what was first thought, the BBB is not impermeable and allows passage of proteins, such as antibodies and other pharmaceutical compounds, into the brain [4].

A possible way to improve delivery of drugs to the brain is the use of colloidal drug carriers such as nanoparticles (NPs), including liposomes, polymeric nanospheres and nanogels [3]. NPs can be loaded with peptides and proteins, facilitating their transfer across biological membranes. In addition, NPs protect their cargo against enzymatic degradation [5]. Thus, these complexes should be highly useful as targeted drug delivery systems.

Liposomes have attracted considerable attention as potential drug carriers that can be targeted to specific organs [6, 7], including the brain $[8,9]$. Liposomes are small artificial vesicles of spherical shape which consist of an aqueous core entrapped by one or more bilayers composed of natural or synthetic, biocompatible and biodegradable lipids similar to biological membranes. The biophysical properties of liposomes such as size, surface charge, lipid composition and amount of cholesterol are variable and are able to control distribution, tissue uptake and drug delivery [10].

Symmetric dendrimeric [11-13] and non-symmetric hyperbranched polymers $[14,15]$, known as dendritic polymers, are nanometer-sized, highly branched macromolecules which consist of a central core, branching units and terminal functional groups. The existence of nanocavities, which can encapsulate various bioactive compounds, is their major structural feature. Furthermore, surface functionalization of dendritic polymers has been established as a successful approach for preparing a wide range of materials including drug delivery systems [16-18]. Another structural feature is the accumulation of a significant number of functional groups on their external surface. This has been 


\section{Chapter 5}

proven to induce strong binding to multiple cell receptors due to the socalled multivalency effect $[19,20]$.

Nanospheres have also been explored as drug carriers [21]. They are sub-micron-sized colloidal structures composed of synthetic and semisynthetic polymers that vary in size from 1 to $1000 \mathrm{~nm}$ in which a drug can be dissolved or encapsulated. Compared with other colloidal carriers, polymeric nanospheres show higher stability in biological fluids. In addition, the use of biodegradable materials for nanoparticle preparation allows sustained drug release at the targeted site [22]. Nanogels are hydrophilic polymers cross-linked in porous networks capable of retaining water-soluble therapeutical peptides and proteins [23-25]. The typical size of nanogels is $10-400 \mathrm{~nm}$. Therefore, they are large enough to avoid clearance from the circulation by glomerular filtration in the kidneys while small enough to limit clearance by the reticuloendothelial system [26]. Nanogels can be designed for stimulusresponsive degradation and drug release [27, 28], and they have also been investigated as vehicles for drug delivery to the brain [29].

Both liposomes and nanospheres are usually rapidly cleared from the blood following intravenous administration. More than $90 \%$ of the NPs are removed from the blood stream within 5 min in mice [30, 31]. Their surface modification with polysorbate 80, poly(ethylene glycol) (PEG) or poly(ethylene oxide) significantly alters the pharmacokinetics and the biological distribution of NPs [32-35].

Tissue specific targeting of NPs can be improved by coating them with peptides that bind to receptors on the target tissue [36]. Upon binding the receptor, the peptide-nanoparticle complex will be taken up by receptor-mediated endocytosis [37]. Receptors on brain endothelial cells, such as the low density lipoprotein receptor (LDLR), transferrin receptor and the insulin receptor can be used for this purpose [38, 39]. 
Due to the potential of various NPs to be used as drug carriers, we have evaluated the efficacy of delivery and safety of liposome, functionalized hyperbranched polyester NPs, poly(glycidol) based nanogels and two types of acrylamide-based NPs functionalized with peptides targeting brain endothelial receptors, in vitro and in vivo. Their hemocompatibility was assessed by in vitro assays, and their cytotoxicity and endothelial uptake were evaluated in various cell types. We investigated the blood clearance rate and in vivo biodistribution of labeled NPs in the brain after intravenous injection in Wistar rats. Here, we provide a detailed report and discussion of our observations.

METHODS

\section{Lipopolysaccharide/Endotoxin Detection and cytotoxicity screening}

Endotoxin content was determined by the PYROGENT Ultra Gel Clot LAL Assay (sensitivity $0.06 \mathrm{EU} / \mathrm{ml}$; Lonza, Basel, Switzerland). The test was performed according to the information supplied by the manufacturer.

The human endothelial cell line EAhy926 (kind gift from Dr. C. J. Edgell) was used for the evaluating the toxicity of the nanoparticles. These cells were cultured at $37{ }^{\circ} \mathrm{C}$ in a humid $95 \%$ air $/ 5 \% \mathrm{CO}_{2}$ atmosphere. Cells were seeded in DMEM, 10\% FBS, $2 \mathrm{mM}$ L-glutamine and $1 \%$ penicillin/streptomycin $24 \mathrm{~h}$ prior to the exposures. NP preparations were tested in concentrations up to $200 \mu \mathrm{g} / \mathrm{ml}$ of reporter peptide and viability assessed by three different assays to confirm the data. All samples were evaluated after $4 \mathrm{~h}$ and $24 \mathrm{~h}$ of exposure by formazan bioreduction using CellTiter 96 AQueous Non-Radioactive Cell Proliferation Assay (Promega, Mannheim, Germany) according to the manufacturer's instructions and a SPECTRA MAX plus 384 plate reader (Molecular Devices, Wals-Siezenheim, Austria). 
Chapter 5

\section{In vitro hemocompatibility}

The hemocompatibility of NPs was assessed by a panel of in vitro tests. NPs were incubated with whole blood for analysis of complement pathway activation, hemolysis and hemostasis activation as described [40].

\section{Peptides}

To evaluate the blood clearance rate and biodistribution of the NPs we attached the reporter peptide 5A to every NP. This peptide contained a carboxyfluorescein and a biotin group, allowing detection by ELISA. Additionally, we used brain targeting peptides 15I and NB03B. The amino acid sequence and modifications of these peptides are shown in Table 1.

\section{Nanoparticles}

In this study NPs of different chemical compositions were used: Liposomes, functionalized hyperbranched aliphatic polyester Boltorn H40 (BH40-polyester), Poly(amidoamine) (PAA), acrylamide and poly(glycidol) (Table 2). A brief description of the synthesis of these NPs is provided below and detailed synthetic routes can be found in the Supporting Information.

\section{Liposomes}

$14.9 \mu \mathrm{mol}$ of 1,2-distearoyl-sn-glycero-3-phosphoethanolamine-N[maleimide(polyethylene glycol)-2000 (DSPE-MAL) was reacted with $14.9 \mu \mathrm{mol}$ of peptide $5 \mathrm{~A}$ using a solution of $0.01 \mathrm{mM}$ tris(2carboxyethyl)phosphine (TCEP). Subsequently, liposomes were prepared by lipid film method. $316.8 \mu \mathrm{mol}$ SPC and $148.5 \mu \mathrm{mol}$ cholesterol were dissolved in the DSPE-MAL-peptide 5A mixture and heated to $60{ }^{\circ} \mathrm{C}$ under bath sonication. The batch was divided in 3 equal 
In vitro and in vivo study of peptide functionalized nanoparticles

parts and DSPE-PEG was post-inserted by co-incubating for $1 \mathrm{~h}$ at $55^{\circ} \mathrm{C}$. Peptides NB03B and 15I were post-inserted by co-incubating the liposomes with an equimolar solution of DSPE-PEG-MAL and peptide for $1 \mathrm{~h}$ at $55^{\circ} \mathrm{C}$.

\section{Hyperbranched polyester NPs}

Hyperbranched aliphatic polyester Boltorn H40, BH40 $\left(\mathrm{M}_{\mathrm{n}}=5100 \mathrm{~g}\right.$ $\mathrm{mol}^{-1}, \mathrm{M}_{\mathrm{w}} / \mathrm{M}_{\mathrm{n}}=1.8$, hydroxyl number $=485 \mathrm{mg} \mathrm{KOH} / \mathrm{g}$ ) bearing 44 hydroxyl end groups was kindly donated by Perstorp AB, Sweden. BH40 with 32 carboxyl groups was prepared by interacting BH40 polyester (0.1 mmol) with succinic anhydride $(4 \mathrm{mmol})$ in anhydrous pyridine (30 ml), under argon atmosphere, at room temperature for 24 hours. Following evaporation of the solvent, the residue was dissolved in acetone and the product was obtained through precipitation in diethyl ether. The crude product was dissolved in a solution of $100 \mathrm{mM}$ $\mathrm{NaHCO}_{3}$ and dialyzed against water. The final product was received after lyophilization and its structure was confirmed by ${ }^{1} \mathrm{H}$ and ${ }^{13} \mathrm{C}$ NMR spectroscopy (see Supporting Information).

Subsequently, $3.87 \mathrm{mg}$ of BH40-polyester (MW 9,043) were dissolved in $1 \mathrm{ml}$ of $0.01 \mathrm{M} \mathrm{pH} 7.4$ Tris buffer containing 5\% dextrose, and $2 \mathrm{mg}$ of peptide $5 \mathrm{~A}$ were added at a final peptide to polymer molar ratio equal to 2.7 (or 12 charge ratio $(-/+)$ ). The solution was stirred for 30 minutes at room temperature and centrifuged at $13,000 \mathrm{rpm}$ for 30 minutes. The supernatant solution was removed and the concentration of the solubilized peptide was determined by its absorbance at $498 \mathrm{~nm}$. An equal volume of the targeting peptide $15 \mathrm{I}(3 \mathrm{mg} / \mathrm{ml})$ was added to the preformed complex BH40-polyester/peptide $5 \mathrm{~A}$ with a charge ratio ca. 4 and the solution was stirred and centrifuged as before. Finally, the supernatant solution was taken and uncomplexed peptides were 
Chapter 5

removed by one-hour dialysis using a dialysis membrane with 3,500 Da cut-off.

\section{Poly(glycidol) based nanogels}

Nanogels were synthesized via inverse mini-emulsion method [41, 42]. For the preparation of the mini-emulsion, $37.5 \mathrm{mg}$ of surfactant (3:1 weight ratio of Span 80 and Tween 80 ) was dissolved in $1.25 \mathrm{ml}$ of $\mathrm{n}$ hexane and was used as organic phase. The aqueous phase consisted of $50 \mathrm{mg}\left(1.1 \times 10^{-2} \mathrm{mM}\right)$ of SH-PG and respective peptides dissolved in 125 $\mu \mathrm{l}$ of $0.04 \mathrm{M}$ PBS buffer ( $\mathrm{pH}$ 7.4). The organic and the aqueous phases were pre-emulsified by magnetic stirring for 10 minutes. After stirring, the system was ultrasonicated under ice cooling for $1 \mathrm{~min}$. Crosslinking was initiated by subsequent addition of $30 \mu \mathrm{l}$ of $0.1 \mathrm{M} \mathrm{H}_{2} \mathrm{O}_{2}$ followed by further sonication for $1 \mathrm{~min}$. The reaction was allowed to proceed for 20 minutes at room temperature with constant stirring followed by quenching of the free thiol groups by 2-hydroxy ethyl acrylate at $\mathrm{pH}$ 7.4. Any further oxidation was stopped by addition of $1.5 \mathrm{ml}$ of acidic water (pH 3). Separation of the nanogels was achieved by centrifugation at $10,000 \mathrm{rpm}$ for 30 minutes followed by decantation of the supernatant. Nanogels present in the aqueous layer were carefully washed with hexane $(2 \times 1.5 \mathrm{ml})$ and THF $(4 \times 2.5 \mathrm{ml})$, dialysed and stored in DI water at $4^{\circ} \mathrm{C}$ for further use.

\section{Synthesis of Poly(amidoamine) NPs}

A series of PAA polymers were synthesized via Michael polyaddition of the primary amine monomers, 4-amino-1-butanol (ABOL) and cPEG$\mathrm{NH}_{2}$, to the $N, N$-cystaminebisacrylamide (CBA) using equimolar monomeric amine/acrylamide ratios. For the synthesis of $\mathrm{p}(\mathrm{CBA}$ ABOL/cPEG-NH 2 ), a co-polymer aiming for $10 \%$ PEG side chains, CBA 
(2.63 g, $10 \mathrm{mmol})$, ABOL (0.89 g, $9.8 \mathrm{mmol})$ and cPEG-NH2 (0.67 g, 0.2 $\mathrm{mmol}$ ) were dissolved in $5 \mathrm{ml} \mathrm{MeOH} / \mathrm{DI}$ water (4/1 v/v) mixture.

Peptide 5A was dissolved in a PBS/EtOH solution and incubated with the $c$ PEG-p(CBA-ABOL) polymers at a 12:1 polymer:peptide ratio.

A similar procedure was carried out for the synthesis of $p(B A P-$ ABOL/CPEG-NH 2 ). The terminal carboxylic acid group present in the side chains of the polymer p(BAP-ABOL/cPEG-NH$) ~(200 \mathrm{mg})$ was activated using EDC (66 mg) and sulfo-NHS (67 mg) in HEPES buffer (10 mM, pH 8). Then, the targeting peptide 15I (15 mg) was dissolved in a mixture of HEPES buffer $(10 \mathrm{mM}, \mathrm{pH} 8)$ and EtOH $(3 / 2 \mathrm{v} / \mathrm{v})$ was added to the mixture.

To prepare the nanosystems with targeting peptide 15I, a similar formulation procedure as previously described was followed, except that $100 \mu \mathrm{l}$ out of the $800 \mu \mathrm{l}$ of polymer used were substituted with targeting peptide-grafted polymer $\mathrm{p}\left(\mathrm{BAP}-\mathrm{ABOL} / 15 \mathrm{I}-\mathrm{g}-\mathrm{CPEG}-\mathrm{NH}_{2}\right)$.

\section{Synthesis of Acrylamide NPs}

Acrylamide NPs were synthesized by the free-radical polymerization method in a microemulsion system as described [43]. The monomers used were: $N$-isopropylacrylamide, $N, N$-dimethylacrylamide and acrylic acid, with methylenebisacrylamide as the cross-linker, sodium dodecyl sulphate as surfactant, and ammonium persulphate as initiator.

\section{In vitro uptake of NPs}

The human cerebral microvascular endothelial cell line, hCMEC/D3, was provided by the group of Pierre-Olivier Couraud (Department of Cell Biology, Institut Cochin, Paris, France) and was first characterized by Weksler et al. [44]. The cells were cultured on fibronectin-coated culture flasks in endothelial cell basal medium (ECBM; Customer Formulation) supplemented with $15 \%$ fetal bovine serum, $2.5 \mathrm{ng} / \mathrm{ml}$ 
basal fibroblast growth factor and $10 \mu \mathrm{g} / \mathrm{ml}$ sodium heparin (both Sigma-Aldrich, St. Luis, USA), and 10000 units $/ \mathrm{ml}$ penicillin $/ 10000 \mu \mathrm{g} / \mathrm{ml}$ streptomycin (both Gibco, Carlsbad, USA).

Cells were seeded onto fibronectin-coated LabTek chamber slides (Nunc, Roskilde, Denmark) in ECBM culture medium (surface 0.7 $\mathrm{cm}^{2} /$ well). After $48 \mathrm{~h}$ cells were incubated with $200 \mu \mathrm{l}$ of various nanoparticle-ECBM suspensions. After the incubation period, cells were washed twice with HEPES buffer including $0.2 \%$ BSA and then fixed with $3.7 \%$ paraformaldehyde at room temperature for 20 minutes. Afterwards cells were washed and incubated with mouse anti-human CD31 antibody (DakoCytomation, Glostrup, Denmark) and the corresponding secondary antibody (goat anti-mouse Alexa Fluor 546; Molecular Probes, Carlsbad, USA) at RT for 1 hour each. The nuclei were stained with Hoechst 33342 (Sigma-Aldrich). The LabTeks were embedded with GelMount (Biomeda, Natutec, Germany) and analyzed by fluorescence microscopy (Olympus IX71 with Delta Vision system, Applied Precision, USA).

\section{Animals and tissue preparation}

2 month old male Wistar rats were obtained from Harlan (Indianapolis, IN). The animals were housed three per cage with ad libitum food and water and a 12:12 hour light:dark cycle. All animal experiments complied with Dutch law and were approved by the ethical committee of Maastricht University.

Three animals per time point were used for each NP. After intravenous injection of NP formulations containing $0.5 \mathrm{mg}$ peptide $5 \mathrm{~A} / \mathrm{kg}$, the animals were anesthetized and either decapitated (unperfused) or transcardially perfused with Tyrode's buffer for 10 minutes to remove residual blood. Subsequently, the brain and liver were dissected and either flash frozen in liquid nitrogen for analysis by ELISA or frozen on 
In vitro and in vivo study of peptide functionalized nanoparticles

a metal platform partially submerged in liquid nitrogen for analysis by immunohistochemistry. CSF was collected before sacrificing the animals. All samples were stored at $-80{ }^{\circ} \mathrm{C}$ until further analysis.

\section{ELISA for the detection of peptide $5 \mathrm{~A}$}

Streptavidin coated ELISA 96-well-microplates (Steffens Biotechnische Analysen, Ebringen, Germany) were used for the detection of $5 \mathrm{~A}$ in plasma and tissue samples as described [43]. Briefly, the carboxyfluorescein group present on the reporter peptide was detected by incubating with monoclonal mouse-anti-fluorescein peroxidaseconjugated IgG (Dianova, Hamburg, Germany) diluted 1:100,000 in PBS with $0.1 \%$ BSA for one hour. Soluble high sensitivity TMB (SDT, Baesweiler, Germany) was used as a chromogenic substrate to visualize bound antibody.

Peptide 5A detection in blood plasma, brain, liver and cerebrospinal fluid after intravenous injection

Detection of peptide $5 \mathrm{~A}$ in blood plasma was performed as described [43]. The brain, liver and cerebrospinal fluid (CSF) of 3 animals per time point were analyzed for peptide $5 \mathrm{~A}$ content by ELISA. Tissue samples were homogenized in lysis buffer (137 mM NaCl, $20 \mathrm{mM}$ Tris, 10\% glycerol, 1\% IGEPAL CA-630 (Sigma), pH 7.4) at a weight to volume ratio of $1: 4$ in a tube containing Lysing Matrix D (MP Biomedicals, Santa Ana, CA). Samples were cooled on ice before and between four rounds of homogenization for 30 seconds in a minibeadbeater (Biospec, Bartlesville, OK). 
Chapter 5

Detection of injected nanoparticles in rat tissue by immunohistochemistry

$10 \mu \mathrm{m}$ thick cryosections were fixed with Somogyi fixative containing glutaraldehyde, blocked with $0.3 \% \mathrm{H}_{2} \mathrm{O}_{2}$ and probed with monoclonal mouse-anti-fluorescein peroxidase-conjugated IgG (Dianova, Hamburg, Germany). Peroxidase activity was visualized with DAB substrate. For immunofluorescence microscopy, the tyramide signal amplification system (Perkin Elmer) was used in conjunction with Alexa fluor 488 labeled streptavidin. As a negative control, the primary antibody was omitted. Brightfield photomicrographs were acquired on an AX70 microscopy workstation (Olympus, Shinjuku, Tokyo, Japan) and fluorescence photomicrographs were acquired on an Olympus BX81 with a disk scanning unit.

RESULTS

\section{In vitro cytotoxicity and hemocompatibility of NPs}

The NPs listed in Table 2 were tested for the presence of endotoxin contamination and potential cytotoxic effects using EAhy926 endothelial cells. When possible, the cytotoxicity assay was performed using up to ten times the expected concentration of peptide loaded NPs in blood after injection ( $200 \mu \mathrm{g} / \mathrm{mL}$ of peptide). Viability of the cells was tested after 4 hours and 24 hours of incubation with the NPs. No decrease in viability was observed for any of the NPs, as evaluated by formazan bioreduction (see Table 3). In addition, most of the samples showed less than $0.6 \mathrm{EU}$ of endotoxin measured by LAL assay. The PAA NPs and in some cases poly(glycidol) nanogels tested at more than $1 \mathrm{EU}$ (see Table 3). In the case of nanogels, the contamination was a result of contaminated water during nanogel purification and these samples 
were not used for in vivo studies. Cell morphology was not affected by the NPs (data not shown).

Additionally, the hemocompatibility of these NPs was evaluated in vitro using human blood (Table 3). Several toxicological reactions potentially occur when NPs are diluted in the blood stream, in particular: Embolisation, hemolysis, cellular activation, but also biological cascades such as coagulation, complement activation, kinin/kininogen, fibrinolysis. Moreover, if one wants to target nanoparticles, the first barrier that the material will encounter is the blood itself and the Reticulo-Endothelial System (RES). The optimization of nanoparticles tailored to reach specific organs, therefore, requires verification of their hemocompatibility, both for toxicological reasons and target efficiency. All of the NPs tested showed good hemocompatibility without any severe adverse reactions.

\section{Uptake of NPs in vitro by human brain endothelial cells}

The uptake of NPs with and without targeting peptides 15I and NB03B in the human cerebral microvascular endothelial cell line hCMEC/D3 was studied. Four different NP compositions were used, containing the reporter peptide 5A (Figure $1 \mathrm{~A}-\mathrm{J}$ ) or Rhodamine (Figure $1 \mathrm{~K}-\mathrm{L}$ ) as a label. Uptake of NPs was observed in all conditions studied for liposomes (A-C), acrylamide (D-F), BH40-polyester (G-H) and PAA (I-J) NPs. In contrast, uptake of poly(glycidol) nanogels was seen only when the nanogels contained a targeting peptide (K-M). 
Chapter 5

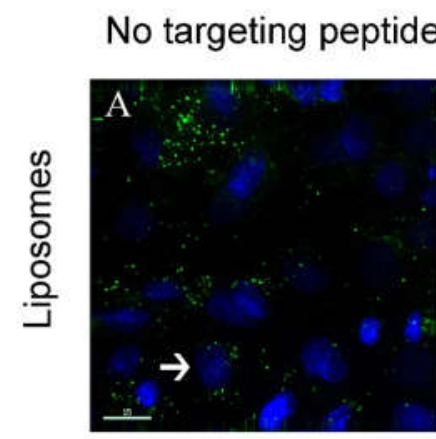

$15 \mid$

REGNB03B
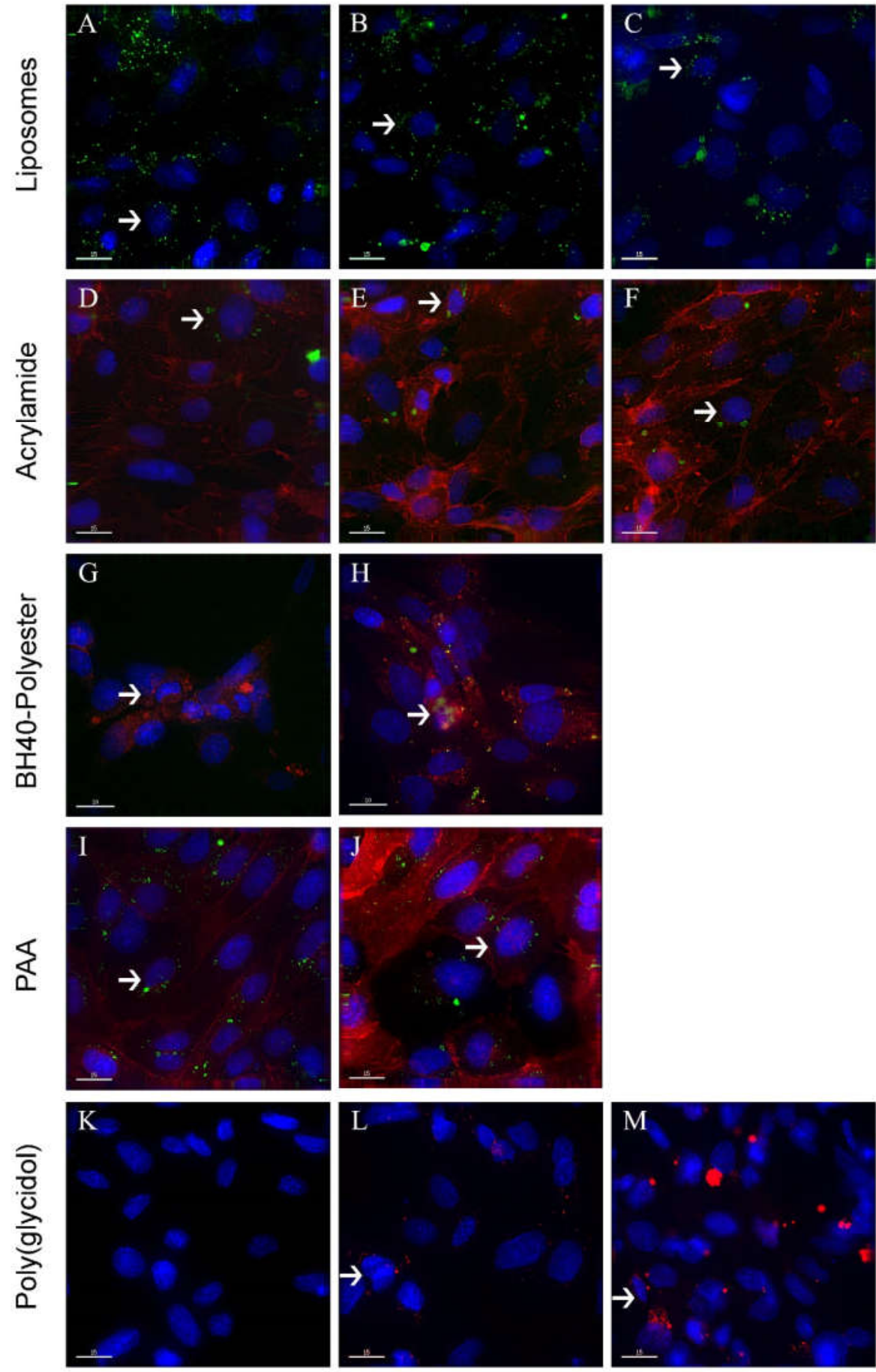
Figure 1: Evaluation of nanoparticle uptake by brain endothelial cells (hCMEC/D3). hCMEC/D3 cells were incubated with different nanoparticles containing a fluorescently labeled reporter peptide, and coated with or without targeting peptides 15I and NB03B for 24h. Representative fluorescent microscopy pictures showing uptake of liposomes (A-C), acrylamide (D-F), polyester ( $G$ and H), PAA-based (I and J) nanoparticles and poly(glycidol) nanogels (K-M). Cell membranes were stained with anti-CD31 antibody (D-F and H-I, shown in red). The BH40-polyester nanoparticles were directly labeled with rhodamine. Cell nuclei were stained with Hoechst dye (blue). Arrows indicate cells containing nanoparticles.

\section{Plasma CONCENTRATIONS OF INTRAVENOUSLY INJECTED NPS}

The aim of this experiment was to determine the time that the NPs remained in circulation and whether this was affected by the presence of a targeting peptide. For this purpose we intravenously injected NPs (Table 2) in Wistar rats, collected repeated blood plasma samples and measured peptide $5 \mathrm{~A}$ concentration by ELISA. For the majority of the NPs injected, we were able to detect the attached peptide $5 \mathrm{~A}$ in plasma (Figure $2 \mathrm{~A}-\mathrm{C}$ and Figure S1). In Figure 2A, we show that the peptide 5A attached to liposomes was detected up to 24 hours after injection. In contrast, peptide 5A attached to acrylamide, BH40-Polyester, PAA NPs and poly(glycidol) nanogels was only detected up to 2 hours. When 15I or NB03B targeting peptides were anchored to liposomes, a reduction of peptide $5 \mathrm{~A}$ plasma concentration by 36 and $64 \%$, respectively, 30 minutes after injection was observed (Figure $2 \mathrm{~A}$ ). The $64 \%$ reduction in plasma concentration observed with NB03B liposomes suggests faster elimination from the circulation in the presence of this peptide, possibly due to increased uptake.

In contrast, no clear effect of the targeting peptides on peptide $5 \mathrm{~A}$ concentration was observed when acrylamide (Figure 2B) hyperbranched polyester (Figure 2C), and poly(amidoamine) (Figure S1A) NPs as well as poly (glycidol) nanogels (Figure S1B) were used. 
Chapter 5
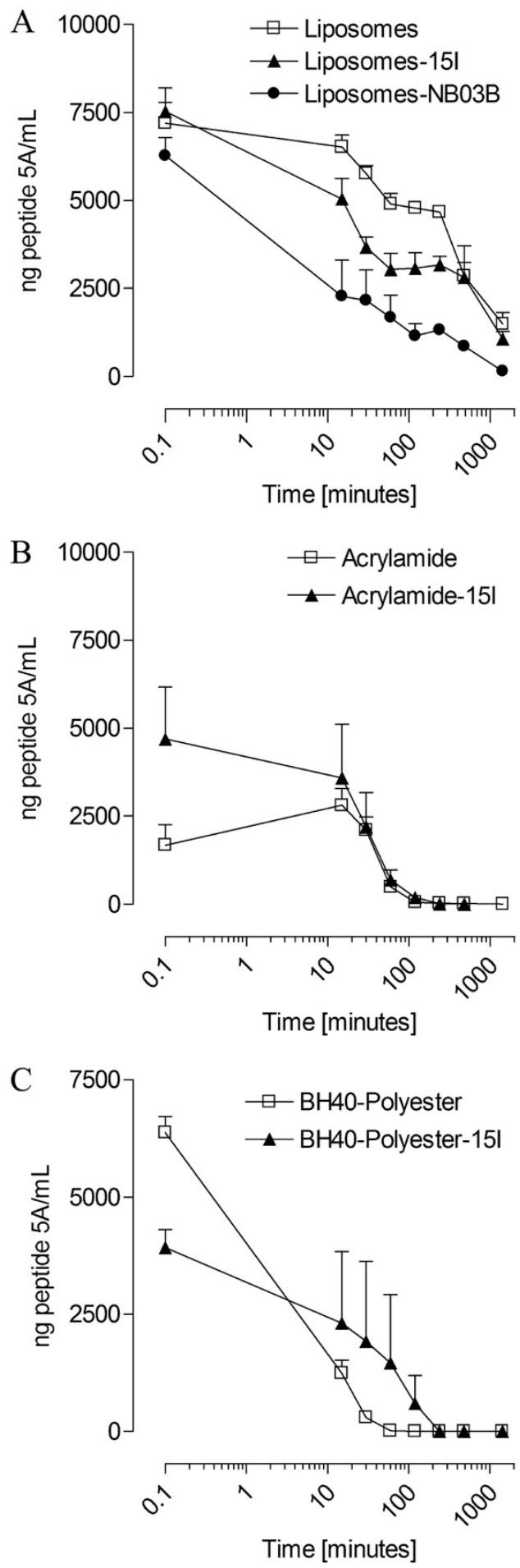
Figure 2: Blood plasma concentration of peptide 5A containing nanoparticles after intravenous injection in rats. Blood was taken immediately and at 15, 30, 60 minutes and at 2, 4, 8 and 24 hours after injection from the tail vein. Plasma was prepared and peptide $5 \mathrm{~A}$ concentration was measured by ELISA. All nanoparticles contained the reporter peptide $5 \mathrm{~A}$, and were coated with or without targeting peptides $15 \mathrm{I}$ and NB03B. Liposomes were detected in plasma up to 24 hours after injection (A) while the other nanoparticles were not detectable in plasma after 4 hours (B and C). Data are shown on a logarithmic time scale as the mean \pm S.E.M. plasma concentration of peptide $5 \mathrm{~A}$ in 3 animals per nanoparticle.

\section{Detection of NPs in the brain, liver and CSF}

To determine whether the NP compositions listed in Table 2 reached the brain, ELISA and immunohistochemistry methods were used to detect peptide $5 \mathrm{~A}$ in brain tissue from intravenously injected animals. To avoid contamination of brain tissue samples with blood from the brain vasculature, the animals were transcardially perfused before removal of the brain at the time of sacrifice. Peptide 5A was detected in brain homogenates by ELISA (Figure 3), although the amount of peptide was below $10 \mathrm{ng}$ per gram of tissue for all nanoparticle-peptide combinations. Interestingly, when the targeting peptide 15I or NB03B were anchored to liposomes, the concentration of peptide $5 \mathrm{~A}$ in the brain increased over time (Figure $3 \mathrm{~A}$ ). Addition of targeting peptides to acrylamide NPs did not result in a difference in peptide $5 \mathrm{~A}$ concentrations in the brain compared to non-targeted NPs (Figure 3B). For BH40-Polyester NPs, lower peptide 5A concentrations with 15I were observed at 2 hours $(\mathrm{p}<0.05), 4$ hours $(\mathrm{p}<0.01)$ and 24 hours $(\mathrm{p}<0.05)$. The same pattern was observed with poly(glycidol) nanogels containing NB03B targeting peptide (Figure 3E), suggesting that the copresence of the targeting and reporter peptides result in a reduced brain uptake. No difference in peptide $5 \mathrm{~A}$ concentration was observed between PAA NPs with and without 15I targeting peptide (Figure 3D). 

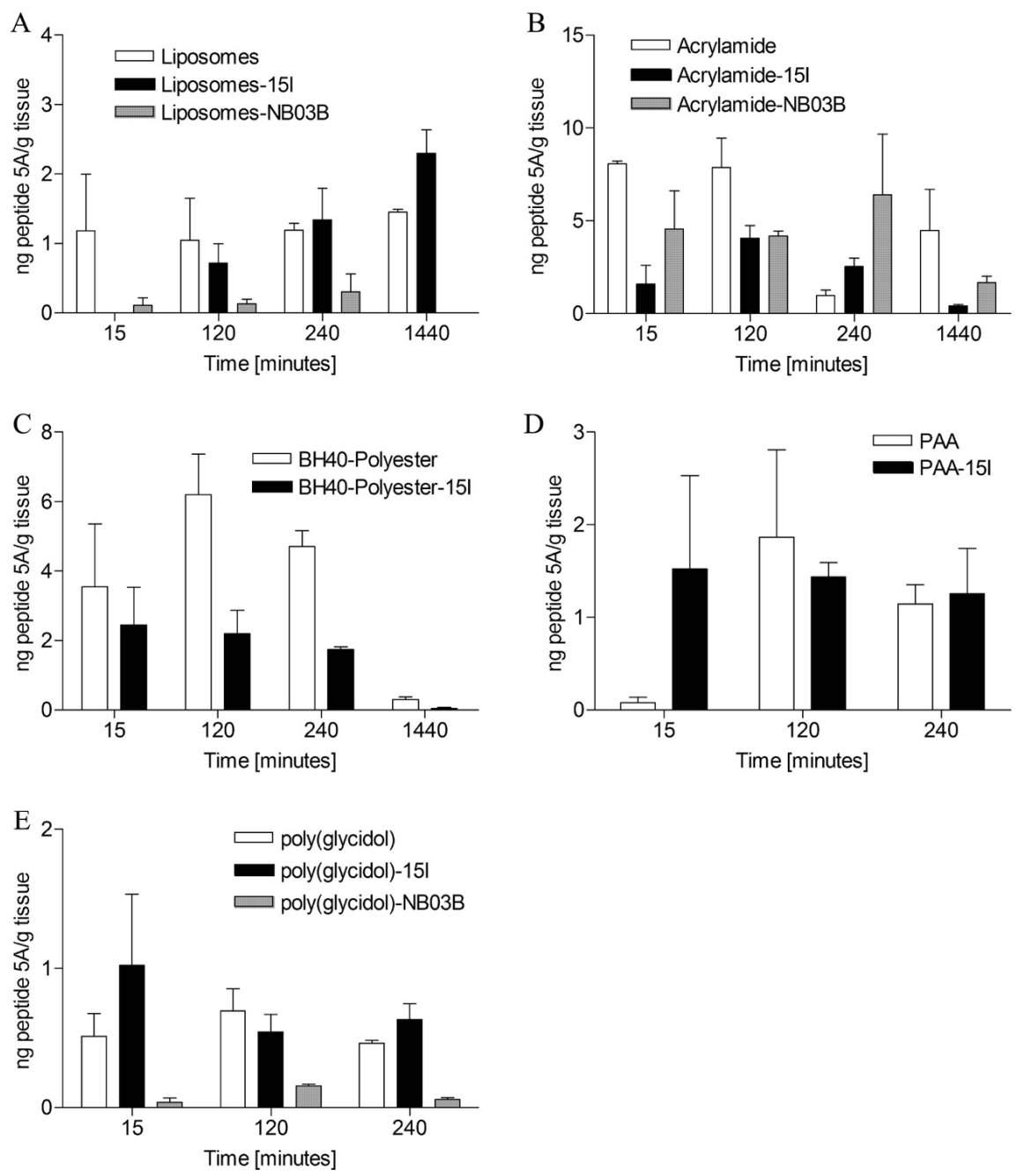

Figure 3: Concentration of peptide 5A in brain homogenate after intravenous injection of nanoparticles. Animals were sacrificed at different time points after injection and the concentration of peptide 5A in brain homogenate was measured by ELISA. All nanoparticles contained the reporter peptide $5 \mathrm{~A}$, and were either coated with targeting peptides $15 \mathrm{I}$ and NB03B, or not. Data are shown as the mean \pm S.E.M. peptide $5 \mathrm{~A}$ concentration of 3 animals.

Because of the role of the liver in the clearance of NPs, peptide $5 \mathrm{~A}$ concentration was also determined in liver homogenates of the same animals (Figure 4). The highest concentrations of peptide $5 \mathrm{~A}$ were 
detected in animals injected with liposomes (Figure 4A) compared to the other NP compositions (Figure 4B-E) where the concentrations detected were significantly lower. Compared to non-targeted liposomes, we observed an increase over time of 15I-liposomes, with the highest concentration after 24 hours $(p<0.05)$. The addition of NB03B targeting peptide to acrylamide NPs resulted in higher uptake of these NPs by the liver at 15 minutes $(\mathrm{p}<0.01), 2$ hours $(\mathrm{p}<0.05)$ and 4 hours $(p<0.01)$ (Figure $4 B)$. No statistically significant differences in liver uptake were observed between non-targeted and targeted BH40Polyester and PAA NPs and also poly(glycidol) nanogels. Furthermore, BH40-Polyster NP and poly(glycidol) nanogel accumulation in the liver was low, as expected, due to their hydrophilic nature.

In parallel to the brain and liver homogenate measurements, we studied whether NPs were present in CSF collected from the same animals described above. Peptide 5A was detected in the CSF of liposome-injected animals up to 24 hours after injection (Figure 5A). Moreover, with the concentration of peptide 5A in CSF (Figure $5 \mathrm{~A}-\mathrm{D}$ ) tended to show the same pattern as brain homogenate (Figure 3 ). 


\section{Chapter 5}
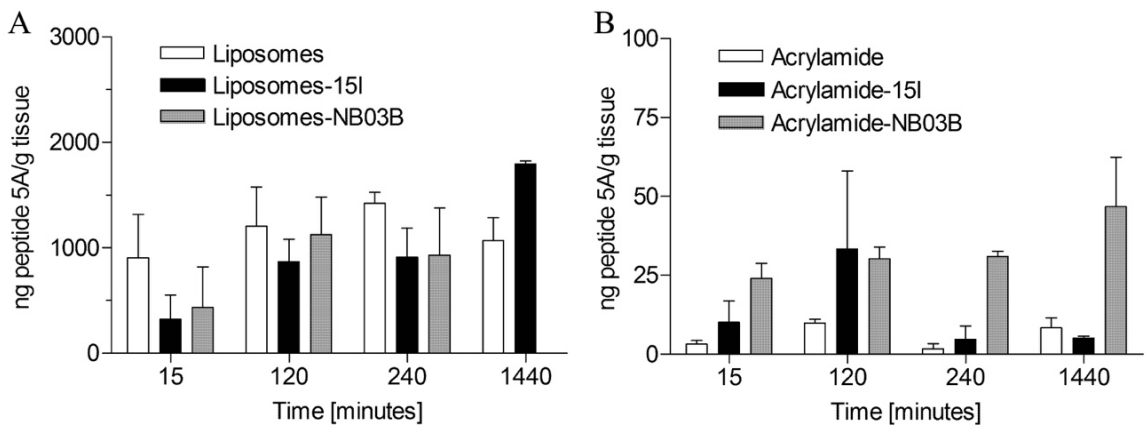

C

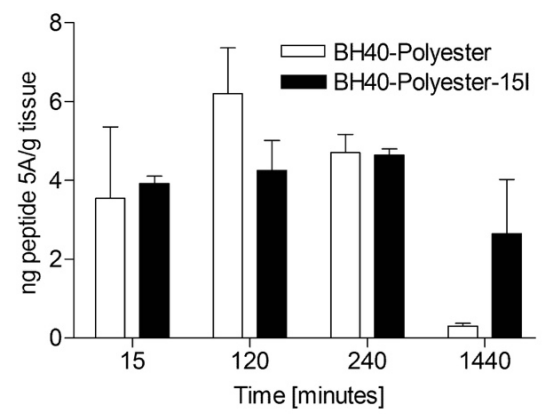

$\mathrm{E}$

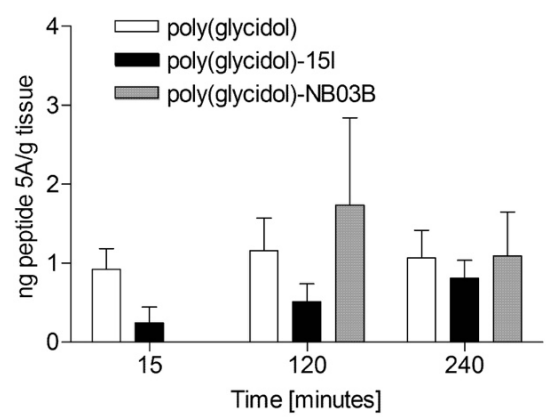

D

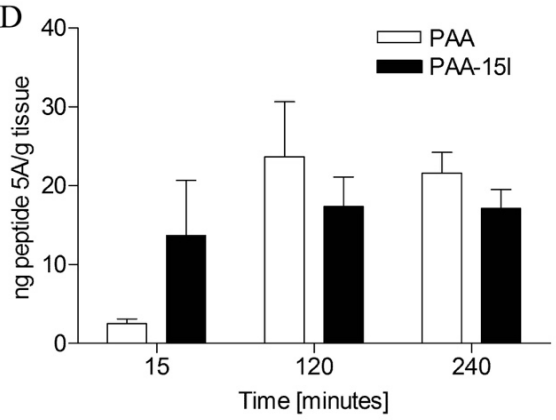

Figure 4: Concentration of peptide $5 \mathrm{~A}$ in liver homogenate after intravenous injection of nanoparticles. Animals were sacrificed at different time points after injection and the concentration of peptide 5A in liver homogenate was measured by ELISA. All nanoparticles contained the reporter peptide $5 \mathrm{~A}$, and were either coated with targeting peptides $15 \mathrm{I}$ and NB03B or not. The combination of Liposomes with NB03B was not measured at 1440 minutes (A). Data are shown as the mean \pm S.E.M. peptide $5 \mathrm{~A}$ concentration of 3 animals. 

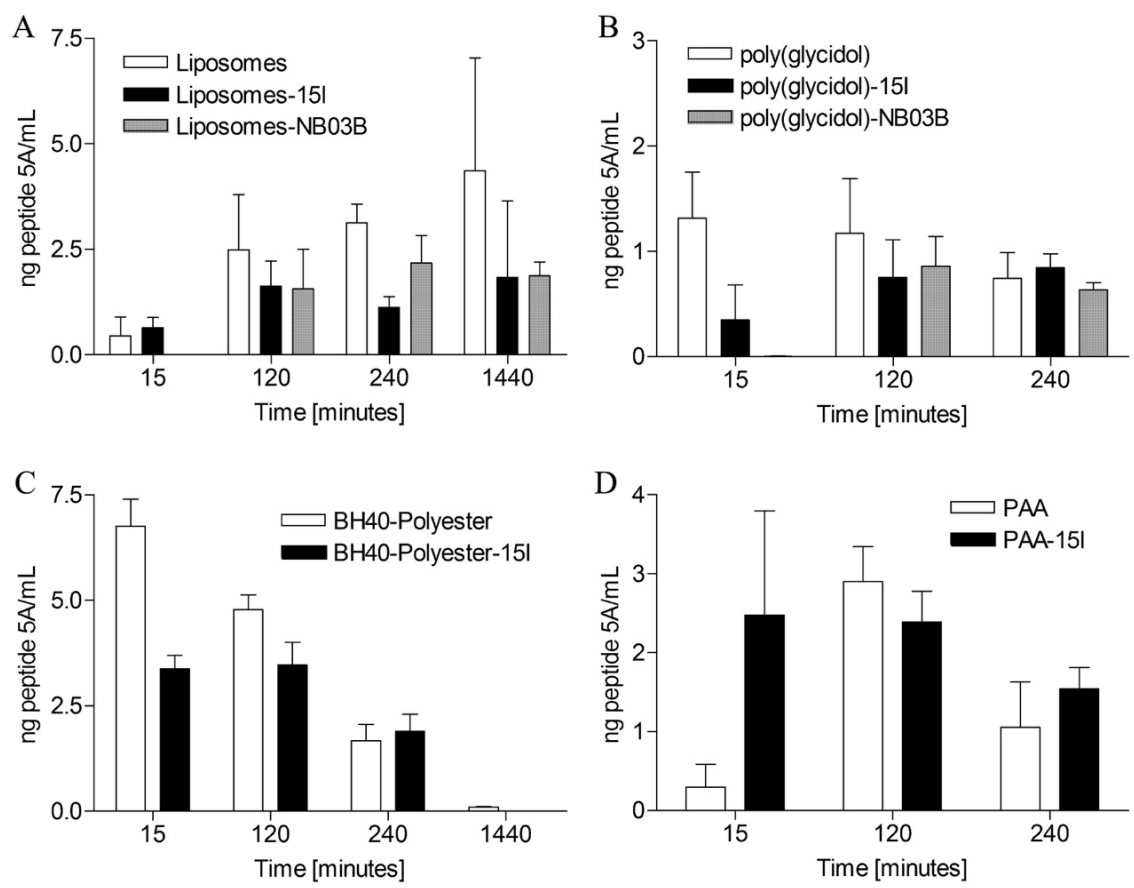

Figure 5: Concentration of peptide 5A in CSF after intravenous injection of nanoparticles. Animals were sacrificed at different time points after injection and the concentration of peptide 5A in CSF was measured by ELISA. All nanoparticles contained the reporter peptide $5 \mathrm{~A}$, and were coated with or without targeting peptides 15I and NB03B. The presence of targeting peptides on the nanoparticles did not result in increased peptide 5A concentration in the CSF (A-C). A higher concentration of peptide $5 \mathrm{~A}$ was observed 15 minutes after injection PAA-15I nanoparticles compared to PAA nanoparticles without 15I targeting peptide (D). Data are shown as the mean \pm S.E.M. peptide 5 A concentration of 3 animals

Immunohistochemical analysis of unperfused brain and liver tissue obtained from rats injected with peptide 5A/NB03B loaded liposomes revealed the presence of peptide $5 \mathrm{~A}$ in the choroid plexus and surrounding blood vessel-like structures (Figures 6 and 7). The strongest staining in the brain was observed 15 minutes after injection (Figure 6A), compared to weaker staining 2 hours after injection (Figure 6B) and almost undetectable levels 24 hours after injection (Figure 6C). Liver tissue from the same animals showed a similar pattern over time (Figure 6D-F). In contrast, peptide 5A was 


\section{Chapter 5}

undetectable by immunohistochemistry in the brains of animals that were transcardially perfused after injection with peptide 5A/NB03B loaded liposomes (data not shown).

Brain

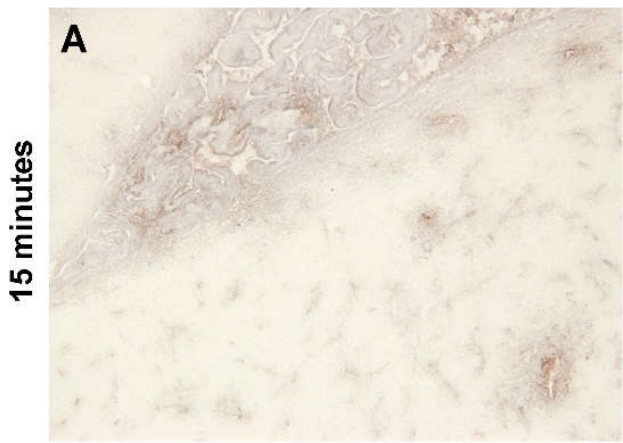

B

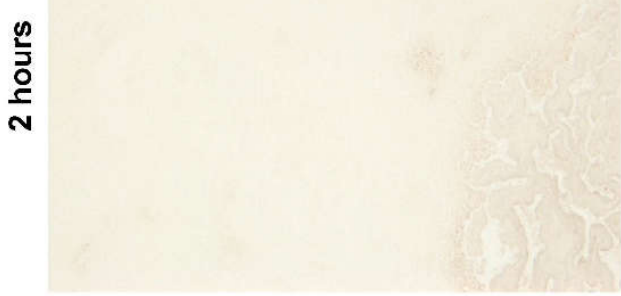

C

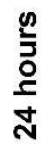

Figure 6: Immunohistochemical detection of peptide $5 \mathrm{~A}$ in brain (A-C) and liver (D-F) tissue sections injected with liposomes containing peptides 5A and NB03B. Peptide 5A was detected with a monoclonal antibody against FITC in brain tissue sections of animals sacrificed without transcardial perfusion 15 minutes (A), 2 hours (B) and 24 hours (C) after injection. 3 animals per time point were analyzed and representative images are shown. Brain and liver photomicrographs from the same animal are shown on each row. Scale bar is $200 \mu \mathrm{m}$. 


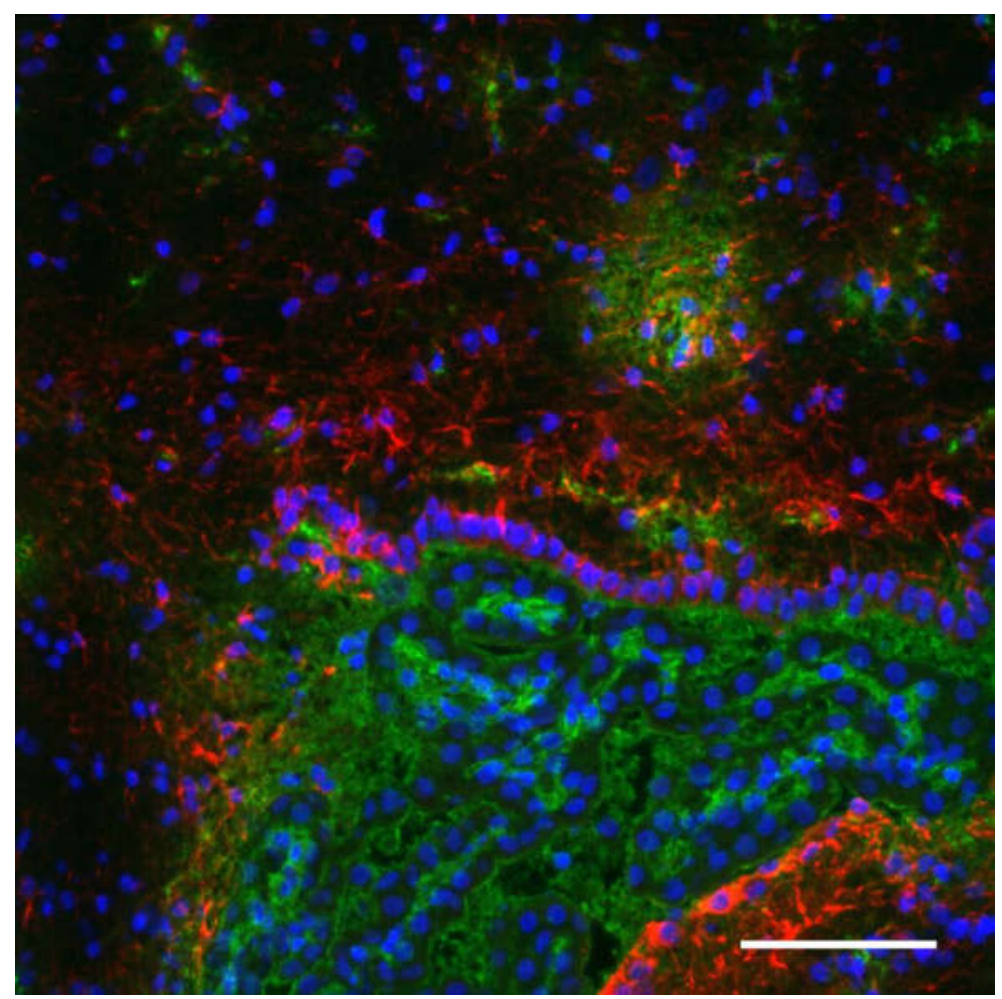

Figure 7: Fluorescence immunohistochemistry of FITC labeled reporter peptide 5A in brain tissue. A $10 \mu \mathrm{m}$ brain section of an unperfused 2 month old Wistar rats 15 minutes after injection with peptide 5A liposomes containing NB03B targeting peptide was stained for FITC and GFAP. Green channel: FITC labeled peptide 5A; Red channel: Astrocyte marker GFAP; Blue channel: Nucleus (Hoechst). Scale bar is $50 \mu \mathrm{m}$.

\section{DISCUSSION}

The aim of this study was the development of NPs functionalized with targeting peptides for specific brain delivery. We report the synthesis of different types of NPs chosen for their ability to carry peptide/protein cargo and their biodegradable nature (liposomes, hyperbranched polyester, poly(glycidol) and acrylamide based) conjugated to targeting peptides. The NPs were labeled with a reporter peptide containing biotin and fluorescein (peptide 5A), and with two peptides containing targeting properties based on the angiopep sequence (peptide 15I) and 
a novel peptide based on a Semliki forest virus (SFV) protein (NB03B). Angiopep peptides are derived from the Kunitz domain of aprotinin and have been proposed as a suitable brain delivery system by utilizing receptor mediated transcytosis via the low-density lipoprotein receptor-related protein at the $\mathrm{BBB}$ [45]. The SFV is a neuroinvasive virus that is thought to cross the BBB [46]. We used a peptide based on a SFV protein with the potential to bind and cross brain endothelial cells. Since the safety of nanomaterials is an important consideration $[47,48]$, initially all NPs were screened for in vitro cytotoxicity and hemocompatibility, and subsequently only the NPs that did not show significant adverse effects were used for in vivo studies. In line with the in vitro toxicity and hemocompatibility experiments, none of the injected NP formulations showed any signs of acute toxicity or other adverse effects in vivo.

Additionally we evaluated the selective uptake of NP compositions by brain endothelial cells (ECs). The representative images in Figure 1 indicate that the nanoparticles can be internalized by brain ECs and that as a consequence transcytosis of the NPs across the cells may be possible. However, the fact that NPs without targeting peptides showed uptake indicates that NPs might not be internalized by a receptormediated pathway, except for the poly(glycidol) based nanogels. Since it is known that physico-chemical properties of NPs are also responsible for cell-nanoparticle interactions, the uptake in brain endothelial cells in vitro may be explained. As shown by Kasper et al. and Freese et al. $[49,50]$, the uptake of silica and polymer-modified gold NPs of different sizes was mediated by a clathrin- and caveolin-1 independent pathway as described by Glebov et al. [51] which demonstrates that a binding to a specific receptor is not essential for NP uptake. The effect of targeting peptides on the blood clearance rate and biodistribution of the NPs was studied after intravenous injection in Wistar rats. After 
analyzing brain homogenates, no preferential uptake of the NPs in brain tissue could be detected. Thus the in vivo experiments are in accordance with the results shown in the in vitro studies. In line with these results, a recent study showed no increase in brain uptake of the enzyme arylsulfatase A when conjugated to angiopep [52]. In contrast, it has been shown that conjugating angiopep- 2 to neurotensin results in a ten-fold increase in brain uptake [53], and it has been reported that angiopep increases uptake of lipid based NPs 2.4-fold in vitro [54].

A fraction of the NPs did reach the brain as confirmed by the ELISA results showing low accumulation of NPs in brain homogenates and CSF. In addition, we detected the fluorescent label on liposomes in the brain of unperfused animals by immunofluorescence microscopy. In contrast, perfusing the brain after injection of liposomes resulted in markedly decreased immunofluorescent signal, limited to the choroid plexus.

The low amounts of NPs detected in the brain could be explained by the following factors: i) the combinations of NPs and targeting peptides did not show sufficient specificity for brain endothelial cells as shown in our in vitro experiments; ii) the low stability of the nanoparticlepeptide complex in vivo e.g. due to enzymatic degradation of the targeting peptide and/or reporter label [55].

Liver homogenate concentrations of acrylamide, BH40-polyester, PAA and poly(glycidol) were similar to those found in brain homogenates while a larger fraction of the injected dose of liposomes was found in the liver. This indicates that the liver only plays a significant role in NP clearance for liposomes.

Interestingly, the anchoring of targeting peptides to liposomes resulted in altered blood plasma levels, with increased clearance from the circulation. 
Chapter 5

In conclusion, we in order to improve brain targeting of NPs, it is essential that the combination of physical characteristics of the NPs and the targeting peptides confer high specificity for brain endothelial cells versus other endothelial cells in different organs. 


\section{REFERENCES}

1. Yi, X., et al., Agile delivery of protein therapeutics to CNS. J Control Release, 2014. 190: p. 637-63.

2. Georgieva, J.V., D. Hoekstra, and I.S. Zuhorn, Smuggling Drugs into the Brain: An Overview of Ligands Targeting Transcytosis for Drug Delivery across the Blood-Brain Barrier. Pharmaceutics, 2014. 6(4): p. 557-583.

3. Brasnjevic, I., et al., Delivery of peptide and protein drugs over the bloodbrain barrier. Prog Neurobiol, 2009. 87(4): p. 212-51.

4. Martinez-Martinez, P., et al., Autoantibodies to neurotransmitter receptors and ion channels: from neuromuscular to neuropsychiatric disorders. Front Genet, 2013. 4: p. 181.

5. Petros, R.A. and J.M. DeSimone, Strategies in the design of nanoparticles for therapeutic applications. Nat Rev Drug Discov, 2010. 9(8): p. 615-27.

6. Eloy, J.O., et al., Liposomes as carriers of hydrophilic small molecule drugs: Strategies to enhance encapsulation and delivery. Colloids Surf B Biointerfaces, 2014.

7. Deshpande, P.P., S. Biswas, and V.P. Torchilin, Current trends in the use of liposomes for tumor targeting. Nanomedicine (Lond), 2013. 8(9): p. 1509-28.

8. Rotman, M., et al., Enhanced glutathione PEGylated liposomal brain delivery of an anti-amyloid single domain antibody fragment in a mouse model for Alzheimer's disease. J Control Release, 2015. 203: p. 40-50.

9. Kuo, Y.C. and C.C. Lin, Rescuing apoptotic neurons in Alzheimer's disease using wheat germ agglutinin-conjugated and cardiolipin-conjugated liposomes with encapsulated nerve growth factor and curcumin. 2015(11782013 (Electronic)).

10. van der Meel, R., et al., Extracellular vesicles as drug delivery systems: Lessons from the liposome field. J Control Release, 2014.

11. Fréchet, J.M.J. and D.A. Tomalia, Dendrimers and Other Dendritic Polymers. Polymer Science. 2001.

12. Newkome, G., C. Moorefield, and F. Vögtle, Dendritic Molecules: Concepts, Synthesis, Perspectives. 1996.

13. Bosman, A.W., H.M. Janssen, and E.W. Meijer, About Dendrimers: Structure, Physical Properties, and Applications. Chem Rev, 1999. 99(7): p. 1665-1688.

14. Huang, Y., et al., Synthesis and therapeutic applications of biocompatible or biodegradable hyperbranched polymers. POLYMER CHEMISTRY, 2015. 6: p. 2794-2812.

15. Calderon, M., et al., Dendritic polyglycerols for biomedical applications. Adv Mater, 2010. 22(2): p. 190-218.

16. Paleos, C.M., et al., Drug delivery using multifunctional dendrimers and hyperbranched polymers. Expert Opin Drug Deliv, 2010. 7(12): p. 1387-98.

17. Gillies, E.R. and J.M. Frechet, Dendrimers and dendritic polymers in drug delivery. Drug Discov Today, 2005. 10(1): p. 35-43.

18. Khandare, J., et al., Multifunctional dendritic polymers in nanomedicine: opportunities and challenges. Chem Soc Rev, 2012. 41(7): p. 2824-48. 


\section{Chapter 5}

19. Mammen, M., S.-K. Choi, and G.M. Whitesides, Polyvalent Interactions in Biological Systems: Implications for Design and Use of Multivalent Ligands and Inhibitors. Angewandte Chemie International Edition, 1998. 37(20): p. 2754-2794.

20. Fasting, C., et al., Multivalency as a Chemical Organization and Action Principle. Angewandte Chemie International Edition, 2012. 51(42): p. 1047210498.

21. Herran, E., et al., Increased antiparkinson efficacy of the combined administration of VEGF- and GDNF-loaded nanospheres in a partial lesion model of Parkinson's disease. Int J Nanomedicine, 2014. 9: p. 2677-87.

22. Vinogradov, S.V., T.K. Bronich, and A.V. Kabanov, Nanosized cationic hydrogels for drug delivery: preparation, properties and interactions with cells. Adv Drug Deliv Rev, 2002. 54(1): p. 135-47.

23. Vermonden, T., R. Censi, and W.E. Hennink, Hydrogels for protein delivery. Chem Rev, 2012. 112(5): p. 2853-88.

24. Chacko, R.T., et al., Polymer nanogels: a versatile nanoscopic drug delivery platform. Adv Drug Deliv Rev, 2012. 64(9): p. 836-51.

25. Albrecht, K., M. Moeller, and J. Groll, Nano- and Microgels Through Addition Reactions of Functional Oligomers and Polymers, in Chemical Design of Responsive Microgels, A. Pich and W. Richtering, Editors. 2011, Springer Berlin Heidelberg. p. 65-93.

26. Letchford, K. and H. Burt, A review of the formation and classification of amphiphilic block copolymer nanoparticulate structures: micelles, nanospheres, nanocapsules and polymersomes. Eur J Pharm Biopharm, 2007. 65(3): p. 259-69.

27. Zha, L., B. Banik, and F. Alexis, Stimulus responsive nanogels for drug delivery. Soft Matter, 2011. 7(13): p. 5908-5916.

28. Singh, S., et al., Embedding of active proteins and living cells in redoxsensitive hydrogels and nanogels through enzymatic cross-linking. Angew Chem Int Ed Engl, 2013. 52(10): p. 3000-3.

29. Azadi, A., M. Hamidi, and M.R. Rouini, Methotrexate-loaded chitosan nanogels as 'Trojan Horses' for drug delivery to brain: preparation and in vitro/in vivo characterization. Int J Biol Macromol, 2013. 62: p. 523-30.

30. Pardridge, W.M., Recent developments in peptide drug delivery to the brain. Pharmacol Toxicol, 1992. 71(1): p. 3-10.

31. Olivier, J.C., et al., Indirect evidence that drug brain targeting using polysorbate 80-coated polybutylcyanoacrylate nanoparticles is related to toxicity. Pharm Res, 1999. 16(12): p. 1836-42.

32. Alyautdin, R.N., et al., Delivery of loperamide across the blood-brain barrier with polysorbate 80-coated polybutylcyanoacrylate nanoparticles. Pharm Res, 1997. 14(3): p. 325-8.

33. Alyautdin, R.N., et al., Significant entry of tubocurarine into the brain of rats by adsorption to polysorbate 80-coated polybutylcyanoacrylate nanoparticles: an in situ brain perfusion study. J Microencapsul, 1998. 15(1): p. 67-74.

34. Kreuter, J., Nanoparticulate systems for brain delivery of drugs. Adv Drug Deliv Rev, 2001. 47(1): p. 65-81. 
35. Kreuter, J., Influence of the surface properties on nanoparticle-mediated transport of drugs to the brain. J Nanosci Nanotechnol, 2004. 4(5): p. 484-8.

36. Fernandes, E., et al., New trends in guided nanotherapies for digestive cancers: A systematic review. J Control Release, 2015.

37. Field, L.D., et al., Peptides for specifically targeting nanoparticles to cellular organelles: quo vadis? Acc Chem Res, 2015. 48(5): p. 1380-90.

38. Wohlfart, S., S. Gelperina, and J. Kreuter, Transport of drugs across the bloodbrain barrier by nanoparticles. J Control Release, 2012. 161(2): p. 264-73.

39. Lajoie, J.M. and E.V. Shusta, Targeting receptor-mediated transport for delivery of biologics across the blood-brain barrier. Annu Rev Pharmacol Toxicol, 2015. 55: p. 613-31.

40. Kuznetsova, N.R., et al., Hemocompatibility of liposomes loaded with lipophilic prodrugs of methotrexate and melphalan in the lipid bilayer. J Control Release, 2012. 160(2): p. 394-400.

41. Singh, S., et al., Mild oxidation of thiofunctional polymers to cytocompatible and stimuli-sensitive hydrogels and nanogels. Macromol Biosci, 2013. 13(4): p. 470-82.

42. Groll, J., et al., Biocompatible and degradable nanogels via oxidation reactions of synthetic thiomers in inverse miniemulsion. Journal of Polymer Science Part A: Polymer Chemistry, 2009. 47(20): p. 5543-5549.

43. Bode, G.H., et al., Detection of Peptide-based nanoparticles in blood plasma by ELISA. PLoS One, 2015. 10(5): p. e0126136.

44. Weksler, B.B., et al., Blood-brain barrier-specific properties of a human adult brain endothelial cell line. FASEB J, 2005. 19(13): p. 1872-4.

45. Demeule, M., et al., Identification and design of peptides as a new drug delivery system for the brain. J Pharmacol Exp Ther, 2008. 324(3): p. 106472.

46. Fazakerley, J.K., Pathogenesis of Semliki Forest virus encephalitis. J Neurovirol, 2002. 8 Suppl 2: p. 66-74.

47. De Jong, W.H. and P.J. Borm, Drug delivery and nanoparticles:applications and hazards. Int J Nanomedicine, 2008. 3(2): p. 133-49.

48. Araujo, F., et al., Safety and toxicity concerns of orally delivered nanoparticles as drug carriers. Expert Opin Drug Metab Toxicol, 2014: p. 1-13.

49. Kasper, J., et al., Interactions of silica nanoparticles with lung epithelial cells and the association to flotillins. Arch Toxicol, 2013. 87(6): p. 1053-65.

50. Freese, C., et al., Uptake of poly(2-hydroxypropylmethacrylamide)-coated gold nanoparticles in microvascular endothelial cells and transport across the blood-brain barrier. Biomaterials Science, 2013. 1(8): p. 824-833.

51. Glebov, 0.0., N.A. Bright, and B.J. Nichols, Flotillin-1 defines a clathrinindependent endocytic pathway in mammalian cells. Nat Cell Biol, 2006. 8(1): p. 46-54.

52. Bockenhoff, A., et al., Comparison of five peptide vectors for improved brain delivery of the lysosomal enzyme arylsulfatase A. J Neurosci, 2014. 34(9): p. 3122-9.

53. Demeule, M., et al., Conjugation of a brain-penetrant peptide with neurotensin provides antinociceptive properties. J Clin Invest, 2014. 124(3): p. 1199-213. 


\section{Chapter 5}

54. Bruun, J., et al., Investigation of enzyme-sensitive lipid nanoparticles for delivery of siRNA to blood-brain barrier and glioma cells. Int J Nanomedicine, 2015. 10: p. 5995-6008.

55. Pernot, M., et al., Stability of peptides and therapeutic success in cancer. Expert Opin Drug Metab Toxicol, 2011. 7(7): p. 793-802.

56. Visser, C.C., et al., Coupling of metal containing homing devices to liposomes via a maleimide linker: use of TCEP to stabilize thiol-groups without scavenging metals. J Drug Target, 2004. 12(9-10): p. 569-73.

57. Uster, P.S., et al., Insertion of poly(ethylene glycol) derivatized phospholipid into pre-formed liposomes results in prolonged in vivo circulation time. FEBS Lett, 1996. 386(2-3): p. 243-6.

58. Ornatska, M., et al., Assembling of amphiphilic highly branched molecules in supramolecular nanofibers. J Am Chem Soc, 2004. 126(31): p. 9675-84.

59. Kontoyianni, C., et al., A novel micellar PEGylated hyperbranched polyester as a prospective drug delivery system for paclitaxel. Macromol Biosci, 2008. 8(9): p. 871-81. 


\section{TABLES}

Table 1: Overview of the peptides used to decorate nanoparticles

\begin{tabular}{|l|l|l|}
\hline $\begin{array}{l}\text { Peptide } \\
\text { name }\end{array}$ & Sequence & Modifications \\
\hline $5 \mathrm{~A}$ & napvsipqKGGC & $\begin{array}{l}\text { Biotin } \\
\text { Carboxyfluorescein }\end{array}$ \\
\hline 15I & CGGKTFFYGGCRGKRNNFKTEEY & \\
\hline NB03B & $\begin{array}{l}\text { HKKWQFNSPFVPRADEPARKGKVHIPF } \\
\text { PLDNITCRVPMAREPTVIHGKREVTLHL } \\
\text { HPDH }\end{array}$ & TAMRA \\
\hline
\end{tabular}

Peptide 5A was used as a reporter peptide. Peptides 15I and NB03B were used as targeting peptides. Lower case amino acid letters denote D-amino acids and upper case L-amino acids.

Table 2: Nomenclature of the nanoparticles used in the study and the peptides attached to the nanoparticles.

\begin{tabular}{|l|l|l|l|}
\hline Nanoparticle & $\begin{array}{l}\text { Reporter } \\
\text { peptide }\end{array}$ & $\begin{array}{l}\text { Targeting } \\
\text { peptide }\end{array}$ & $\begin{array}{l}\text { Nomenclature nanoparticles } \\
\text { (name nanoparticle } \\
\text { targeting peptide) }\end{array}$ \\
\hline Liposomes & peptide 5A & none & Liposomes \\
\hline & peptide 5A & peptide 15I & Liposomes-15I \\
\hline & peptide 5A & NB03B & Liposomes-NB03B \\
\hline BH40-polyester & peptide 5A & none & BH40-polyester \\
\hline poly(amidoamine)(PAA) & peptide 5A & none & PAA \\
\hline & peptide 5A & peptide 15I & PAA-15I \\
\hline Acrylamide & peptide 5A & none & Acrylamide \\
\hline & peptide 5A & peptide 15I & Acrylamide-15I \\
\hline & peptide 5A & NB03B & Acrylamide-NB03B \\
\hline poly(glycidol) & peptide 5A & none & poly(glycidol) \\
\hline & peptide 5A & peptide 15I & poly(glycidol)-15I \\
\hline & peptide 5A & NB03B & poly(glycidol)-NB03B \\
\hline
\end{tabular}

All nanoparticles were coated with a reporter peptide. Additionally, some nanoparticles were coated with both a reporter and a targeting peptide. 


\section{Chapter 5}

Table 3: Summary of the cytotoxicity assay studies with the peptidecoated nanoparticles.

\begin{tabular}{|c|c|c|c|c|c|c|c|c|}
\hline \multirow[b]{2}{*}{$\begin{array}{l}\text { Nomenclatur } \\
\text { e } \\
\text { nanoparticle }\end{array}$} & \multirow{2}{*}{$\begin{array}{c}\text { Concentratio } \\
\mathrm{n}(\mu \mathrm{g} \\
\text { reporter } \\
\text { peptide } / \mathrm{ml})^{\mathrm{a}}\end{array}$} & \multicolumn{2}{|c|}{ Cell viabilityb } & \multirow{2}{*}{$\begin{array}{c}\text { Endotoxi } \\
n \\
(\mathrm{EU} / \mathrm{mL}) \\
\mathrm{c}\end{array}$} & \multicolumn{4}{|c|}{ Hemcompatibility } \\
\hline & & $4 \mathrm{~h}$ & $24 \mathrm{~h}$ & & $\begin{array}{c}\text { Hemolysi } \\
\text { s }\end{array}$ & $\begin{array}{c}\text { Compleme } \\
\text { nt } \\
\text { activation }\end{array}$ & $\begin{array}{l}\text { Quic } \\
\mathrm{k}\end{array}$ & $\begin{array}{c}\mathrm{APT} \\
\mathrm{T}\end{array}$ \\
\hline Liposomes & 200 & $\begin{array}{c}105 \pm \\
5\end{array}$ & $\begin{array}{c}110 \pm \\
4\end{array}$ & $<0.06$ & $<2 \%$ & 380 & 100 & 100 \\
\hline $\begin{array}{l}\text { Liposomes- } \\
15 \mathrm{I}\end{array}$ & 200 & $\begin{array}{c}109 \pm \\
9\end{array}$ & $\begin{array}{c}105 \pm \\
3\end{array}$ & $<0.06$ & $<2 \%$ & 420 & 100 & 100 \\
\hline $\begin{array}{l}\text { Liposomes- } \\
\text { NB03B }\end{array}$ & 200 & $\begin{array}{c}107 \pm \\
2\end{array}$ & $\begin{array}{c}100 \pm \\
2\end{array}$ & $<0.06$ & $<2 \%$ & 700 & 100 & 100 \\
\hline $\begin{array}{c}\text { BH40- } \\
\text { polyester }\end{array}$ & 200 & $\begin{array}{c}101 \pm \\
3\end{array}$ & $95 \pm 4$ & $<0.06$ & $<2 \%$ & 150 & 100 & 30 \\
\hline $\begin{array}{c}\text { BH40- } \\
\text { polyester-15I }\end{array}$ & 200 & $\begin{array}{c}102 \pm \\
2\end{array}$ & $99 \pm 3$ & $<0.06$ & $<2 \%$ & 120 & 100 & 40 \\
\hline PAA & 200 & $95 \pm 5$ & $96 \pm 5$ & $\geq 1$ & $<2 \%$ & 136 & 98 & 100 \\
\hline PAA-15I & 80 & $\begin{array}{c}103 \pm \\
2\end{array}$ & $85 \pm 3$ & $\geq 1$ & $<2 \%$ & 189 & 97 & 100 \\
\hline Acrylamide & 200 & $\begin{array}{c}107 \pm \\
4\end{array}$ & $\begin{array}{c}105 \pm \\
4\end{array}$ & $<0.06$ & $<2 \%$ & 100 & 100 & 100 \\
\hline $\begin{array}{c}\text { Acrylamide- } \\
15 \mathrm{I}\end{array}$ & 200 & $\begin{array}{c}100 \pm \\
5\end{array}$ & $96 \pm 6$ & $<0.06$ & $<2 \%$ & 115 & 95 & 99 \\
\hline $\begin{array}{l}\text { Acrylamide- } \\
\text { NB03B }\end{array}$ & 200 & $98 \pm 3$ & $\begin{array}{c}104 \pm \\
4\end{array}$ & $<0.06$ & $<2 \%$ & 110 & 98 & 97 \\
\hline $\begin{array}{c}\text { poly(glycidol } \\
\text { ) }\end{array}$ & 250 & $98 \pm 4$ & $\begin{array}{c}100 \pm \\
1\end{array}$ & $<0.06$ & $<2 \%$ & 105 & 99 & 96 \\
\hline $\begin{array}{c}\text { poly(glycidol } \\
\text { )-15I }\end{array}$ & 250 & $90 \pm 7$ & $98 \pm 6$ & $<0.06$ & $<2 \%$ & 110 & 95 & 98 \\
\hline $\begin{array}{c}\text { poly(glycidol } \\
\text { )-NB03B }\end{array}$ & 250 & $98 \pm 3$ & $95 \pm 1$ & $<0.06$ & $<2 \%$ & 107 & 98 & 99 \\
\hline
\end{tabular}


Table 3: The concentrations shown are determined by the amount of reporter peptide coated on the nanoparticles. bThe viability was determined by MTT reduction of EAhy926 cells incubated with nanoparticles at the concentration shown in column 2. cEndotoxin levels were quantified using a commercial assay. Values of $<0.06$ are below the detection threshold. ${ }^{\mathrm{d} H e m o c o m p a t i b i l i t y}$ data include: hemolysis, complement activation, and hemostasis activation (Quick and TCA) after a 15 min incubation of the NPs at $37^{\circ} \mathrm{C}$ in whole blood. Hemolysis percent represent free plasma hemoglobin released as a result of contact with the test material divided by the total blood hemoglobin multiplied by 100 . Complement activation is expressed as a \% of C3a concentration, adopting normal blood incubated in the same conditions as $100 \%$. Ctrl + : blood incubated with Zymosan. Quick and TCA hemostasis assays are reported in \% of the clotting ability of the sample compared to the clotting ability of a standard human plasma normalized to 100 . 
Chapter 5

SUPPORTING INFORMATION

Supplementary figures and tables

\begin{tabular}{|c|c|}
\hline $\begin{array}{l}\text { Peptide } \\
\text { Code }\end{array}$ & Peptide Sequence \\
\hline $\begin{array}{l}\text { Peptide 5A } \\
(\mathrm{MW}= \\
1753)\end{array}$ & $\begin{array}{c}\mathrm{SH}_{1} \\
\text { BIO-napvsipqKGGC-CONH} \mathrm{C}_{2} \\
\text { CARB }\end{array}$ \\
\hline $\begin{array}{l}\text { Peptide } \\
15 \mathrm{I} \\
(\mathrm{MW}= \\
2646)\end{array}$ & $\begin{array}{c}\text { SH } \\
\mathrm{H}_{2} \mathrm{~N}-\mathrm{CGGKTFFYGGCRGKRNNFKTEEY-CONH} \\
2\end{array}$ \\
\hline $\begin{array}{l}\text { Peptide } \\
\text { REGNB03B } \\
\text { (MW=729 } \\
5 \text { ) }\end{array}$ & $\begin{array}{l}\text { 5-TAMRA- } \\
\text { HKKWQFNSPFVPRADEPARKGKVHIPFPLDNITCRVPMAREPTVIH } \\
\text { GKREVTL HLHPDH-COOH }\end{array}$ \\
\hline
\end{tabular}

Table S1: Schematic overview of the peptides used in this manuscript. BIO: biotin, CARB: Carboxyfluorescein. Lower case letter denote D-amino acids. 
In vitro and in vivo study of peptide functionalized nanoparticles
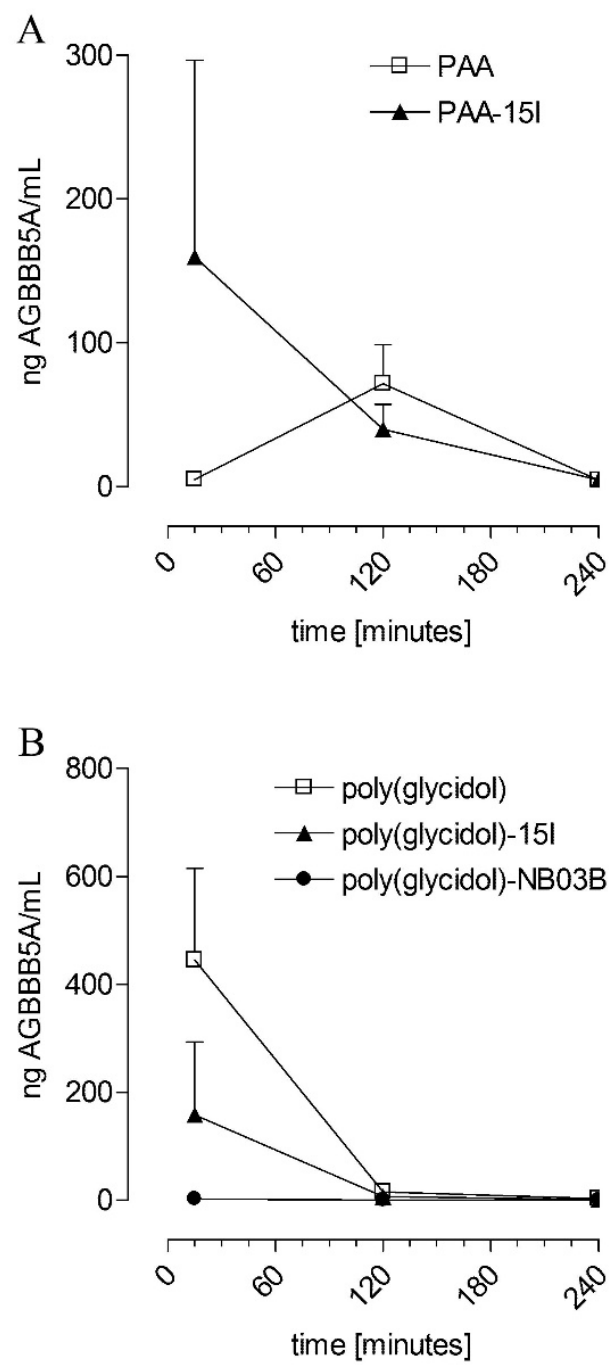

Figure S1: AGBBB5A plasma concentration after intravenous injection of NPs. 
Chapter 5
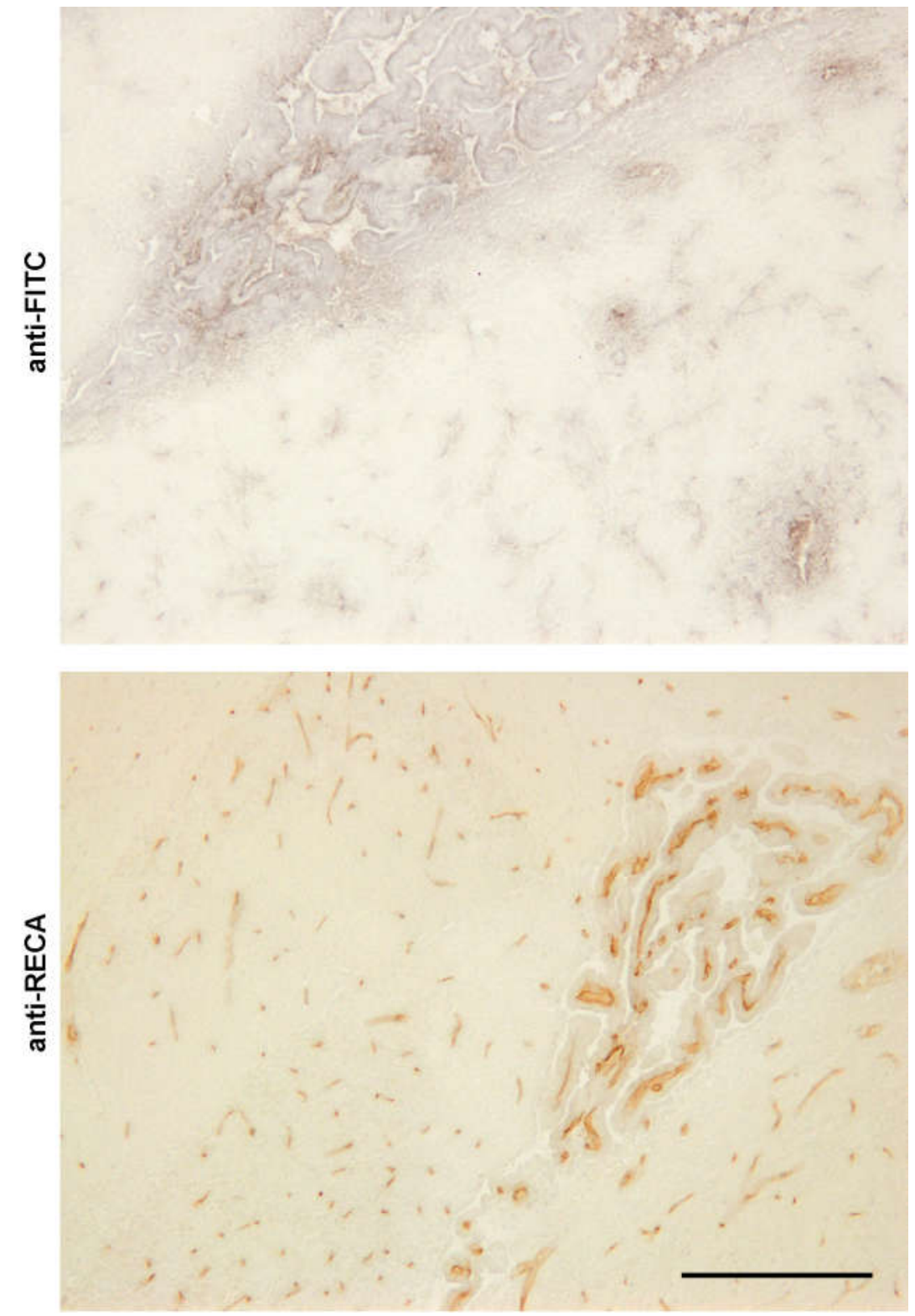

Figure S2: Anti-FITC (A) and anti-RECA (B) staining of perfused brain tissue from animals injected with liposomes containing peptides 5A and REGNB03B. 
In vitro and in vivo study of peptide functionalized nanoparticles

SUPPLEMENTARY METHODS

\section{RECA immunohistochemistry in rat brain tissue}

Rat brain cryosections of $10 \mu \mathrm{m}$ thickness were fixed using Somogyi fixative with glutaraldehyde for 10 minutes at $4{ }^{\circ} \mathrm{C}$, washed with Tris buffered saline (TBS), blocked with $0.3 \% \mathrm{H}_{2} \mathrm{O}_{2}$ in TBS for 30 minutes at room temperature and washed with TBS again. The section were incubated with mouse anti-RECA-1 (HyCult Biotechnology), diluted 1:100 in TBS overnight at $4{ }^{\circ} \mathrm{C}$, washed with TBS, incubated with biotinylated donkey anti-mouse IgG (1:400 in TBS) for 90 minutes at room temperature and washed with TBS. Subsequently, the sections were incubated with Vectastain $\mathrm{ABC}$ reagent for 90 minutes at room tempartature, washed with TBS, washed with Tris-Hcl and incubated with a 3,3'-diaminobenzidine/Tris- $\mathrm{HCl}$ solution containing $\mathrm{NiCl}$ and $\mathrm{H}_{2} \mathrm{O}_{2}$ for 10 minutes at room temperature. After dehydrating in an 50, 70, 96 and 100\% ethanol series, the sections were incubated in ultraclear and coverslipped with pertex.

\section{Nanoparticle synthesis}

\section{Liposome materials}

1,2-distearoyl-sn-glycero-3-phosphoethanolamine-N-

methoxy(polyethylene glycol)-2000] monosodium salt (DSPEPEG2000) and soy phosphatidylcholine, type SPC-3, were from Lipoid GmbH (Ludwigshafen, Germany). 1,2-Distearoyl-sn-glycero-3phosphoethanolamine-N-[maleimide(polyethylene glycol)-2000] (ammonium salt) (DSPE-PEG-MAL) was purchased from Avanti Polar Lipids, Inc. and stearoyl N-(3-Maleimide-1-oxopropyl)-L- $\alpha$ phosphatidylethanolamine (DSPE-MAL) was obtained from NOFCorporation, Japan. Sepharose CL4B, tris(2-carboxyethyl)phosphine 
Chapter 5

(TCEP) hydrochloride, cysteine and cholesterol were obtained from Sigma-Aldrich (St. Louis, MO).

Preparation of Liposomes

Initially, DSPE-MAL-peptide 5A was prepared which was subsequently anchored to the liposomal bilayer. Specifically, $14.9 \mu \mathrm{mol}$ of peptide $5 \mathrm{~A}$ reacted with $14.9 \mu \mathrm{mol}$ of DSPE-MAL in a 10/1 (v/v) mixture of 0.01 $\mathrm{mM}$ TCEP [56] in ethanol and glucose-phosphate buffer pH 7.4 (294.5 $\mathrm{mM}$ glucose and $10 \mathrm{mM}$ sodium phosphate $\mathrm{pH} 7.4$, osmolality $=310$ mOsmol $/ \mathrm{kg}$ ) at a final lipid concentration $\sim 3.3 \mathrm{mM}$. The reaction mixture was warmed up to $60{ }^{\circ} \mathrm{C}$ until a clear solution was obtained, and incubated for 4 hours under intermittent swirling. The reaction was halted and unreacted groups were shielded by adding $0.02 \mathrm{ml}$ of 100 $\mathrm{mM}$ cysteine in glucose-phosphate buffer $\mathrm{pH}$ 7.4.

Liposomes were prepared using the lipid film method by dissolving $316.8 \mu \mathrm{mol}$ SPC and $148.5 \mu \mathrm{mol}$ cholesterol in the DSPE-MAL-peptide $5 \mathrm{~A}$ to which $2 \mathrm{ml}$ of ethanol were added for rinsing purposes and the mixture was heated to $60^{\circ} \mathrm{C}$ under bath sonication until a clear yellow solution was obtained. A film was formed by rota-evaporation at $60^{\circ} \mathrm{C}$ under minimal pressure in a round bottom flask. The film was hydrated at a total lipid concentration of $100 \mathrm{mM}$ by the addition of glucosephosphate buffer pH 7.4 and bath sonication at $60{ }^{\circ} \mathrm{C}$, followed by 6 cycles of extrusion in a $10 \mathrm{ml}$ LIPEX $^{\mathrm{TM}}$ Thermobarrel Extruder (Northern Lipids, Burnaby, Canada) under Nitrogen 5.0 pressure, through polycarbonate membranes with a $80 \mathrm{~nm}$ pore size (Nuclepore TrackEtched Membranes (Whatman, Little Chalfont, United Kingdom). All steps were performed under aseptic conditions, and preparations containing dyes were shielded from light as far as feasible throughout the process.

The batch was divided into 3 equal parts. DSPE-PEG dissolved in glucose-phosphate buffer $\mathrm{pH} 7.4$ was post-inserted at $1 \mathrm{~mol} \%, 1 \mathrm{~mol} \%$ 
In vitro and in vivo study of peptide functionalized nanoparticles

and 2 mol\% levels (as percentage of total lipid) by their co-incubation for $1 \mathrm{~h}$ at $55^{\circ} \mathrm{C}$.

Preparation of Liposomes-NBO3B and Liposomes-15I

$4.95 \mu \mathrm{mol}$ DSPE-PEG-MAL was dissolved in DMSO (lipid concentration: $\sim 5 \mathrm{mM}$ ) and the solution was added to an equimolar amount of peptide REGNB03B. After addition of aqueous glucose-phosphate buffer pH 7.4 and TCEP to a final concentration of $0.015 \mathrm{mM}$ the mixture contained $\sim 24 \%$ aqueous buffer and was incubated overnight at ambient temperature. In order to halt the reaction and shield unconjugated maleimide groups $0.02 \mathrm{ml}$ of $100 \mathrm{mM}$ cysteine in glucose-phosphate buffer $\mathrm{pH} 7.4$ was added to the reaction mixture. The DSPE-PEG-MALREGNB03B conjugate was inserted by post-insertion [57] at a $1 \mathrm{~mol} \%$ level of the total lipid into Liposomes-NB03B by their co-incubation for $1 \mathrm{~h}$ at $55^{\circ} \mathrm{C}$.

Peptide 15I and DSPE-PEG-MAL were dissolved together in equimolar amounts in glucose-phosphate buffer pH 7.4 containing 0.02 mM TCEP at a lipid concentration of $\sim 15.6 \mathrm{mM}$ followed by 2 hours incubation at $60{ }^{\circ} \mathrm{C}$. The DSPE-PEG-MAL-peptide 15I conjugate was inserted at a 1 mol\% level of the total lipid into Liposomes-15I by their co-incubation for $1 \mathrm{~h}$ at $55^{\circ} \mathrm{C}$.

Replacement of the extra-liposomal medium and final composition

Finally, the extra-liposomal medium of the liposomes was eluted over a $20 \mathrm{ml}$ Sepharose CL4B column, which was pre-equilibrated with the glucose-phosphate buffer pH 7.4. Eluent was collected in 251 -ml fractions and liposome containing fractions (typically fraction 3-10) were identified on the basis of the fluorescence profile measured after appropriate dilutions for TAMRA label ( $\lambda_{\text {exc: }} 556 \mathrm{~nm}-\lambda_{\text {em }} 582 \mathrm{~nm}$ ) and/or FITC ( $\lambda_{\text {exc }}: 495 \mathrm{~nm}-\lambda_{\text {em }}: 520 \mathrm{~nm}$ ) using a Varian Cary Eclipse Fluorescence Spectrophotometer equipped with well plate reader (Varian Inc.). Clear liposome fraction peaks were obtained in the 


\section{Chapter 5}

elution profile, but no baseline separation was obtained probably due to adsorption phenomena to the sepharose column material. The final contents of labels in the liposomal fraction was corrected for the percentage of fluorescence observed in liposomal fractions which amounted to 57\% for peptide 5A-liposomes, 52\% (TAMRA) and 44\% (FITC) for peptide 5A-\&REGNB03B liposomes, and 60\% for peptide 5A and peptide 15I liposomes. The liposomal dispersions were filtered through $0.22 \mu \mathrm{m}$ Durapore PVDF sterile filters (Millipore). The filter remained red after filtration of Liposomes-NB03B, indicating some peptide had remained adsorbed to this filter material.

For PEGylated lipids the location of the hydrophilic part of the lipidPEG-peptide conjugates at the liposomal membrane this is indicated, e.g., for post-inserted lipid added to the outside of the preformed liposomes. Additional cysteine moieties conjugated to all maleide groups may be present in all batches (see preparation procedure). For all batches the extra-liposomal medium was $294.5 \mathrm{mM}$ glucose and 10 $\mathrm{mM}$ sodium phosphate in water $\mathrm{pH} 7.4$, osmolality $=310 \mathrm{mOsmol} / \mathrm{kg}$. The conjugation of the peptide $5 \mathrm{~A}$ to a non-PEGylated lipid was performed in order to avoid aggregation phenomena that occurred when both this peptide and REGNB03B were coupled to the distal end of the DSPE-PEG chains (data not shown)

Size measurements

Lipsomal sizes were measured using a Beckman Coulter N4 Plus particle sizer, equipped with a $633 \mathrm{~nm} \mathrm{HeNe}$ excitation source instrument after dilution of the samples in water. Size stability when stored at $2-8{ }^{\circ} \mathrm{C}$ was demonstrated for development batches of these peptide liposomes for 4 months (data not shown). The liposome size upon production and stress testing ( 3 times freezing $\left(-20{ }^{\circ} \mathrm{C}\right.$ ) and thawing (at ambient temperature) is presented in the below table. 
In vitro and in vivo study of peptide functionalized nanoparticles

Table 1: Unimodal size characteristics of liposomes after extrusion, final sterile filtration of the peptide-conjugated PEG- liposomes and after 3 time freezing thawing (3xFT).

\begin{tabular}{|l|l|l|l|}
\hline Description & $\begin{array}{l}\text { Unimodal } \\
\text { mean } \\
(\mathrm{nm})\end{array}$ & $\begin{array}{l}\text { Unimodal } \\
\text { SD (nm) }\end{array}$ & PDI \\
\hline $\begin{array}{l}\text { Liposomes } \\
\text { (batch 1 - after 5x extrusion) }\end{array}$ & 88.2 & 25.7 & 0.254 \\
\hline $\begin{array}{l}\text { Liposomes } \\
\text { (batch 1 - after filtration) }\end{array}$ & 97.9 & 32.9 & 0.201 \\
\hline $\begin{array}{l}\text { Liposomes } \\
\text { (batch 1 - 3x FT) }\end{array}$ & 100.2 & 27.9 & 0.062 \\
\hline $\begin{array}{l}\text { Liposomes } \\
\text { (batch 2 - after filtration) }\end{array}$ & 110.6 & 36.8 & 0.213 \\
\hline $\begin{array}{l}\text { Liposomes } \\
\text { (batch 2 - 3x FT) }\end{array}$ & 110.6 & 38.6 & 0.238 \\
\hline $\begin{array}{l}\text { Liposomes } \\
\text { (batch 3 - after filtration) }\end{array}$ & 78.9 & 25.9 & 0.252 \\
\hline $\begin{array}{l}\text { Liposomes } \\
\text { (batch 3 - 3x FT) }\end{array}$ & 87.2 & 25.9 & 0.079 \\
\hline
\end{tabular}

From the data in the above table we can conclude the liposomes possess size characteristics that are considered appropriate for enhanced circulation times (smaller than $150 \mathrm{~nm}$ ). All batches were stable upon freezing thawing and, therefore, in principle suitable for storage in the frozen state, a property that can be ascribed to the intra- and extraliposomal presence of the cryoprotectant glucose. 
Chapter 5

Synthesis of carboxylated hyperbranched polyester with 32 carboxylate groups (BH40-polyester)

The polyester was further fractionated by precipitation as described in the literature [58] in order to remove low molecular weight fractions. Using this procedure, the polydispersity index of the fractionated $\mathrm{BH} 40$ was found to be considerably lower as determined by SEC $\left(\mathrm{M}_{\mathrm{w}} / \mathrm{M}_{\mathrm{n}}=\right.$ 1.21) [59]. $N$-Hydroxybenzotriazole (HOBt) and 2-(1 H-benzotriazole-1yl)-1,1,3,3-tetramethyluronium (HBTU) were purchased from Anaspec. Sephadex-25, $\quad N, N$-Disopropylethylamine (DIEA), $\quad N$-Boc-1,3diaminopropane, Rhodamine-isothiocyanate and succinic anhydride were purchased from Sigma-Aldrich. Fluorescein isothiocyanate (FITC) was purchased from Invitrogen (Carlsbad, CA).

BH40-polyester characterization

${ }^{1} \mathrm{H}$ and ${ }^{13} \mathrm{C}$ NMR spectra were recorded in $\mathrm{D}_{2} \mathrm{O}$ by a BrukerAvance DRX spectrometer operating at 500 and $125.1 \mathrm{MHz}$, respectively.

${ }^{1} \mathrm{H}$ NMR (500 MHz, $\mathrm{D}_{2} \mathrm{O}$ ): $\delta=1.00-1.22$ (m, $\underline{\mathrm{CH}}_{3}, \mathrm{C}_{2} \mathrm{CH}_{3}$ ), 2.30-2.45 (t, $\mathrm{C}_{2} \mathrm{CH}_{2} \mathrm{COO}^{-}$), 2.45-2.60 (t, $\left.\mathrm{CH}_{2} \mathrm{C}_{2} \mathrm{COO}^{-}\right), 3.50-3.70\left(\mathrm{~m}, \mathrm{OCH}_{2}\right), 4.01-$ 4.45 (m, polymer scaffold $\mathrm{C}_{2} \mathrm{OCO}$ ).

${ }^{13} \mathrm{C}$ NMR (125.1 MHz, $\left.{ }_{2} \mathrm{O}\right): \delta=17.8\left(\mathrm{CH}_{3}\right), 30.2\left(\mathrm{CH}_{2} \mathrm{CH}_{2} \mathrm{COO}^{-}\right), 31.9$ $\left(\mathrm{CH}_{2} \mathrm{CH}_{2} \mathrm{COO}-\right), 46.3\left(\mathrm{CH}_{3}(\mathrm{OH}) \mathrm{CCH}_{2}\right), 63.5-67.5\left(\mathrm{CH}_{2} \mathrm{OH}, \mathrm{CCH}_{2} \mathrm{O}\right), 173-$ 176 (ester CO), 180.5 (COO-).

Preparation of BH40-polyester-FITC and BH40-polyester-Rh

- Synthesis of FITC- $\left(\mathrm{CH}_{2}\right)_{3}-\mathrm{NH}_{2}$ and $\mathrm{Rh}-\left(\mathrm{CH}_{2}\right)_{3}-\mathrm{NH}_{2}$

$N$-Boc-1,3-diaminopropane $(0.3 \mathrm{mmol})$ was dissolved in about $10 \mathrm{ml}$ of dry DMF in the presence of triethylamine $(0.6 \mathrm{mmol})$. To this solution, FITC or Rhodamine-isothiocyanate $(0.3 \mathrm{mmol})$, dissolved in the same solvent, was added. The mixture was stirred overnight at room temperature, before subsequent solvent removal under vacuum. The product was recovered after precipitation under diethyl ether. The 
In vitro and in vivo study of peptide functionalized nanoparticles

material obtained was further purified by flash chromatography employing as eluting solvent a mixture of water/methanol (1:1). The so-obtained product was deprotected using a mixture of trifluoroacetic acid/DMF (1:3). The final compound was obtained through precipitation by diethyl ether and its structure was confirmed by ${ }^{1} \mathrm{H}$ NMR spectroscopy. The ratio between the FITC or Rhodamine moiety and the free amino group was $1 / 1$, as established from the integration of the peaks at $2.80 \mathrm{ppm}$ ( $\alpha$-methylene group relative to amino group) and at $6.55 \mathrm{ppm}$ attributed to the ortho-aromatic protons relative to the hydroxyl groups of FITC or at $0.85 \mathrm{ppm}$ attributed to protons of $\mathrm{CH}_{3}$ of Rhodamine moiety.

- Synthesis of BH4O-polyester-FITC and BH4O-polyester-Rh.

To $0.014 \mathrm{mmol}$ BH40-polyester, dissolved in $15 \mathrm{ml}$ of dry DMF, 0.03 mmol of FITC- $\left(\mathrm{CH}_{2}\right)_{3}-\mathrm{NH}_{2}$ or Rh- $\left(\mathrm{CH}_{2}\right)_{3}-\mathrm{NH}_{2}$, dissolved in $10 \mathrm{ml}$ of anhydrous DMF, were added. Subsequently, equimolar quantities of HBTU (0.03 mmol), HOBt and $N, N$-diisopropylethylamine dissolved in 1 $\mathrm{ml}$ DMF, were added. The mixture was allowed to react overnight, under argon atmosphere, at room temperature. The solvent was reduced under vacuum and the product was precipitated with diethyl ether. The so-obtained materials were dissolved in $2 \mathrm{ml}$ of $100 \mathrm{mM}$ $\mathrm{NaHCO}_{3}$. The mixture was loaded to a Sephadex G-25 column $(40 \mathrm{~cm} \mathrm{x}$ $2.5 \mathrm{~cm}$ ) using a solution of $100 \mathrm{mM} \mathrm{NaHCO} 3$ as eluent. Following lyophilization and dialysis against water, the labeled products were obtained as colored solids. The introduction of FITC- or Rhodaminemoiety was established by ${ }^{1} \mathrm{H}$ NMR spectroscopy. Specifically, two fluorescein moieties were attached to one molecule of modified dendritic polymer as established by integrating the peaks at $\sim 2.40 \mathrm{ppm}$ and $\sim 2.50$, attributed to the protons of the $\alpha-$ and $\beta-\mathrm{CH}_{2}$ relative to the carboxylic moieties, respectively, and the peak at $6.55 \mathrm{ppm}$ attributed to the ortho-aromatic protons relative to the hydroxyl groups of FITC. 
Chapter 5

Additionally, two Rhodamine moieties were, on average, attached at the dendritic polymers as determined from the integral ratio of the signal at $0.85 \mathrm{ppm}\left(\mathrm{CH}_{3}\right.$ of Rhodamine moiety) relative to the signal at 1.00-1.22 ppm attributed to the protons of $\mathrm{CH}_{2}$ and $\mathrm{CH}_{3}$ of the polymer scaffold.

\section{Poly(amidoamine) (PAA) nanoparticles}

\section{Materials}

All monomers, 4-amino-1-butanol (ABOL, Sigma-Aldrich), alpha-aminoomega-carboxy-poly(ethylene glycol) hydrochloride (cPEG-NH $\mathrm{N}_{2} \quad \mathrm{M}_{\mathrm{w}}$ $3000 \mathrm{~g} / \mathrm{mol}$ ) (cPEG-NH , Iris Biotech GmbH, Marktredwitz, Germany), 1,4-bis(acryloyl)piperazine (BAP, Sigma-Aldrich), and $N, N^{\prime}$ cystaminebisacrylamide (CBA, Polysciences) were purchased in the highest purity and used without further purification. $N$-(3Dimethylaminopropyl)-N'-ethylcarbodiimide hydrochloride (EDC, Fluka), $N$-Hydroxysulfosuccinimide sodium salt (Sulfo-NHS, Aldrich), phosphate buffered saline (PBS, 0.01 M, pH 7.4, B. Braun, USA), ethanol (EtOH, Emsure), and methanol ( $\mathrm{MeOH}$, Biosolve, Dieuze, France) were used as received. Deionized water (DI water) was obtained from a MilliQ-water purification system (Millipore, Billerica, MA).

Synthesis

Polymerization was carried out in the dark at $45^{\circ} \mathrm{C}$ under nitrogen atmosphere and was allowed to proceed for 6 days yielding to a viscous solution. In a final stage, $10 \mathrm{~mol} \%$ excess ABOL $(0.09 \mathrm{~g}, 1 \mathrm{mmol})$ was added to the reaction mixture in order to consume any unreacted acrylamide groups after polymerization. Stirring was continued for two days at $45{ }^{\circ} \mathrm{C}$. Subsequently, the resulting solution was diluted with $30 \mathrm{ml}$ DI water, acidified with $4 \mathrm{M} \mathrm{HCl}$ aqueous solution to $\mathrm{pH} \sim 5$, and then purified and isolated by ultrafiltration ( $5 \mathrm{~kg} / \mathrm{mol}$ cut-off) with filtrated acidic DI water ( $\mathrm{pH} \sim 5$ ), followed by freeze-drying. 
In vitro and in vivo study of peptide functionalized nanoparticles

cPEG-p(CBA-ABOL)/peptide 5A nanoparticle solutions (PAA NPs) were prepared by adding a PBS solution (10 mM, pH 7.4) of cPEG-p(CBAABOL) $(800 \mu \mathrm{l}, 6 \mathrm{mg} / \mathrm{ml})$ to a PBS/EtOH solution $(3 / 2 \mathrm{v} / \mathrm{v})$ of reporter peptide $5 \mathrm{~A}(200 \mu \mathrm{l}, 2 \mathrm{mg} / \mathrm{ml})$, corresponding to a polymer/reporter peptide weight ratio $12 / 1$, followed by vortexing for 5 seconds and incubating at room temperature for 30 minutes.

Preparation of PAA-15I NPS

For the synthesis of the polymer, a similar procedure was run for the synthesis of $\mathrm{p}\left(\mathrm{BAP}-\mathrm{ABOL} / \mathrm{CPEG}-\mathrm{NH}_{2}\right)$, in this case using only DI water only as solvent for the polymerization reaction. The terminal carboxylic acid group present in the side chains of the polymer $p(B A P-$ ABOL/cPEG-NH 2 ) (200 mg) was activated using EDC (66 mg) and sulfoNHS (67 mg) in HEPES buffer (10 mM, pH 8). Then, the targeting peptide 15I (15 mg) dissolved in a mixture of HEPES buffer $(10 \mathrm{mM}, \mathrm{pH}$ 8) and $\mathrm{EtOH}(3 / 2 \mathrm{v} / \mathrm{v})$ was added to the mixture, and the reaction was run overnight at room temperature, using 10 equivalents of EDC and NHS over carboxylic acid group, and 10\% excess polymer over peptide. The conjugated polymer was collected as powder after ultrafiltration ( 5 $\mathrm{kg} / \mathrm{mol}$ cut-off) and freeze-drying.

Synthesis and characterization of PAAs

A series of functionalized PAAs were synthesized by Michael-type polyaddition of $\mathrm{ABOL}$ and $\mathrm{CPEG}-\mathrm{NH}_{2}$ to $\mathrm{CBA}$ and $\mathrm{BAP}$, and were coded in terms of the used bisacrylamide and the primary amine monomers: $\mathrm{p}\left(\mathrm{CBA}-\mathrm{ABOL} / \mathrm{cPEG}-\mathrm{NH}_{2}\right)$ and $\mathrm{p}\left(\mathrm{BAP}-\mathrm{ABOL} / \mathrm{CPEG}-\mathrm{NH}_{2}\right)$. The butylene side chains terminated by a hydroxyl group originating from the $\mathrm{ABOL}$ units have been shown that this hydroxybutyl side group favorably contributes to the efficiency in DNA transfection, presumably by increasing the endosomolytic properties. $\mathrm{CPEG}-\mathrm{NH}_{2}$ side chains are included to induce a stealth effect. 


\section{Chapter 5}

The polymers were obtained in ca. 35\% yield as their $\mathrm{HCl}$-salt after ultrafiltration and lyophilization. The ${ }^{1} \mathrm{H}$ NMR spectra of the polymers were in full accordance with the expected structure. The absence of any proton signals between 5 and 7 ppm shows that the polymer did not contain any residual acrylamide end groups (data not shown). The fraction of cPEG chains incorportated in the cPEG-p(BAP-ABOL) and cPEG-p(CBA-ABOL) polymers was determined by comparing the integrals of the ${ }^{1} \mathrm{H}$ NMR signals attributed to the methylene protons in the PEG and the methylene protons of the PAA polymer, and was in accordance with the feed ratio aiming for a SS-PAA with 10\% PEG side chains (data not shown).

Peptide condensation in nanoparticles: physical characterization and loading efficiency

At physiological $\mathrm{pH}$ ( $\mathrm{pH} 7.4$ ), the PAAs are present as polycations due to partial protonation of the tertiary nitrogens in the main chain of the polymer. Charge interaction with the reporter peptide $5 \mathrm{~A}$ can be expected since this peptide has a net negative charge under these conditions. The cPEG-p(CBA-ABOL) was used to form nanosystems including the reporter peptide $5 \mathrm{~A}$ and the targeting peptide $15 \mathrm{I}$.

Particle size and zeta-potential measurements

Particle size and zeta potential measurements of the nanocomplexes were determined by dynamic light scattering (DLS) at $25^{\circ} \mathrm{C}$ with a Zetasizer Nano ZS (Malvern Instruments, Malvern, UK) using a wavelength of $532 \mathrm{~nm}$. The values of both size and zeta potential were recorded as the mean of three measurements.

\section{Acrylamide NPs}

\section{Materials}

N-isopropylacrylamide (NIPAAm, 97\%), N,N-dimethylacrylamide (DMAAm, 99\%), acrylic acid (AAc, 99\%), methylenebisacrylamide 
(MBAAm, 99\%), sodium dodecyl sulphate (SDS, ReagentPlus $\geq 98.5 \%$ ) and ammonium persulphate (98+\%, A.C.S reagent) were all purchased from Sigma-Aldrich and used without further purification unless otherwise stated. Pentafluorophenyl methacrylate (PFM) was purchased from Apollo Scientific (Bredbury, United Kingdom), cystamine hydrochloride (purum $\geq 97.0 \%$ ) and Alexa Fluor® 660 carboxylic acid succinimidyl ester were obtained from Invitrogen.

Acrylamide NPs were synthesized by a free-radical polymerization method in a microemulsion system, where the monomers used were $\mathrm{N}$ isopropylacrylamide, $N, N^{\prime}$-dimethylacrylamide and acrylic acid, the cross-linker was methylenebisacrylamide, the surfactant, sodium dodecyl sulphate, and the initiator, ammonium persulphate.

For the synthesis of the NPs, a three-neck bottom-flask was charged with $\quad N$-isopropylacrylamide $(0.35 \mathrm{~g}, 3.09 \mathrm{mmol}), \quad N, N^{\prime}$ dimethylacrylamide $(0.04 \mathrm{~g}, 4.5 \mathrm{mmol})$, acrylic acid $(0.05 \mathrm{~g}, 3.6 \mathrm{mmol})$, methylenebisacrylamide $(0.01 \mathrm{~g}, 1.54 \mathrm{mmol})$, sodium dodecyl sulphate ( $0.02 \mathrm{~g}, 5.76 \mathrm{mmol}$ ) and $117 \mathrm{ml}$ of DI water. The reaction mixture was heated at $70^{\circ} \mathrm{C}$ in a hot plate under reflux conditions, nitrogen atmosphere and stirring for four hours. After a few minutes, when the reaction mixture was homogeneous and started to reflux, ammonium persulphate $(0.036 \mathrm{~g}, 8.21 \mathrm{~mol})$ was added. After one hour of reaction, pentafluorophenyl methacrylate $(3.8 \mathrm{mmol})$ was added and the reaction mixture was further refluxed for 30 minutes. The obtained NPs were further modified by the addition of the desired coating molecule. For thiolating, cystamine hydrochloride $(0.015 \mathrm{~g}, 3.8 \mathrm{mmol})$ was added, for labeling, Alexa Fluor 660 carboxylic acid succinimidyl ester $(10 \mu \mathrm{g}, 9$ mmol). The peptide decoration was achieved adding peptide 5A (1.055 $\mathrm{mg}, 0.39 \mathrm{~mol})$. Nanoparticle solutions were dialyzed with dialysis membranes (nominal MWCO 6,000-8,000). 
Chapter 5

\section{Poly(glycidol) nanogels}

\section{Materials}

Thiol functionalized poly(glycidol) (SH-PG) $(\mathrm{Mn}=6100 \mathrm{~g} / \mathrm{mol}, \mathrm{Mw} / \mathrm{Mn}$ =1.17, 15 thiol groups), n-hexane ( $\geq 95 \%$, Sigma-Aldrich), THF (99\%, VWR, Radnor, PA), hydrogen peroxide (30\%, VWR), Span 80 (SigmaAldrich), and Tween 80 (Sigma-Aldrich), 2-hydroxy ethyl acrylate (96\%, Sigma), were used as received. Phosphate buffered saline (PBS) from Sigma-Aldrich was dissolved in DI water to $0.04 \mathrm{M}$ concentration (pH 7.4). In addition, PMMA disposable cuvettes $(12.5 \times 12.5 \times 45 \mathrm{~mm})$ (Plastibrand, Essex, CT), $5 \mu \mathrm{m}$ Minisart syringe filters (Sartorius stedim, Göttingen, Germany) and Dialysis membrane MWCO $=3500$ Dalton (Spectrum Laboratories, Rancho Dominguez, CA) were used. 
In vitro and in vivo study of peptide functionalized nanoparticles 
Chapter 5 


\section{GENERAL DISCUSSION}

Lipid metabolism, and specifically ceramide metabolism, is an often overlooked yet important aspect of biology. In this thesis, we show that CERT/GPBP has previously unknown immune system functions involving SAP and complement activation. In addition, we investigated novel nanoparticle based methods for drug delivery to the brain, resulting in the establishment of a reliable ELISA based detection method for nanoparticles and an extensive characterization of five different nanoparticle formulations in vitro and in vivo.

In Chapter 1 we demonstrate that CERT/GPBP specifically binds serum amyloid $\mathrm{P}$ (SAP) in its physiological conformations, pentamers and decamers. The START domain in CERT/GPBP is important for this interaction. SAP and CERT/GPBP form complexes in blood and partly colocalize in amyloid plaques from Alzheimer disease patients. These data suggest the existence of complexes of SAP and GPBP under physiological and pathological conditions. These complexes are important for understanding basement membrane, blood physiology, and plaque formation in Alzheimer disease.

Expanding on the hypothesis that CERT/GPBP is involved in innate immunity, we report a novel function of CERT/GPBP in complement activation in Chapter 2. Both CERT isoforms, when immobilized, were found to bind the globular head region of $\mathrm{C} 1 \mathrm{q}$ and to initiate the classical complement pathway, leading to activation of C4 and C3, as well as generation of the membrane attack complex C5b-9. In addition, we show that $\mathrm{C} 1 \mathrm{q}$ binds to endogenous GPBP on the surface of apoptotic cells, suggesting that CERT/GPBP could be a receptor for C1q on apoptotic cells. These results demonstrate the role of CERTs in innate immunity, especially in the clearance of apoptotic cells. Identifying the precise binding site of C1q on CERT/GPBP is essential 
for potentially modulating this interaction. The most likely candidate binding site is the Glu²97-Xxx-Lys ${ }^{299}$-Xxx-Lys ${ }^{301}$ motif, which has been described as a C1q binding site in IgG.

In Chapter 3 we used design-based stereology to quantify the number of CERT/GPBP immunoreactive cells in the striatum of 6hydroxydopamine (6-OHDA) lesioned rats as an animal model of Parkinson's disease (PD). In addition, gray value measurement was performed to quantify CERT/GPBP immunoreactivity-levels within individual cells. No difference in the striatal expression levels of CERT/GPBP proteins was found between diseased and control animals, suggesting that the expression pattern of CERT/GPBP in the striatum is not affected in the 6-OHDA rat model of PD. The unchanged expression of CERT/GPBP might be due to the nature of the 6-OHDA model, which acutely damages dopaminergic cells without the protein aggregation and associated inflammation seen in PD.

Chapter 4 describes an enzyme linked immunosorbent assay (ELISA) for the detection of peptides functionalized with biotin and fluorescein groups. We were able to accurately measure peptides bound to pentafluorophenyl methacrylate nanoparticles in blood plasma of rats after injection, with a detection limit of $1 \mathrm{ng} / \mathrm{mL}$. This method can be extended to detect nanoparticles with different chemical compositions.

In Chapter 5 we evaluated the efficacy of delivery and safety of liposome, polyester, poly(glycidol) and acrylamide based nanoparticles functionalized with peptides targeting brain endothelial receptors, in vitro and in vivo. We detected labelled nanoparticles in brain homogenate, liver homogenate, in cerebrospinal fluid and blood plasma after injection. None of the combinations of nanoparticles and targeting peptides tested showed significant uptake in the brain. Based on both the in vitro and in vivo results, we concluded that both the physical characteristics of the nanoparticles and the targeting peptides used 
need to allow for preferential binding to brain endothelial cells compared to endothelial cells of other tissues for efficient blood-brain barrier transport.

One of the important and as of yet unresolved questions regarding CERT/GPBP is how to reconcile the apparently widely divergent functions of ceramide transport between the ER and Golgi on the one hand, and innate immune system interactions via SAP and C1q on the other hand. Part of the answer might lie in the differences in localization of the various CERT isoforms. Whereas the 598 amino acid CERT is located intracellularly, the longer 624 amino acid CERT/GPBP is found as a soluble extracellular protein. In addition, a membrane bound isoform that is the result of non-canonical translation has been identified. Whether these extracellular isoforms interact with ceramides, and the functional implications of such interactions remain to be elucidated.

However, it is becoming increasingly clear that ceramides are intricately linked to inflammatory processes. For example, specific ceramides have been shown to regulate the activation and migration of neutrophils in experimental autoimmune encephalitis (Eberle, Ebel et al. 2015). Ceramides are also known to activate inflammasomes (Vandanmagsar, Youm et al. 2011, Grassme, Carpinteiro et al. 2014), innate immune system sensors that induce inflammation in response to microbes or protein aggregates such as amyloid-beta (Guo, Callaway et al. 2015).

Therefore, it is possible that CERT/GPBP regulates inflammatory processes in response to ceramide. The recent development of the CERT inhibitor HPA-12 (Yasuda, Kitagawa et al. 2001, Duris, Wiesenganger et al. 2011) offers exciting novel ways to study the function of this protein. HPA-12 blocks the ceramide transport function of CERT by occupying the hydrophobic ceramide binding pocket in the 
CERT protein. It would be interesting to investigate whether ceramide binding inhibition of CERT by HPA-12 affects the interaction with SAP and C1q, or the presence of CERT on apoptotic cells. In addition, discovering novel proteins that interact with CERT/GPBP, for example by means of a yeast two-hybrid system, would help clarifying the role of ceramide transporters in inflammation and sphingolipid metabolism. Another important aspect of ceramides is the poorly understood functional implications of differences in acyl chain length. In this respect it is important to use methodology that is able to distinguish between different ceramide species. One technique useful for studying ceramides is mass spectrometry imaging. Recent technical advancements have dramatically increased the spatial resolution, allowing for quantification of ceramides in tissue at a cellular level. It would be relatively straightforward to construct a three dimensional map of the brain, overlaying different ceramide species, amyloid-beta, CERT/GPBP and inflammation markers. 


\section{REFERENCES}

Duris, A., T. Wiesenganger, D. Moravcikova, P. Baran, J. Kozisek, A. Daich and D. Berkes (2011). "Expedient and practical synthesis of CERT-dependent ceramide trafficking inhibitor HPA-12 and its analogues." Org Lett 13(7): 1642-1645.

Eberle, M., P. Ebel, C. A. Mayer, J. Barthelmes, N. Tafferner, N. Ferreiros, T. Ulshofer, M. Henke, C. Foerch, A. M. de Bazo, S. Grosch, G. Geisslinger, K. Willecke and S. Schiffmann (2015). "Exacerbation of experimental autoimmune encephalomyelitis in ceramide synthase 6 knockout mice is associated with enhanced activation/migration of neutrophils." Immunol Cell Biol.

Grassme, H., A. Carpinteiro, M. J. Edwards, E. Gulbins and K. A. Becker (2014). "Regulation of the inflammasome by ceramide in cystic fibrosis lungs." Cell Physiol Biochem 34(1): 45-55.

Guo, H., J. B. Callaway and J. P. Ting (2015). "Inflammasomes: mechanism of action, role in disease, and therapeutics." Nat Med 21(7): 677-687.

Vandanmagsar, B., Y. H. Youm, A. Ravussin, J. E. Galgani, K. Stadler, R. L. Mynatt, E. Ravussin, J. M. Stephens and V. D. Dixit (2011). "The NLRP3 inflammasome instigates obesity-induced inflammation and insulin resistance." Nat Med 17(2): 179-188.

Yasuda, S., H. Kitagawa, M. Ueno, H. Ishitani, M. Fukasawa, M. Nishijima, S. Kobayashi and K. Hanada (2001). "A novel inhibitor of ceramide trafficking from the endoplasmic reticulum to the site of sphingomyelin synthesis." LBiol Chem 276(47): 43994-44002. 
General discussion 


\section{VALORIZATION APPENDIX}

Dementia imposes an enormous social and economic burden on society. Over 46 million people suffer from dementia today, and this is expected to increase to 131 million by 2050 . The worldwide cost of dementia is estimated to be US $\$ 818$, and projected to be a trillion dollar by 2018 (1). These statistics make finding new cures for dementia a matter of urgency and importance to the wellbeing of today's ageing societies and countries healthcare budgets. Unfortunately, although progress has been made towards effective therapeutics, no cure for dementia is currently available. One of the reasons progress towards a cure has been slow is a lack of understanding of the fundamental disease processes.

In this thesis, I describe our research on a novel complement system activator, the ceramide transfer protein. This is the first time it has been shown that CERT is able to activate complement. Our findings with regards to CERT represent an important step in understanding the mechanisms of dementia and other diseases, in which complement activation via $\mathrm{C} 1 \mathrm{q}$ plays an important role (such as systemic lupus erythematosus to cancer, kidney disease, organ transplantation, pregnancy disorders, multiple sclerosis and severe trauma (2-6). Modulating complement activation has potential therapeutic applications for these conditions.

The success of potential therapies for dementia depends on their specificity as well as efficiency. In the second part of this thesis, I provide an account of our research on targeting nanoparticles to the brain for drug delivery, where we attempted to identify nanoparticles with the highest specificity. We characterized a range of nanoparticle formulations to have varying specificity towards the brain, showing that this is a promising drug delivery method, albeit in need of further 
development. As part of this research we also carried out toxicity tests. This type of research in vitro and in animals is an important first step to select therapies safe for human use. In spite of not providing clear-cut conclusions, this study is an important increment to the field, on which future research can be built.

The work described in this thesis is a combination of basic research (Chapters 1 to 3 on the role of CERT in complement activation and neurodegenerative disease) as well as research that is more directly applicable (Chapters 4 and 5 on nanoparticle targeting). While governments and other policy makers, especially in the Netherlands, understand the value of applicable biomedical research, they are less and less willing to fund basic science. Budgets are increasingly focused on applied research that has immediate, direct and tangible benefits to society. This is, in my opinion, a worrying trend since basic science is essential to long term technological advancement, prosperity and improvements to healthcare, even if it provides few short term benefits to society. This is illustrated by the way certain important discoveries in biomedical science were made, such as the green fluorescent protein and Taq DNA polymerase. The first, now ubiquitous in practically every laboratory, was discovered by researching how jellyfish glow (7). Taq DNA polymerase, essential for PCR, was discovered thermophilic bacteria, in the context of a study on the thermal control of photosynthesis (8).

Taken together, I am satisfied that the work presented here constitutes contributions to the fields of dementia research and immunology that will bring us a step closer to combating this disease. At the same time I do hope that society will arrive at the conclusion that basic research, however abstract and obscure, is an indispensable element of science. 


\section{REFERENCES}

1. Prince MJ. World Alzheimer Report 2015: The Global Impact of Dementia: an Analysis of Prevalence, Incidence, Cost and Trends. 2015. 2. Montero RM, Sacks SH, Smith RA. Complement-here, there and everywhere, but what about the transplanted organ? Semin Immunol. 2016 Jun;28(3):250-9.

3. Ricklin D, Reis ES, Lambris JD. Complement in disease: a defence system turning offensive. Nat Rev Nephrol. 2016 May 23;12(7):383401.

4. Kouser L, Madhukaran SP, Shastri A, Saraon A, Ferluga J, AlMozaini M, et al. Emerging and Novel Functions of Complement Protein C1q. Front Immunol [Internet]. 2015 Jun 29 [cited 2016 Sep 13];6. Available from: http://journal.frontiersin.org/Article/10.3389/fimmu.2015.00317/abs tract

5. Huber-Lang M, Gebhard F, Schmidt CQ, Palmer A, Denk S, Wiegner R. Complement therapeutic strategies in trauma, hemorrhagic shock and systemic inflammation - closing Pandora's box? Semin Immunol. 2016 Jun;28(3):278-84.

6. Morgan BP, Harris CL. Complement, a target for therapy in inflammatory and degenerative diseases. Nat Rev Drug Discov. 2015 Oct 23;14(12):857-77.

7. Shimomura 0 . The discovery of aequorin and green fluorescent protein. J Microsc. 2005 Jan;217(1):3-15.

8. Brock TD. The value of basic research: discovery of Thermus aquaticus and other extreme thermophiles. Genetics. 1997;146(4):1207-1210. 
Valorization appendix 


\section{SUMMARY}

Alzheimer's disease (AD) is an enormous and increasing burden on society in many developed countries. Despite intense research efforts, there is still no effective cure. This indicates that we should direct more of our research effort to understanding the basic pathological processes of this disease and methods of drug delivery. It has recently emerged that sphinglolipids, and in particular ceramides, are involved in the pathological processes of $\mathrm{AD}$, but the exact mechanisms are currently unknown. The research described in this thesis is focused on two topics: The first topic is ceramide transporters and inflammation in neurodegenerative disease (Chapter 1-3), the second is nanoparticles for delivery of drugs to the brain (Chapters 4 and 5).

In Chapter 1 we investigated the interaction between ceramide transporters (CERT) and Serum Amyloid P component (SAP). SAP is a non-fibrillar glycoprotein belonging to the pentraxin family of the innate immune system. We demonstrated that CERT specifically binds serum amyloid P (SAP) in its physiological conformations, pentamers and decamers. The START domain in CERT is important for this interaction. SAP and CERT form complexes in blood and partly colocalize in amyloid plaques from AD patients.

Additionally, we report a novel function of CERT/GPBP in complement activation in Chapter 2. Both CERT isoforms were found to bind the globularhead region of $\mathrm{C} 1 \mathrm{q}$ and to initiate the classical complement pathway. In addition, C1q was shown to bind to endogenous CERT on the surface of apoptotic cells. These results demonstrate the involvement of CERTs in innate immunity, especially in the clearance of apoptotic cells.

In Chapter 3 we used design-based stereology to quantify the number of CERT immunoreactive cells in the striatum of 6-hydroxydopamine (6- 
OHDA) lesioned rats as a model of Parkinson's disease (PD). No difference in the striatal expression levels of CERT/GPBP proteins was found between diseased and control animals, suggesting that the expression pattern of CERT in the striatum is not affected in the 6OHDA rat model of PD.

Chapter 4 describes development of an enzyme linked immunosorbent assay (ELISA) for the detection of peptides functionalized with biotin and fluorescein groups. We were able to accurately measure peptides bound to pentafluorophenyl methacrylate nanoparticles in blood plasma of rats after injection, with a detection limit of $1 \mathrm{ng} / \mathrm{mL}$. This novel method is a valuable tool in determining the effectiveness of nanoparticle targeting.

In Chapter 5 we evaluated the efficacy of delivery and safety of liposome-, polyester-, poly(glycidol)- and acrylamide-based nanoparticles functionalized with peptides targeting brain endothelial receptors, in vitro and in vivo. We detected labelled nanoparticles in brain homogenate, liver homogenate, in cerebrospinal fluid and blood plasma after injection. Based on both the in vitro and in vivo results, we concluded that the physical characteristics of the nanoparticles and the targeting peptides used need to allow for preferential binding to brain endothelial cells compared to endothelial cells of other tissues for efficient blood-brain barrier transport. 


\section{CURRICUlum VitAE}

Gerard Hendrik Bode was born on the $25^{\text {th }}$ of May, 1983 in Groningen, the Netherlands. After obtaining his high school diploma in 2001, he studied Econometrics and Artificial Intelligence at the Rijks Universiteit Groningen. In 2004, he started his bachelor in molecular life sciences at Maastricht University, the Netherlands. Subsequently, he enrolled in the master clinical molecular life sciences at the transnational University Limburg and obtained his degree in 2009. He started his $\mathrm{PhD}$ at Maastricht University's department of neuroscience in the lab of prof. dr. Marc de Baets in December 2009, under the supervision of dr. Pilar Martinez. 


\section{LIST OF PUBLICATIONS}

- Detection of Peptide-based nanoparticles in blood plasma by ELISA.

Bode GH, Pickl KE, Sanchez-Purrà M, Albaiges B, Borrós $S$, Pötgens AJ, Schmitz C, Sinner FM, Losen M, Steinbusch HW, Frank HG, Martinez-Martinez P; European NanoBioPharmaceutics Research Initiative. PLoS One. 2015

- Complement activation by ceramide transporter proteins. Gerard H. Bode, Mario Losen, Wim A. Buurman, Robert Veerhuis, Peter C. Molenaar, Harry W.M. Steinbusch, Marc H. De Baets, Mohamed R. Daha, Pilar Martinez-Martinez Journal of Immunology 2014

- Goodpasture antigen-binding protein/ceramide transporter binds to human serum amyloid P-component and is present in brain amyloid plaques.

Mencarelli $C$, Bode GH, Losen M, Kulharia M, Molenaar PC, Veerhuis R, Steinbusch HW, De Baets MH, Nicolaes GA, MartinezMartinez $P$.

J Biol Chem. 2012

- Unchanged expression of the ceramide transfer protein in the acute 6-OHDA neurodegenerative model.

Mencarelli $C$, Bode GH, Vlamings $R$, Janssen $M L$, Losen $M$, De Baets MH, Steinbusch HW, Temel Y, Martinez-Martinez $P$. Neurosci Lett. 2012 
- Low Current-driven Micro-electroporation Allows Efficient In Vivo Delivery of Nonviral DNA into the Adult Mouse Brain.

Vry JD, Martínez-Martínez P, Losen M, Bode GH, Temel $Y$, Steckler T, Steinbusch HW, Baets MD, Prickaerts J.

Mol Ther. 2010

- An in vitro and in vivo study of peptide-functionalized nanoparticles for brain targeting: The importance of selective blood-brain barrier uptake.

Gerard H. Bode, Gregory Coué, Christian Freese, Karin E. Pickl, Maria Sanchez-Purrà, Berta Albaiges, Salvador Borrós, Ewoud C. van Winden, Leto-Aikaterini Tziveleka, Zili Sideratou, Johan F. Engbersen, Smriti Singh, Krystyna Albrecht, Jürgen Groll, Martin Möller, Andy J.G. Pötgens, Christoph Schmitz, Eleonore Fröhlich, Christian Grandfils, Frank M. Sinner, C. James Kirkpatrick, Harry W.M. Steinbusch, Hans-Georg Frank, Ronald E. Unger, Pilar Martinez-Martinez

Manuscript submitted 
List of publications 


\section{DANKWOORD}

Allereerst wil ik graag het promotieteam bedanken. Professor Marc de Baets, hartelijk bedankt voor de kans om mijn PhD bij de neuroimmunologie groep aan te vangen, en de continue aandacht voor de voortgang van mijn project.

Pilar Martinez, thank you for your limitless enthusiasm for my project, especially anything GPBP related, and your positive attitude.

Mario Losen, bedankt voor het helpen oplossen van allerlei technische problemen, en het het meedenken over de opzet van experimenten.

Ali and Frank, for keeping me fit with our moutainbike trips.

All the members of the neuroimmunology group, especially Alejandro, Jo, Chiara, Kathleen, Marko, Carolin, Gisela and Marina.

Alejandro, for meticulous planning our exciting holiday adventures, and everyone else who joined (Jo, Kathleen, Marko, Chiara, Maria, Pablo and others) for making these trips a great experience.

Boris, Jelle en Giel, voor de welkome afleiding op de altijd gezellige vrijdagavonden.

Gosia, for your excellent feedback and corrections, support, and making sure I finished this book in time. 


\section{Notes}


Notes

201 


\section{Notes}

